\title{
Through Fiction's Mirror
}

\section{Abjects in Neo-Victorian Fiction}

\author{
Dissertation \\ zur Erlangung des philosophischen Doktorgrades \\ im Studiengang Englische Philologie (Anglistik) \\ an der Philosophischen Fakultät der Georg-August-Universität Göttingen \\ vorgelegt von Jan-Erik Ella \\ aus Kiel
}

Göttingen, 2016 
Erstgutachter: Prof. Dr. Brigitte Glaser Zweitgutachter: Prof. Dr. Barbara Schaff

Datum der mündlichen Prüfung: 28.06.2016

Revidierte Fassung August 2018 


\section{Table of Contents}

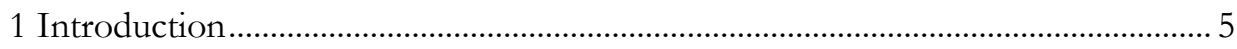

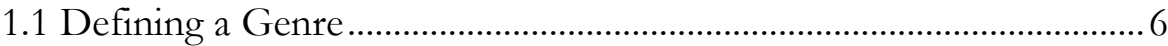

1.2 A Short History of the Victorian Revival and the Neo-Victorian

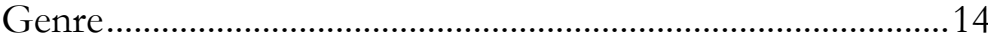

1.3 Retro- vs. Neo-Victorian: Outlining two Contrary Trends.....................18

2 Exploring the Collective Victorian Unconscious ........................................................24

2.1 Psychoanalysis, Post-Structuralism and Literature ................................24

2.2 Freud's Uncanny and the 'Domestic Gothic'.......................................27

2.3 Abjection and the Abject....................................................................28

2.4 Individual Self and Collective Cultural Identity .....................................33

2.5 Confronting the Shadow/Purifying the Abject .....................................34

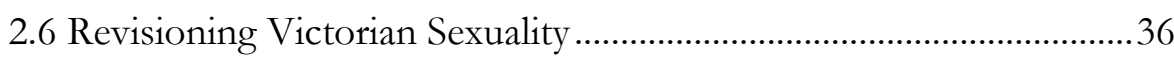

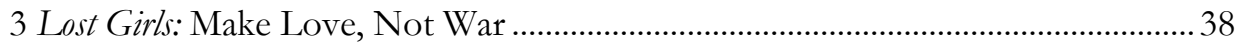

3.1 Creating a Different Kind of Pornography ...........................................38

3.2 Therapeutic Re-Telling ...........................................................................4 


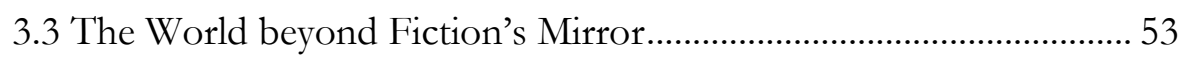

3.4 Daunting Shadows: Fencing the Middle-class in................................ 62

3.4 Relating the Past to the Present: Lost Girls as a Neo-Victorian Text 71

4 Two Sides of the Same Coin: Michel Faber's The Crimson Petal and the White .......74

4.1 Abject Monogamy: A Scathing Look at Traditional Relationship Models 81

4.2 Following the Prostitute: A Journey into Abjection ........................... 95

5 Sexual Deviation: Beyond Heteronormativity..........................................................105

5.1 Afterimage: The Tyranny of the Norm ................................................. 111

5.2 Oscar Wilde and the Candlelight Murders: The Love that Dare Not Speak its Name ...................................................................... 121

5.3 The Master: A Life of Denial ............................................................... 126

6 Madness and Subversion: Victorian Spiritualism and Occultism...........................131

6.1 "The Conjugial Angel”: The Medium as Gifted................................ 137

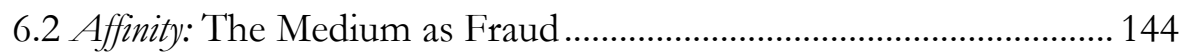

6.3 In the Red Kitchen: Mediumship as Repressed Trauma ...................... 147

6.4 Penny Dreadful: Mediumship as Aberrancy ........................................ 153

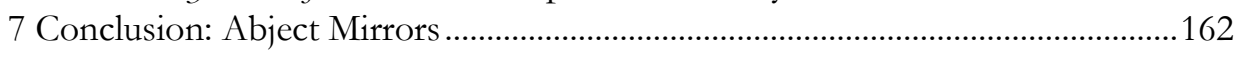

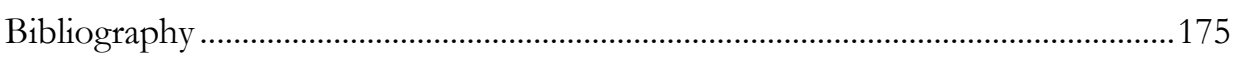




\section{Introduction}

Queen Victoria is everywhere. Despite her diminutive size, the erstwhile widow of Windsor continues to cast a long shadow. Not only as a monarch who came to be a symbol of British colonialism and of the vicissitudes of a society transformed by industrialization, but also as the embodiment of her era's morality and culture. From modernism to the contemporary era, Victoria has loomed large in the collective cultural imagination. Even a cursory look at contemporary British popular culture reveals how strongly the Victorian era's presence persists to this day. It manifests in the shape of numerous film adaptations of famous Victorian novels; it is reflected by the neo-Victorian aesthetic that can be found in certain works of architecture and design; and last but not least, it takes the form of a vast plethora of literary publications set during Queen Victoria's reign, which have been amassing exponentially since the 1980s. These 'neo-Victorian' texts are not merely a nostalgic imitation of well-known predecessors, but tend to focus on the era's repressed aspects: sexuality seems to be of particular interest to contemporary authors. Instead of portraying the Victorian era as nothing more than an exotic 'other', the taboos of the past reconnect it to contemporary cultural discourses and areas of conflict. Themes that could not be fully explored by $19^{\text {th }}$ century authors without risk of censorship or even legal repercussions are now projected back into the past, highlighting the roots of present societal changes. Before any further analysis, however, it shall be prudent to establish some core terminology, starting with 'neo-Victorianism' itself. 


\subsection{Defining a Genre}

Critical research has only recently started to explore the characteristics and generic boundaries of this particular phenomenon, as evidenced by the fact that the first issue of the Journal for Neo-Victorian Studies (henceforth abbreviated as NVS) only appeared in autumn 2008, and John Kucich and Dianne F. Sadoff still postulate a "critical gap" (xi) in regard to this topic as recently as the year 2000. The very term neo-Victorianism is still slightly under-defined and contested, even though it has "gained both popular and critical currency" (Hadley, 3) within the last decade.

In its opening issue, the NVS published two essays that addressed this lack of specificity with regards to its principal critical term, yet neither of these could hope to resolve the issue conclusively. Instead, Marie-Luise Kohlke points out:

What this introduction will not, indeed cannot pretend to do, then, is provide the (still) missing definitions or delineate possible generic, chronological, and aesthetic boundaries - objectives which more properly belong to the project ahead. The same refusal of pre-emption also underlies the editorial board's decision to adopt the widest possible interpretation of 'neo-Victorian', so as to include the whole of the nineteenth century, its cultural discourses and products, and their abiding legacies, not just within British and British colonial contexts and not necessarily coinciding with Queen Victoria's realm; that is, to interpret neo-Victorianism outside of the limiting nationalistic and temporal identifications that 'Victorian', in itself or in conjunction with 'neo-', conjures up for some critics. (2)

Kohlke's decision to settle on a deliberately open interpretation of both Neo-Victorianism and the historical era it alludes to is a prudent one, as the subject clearly merits some further research.

In and of itself, such a loose definition need not be a stumbling block to further critical pursuits. Quite the contrary, by keeping the definition as open as possible, scholarly research can more easily focus on elements that might be overlooked if the genre's established boundaries are too closely drawn. Furthermore, even firmly established literary genres are often quite difficult to pin down: for example, "[t]he term 'science fiction' resists easy definition. This is a strange thing, because most people have a clear sense of what science fiction is" (A. Roberts, 1). Roberts's observation reveals a problem at the heart of every categorization: genre-boundaries are ultimately arbitrary, a convenience of communication, providing a short cut. If they are too closely examined, post-structuralist deconstruction becomes virtually inevitable. Definitions that are too broad are insufficiently distinct from other categorizations, while narrower terms will exclude texts that need to be considered part of the genre that is to be described. Nonetheless, it is debatable whether every contemporary fictional text that is set in the nineteenth century qualifies as neo-Victorian by default, and it will be necessary to outline distinctive generic qualities of neo- 
Victorianism in order to distinguish it sufficiently from other genres set within the same historical epoch.

In the same issue of the NVS, Andrea Kirchknopf attempts to establish such a distinction in her essay "(Re-)Workings of Nineteenth-Century Century Fiction: Definitions, Terminology, Contexts", which contrasts and evaluates the most commonly used terms that had been suggested for this genre up to that point. Surprisingly, she concludes that the term post-Victorian should take precedence over the more commonly used neo-Victorian, arguing that the latter lacks "an emphasis on the postmodernist influence in these texts" (Kirchknopf, 66). Her suggestion has remained largely unheeded, however, as suggested by the fact that the term post-Victorian has been widely ignored by subsequent critical research - and this study is no exception to that trend, for reasons that will be discussed in more detail in a later chapter. Kirchknopf's attempt at defining the nature of the genre, however, is a valuable contribution to the ongoing scholarly debate: "[B]y creating a dialogue between narratives of the present day and the nineteenth century, strongly based on the concept of intertextuality, contemporary rewrites manage to supply different perspectives from the canonized Victorian ones" (54).

The observation that neo-Victorian fiction qualifies as dialogic literature (in the Bakhtinian sense) is vitally important: the nineteenth century is still exceptionally present in the collective imagination, due to a large number of literary texts that are now part of the canon. Readers may feel that they know the Victorian era by virtue of having read novels by Dickens, the Brontë sisters, Elizabeth Gaskell and many others. This sense of familiarity, however, can be quite misleading, as these literary texts were subject to rigorous censorship (both by official authorities and at the hands of the authors themselves), and as such may not create a more accurate picture of the 1800s than the Arthurian romances did in relation to the Middle Ages. It is not historical fact that is seized upon and often challenged by neo-Victorian literature - it is the traditional image of the Victorian era within the collective cultural imagination, as coined by canonical Victorian texts. For example, regardless of whether Victorian women were brought up to be sexually repressed even in private, $19^{\text {th }}$ century literature has established the stereotype of the sexless child-wife and the angel in the house. Neo-Victorian literature actively seizes upon these tropes and deliberately emulates, deconstructs, or subverts them.

Ann Heilmann and Mark Llewellyn come to a similar conclusion: "[T] he 'neoVictorian' is more than historical fiction set in the nineteenth century. To be [considered a part of this sub-genre], texts (literary, filmic, audio/visual) must in some respect be self-consciously engaged with the act of (re)interpretation, (re)discovery, and (re)vision concerning the Victorians" (4; emphasis in original)." This constitutes a feasible working definition and helps to narrow the category down considerably. Neo-Victorian fiction engages in a dialogue with the parent texts it seizes upon (either directly or indirectly): even novels that are not conceived as re-writings of pre-existing Victorian texts highlight aspects of the epoch that were virtually absent from the historical 
precursors. Different fictionalized versions of the era clash and combine into a much more heterogeneous image, potentially re-defining the way the collective cultural imagination pictures the past.

Kate Mitchell conceives of neo-Victorian fiction as "memory texts" (8) that contribute to an ongoing process of editing the image of the Victorian age (and contemporary society's position in relation to it) within the collective cultural imagination: " $[T]$ his takes the form not of seamless continuity but of a series of flashes and repetitions that suggest the alterity of the past, its difference, while also, paradoxically, producing a shock of recognition" (8). This tense ambivalence between sameness and otherness, between familiarity and distance constitutes one of the genre's most central aspects that this study will explore in subsequent chapters.

I argue that one of neo-Victorianism's primary focal points lies in what Julia Kristeva called the abject. Unlike nostalgic historical fiction, neo-Victorian texts tend to seize upon socio-cultural issues that were considered strictly taboo in the nineteenth century, and therefore rarely appeared in the sanitized popular fiction of that day and age. These abjects form the foundation for several ongoing societal discourses that are prominently present in contemporary British society: gender roles, non-normative sexuality, marginalized minorities, or even the conflict between the natural sciences and spiritual world views. This dissertation therefore aims to contribute to the ongoing scholarly debate on the definition and demarcation of the neo-Victorian genre by offering a terminology that distinguishes further between neo-Victorian fiction and more traditional historical novels set in the nineteenth century. As Louisa Hadley points out:

The idea that the Victorians are both 'in and out of history' is fundamental to understanding the contemporary return of the Victorians. Clearly the Victorians are 'in history', not only by virtue of being dead and gone, but also because of their position within historical narratives... Yet the Victorians are also 'out of history'; within the contemporary imagination, there is a tendency to remove the Victorians from their specific historical context (8).

Specifically, neo-Victorian fiction employs the Victorian era as both a stand-in and a foil for contemporary British society. Many cultural discourses that dominate twenty-first century society are directly related to (and rooted in) transformative cultural processes which can be traced back to the effects of industrialization - and thus, by extension, to the Victorian era. New communication technologies, faster travel and international trade changed the very lives of the Victorians on a fundamental level, already foreshadowing the "global village"1 that we find ourselves in. Industrial production gradually eliminated the agrarian lifestyle that had shaped

1 The 'global village' is a term that was popularized by Marshall McLuhan's The Gutenberg Galaxy: The Making of Typographic Man (1962). McLuhan predicted the importance of information technology in bringing the cultures of the world in closer contact, and his terminology has since entered common parlance. 
mankind's history and culture throughout most of recorded history, creating new conflicts as well as new opportunities.

Even more important for this study, however, are socio-cultural transformations that changed people's perception of the world and their own place within it. New scientific discoveries gradually started to challenge the religious world view that had dominated European thought for millennia. For example, advances in geology and paleontology revealed that the Earth was significantly older than the 6,000 years postulated by the Bible, and Darwin's evolution by means of natural selection jeopardized the concept of a static biosphere created by the Abrahamic god. The natural sciences unhinged the very foundations upon which many societal norms and conventions had been based up until this point. The first wave of feminism started to fight for a more emancipated society, once both the religious validation and the material constraints that had circumscribed the status of women had started to disappear quickly. ${ }^{2}$ The parallels to contemporary discourses are readily apparent: when contemporary scientists like Richard Dawkins challenge Biblical literalism or even religion in general, it is easy to note the parallels to the Darwinian controversy sparked by the original publication of The Origin of Species in 1859. For example, the gender wage gap or the absence of women in high-ranking positions demonstrates that the emancipatory struggle for equal rights is far from over. As of 2011, the average part-time pay gap in the UK was at 34.5\% (Perfect, 7), while "women made up only $12.5 \%$ of the members of the corporate boards of FTSE 100 companies" (Lord Davies, 5) in 2010. Although the number of female board members increased in comparison to previous data from 2004, a "report by the Equality and Human Rights Commission (2008) suggested that at the current rate of change it will take more than 70 years to achieve gender-balanced boardrooms in the UK's largest 100 companies" (Lord Davies, 5). Victorian middle-class gender ideology may no longer dominate societal discourses, but its heritage persists to this day.

On the other hand, the Victorians are also recognizably 'other', first of all by being so far removed from the present: "Close enough for us to be aware that we have descended from them and yet far enough away for there to be significant differences in life-styles, the Victorians occupy a similar place to our grandparents" (Hadley, 7). Seizing upon the generational analogy, it is easy to see the family resemblance between present-day Great Britain and the Victorian Empire; yet like an ancestor's faded photograph, the Victorians are distant enough not to spark a Freudian identity crisis. As such, the Victorian age constitutes an ideal historical canvas for contemporary projections, allowing authors to explore culturally relevant issues in a setting that is conveniently remote, yet similar enough to still allow for a certain degree of identification. By focusing on the Victorian abjects that were rarely

\footnotetext{
2 Victorian scholars tried to justify typical middle-class norms such as gender roles or the homosexuality taboo by means of medical science, replacing the religious foundation with a scientific one. However, all of these attempts turned out to be pseudo-scientific and were discarded in the long run.
} 
fully articulated or even addressed in the most remembered literary texts of the nineteenth century, neo-Victorianism helps to contextualize contemporary interand intra-cultural conflicts within a distinct historical continuity.

This study seizes upon the work of Hadley and Mitchell by conceiving of neoVictorianism as a form of 'memory work' that helps to establish a contemporary cultural identity in relation to an ambivalent Victorian 'other'. Yet it goes one step further in asserting that what neo-Victorian fiction engages in qualifies as a kind of Jungian 'shadow work'. Neo-Victorianism does not merely focus on similarities and differences between the Victorian era and contemporary society. It specifically shines a light on the suppressed sides of the collective Victorian middle-class identity (as reflected by Victorian mainstream literature), which still form the basis of contemporary cultural neuroses and blind spots - and then seeks to re-integrate and absorb these abjects through the cathartic resolution granted to fictional protagonists that rally against the norms of the society they live in.

The following chapter will provide a short history of the Victorian revival, in order to deduce the specific characteristics of the neo-Victorian in relation to a more traditional approach to historical fiction, and also to clearly place the genre within a historical context. It will also establish a distinction between neo- and pseudo-Victorian fictions, which are based on almost diametrically opposed approaches to re-appropriations of the Victorian era. Naturally, this clear-cut distinction can only be maintained up to a certain point, as there are pseudo-Victorian texts that contain elements of the neo-Victorian and vice versa. However, it is important to define some of the distinct generic qualities of neo-Victorianism in order to distinguish it from different literary approaches to that specific historical period.

Chapter 2 will be devoted to Kristeva's concept of the abject and its applicability to neo-Victorian fiction. Specifically, this section will compare Freud's uncanny with Kristeva's abject, outline the similarities and differences between the two, and then forward the dissertation's thesis that neo-Victorianism is particularly concerned with the suppressed aspects of Victorian culture within the collective cultural imagination of Great Britain and - to a certain degree - its former colonies. This dialogic Jungian shadow work (which directly engages specific stereotypes associated with the nineteenth century that have been fostered by canonical literary texts of that era, as well as by Modernist revisionism) contributes to contemporary discourses relating to cultural identity, and - if we follow Kristeva - contains functions that have been formerly delegated to the realm of religion by trying to engage and resolve the abjects within a specific culture.

Chapters 3-6 of this study will be devoted to textual work, analyzing specific key texts to substantiate its central thesis. It will focus on various Victorian abjects that are to be found within the novels discussed in these chapters, demonstrating how the nineteenth century is used to project contemporary societal discourses into a more comfortable distance, re-visioning the Victorian age within the collective cultural imagination. First among these various abjects will be several topics connected 
to sexuality: prostitution, pornography, homosexuality, and - by extension - gender issues.

Alan Moore's Lost Girls features three protagonists taken from popular Victorian children's literature - and then interprets their fantastic adventures in terms of their sexual awakening, veiled in Freudian symbolism. The aristocratic Alice (from Lewis Carrol's Alice in Wonderland and Through the Looking Glass), for example, was sexually molested by one of her father's acquaintances: a nervous man only known to her as "Mr. Bunny", who repeatedly checked his watch while groping her because he feared detection. As a result of these unwelcome ministrations, Alice has withdrawn into autoerotic fantasies and shuns the company of men, instead embracing a life of homoerotic decadence that makes her a social outcast. Wendy (from J.M. Barrie's Peter Pan), on the other hand, has repressed her memories of her sexual adventures with the working-class boy Peter, and vows to protect her family from any similar occurrences. As a result, her sex life is virtually non-existent, only manifesting in her shadow. (The third protagonist, Wendy from Lyman Frank Baum's The Wizard of $\mathrm{O}_{z}$, will be omitted from this analysis for two specific reasons: her plot takes place in the United States of America rather than the British empire, and her pivotal experiences take place in the 1900s, several years after Queen Victoria's death.)

The graphic novel's primary purpose is to serve as erotic entertainment, yet the contrast between Wendy and Alice (as representatives of the middle-class and the aristocracy, respectively) merits a closer look. Both of these women suffer from certain neuroses as a result of their past experiences, but these psychological hangups take a very distinct shape according to the class these characters hail from. The narrative is interspersed with references to other Victorian (and early modern) literature, reflecting upon the nature, limitations and functions of erotica: the graphic novel's culmination shows the outbreak of World War I, contrasting the psychosexual catharsis of the three female protagonists with a collective madness (supposedly born of sexual repression) that plunges most of Europe into violent conflict.

Michel Faber's The Crimson Petal and the White (first published in 2002), in turn, is deliberately designed as a counterpoint to the sanitized, canonical novels of the Victorian age, setting itself up as fundamentally different from "other stories" (Crimson Petal, 2) that have already acquainted the reader with the nineteenth century and its culture. Its uncensored portrayal of numerous Victorian abjects stands in marked contrast to the (self-) censored images communicated by most Victorian 'classics', which could barely allude to certain taboo topics. The novel introduces a prostitute as its protagonist whose very appearance marks her as a 'fallen woman': stricken by a congenital skin disease, her body is covered with red, symmetric stripes of dry skin that relate her to William Blake's Tyger from the Songs of Innocence and Experience. ${ }^{3}$ Even though the 'fallen woman' was a common element in Victorian literature, such

${ }^{3}$ Her foil, the innocent middle-class lady Agnes Rackham, is in turn tied to Blake's Lamb by virtue of her first name, which is derived from the Greek 'agnus'. 
characters were usually doomed to die. Faber's protagonist, on the other hand, suffers no such fate: the closing chapter of the novel deliberately refuses to resolve the plot, violating the conventions of Victorian story-telling and leaving the reader with virtually no clues as to how the final events might play out.

The third novel in this section will be Helen Humphrey's Afterimage, which is loosely inspired by the Victorian photographer Julia Margaret Cameron (1815-1879) and her pioneering work of establishing photography as a serious art form. Even though Humphrey's novel does not set out to deliberately violate Victorian conventions as such, its subject matter clearly places it in the category of neo-Victorianism, reflecting upon the unspoken and repressed aspects of Victorian culture as manifested by its lead characters.

Its three principal protagonists are caught in a relationship triangle dominated by repression and the class divide: the aristocratic Lady Isabel once maintained a quasi-lesbian, symbiotic relationship with a servant's daughter, until her father forbade her any further contact with the girl. She now tries to re-enact this aborted relationship by projecting memories of her childhood friend upon the Irish servant girl Annie Phelan, who serves as a muse and a model for her mistress's artistic pursuits. Isabel's husband Eldon, in turn, is trapped in a dysfunctional relationship with his wife, as the couple has not managed to maintain any sense of intimacy since several pregnancies culminated in a miscarriage. His relationship with Annie Phelan is mostly platonic and centered around their shared interest in literature. It is a sense of kinship rather than physical attraction that draws these two to each other.

The uneven power dynamics between Afterimage's protagonists revolve around sexual sentiments that elude any attempt at expressing them, with societal conventions providing an insurmountable stumbling block to all involved parties. In the end, it is the Irish servant girl Annie who manages to assert her position better than any of the other characters, although it also means that she must abandon the budding relationship with her mistress.

Following this is a comparison between Gyles Brandreth's Oscar Wilde and the Candlelight Murders (henceforth abbreviated as Candlelight Murders) and Colm Toibín's The Master, both of which place a (more or less heavily) fictionalized Victorian author in the protagonist's role. A comparison between these two novels is especially rewarding because they hail from very different literary genres, pursue their subject matter in a very disparate manner - and yet exhibit similarities that are distinctly neo-Victorian because they turn a twenty-first century gaze upon the abjects of the late Victorian age; in this case, the (more or less) repressed homosexuality of Henry James and Oscar Wilde, respectively.

Brandreth's Candlelight Murders is - as the title suggest - a crime novel that places heavily fictionalized versions of Oscar Wilde and his friend and biographer Robert Sherard in investigative roles inspired by Arthur Conan-Doyle's Sherlock Holmes and Dr. Watson. Despite this decidedly ahistorical premise, Brandreth intersperses 
the plot with diverse biographical minutiae, allowing Sherard (who acts as narrator) to reflect upon his close friend's problematic sex life and interpersonal relationships.

Toibin's The Master, on the other hand, is a 'literary' novel exploring the rich inner life of Henry James (and his unarticulated homosexuality), often aiming to establish a connection between James's repressed feelings and the creative processes that resulted in his most well-known literary works.

The final section of my analysis will focus on another prominent theme of neoVictorian fiction: its particular focus on Spiritualism and the occult. This might seem to be an odd choice, given that the preceding chapters focused on different aspects of repressed sexuality, whereas esotericism does not necessarily connect to this topic. There is a thread connecting these seemingly disparate elements, however: gender roles and the position of women within society.

While Spiritualism might not appear to be a cultural abject (that is, a taboo concept that is part of and yet apart from society) at first glance, it is important to keep in mind that female mediums were often pathologized by Victorian mainstream society, to the point where some prominent Spiritualists were in danger of being confined in an asylum. ${ }^{4}$

Alternative world views were perceived as a threat to the dominant social order, especially if - as in the case of Spiritualism - they subverted Victorian norms and values by appropriating them in a new context. The spiritualist séance placed women in a position of authority on account of the very weaknesses attributed to them by Victorian mainstream society. As such, the movement was infused with a strong ambivalence that could be (and often was) perceived as a threat to the patriarchal status quo.

Antonia S. Byatt's novella "The Conjugial Angel” explores the power dynamics within the Spiritualist movement by placing its female characters in a position that highlights both their power and their impotence. Byatt's medium is besieged by a man who belongs to the same circle of Spiritualists and seeks to win her hand in marriage. Even though she has no desire to concede to his wishes, she feels that she will ultimately have no choice but to give in - and the psychological power struggle between these two characters exerts a strong influence upon the séance. The medium is empowered by her Spiritualist beliefs - yet simultaneously at the mercy of male members of the assembled group, who seek to wrest doctrinal control from her by quoting Swedenborg and the Bible.

On a similar note, Michèle Roberts's In the Red Kitchen highlights the way in which male-dominated Victorian science attempted to incorporate and assimilate or else pathologize - Spiritualism. Roberts's female protagonists are characterized in a fashion that encourages a (post-)Freudian interpretation of their numinous experiences, suggesting that their altered states of consciousness are the result of

${ }^{4}$ A prominent example of this was Georgina Weldon, whose husband cited her interest in Spiritualism as proof of her alleged insanity, unsuccessfully attempting to institutionalize her. (cf. Nicholson \& Porter (eds.), vii). 
psychological scars sustained by sexual abuse. Yet at the same time, these episodes are not conceived of as predominantly malignant manifestations of mental disease, but even contain a certain potential for spiritual healing. The novel is deeply sympathetic with regards to its protagonists, portraying a scientist's attempt at having a medium confined in an asylum as a blatant attempt at getting rid of a discarded mistress and a potential scandal.

Sarah Waters's Affinity, on the other hand, promotes a strictly rationalist view of Spiritualism, while simultaneously exploring the power imbalances and social mechanics underlying all character constellations in the novel. As such, it provides a strong contrast to the other texts in this section, which tend to portray Spiritualism as a genuine spiritual practice rather than deliberate fraud. Waters's medium Selina Dawes, however, is revealed to be a consummate actress who feigns innocence as well as supernatural talent in order to escape from prison. Both her intended victim Margaret Prior and the reader are encouraged to believe in her sincerity as well as her preternatural abilities, only to see their faith shattered by the conclusion.

In my conclusion, I will use Alan Moore's graphic novel From Hell as a reference point, which conceives of the Whitechapel murders of 1888 as an occult ritual intended as social engineering, symbolically assuring man's continued dominance over women and promoting the ideal of reason (as opposed to supposedly 'female' irrationality). Jack the Ripper, here identified as the Royal Surgeon Sir William Gull, apparently succeeds in his endeavor, embedding the Ripper-myth within the collective unconscious and becoming an almost godlike archetypal figure. But instead of re-asserting patriarchy and the ideals of the Enlightenment, his deeds give birth to the horrors of the twentieth century, not only inspiring various British serial killers but also foreshadowing the Holocaust (among other events). Moore's graphic novel reinforces the ties between the Victorian past and contemporary society, focusing on the repressed, unconscious and (for the most part) negative aspects of this relationship. It serves as a particularly fitting demonstration of how Victorian abjects are employed in neo-Victorian fiction, combining the retroactive talking back of what Helen Davies calls 'ventriloquism' with the more receptive looking back of Kate Mitchell's 'memory work's.

\subsection{A Short History of the Victorian Revival and the Neo- Victorian Genre}

To establish a sense of what constitutes neo-Victorian fiction, it is necessary to examine the Victorian era - or more precisely: contemporary conceptions of the same. Only after providing a clear idea of what contemporary authors and audiences mean

${ }^{5}$ Mitchell's memory work is an active process that constructs certain images of the past, but her terminology implies a stronger reliance on established memories of a factual past than the clearly projective 'ventriloquism' invoked by Davies. 
when they speak of 'the Victorian era' will it be possible to demonstrate how the neo-Victorian genre relates to this specific period.

Heilmann and Llewellyn hold that the genre supposedly tends "to be driven by a desire to illuminate and occasionally even 'correct' aspects of the Victorian age, or the Victorians' attitudes to the specifics of sex, gender, and erotic relationships" (8). Even though this observation is certainly valid at its core, I would contend that this characterization is slightly misleading, because it misses an important detail: it is not the Victorian age as such that is illuminated and 'corrected' by neo-Victorian fiction - it is the period's image within the collective cultural imagination, as established by canonical Victorian literature and several other factors. The so-called "repressive hypothesis" (The History of Sexuality, 10) with its underlying assumption of universal Victorian frigidity is so commonly addressed by neo-Victorian texts not because the Victorians 'were like that', but because repression is so persistently associated with that era in our collective imagination. "[W]e never really encounter 'the Victorians' themselves but instead a mediated image like the one when we glance into our rearview mirror while driving" (Joyce, 5). It is this image within the collective cultural memory that neo-Victorian fiction engages in a variety of ways: it shines "a sudden, revealing searchlight into obscure recesses, hitherto undivined" (8), as Lytton Strachey put it in Eminent Victorians.

In the collective cultural imagination of Great Britain and its former colonies, the Victorian era is still strongly associated with hypocrisy, sexual repression, and rigid social norms. "In our culture the Victorian age has a special place: more than any other era it awakens in us our capacities to feel hostile towards a past way of life, to perceive the past as alien, unenlightened, and silly" (1), Michael Mason observes in the opening lines of The Making of Victorian Sexuality. This preconception (or even prejudice) is at least partially owing to the lasting cultural impact of specific nineteenth century texts, such as Coventry Patmore's poem "The Angel in the House" with its proposed ideal of de-sexualized femininity, or the notorious childwives to be found in most of Charles Dickens's novels. These mid-Victorian selfconceptions formed the basis of later criticism - regardless of whether they were accurate portrayals of Victorian society or not. 6 "The Victorians invented many things - including themselves. But in the very act of creation lay the seed of destruction" (Taylor, 3). Shortly after the turn of the $20^{\text {th }}$ century, the epoch's idealized self-image became synonymous with excessive prudishness and hypocrisy. For example, Lytton Strachey's Eminent Victorians illustrates how the modernists satirized the Victorian mode of biographical hero worship, and reveals the Late Victorian

${ }^{6}$ Non-fictional sources from that period tend to suggest that the idealized image painted in these texts is at the very least exaggerated, inviting comparisons with the relationship between Arthurian romances and the realities of knighthood and aristocratic life in the $12^{\text {th }}$ century CE: the ideals expressed in these fictional texts may very well have influenced - and to some degree reflected - the most dominant cultural currents of their respective day and age, yet historical reality differed from these narratives. 
texts challenged (or at least highlighted) these ideological conceptions, particularly within the last twenty years of Queen Victoria's reign. Yet in retrospect, the images created by Dickens, Eliot and the Brontës turned out to be considerably more persistent than alternate portrayals of that era. In the collective cultural imagination, the Victorian period continues to be associated with domestic angels and hypocritical patriarchs.

Another factor that greatly contributed to the current image of the Victorian era was the Modernist movement and its blatantly anti-Victorian stance. Many members of the Bloomsbury group had a strained relationship with their parents' generation, conceiving of Victorianism in terms of "repression, realism, materialism, and laissez-faire capitalism" (Bullen, 2), all of which clashed with their own artistic and political ideals. If criticism of Victorian ideals had already set in during the 1880s in a gradual transition towards modernism, it reached new heights in the years following World War I. Lytton Strachey's Eminent Victorians is a prime example of the oedipal iconoclasm that dominated the inter-war years: Strachey's biographical sketches focus on prominent Victorian personalities that had been worshipped as heroes by his parents' generation, and then knocks these illustrious individuals off of their pedestals by highlighting their most ridiculous human frailties. On a similar note, the poet Ezra Pound declared: "The odour of defunct Victoriana is so unpleasant that we are content to leave the past where we find it" (qtd. in OED), and Virginia Woolf famously asserted that human character underwent a fundamental transformation "on or about December 1910" (4). Their desire to break free from the stifling influence of their immediate forebears drove them to construct a radical dichotomy between the Victorian past and the 'modern' age - regardless of whether it actually existed.

The whole Modernist movement was built around the (somewhat misleading) notion that their artistic pursuits were radically different from those of their Victorian predecessors, even though the profound rift they postulated turns out to be mostly illusory: In retrospect, it becomes quite clear that Modernism evolved rather seamlessly from cultural and artistic influences that were already present in the late Victorian period - including far-reaching criticism of Victorian ideals and artistic pursuits.

What is often overlooked... is just how quickly the modernist critique of the Victorian era down to the 1880s had set in prior to 1918. In their onslaught against what they saw as the excessive moralism of George Eliot, the journalistic style of Charles Dickens, the insincerity of William Thackeray and the melancholia of Alfred

7 Woolf's attitude towards the Victorians was potentially less one-sided than this isolated comment might suggest. Steve Ellis has published an extensive analysis of Virginia Woolf's oeuvre, titled: Virginia Woolf and the Victorians. He describes Woolf's relationship with the past as ambivalent rather than antithetical, arguing that her works ought to be regarded as post-Victorian rather than Modernist. While this conclusion is debatable, the textual evidence provided does suggest that Woolf's stance regarding the Victorian era was indeed more complex. 
Tennyson, Bloomsbury followed where late nineteenth-century critics such as Henry James and Arnold Bennett had already led... [T] he reputations of early and mid-Victorian men and women of letters were already at rock-bottom in the decade prior to the First World War (Taylor, 4).

The radical difference between Modernism and its immediate forebears must therefore be regarded as a cultural myth - although an exceptionally persistent one.

Accurate or not, the Modernists' depictions of the Victorian past strongly influenced the period's image within Great Britain's collective cultural imagination and memory, and their influence can still be detected in neo-Victorian texts. For although postmodernism tends to take a less negative stance in relation to Victorian culture and art (having outgrown the oedipal 'anxiety of influence' that prevailed throughout the first half of the twentieth century), it is directly indebted to its immediate predecessor. Even in the early twenty-first century, the Victorian era's stereotypical image within the collective imagination is still strongly indebted to Modernist accusations of sexual repression and moral hypocrisy.

For example, it is still widely believed that the Victorians were so sexually repressed as to even cover the legs of their pianos, and the Queen supposedly described the ideal approach to marital sexual intercourse with the phrase: "Lie back and think of England". Both of these historical anecdotes are demonstrably incorrect, as Matthew Sweet establishes in Inventing the Victorians: the notorious piece of marital advice originated in a private journal written in 1912 by a certain Lady Hillingham (cf. Sweet, 233); and the infamous covered piano legs were originally found in Captain Frederick Marryat's A Diary in America (1839), who attributed this specific custom to the supposedly prudish Americans. The imagery of clothed piano legs subsequently became a Victorian "standard satirical shorthand" (Sweet, xv) for excessive prudery - a practice to be mocked rather than emulated even during the mid-Victorian period.

Despite this persistent negative imagery, the Victorian era started to recover some cultural prestige in the second half of the twentieth century, when nineteenth century art, architecture and literature gradually ceased to be regarded as not "merely unfashionable, [but] an immoral monstrosity" (Burton, 121). Post-war Britain in particular started to embrace the Victorian past once more, regarding it with a certain sense of nostalgia.

It was in this particular cultural climate that the first neo-Victorian novels were published, standing in marked contrast to the more prevalent nostalgic escapist literature that painted the Victorian past in gilded tones: Jean Rhys's Wide Sargasso Sea (1966) and John Fowles's The French Lieutenant's Woman (1969) both challenge conventional depictions of the Victorian period by contrasting them with a very distinct perspective: Rhys provided a voice for the marginalized character of Bertha Mason, Mr. Rochester's (supposedly) insane wife from Charlotte Brontë's Jane Eyre, thereby providing a post-colonial look at one of the most famous Victorian novels. Bertha's tale retroactively reveals some of the colonialist prejudices and stereotypes inherent 
to Brontë's text. Fowles, on the other hand, deliberately pierced the fourth wall of literary realism, contrasting aspects of Victorian culture with their post-modern equivalents and commenting on the act of creating his fictional text.

Their attempt at re-visioning Victorianism constitutes the foundation of the neo-Victorian genre as such and distinguishes it from retro-Victorian attempts at straightforward emulation of Victorian parent texts. However, throughout the following decade, neo-Victorianism was a marginal phenomenon at best and literary texts that could be characterized as 'neo-Victorian' were far and in-between. This changed at the turn of the 1980s, when the Victorian age experienced a soaring revival within British culture. Kate Mitchell advances the idea that this phenomenon was due to the fact that the last witnesses of Victorianism had all but passed away at this point:

It is, perhaps, no coincidence that neo-Victorian fiction achieves momentum at around the time when personal memory of the Victorians was slipping away. By the 1980s there could be few, if any, Victorians left; at least, very few who were born early enough to have any personal memory of the period itself (12).

Whatever the case may be, the number of neo- and retro-Victorian publications virtually exploded from the 1980s onward. And it is at this point that the distinction between neo- and retro-Victorianism needs to be firmly established.

\subsection{Retro-vs. Neo-Victorian: Outlining two Contrary Trends}

While the number of literary texts set in the Victorian period has multiplied exponentially over the course of the last thirty years, not all these publications betray the kind of revisionist perspective that's characteristic of neo-Victorian literature. There is another approach to the topic, commonly associated with the genre of the popular historical novel, a literary angle that does not seek to shine a critical light on its setting, but merely uses it as a scenic (and often romanticized) backdrop. In the case of the Victorian age, the term 'retro-Victorian' offers itself as a fitting terminology for such fictions. Retro-Victorian literature primarily seeks to emulate and reproduce the style, content and narrative mode of its Victorian parent texts, aiming for nostalgic imitation instead of engaging its subject matter from a more contemporary perspective. Many publications belonging to this genre are crime or romance novels primarily intended as popular entertainment, reproducing (and recycling) plots and motifs taken from Charlotte Brontë, Sir Arthur Conan Doyle, or others. They tend to romanticise the Victorian past to the point where it appears to be a veritable 
golden age, standing in stark contrast to the harsh realities of twentieth or twentyfirst century life. ${ }^{8}$

This particular attitude was also instrumental in shaping the 1983 campaign of British Prime Minister Margaret Thatcher, who appealed to a conservative sense of nostalgia by espousing (supposedly) Victorian morality: "In the run up to the 1983 General Election, Thatcher invoked 'Victorian values' in an attempt to capitalize on the cultural value of the Victorians and to assert a direct lineage between the values of the Victorian era and her own political values." (Hadley, 8)

Interestingly enough, Thatcher did not necessarily seek to contest the Modernist conception of the Victorian age as an era of repression and unbridled capitalism, but instead sought to portray these qualities in a positive light, just as the Reagan administration tried to portray greed as a virtue rather than a vice. ${ }^{9}$ From a conservative point of view, her choice was an obvious one: the Victorian era marked the heyday of the British Empire, communicating a pronounced sense of mission and national identity that could easily be utilized as a rallying point for British conservatives in the 1980s. An appeal to "Victorian values" clearly implied a return to Britain's former glory.

It is debatable how much of an influence the Thatcherite re-appropriation (and re-interpretation) of Victorian morality had on the Victorian revival of the 1980s, yet it is clear to see that her particular stance must be characterized as retro- rather than neo-Victorian. (This is especially true since her image of the Victorians does not withstand scrutiny: whereas Thatcher sought to idealize the nineteenth century as an entrepreneurial paradise of free trade and 'laissez faire' capitalism, the actual Victorian age saw the rise of the welfare state, unionization and labour rights.)

Even beyond the Thatcher-years, nostalgia remained a fundamental element of retro-Victorianism, and played a strong part in genres such as the 'heritage film' of the 1980s and beyond. In this genre, the Victorian other tends to become an ideal to aspire to - and more often than not bears little resemblance to its actual historical template.

However, this renewed interest in the Victorian age also invigorated the neoVictorian genre and its distinct approach to the past. Unlike the nostalgic historical

8 This idealized portrayal can even be observed in American films such as James Mangold's Kate and Leopold (2001). The titular Duke Leopold is consistently depicted as an immaculate gentleman, and his treatment of women in particular - which is supposedly based on Victorian morality - is characterized in an overwhelmingly positive fashion. In fact, his stiff mannerisms are repeatedly contrasted with the "disrespectful" manners of contemporary society, suggesting that treating women as equals means to deprive them of the courtesy they deserve. Ultimately, the female protagonist is so smitten by Leopold's conduct that she travels back in time to live out the rest of her days at his side, in the waning years of the Victorian era.

${ }^{9}$ The phrase "Greed is good" is often associated with Ronald Reagan, even though it was originally coined in a slightly modified form by stock broker Ivan Boesky, who served as an inspiration for the character Gordon Gecko in Oliver Stone's film W all Street. However, even if President Reagan never actually uttered those words, they characterize his economic ideal (and the zeitgeist of that era) quite well. 
novels mentioned before, neo-Victorianism does not tend to construct a fictional golden age. Instead, it engages in a dialogue with the past that never fully relinquishes its contemporary perspective, even when the narrative emulates Victorian genres and forms. Whereas a retro-Victorian re-writing would simply reproduce a Victorian parent text (and, by extension, a variation of supposedly Victorian morality), a neo-Victorian pastiche might seize upon a plot thread or character that had been marginalized in a nineteenth century novel - and then draw attention to the suppressed socio-cultural conflicts that had been hidden in the original. A relatively recent example of this is Peter Carey's Jack Maggs (1997), which seizes upon Charles Dickens's Great Expectations to provide a different perspective on the character of Abel Magwitch (who serves as a barely disguised model for Carey's titular character). Carey portrays Jack Maggs as a maligned ex-convict grown rich in exile, who yearns for a return to his British homeland - as exemplified by his "adoption" of the undeserving Henry Phipps. However, it soon becomes perfectly obvious that a re-integration into the Empire's heartland and culture is impossible, and the novel concludes with Maggs leading a successful and fulfilled life in Australia. Carey does not merely seek to reproduce or allude to Dickens's famous novel. Instead, (like Jean Rhys before him,) he draws attention to Victorian prejudices inherent to the parent text, providing a fictionalized account of the creative processes that culminated in Great Expectations by inserting a barely disguised version of Charles Dickens into the text and making him witness to the events described therein. Since Great Expectations communicates negative stereotypes in relation to the penal colonies in the form of its portrayal of the exiled convict Magwitch, Peter Carey portrays his fictionalized stand-in for Dickens as a hypocrite who serves as the personification of British prejudice in relation to Australia.

Part of the appeal inherent to neo-Victorianism lies in the discrepancy between the familiar image of Victorian propriety and the silenced (or at the very least marginalized) perspectives provided by Victorian literature. But the genre's primary impetus is not based on an appetite for yesteryear's scandals or even the iconoclastic joy of tearing down the shrine of Thatcherite conservative morality: instead, neoVictorian fiction portrays the Victorian era as a double for contemporary British society. Even though Victorian taboos and prejudices are rarely identical with our own, traces of their influence persist in contemporary culture. To look at the Victorians means to gaze at a reflection of a past that still informs present cultural mores, if only obliquely so. Where retro-Victorianism clearly flirts with the concept of an idealized 'other', neo-Victorianism approaches its subject with a more analytical, self-reflective gaze.

Naturally, the dichotomy of neo- vs. retro-Victorianism can only be maintained up to a certain point. It may very well be possible to find neo-Victorian elements within a retro-Victorian pastiche - and vice versa. However, even casual readers may recognize the profound difference between A.S. Byatt's Possession: A Romance and (to mention a random example) Louise Allen's The Lord and the Wayward Lady. 
Whereas Byatt's novel not only engages with the past from a scholarly perspective, but deliberately draws attention to its own meta-fictional nature, Allen's novel basically announces its status as a formulaic historical romance in its choice of a title. As Ann Heilmann and Mark Llewellyn state:

J]ust as not all narratives published between 1836 and 1901 are Victorian, so all fictions post-1901 that happen to have a Victorian setting or re-write a Victorian text or a Victorian character do not have to be neo-Victorian, [lacking] the metahistoric and metacultural ramifications of such historic engagement (6).

Apart from the different literary quality of the two novels mentioned above, there's also a fundamental divergence in how they approach their subject matter. These approaches are encapsulated in the terms neo- and retro-Victorianism.

The prefix neo- already suggests a very specific relationship between this genre and the historical precursor it alludes to. Neo-Victorian fiction is "new" insofar as it applies a contemporary perspective to the Victorian age, even when it imitates its forms. It may not necessarily challenge certain stereotypes that have become associated with the Victorian period, but it nonetheless engages in a sort of dialogue with its literary forebears. The exact relationship between the contemporary era and the nineteenth century is portrayed differently by individual neo-Victorian texts, of course, but it is quite clear that part of the appeal of re-defining or re-evaluating the past lies in a considerable potential for re-defining or re-evaluating the present. For this reason, the term neo-Victorian clearly suggests itself as the preferable alternative to Kirchknopf's post-Victorian, which might actually be applied to any text published after 1901.

Because of the genre's potential for the creation of a sense of cultural identity by means of contrasting it with another distinct culture, the Indian scholar Sudha Shastri has compared Victorianism (that is, a contemporary - and potentially scholarly - engagement with the Victorian past) to Edward Said's Orientalism: "Like the Orientalist, the Victorianist studies Victoriana with authority in spite, or perhaps because of being an outsider. The idea that the 'other' - be it the Victorian or the Orient - needs to be represented, is the result of a claim to privileged knowledge" (Shastri, 2). The idea that our distance to the Victorian past enables us to see aspects of it that were virtually invisible to the Victorians due to their proximity does indeed seem to be one of the underlying characteristics of neo-Victorianism.

Shastri is quick to point out that in spite of the similarities between Victorianism and Orientalism, the construction of a historical 'other' possesses significantly less conflict potential than its cultural equivalent (ibid.), but that conclusion appears to be somewhat premature. Margaret Thatcher's instrumentalization of 'Victorian' values in the 1983 campaign is but one example of the socio-political dimension inherent to appropriations of an historical 'other'. Through her interpretation of (supposedly) Victorian morality and its sharp contrast with twentieth century mores, 
Thatcher created an ideological matrix that located her political goals within an idealized past that was to be re-gained and re-created. Conversely, this placed her opponents in the role of people who had lost touch with the values that had turned Britain into the most powerful nation in the world, as signified by the end of the Empire in the post-war years and the economic crisis of the 1970s. While this interpretation of the situation was indubitably spurious, and misrepresented both the Victorians and the historical chain of events, the vision's appeal convinced the British public and contributed to Thatcher's success. Thus, even though the Victorians themselves have nothing to fear from contemporary re-visions and re-constructions of their culture, the contrast and comparison between contemporary society and the past can be just as politically charged as a stereotypical dichotomy between 'East' and 'West'. Another example of this can be found in the 'repressive myth' postulated by Foucault, and substantiated by Marcus, Sweet and others: the image of the sexually repressed Victorians played an instrumental part in the sexual revolution and contributed to the impression that contemporary society is indefinitely more liberal by contrast. This process bears a certain similarity to the myth of the iron maiden', a supposedly medieval (but almost certainly fictional) torture device commonly reproduced in the $19^{\text {th }}$ century to illustrate how enlightened and progressive then-contemporary society was in contrast with the past.

However, few - if any - neo-Victorian texts seek to actively enforce their specific revisionist perspective as a 'corrected', authentic version of the past, as they do not disguise their status as fiction rather than fact. They may exert some influence upon the collective imagination, and influence the way in which the Victorians are remembered. But their fictional nature places them in a realm beyond the demands of factuality. They are story, not history, participating in the memory work of mythmaking.

Neo-Victorian novels...emerge from, contribute to and dramatise a continuing desire for cultural memory today. Acknowledging that arriving at a final, complete version of the past is impossible and, indeed, undesirable, these novels shift the aim and focus of historical recollection from the production of an accurate account of past events to the always-unfinished process of remembering. (Mitchell, 182; original emphasis)

Unlike Orientalist fiction, which - either consciously or unconsciously - perpetuated very specific conceptions of cultural identity by means of a dichotomy between the Western 'self' and the Oriental 'other', neo-Victorian fiction is characterized by a sense of self-reflexivity that undermines such a clear-cut polarization. Instead, the Victorian other becomes a mirror-image for the present, exploring "both our continuity with, and our difference from, our Victorian forebears" (Mitchell, 177). This is especially true with regards to aspects of Victorian society that could not be fully articulated in nineteenth century fiction: societal taboos and cultural blind spots that 
contributed to a store of repressed material within the Victorian cultural identity, and that continued to influence subsequent generations. 


\section{Exploring the Collective Victorian Unconscious}

\subsection{Psychoanalysis, Post-Structuralism and Literature}

Analyzing literary texts through the lens of psychoanalysis has become such a wellestablished and widely used critical approach that few people will find it necessary to justify this methodological angle. After all, the whole discipline of psychoanalysis has been closely associated with literature since its founding days: Sigmund Freud's 'Oedipus complex' is closely indebted to ancient Greek drama, and Carl Gustav Jung pointed to R.L. Stephenson's Dr Jeckyll and Mr Hyde to illustrate the concept of the shadow archetype (just to mention two prominent examples). Time and again, literary sources were employed to point out supposedly universal psychological concepts - and throughout the twentieth century, various critics applied these concepts to other fictional texts in turn.

Among the greatest achievements of Freudian theory has been the invention of a new language capable of giving shape, through images, to the subjective and private experiences of the unconscious. It is a figurative and imaginative language with a terminology of its own and an ability to play various roles within and between one's psychology. In doing so, it succeeds in creating a true dramatization of consciousness. (Idelson, 12)

However, the psychoanalytic approach is not without its problems - the most prominent of which is tied to the discipline's initial claims of scientific veracity. Freud and Jung believed their models to be objective and universally valid descriptions of the human psyche, instead of (inter-)subjective constructs belonging to a specific historical and cultural context. (And in fact, many pioneers of psychoanalysis ended up as bitter rivals because each of them claimed that their respective models were the only accurate representation of the human psyche.)

As literary and cultural studies are not claiming the status of a natural science, this issue might seem negligible as far as the value of psychoanalytical approaches to literature is concerned. Yet to place this study on firm methodological ground, it 
is necessary to establish its position in relation to the psychoanalytical meta-narrative:

Like the French post-structuralists, I contest the notion that psychoanalytical concepts constitute an objective description of reality. Instead, they are to be regarded as artificial, inter-subjective models that allow us to interpret cultural and psychological phenomena through a very specific lens, often closely tied to a specific language and its inherent symbolic concepts. Following Ferdinand de Saussure's observations, language needs to be understood as a self-referential medium instead of a set of labels attached to pre-existing categories.

If words had the job of representing concepts fixed in advance, one would be able to find exact equivalents for them as between one language and another. But this is not the case. French uses the same verb louer ('hire, rent') both for granting and for taking a lease, whereas German has two separate verbs, mieten and vermieten: so there is no exact correspondence between the values in question. (de Saussure, 114f.)

A person socialized by means of the German language will have a slightly different way of conceptualizing the act of renting when compared to a French native speaker, and thus embrace a distinct perception of the world around them. Language, as part of what Jacques Lacan called the 'symbolic order' of a culture, constructs our conception of reality and our place within it by structuring and interpreting our sensory perceptions; and, unsurprisingly, different languages communicate different versions of reality. "Man speaks, then, but it is because the symbol has made him man" (Lacan). The Symbolic (order), whose primary and most basic manifestation is language, is inextricably tied to what is colloquially called 'culture'. It allows for the exchange of abstract ideas, defines our conception of self (both on an individual and on a collective level), and shapes the way we perceive reality.

Freud's concept of the 'uncanny', for example, is intrinsically tied to the German language and the specific relationship between the terms 'heimlich' and 'unheimlich', and as such communicates a way of conceptualizing the world that may not apply to other languages. Even English, as a West-Germanic language, does not feature a corresponding dichotomy of terms. ('The uncanny' does not communicate the same kind of ambivalence as 'das Unheimliche', even if it allows for a rough approximation of Freud's concept.) Accordingly, Freud's observations regarding the ambivalent and quasi-familiar nature of the uncanny can hardly be applied to every socio-cultural context, but specifically describe a distinctly German way of categorizing specific emotions. These emotional experiences may actually be part of a shared human experience that transcends most historical and cultural borders, drawing upon the same neurochemical impulses in each individual human being. However, different symbolic orders greatly influence the way each individual relates to these experiences, interpreting and compartmentalizing them according to normative terms belonging to a specific language. Naturally, psychoanalysis provides a 
valid interpretation of certain mental states, and it is even possible for people from other cultural spheres to follow Freud's line of argument, and to agree with his conclusions. But the (inter-)subjectivity of this approach needs to be acknowledged, despite Freud's firmly held conviction that the principles he was describing were as universal and objective as Newtonian laws of mechanics. As John Kerr observes in A Most Dangerous Method:

Transparently, the fact that Freund and Jung could ultimately arrive at two different schools of depth psychology indicates that psychoanalysis, despite its claims, was not a science. In fact, no sooner had they first institutionalized their endeavor than the two men began to realize, Freud perhaps more wittingly than Jung, that it was only by enforcing an ideological conformity upon their followers that they could create the appearance of generating homogeneous results. (Position 10092, Kindle file)

Julia Kristeva is even more daring in her choice of etymologies, linking the term 'perversion' to the father (Fr. 'père') (cf. Kristeva, 2) even though any similarity between these terms is purely coincidental and does not extend beyond the phonetic level. However, it is quite likely that the post-structuralist Kristeva was intensely aware of the subjectivity of her approach, and never intended it to be anything other than a personal interpretation of the French symbolic order. Even if the etymology is 'false' in terms of historical linguistics, the association may very well be unconsciously present in French society, or else be constructed by Kristeva to communicate a specific idea. As Catherine Belsey puts it:

[A] community needs a signifying system: social organization and social exchange, the ordering of the processes of producing the means of subsistence, is impossible without the existence of a signification. Language therefore comes into being at the same time as society. This suggests that while the individual sign is arbitrary there is an important sense in which the signifying system as a whole is not. (39)

In this, the difference between Freud's structuralism and Kristeva's post-structuralism comes to the fore: While Freud still operated under the belief that his findings possessed universal and scientifically objective validity, Kristeva and the other poststructuralists conceived of language as a highly (inter-)subjective and self-referential medium whose meaning is fluid and malleable, a multi-directional process of communication depending on all involved parties. Accordingly, just as each individual language confers a different way of categorizing, interpreting and constructing reality, Kristeva's critical models provide $a$ possible approach to specific phenomena, rather than a claim of universal applicability.

This study will embrace the same spirit: it provides a possible interpretation of neo-Victorianism, but by no means insists that this is the only valid approach to the phenomenon. 


\subsection{Freud's Uncanny and the 'Domestic Gothic'}

Neo-Victorianism is often linked to a genre that enjoyed a considerable popularity in the 1860s and 1870s: the so-called 'sensation novel'. Sensation novels provided "a unique mixture of contemporary domestic realism with elements of the Gothic romance, the Newgate novel of criminal 'low life', and the 'silver fork' novel of scandalous and sometimes criminal 'high life"' (Brantlinger, 1). In this specific context, the genre's ties to the Gothic novel are of particular interest: Like the fictions of Radcliffe, Lewis et al., sensation novels typically featured a plot revolving around dark family secrets, sexual deviance and scandalous crimes. But whereas the stereotypical Gothic novel was almost universally set on the Catholic continent, sensation novels usually chose the very heartland of the British Empire as their setting. And whereas the tormented villains in a typical Gothic romance were often marked as foreigners by their name and appearance, the sensation novel's antagonists heralded from the very social class that was supposed to be the backbone of British (and, by extension, Western) civilization. For example, Lewis's sinister monk Antonio is clearly characterized as other, by his status as a Catholic cleric as well as by his Spanish name. The same cannot be said about Mary Elizabeth Braddon's murderous bigamist Lady Audley, however. Whereas the British gothic novel often contained a strong anti-Catholic sentiment that encouraged readers to contrast the decadence and corruption of the Continent with the reasonable foundations of Anglicanism and British common sense, the sensation novel did not allow for such a comfortable dichotomy. Instead, this genre could be read as an attack on the idealized self-image of the Victorian bourgeoisie, challenging the notion that crime and immorality were confined to foreign races or the wretched lower classes.

Thus, the Gothic romance and the sensation novel can be used to illustrate the difference between Sigmund Freud's 'uncanny' and Julia Kristeva's 'abject'. The Gothic novel clearly draws upon an uncanny element that is conceived of as distinctly other: "something familiar ['homely', 'homey'] that has been repressed and then reappears" (The Uncanny, 152). Based on the etymology of the German term 'unheimlich' and its original antonym 'heimlich', Freud argued that the uncanny was linked to the same kind of unconscious desires and repressed memories that also formed the basis of phobic neuroses and other psychological problems. Repressed material with all its attendant fears and unconscious desires is thus projected upon a foreign object, and thereby rendered simultaneously familiar and alien, frightening and alluring. The exotic continental locales commonly associated with the gothic novel bespeak an externalization of the 'uncanny': the seemingly supernatural terrors and horrid family secrets all take place in a remote time and space, creating a sense of distance that not only allows for dissociation but also gives the readers an opportunity to project their own repressed desires upon this historical canvas.

However, this is not what the typical sensation novel aimed for: this genre (which has sometimes been characterized as 'domestic Gothic') does not allow for the comfortable distance of a subject-object dichotomy, but instead focuses on 
potential dark sides hidden within the very fabric of the Victorian collective cultural identity, existing within the borders of the symbolic order without actually belonging to the same. It was this aspect in particular that rendered the sensation novel so scandalous to Victorian audiences (and probably also contributed a great deal to its popularity). Instead of uncanny objects, the genre confronted its readers with what Julia Kristeva calls abjects. And whereas the uncanny might already cause feelings of discomfort due to its ambivalent nature, abjects disrupt the self/other-dichotomy even further.

\subsection{Abjection and the Abject}

Kristeva defines the abject as something that does not fit within the clear-cut demarcation lines we construct between the 'self' and the 'other'; neither subject nor object, abjects can be neither internalized nor externalized, producing feelings of revulsion and horror:

There looms, within abjection, one of those violent, dark revolts of being, directed against a threat that seems to emanate from an exorbitant outside or inside, ejected beyond the scope of the possible, the tolerable, the thinkable. It lies there, quite close, but it cannot be assimilated... When I am beset by abjection, the twisted braid of affects and thoughts I call by such a name does not have, properly speaking, a definable object... the abject has only one quality of the object - that of being opposed to I. (1)

Like Freud's 'uncanny', which derives its horror from being poised between the frighteningly other and the strangely familiar, the 'abject' is too close for comfort: it persists between the artificial boundaries of the 'symbolic order' imposed by language and culture, a disruptive element whose very existence conflicts with the societal ideal. Unlike the uncanny, however, it stands apart from the usual subject-object-relation, and is perceived in terms of contamination and defilement.

Literally speaking, abjects take the shape of all kinds of bodily fluids and excretions: sweat, saliva, semen, menstrual blood, excrement - in short, all those gross effluents that are inextricably tied to our bodies yet are not perceived as an intrinsic part of us (or our 'selves'). Our negative reaction to the presence of some of these substances is instinctual, and as such manifests from a very early age onwards, potentially preceding the development of a full-fledged sense of self.

If... a space becomes demarcated, separating the abject from what will be the subject and its objects, it is because a repression that one might call "primal" has been effected prior to the springing forth of the ego, of its objects and representations. The latter, in turn, as they depend on another repression, the "secondary" one, arrive only a posteriori on an enigmatic foundation that has already been marked off; its return, in a phobic, obsessional, 
psychotic guise, or more generally and in more imaginary fashion in the shape of abjection, notifies us of the limits of the human universe. (Kristeva, 11; original emphasis)

Accordingly, the 'abjects' (and our visceral negative response to their presence) cannot really fit within the boundaries we construct for ourselves (or instead: the boundaries which construct us); they create a dissonance, an irritating impurity that chafes at the foundations of our elaborately constructed identities. In contrast to Freud's uncanny, which is more firmly located within the symbolic subject-objectdichotomy of the symbolic order, the abject stands outside and is fundamentally excluded from these concepts.

Kristeva strongly associates this concept with physicality (and a stage of an infant's life that immediately precedes their introduction to the symbolic order and the development of a sense of self). I would argue, however, that this phenomenon is neither limited to the bodily excretions referenced earlier, nor does it only apply to individual identity constructs. The very same revulsion (and the need to purge or purify the abject) is also present in the way society deals with parts of themselves that are neither 'self' nor 'other'.

Metaphorically speaking, the 'abject' may also refer to all those aspects of a society or culture that do not fit into their idealized self-conception, yet cannot be divorced from them: prostitution, crime, poverty and other social ills that exist precisely because, not despite the way a specific society is structured. In this capacity, the abject also applies to collective cultural identities. It exists in all the dark aspects that a society cannot incorporate within its idealized self-conception. It constitutes the dissonances that lie at the heart of each identity construct, the unresolved self-contradictions that violate the symbolic order.

The Victorian age provides a good example of this in the shape of the sex industry: the collective Victorian super-ego (as represented by the ideals of middleclass morality) put a pronounced taboo on sexuality, especially as far as women were concerned. Ideally speaking, middle and upper-class women were expected to be oblivious with regards to the whole topic, persisting in a state of ethereal innocence and only engaging in marital relations in order to please their baser husbands. Some physicians went so far as to declare a woman who exhibited signs of sexual desire to be suffering from hysteria, and prostitutes were not only characterized as social misfits, but as physiological aberrations violating the natural order. For example, in 1870, William Acton declared from the pages of the medical journal The Lancet:

What is a prostitute? She is a woman who gives for money that which she ought to give only for love... She is a woman with half the woman gone, and that half containing all that elevates her nature, leaving her as a mere instrument of impurity; degraded and fallen she extracts from the sin of others the means of living, corrupt and dependent on corruption, and therefore interested directly in the increase of immorality - a social pest carrying 
contamination and foulness to every quarter to which she has access. (qtd. in Attwood, 36)

One of “Acton's chief purposes... [was] to humanize the prostitute, to educate or persuade his respectable audience... as a fellow human being” (Marcus, 5). And yet, despite his desire for reform and the betterment of their lot, his depiction of the "social pest" clearly defines prostitutes as abjects, as "instruments of impurity". Their implied corruption extends beyond the merely physical risk of spreading contagious diseases. Acton's usage of the word 'sin' gives his description a clearly spiritual dimension, depicting prostitutes as agents - and victims - of metaphysical evil. Most important in this context, however, is the phrase "a woman with half the woman gone": it conveys much about the way femininity was constructed and defined during the Victorian age, specifically with regards to sexuality. Essentially, a woman who deviates from the socially accepted path of monogamous, patriarchal marriage is not only a social outcast, but ceases to be a "real" woman, becoming a kind of indeterminable creature beyond the clear-cut gender categories available to society. In other words: she becomes an abject. It is debatable whether this particular point of view bore too much of a resemblance to the societal consensus at the time, but it is quite clear that prostitution was incompatible with the idealized selfimage of Victorian society, and that its practitioners had no place in middle-class circles.

Despite such negative sentiments, and in spite of legislative initiatives such as the Contagious Diseases Act of 1864, prostitution continued to be a thriving business throughout the nineteenth century (cf. Marcus). By placing such a strong taboo on sexuality, it was forced into what C.G. Jung called the 'shadow', persisting in the repressed regions of the collective cultural identity - and re-emerged in a twisted form, seeking an outlet. ${ }^{10}$ In addition to actual sex work, pornographic materials were produced and sold at an unprecedented rate - regardless of the Obscene Publications Act of 1857, which turned the distribution of erotica from a misdemeanor into a statutory offense. Apparently, there existed an enormous discrepancy between the Victorian middle-class ideal (or super-ego) and the abject reality of that day and age. This is hardly unexpected. "To each ego its object, to each super-ego its abject" (Kristeva, 2).

It should be noted that the object in this particular context refers to a psychoanalytical concept developed by Sigmund Freud and - more importantly here Jacques Lacan: the 'object' denotes a desire that cannot be fulfilled, an 'other' (objet petit a) that is sought after but can never be part of the subject/self by virtue of its place within the symbolic order of language. At first glance, it might seem puzzling

10 There were other factors involved in the sex trade's boom, of course, such as the crushing poverty that drove many working class women to prostitution. But there clearly existed not only a strong supply of women who were willing - or forced - to trade their bodies for coin, but also a strong demand that could not be filled by the de-sexualized domestic angels envisioned as the bourgeois ideal of matrimony. 
that the abject with its associations of revulsion and horror should in any way correspond to the object, which is connected to feelings of desire and want. Yet a closer look at Kristeva's statement reveals the parallels between the two concepts: if the object is first and foremost defined by its otherness, its difference and isolation from the ego, then the abject is in turn characterized by being distinctly other in relation to the super-ego. After all, the super-ego refers to the normative values, behavioral restrictions and - last but not least - cultural ideals a person acquires during the process of socialization. Accordingly, abjects are all those concepts that do not fit within the confines of these norms, standing apart from the clear-cut cultural constructs and posing a threat to the same. This threat, in turn, prompts feelings of disgust and abjection.

An individual's or a culture's abjects cannot be accommodated within (or placed without) the established symbolic order. The resulting cognitive dissonance is virtually insurmountable: "'[S]ubject' and 'object' push each other away, confront each other, collapse, and start again - inseparable, contaminated, condemned, at the boundary of what is assimilable, thinkable: abject" (Kristeva, 18). The only possible reaction left is a sense of physical repulsion, a primal, bodily reflex.

A passage from Wilkie Collins's sensation novel The New Magdalen illustrates this point quite well: it depicts an exchange between two women who are forced to share a room; one of them is a young middle-class lady called Grace Roseberry, the other a repentant prostitute called Mercy Merrick, working as a nurse in a French military hospital. Grace repeatedly tries to befriend the other woman, yet Mercy rejects her advances, eventually revealing her sordid past:

"Have you ever read of your unhappy fellow-creatures (the starving outcasts of the population) whom Want has betrayed to Sin?... I was once one of those women", she said, quietly. Grace sprang to her feet with a faint cry. She stood petrified - incapable of uttering a word. (Collins, 11)

Grace's reaction betrays an almost physical sense of revulsion, prompting her to shrink back in horror. The abject she reacts to is not a source of tangible contamination, and yet her immediate response is indistinguishable from that of a person who retreats from some revolting substance. The pollution she fears is of a socio-cultural nature, and even though the novel clearly tries to engender sympathies with the former prostitute, (and is in fact one of the few texts that actually allow a 'fallen' woman to survive,) its challenge to the underlying norms is of a limited scope: the former prostitute's claim to redemption and sympathy rests solely on the fact that she has renounced her former profession, and would fervently wish to become a domestic angel. Finally, even the fallen woman herself seems to agree that there is an infectious stain upon her, as she encourages Grace Roseberry to hold her distance: "Move your chair a little farther away from me" (Collins, 11).

Thus, even though The New Magdalen is unconventional in its choice of a protagonist and in its willingness to offer her a redeeming resolution (both of which 
mark its author as a social critic campaigning for cultural change), it still perpetuates some of the norms of its day, placing very specific conditions on the prostitute's eventual return to the established social order. To be reintegrated, Mercy must first cease to be an abject and undergo an almost ritualized moral cleansing process that serves as the novel's overarching plot. Only after having proven herself to be a paragon of self-effacing Christian morality can Mercy hope for a limited form of reintegration, earning the acceptance of a small circle of deserving friends and loved ones. In other words: The New Magdalen continues to perpetuate the norms of its day, even while it campaigns for reforms. Instead of challenging the sinner/saintdichotomy at the heart of Victorian gender ideology, the novel describes the ascendancy of a domestic angel whose purity and virtue outshine the obvious stains on her past.

It is at this point that neo-Victorian fiction can offer a perspective unavailable to the Victorians themselves: written from the distance of more than a hundred years, and imbued with cultural values that are quite distinct from Victorian middleclass morality, neo-Victorian texts can explore angles that were simply unthinkable within the confines of nineteenth century mainstream literature, creating an alternate history that redeems and reintegrates historical abjects. Thus, neo-Victorianism contributes to a kind of collective Jungian 'shadow work', confronting and expanding cultural limitations and boundaries:

[T] he centralization of non-normative protagonists in neo-Victorian fiction participates in the gradual expansion of cultural norms to accommodate a diversity of social subjects, with the potential to advocate for transformative changes to the political equality of such subjects beyond the narrative. (S. Carroll, 195)

Although it is doubtful whether most neo-Victorian fiction actively and deliberately engages in this kind of social engineering, it clearly stands to reason that the genre's characteristic challenge to Victorian norms also serves as a challenge to contemporary conventions, especially in areas where current societal discourses have not yet arrived at a broad consensus. Sarah Waters's neo-Victorian novels are a prominent example of this, transposing queer discourses and terminology into the nineteenth century and giving a voice to lesbian relationships that could not be found in Victorian mainstream literature. (In fact, given that the concept of homosexuality as an integral part of a person's identity was not yet an established part of a broad societal consensus in the late 1800s, it would have been virtually impossible for Victorian texts to portray this kind of relationship.)

Literature may here exert a function that was historically associated with religion, first an foremost: it breaks down the boundaries that set our symbolic order apart from the abject, and helps to re-integrate and cleanse it.

The various means of purifying the abject - the various catharses - make up the history of religions, and end up with that catharsis par excellence called 
art, both on the far and near side of religion. Seen from that standpoint, the artistic experience, which is rooted in the abject it utters and by the same token purifies, appears as the essential component of religiosity. That is perhaps why it is destined to survive the collapse of the historical forms of religion. (Kristeva, 17)

\subsection{Individual Self and Collective Cultural Identity}

One of the most important ideas Freudian psychoanalysis contributed to subsequent discourses on identity was the observation that the 'self is not an essentially static concept, but a complex, multi-faceted, malleable construct. Instead of defining the psyche as the immutable essence of a person (in lieu with religious conceptions of the 'soul'), Freud held that man's consciousness and identity consisted of diverse (potentially conflicting) parts: "We assume that mental life is the function of an apparatus to which we ascribe the characteristics of being extended in space and of being made up of several portions [namely the super-ego, the ego, and the $i d$ ]" ( $A n$ Outline of Psychoanalysis, 13). Even though this particularly Freudian, tripartite model of the psyche has fallen into disfavor in contemporary psychology, it exerted an enormous influence upon the collective cultural consciousness of Western civilization, and its terminology has entered everyday speech. It may not be objectively, scientifically accurate (as Freud might have insisted), but it allowed for a new approach to how people think about themselves and their sense of "I".

Keeping this in mind, it is nonetheless quite clear that identity is indeed a multifaceted construct, both on an individual and on a collective level. Cultural identity is often defined by what Emmanuel Lévinas calls 'alterity': a clear demarcation line that separates the self from the not-self - or, in the case of cultures, $u s$ from them. According to Lévinas, occidental philosophy suffered from a tendency to brutally define the 'other' according to its own categorizations, never bothering to engage foreign symbolic orders on their terms (see: V. Nünning, 383). A closer look at other cultures suggests that this phenomenon is hardly limited to the European history of ideas. Even relatively heterogeneous societies may achieve a strong sense of shared identity if they contrast themselves with a stereotypical other - the image of another cultural community whose values supposedly run contrary to one's own. History offers numerous examples of this: the ancient Greeks coined the term 'barbarian'; the Japanese conceive of foreigners as 'gai-jin'; the British Empire regarded its colonial subjects as primitive 'orientals'; and in the United States of America, socialist is a term that conjures up Cold War anxieties to this day.

Previous chapters of this study have already alluded to the idea that neo-Victorian fiction conceives of the Victorian age as both a foil and a mirror for contemporary society, establishing an ambivalent and tension-laden relationship between Great Britain's past and its present, often defying the us-them-paradigm by drawing 
attention to similarities and differences between the Victorians and contemporary society.

Whereas the Modernists clearly conceived of the Victorians as the 'other' against which they could define their own distinct collective identity, neo-Victorianism is as much interested in the commonalities as in the differences between the Victorian era and the early twenty-first century. As such, the parallels between Orientalism and (neo-)Victorianism proposed by Sudha Shastri are indeed somewhat limited, as the Victorians are never placed in the same kind of opposition as the former colonial subjects of the Empire. Instead, they provide an opportunity for projection, enabling authors to place contemporary societal conflicts in a past that is similar enough to allow for identification, and yet remote enough to provide a sense of distance. It is this particular approach that encourages the pronounced focus on Victorian abjects: they are not merely connected to a bygone historical period, but directly linked to British contemporary cultural identity.

Neo-Victorianism's contribution to the process of cultural memory might help to create a renewed sense of cultural tradition by establishing (or, to a certain degree, re-discovering) the very ties to the Victorian past that the Modernists sought to deny so vehemently. Neo-Victorian fiction places post-modern Britain and its former colonies in a historical continuity that invites the reader to identify similarities between the Victorians and us - even while maintaining an ambivalent relationship with the Victorian past. In contrast to the Orient, whose assumed alterity has been used to strengthen the collective cultural identity of the Occident by means of contrast, the Victorian age is placed in a state of ambivalence. What function does this approach serve within the context of cultural memory, then?

\subsection{Confronting the Shadow/Purifying the Abject}

This study maintains that neo-Victorian literature casts the Victorians in a role that bears a striking similarity to what the Swiss psychoanalyst Carl Gustav Jung called the 'shadow' archetype. In Jung's structuralist model of the psyche, archetypes are innate mythological or primordial images residing within the 'collective subconscious' that are instrumental in the construction of our individual sense of identity: they reflect supposedly universal qualities of the human condition, and are reflected by mythological figures such as gods, heroes, or spirits. One of these is the shadow, which bears some distinct similarity to Kristeva's 'abject', insofar as it incorporates aspects that are dissociated from the idealized self-image, yet undeniably constitute a part of the self. Repressing or denying this aspect of one's psyche produces considerable negative side effects, as the displaced and unwanted aspects of one's personality will fester and grow in the unconscious regions of the mind, seeking to assert control. In Carl Gustav Jung's words: "Everyone carries a shadow, and the less it is embodied in the individual's conscious life, the blacker and denser it is" (Psychology and Religion: West and East, 131). The stereotypical image of Victorian 
gentlemen who visit prostitutes and peruse pornographic materials even while they publicly denounce sexual immorality illustrates this principle quite well.

Like Kristeva's abject, Jung's shadow archetype supposedly hearkens back to an early phase in the development of the human psyche, incorporating all sorts of instinctual urges and unconscious drives that clash with the norms and values of civilized Man - or, in Kristeva's/Lacan's terms, with the established symbolic order. This study regards Jung's model of the archetypes as a poetic approach to the human psyche rather than an objective description of the same. Nonetheless, Jung's approach constitutes a valid method of interpreting culture and literature, as long as the artificial nature of its meta-narrative level is acknowledged.

Both Jung's shadow archetype and Kristeva's abject are not only indicative of disruptive elements within specific identity constructs; they are also closely linked to the religious sphere, as well as to artistic pursuits: Kristeva notes that most cultures and religions are invested with elaborate purification rituals specifically aimed at eliminating the taint of abjection - and that this pursuit may also provide a strong foundation for artistic endeavors:

Abjection accompanies all religious structurings... The various means of purifying the abject - the various catharses - make up the history of religions, and end up with that catharsis par excellence called art, both on the far and near side of religion. (Kristeva, 17; emphasis in original)

Just as Kristeva alludes to the strong ties between religion and abjection, Jung describes working with the shadow in terms of spiritual initiation, employing imagery that is strongly reminiscent of various archaic rituals and techniques.

Wie viel weiß der Mensch aber von sich selber? Es ist nach aller Erfahrung sehr wenig. Für das Unbewußte bleibt daher noch viel Raum übrig... Die nötige und benötigte Reaktion des kollektiven Unbewußten drückt sich in archetypisch geformten Vorstellungen aus. Die Begegnung mit sich selber bedeutet zunächst die Begegnung mit dem eigenen Schatten. Der Schatten ist allerdings ein Engpaß, ein schmales Tor, dessen peinliche Enge keinem, der in den tiefen Brunnen hinuntersteigt, erspart bleibt. (Archetypen, 24)11

The "deep well" with its "embarrassing tightness" clearly signifies a (re)birth, following upon a transformative confrontation with the unknown aspects within one's own psyche (and the attendant 'death' of the false self-image that persisted prior to the attainment of these insights).

${ }^{11}$ How much does Man know about himself? According to common experience, it amounts to very little. Accordingly, there is much space left for the unconscious... The necessary and needed reaction of the collective unconscious expresses itself in archetypal conceptions. Encountering oneself means first and foremost encountering one's own shadow. The shadow, however, is a choke point, a narrow gate whose embarrassing tightness afflicts everyone who climbs down into the deep well. [my translation] 
If we conceive of the Victorian era as the collective shadow archetype of contemporary British society, and keep in mind how the Modernists sought to suppress their ties to their parents' generation, then neo-Victorianism might indeed contribute to a sort of healing process that re-integrates the past while simultaneously fostering a greater awareness of its less healthy aspects. It encourages identification with the Victorian 'other', even while it highlights the abjects of that particular age, thus allowing contemporary readers to reflect upon the (potentially historical) roots of their own cultural sensibilities. By deconstructing the (pseudo-)Victorian ideal communicated by the literary mainstream of the nineteenth century and the historical novels of the contemporary era, we might develop a greater awareness for the non-reflective, unconscious blind spots within our own symbolic order.

\subsection{Revisioning Victorian Sexuality}

At first glance, the topic of sexuality does hardly appear to be a blind spot within the contemporary era's collective cultural consciousness: we tend to regard our own culture as sexually liberated, progressive, and emancipated - the virtual antithesis of the sexual repression we commonly associate with Victorianism. ${ }^{12}$ Naturally, this self-perception is not wholly inaccurate: many positive societal changes have been effected within the last century, particularly as far as women's rights are concerned. At the surface level, Western society is now considerably more permissive with regards to sexuality than it used to be a hundred or even fifty years ago. Young women can venture into public without a chaperone, the cult of virginity has mostly receded to the extremely religious fringes of society, and an exposed ankle does no longer qualify as immoral - even in the most conservative circles. Lifestyle magazines are brimming with bedroom advice (thus, unbeknownst to most readers, following a whole tradition of "medical and popular literature on the topics of love and marriage" (Urban, 28) created by none other than the Victorians), and advertising companies sell products by unabashedly associating them with erotic stimuli. In short, contemporary Western culture seems to bear very little resemblance to Victorian times, when even such an innocent act as talking to a man in an otherwise empty room could permanently ruin the reputation of an unmarried girl.

However, one does not need to look very far in order to discover that even today, sexuality and gender are still highly volatile topics at the heart of many an intra-cultural conflict: discrimination against LGBTQI* people, the wage gap between male and female employees, and the all too common objectification of the female body all bear testimony to the fact that we have inherited a substantial abject heritage from the past. Our discourses on these topics are directly related to those

${ }^{12}$ Foucault argues that this "repressive hypothesis" is at least partially incorrect, as the nineteenth century saw an unprecedented amount of discussion on the topic of sex, basically forming the foundation of our present status quo. (10f.) 
of our Victorian predecessors, down to the very way we think about concepts such as sexual orientation or normative relationship models.13 And even though some Victorian abjects have finally ceased to be outside of the symbolic order of Western culture, there is still a teeming underground of sexual taboos and non-normative behaviours that continue to incite feelings of abjection.

Neo-Victorian fiction seizes upon both the similarities and the discontinuities between the past and the present, approaching the topic of sexuality and gender roles from several different directions. On the one hand, it draws upon the familiar stereotype of the Victorian other, established by authentic nineteenth century novels (and their rigorous self-censorship) as well as by Modernist interpretations of the past. On the other hand, neo-Victorian novels habitually challenge commonly held assumptions about the Victorian age or at least introduce other voices that show the reader a very different version of the nineteenth century. They engage in an intertextual dialogue with their literary predecessors. By focusing on the abject sexual underpinnings of Victorian culture, neo-Victorian literature not only aims to change the reader's perception of the past, but also pinpoints the roots of contemporary issues in an historical setting. More often than not, the protagonists in neoVictorian novels clash with the normative standards of their society. They engage in a cultural struggle that does not only foreshadow societal changes (that will eventually lead to our current status quo), but also touches upon conflicts that are still manifest in contemporary culture. Victorian middle-class ideology with its separate spheres and domestic angels might be (mostly) gone, but its heritage continues to exert some influence - especially with regards to abjects buried within our collective subconscious.

The discrepancy between the moral ideals of the Victorian bourgeoisie (as reflected by the popular novels of that day and age) and the reality of Victorian everyday life (as revealed by historical sources and marginalized voices) creates an ambivalence that begs to be explored in greater detail. Thus, neo-Victorian fiction tends to play with the reader's expectations, combining well-known motifs with startlingly new perspectives. It gives a voice to the marginalized and the silent, draws close attention to the literal and metaphorical filthy aspects of the era, and insists on leaving on the lights in the bedroom, depicting nudity and sex in graphic detail. The familiar imagery from diverse Victorian parent texts is still there, but it is usually subverted and called into question, as the following chapters will show.

${ }^{13}$ For example, Richard von Krafft-Ebing's Psychopathia Sexualis popularized (and in some cases coined) a wide range of medical terms pertaining to sexuality that are now an intrinsic part of our collective cultural consciousness, such as homo- and heterosexuality. (Naturally, most deviations from the societal norms of that day were considered pathological at the time - a perception that has changed in some cases, even if the terminology is still the same.) And when cultural conservatives talk about 'traditional' family structures today, they usually mean the 'core family' consisting of a single couple and their children - a model that is inextricably linked to the rise of the middle-class. 


\section{Lost Girls: Make Love, Not War}

\subsection{Creating a Different Kind of Pornography}

Sexually progressive cultures gave us mathematics, literature, philosophy, civilization, and the rest, while sexually restrictive cultures gave us the Dark Ages and the Holocaust. Not that I'm trying to load my argument, of course. (Alan Moore: 25,000 Years of Erotic Freedom, 39)

Sometimes, neo-Victorian novels do not only explore Victorian taboo subjects, but also offend contemporary sensibilities, pushing beyond the limits of socially accepted norms. They touch upon areas of life that potentially qualify as 'abject' within the current cultural zeitgeist, such as the sex industry in its many guises. The graphic novel Lost Girls (co-authored by Melinda Gebbie and Alan Moore) clearly falls into this category: the mere fact that it is pornographic in nature suffices to place it at the very edge of - or even beyond - the commonly accepted territory of entertainment and art, but that is hardly the only aspect of the novel that renders it controversial, as the following analysis will demonstrate.

Lost Girls was first published in toto in 2006, although its genesis spanned almost two decades, starting in 1989 or 1990 (cf. Shindler). Its first four chapters had already seen print in various comic anthology magazines that, according to Alan Moore, "collapsed under it" (ibid.). But despite these difficulties, Moore and Gebbie continued to work on the material for sixteen years. When it was finally printed in 
full, it took the shape of a lavish hardcover edition in three volumes, thus mark(et)ing it as art rather than 'smut'. Moore's fellow comic book author Neil Gaiman remarked upon this as follows:

Top Shelf has taken the traditional approach of a respectable publisher when faced with the problem of bringing out pornography, and has chosen to package it elegantly, expensively and beautifully, thus pricing, shaping, signalling and presenting it to the world, not as pornography, but as erotica.

Moore and Gebbie, however, consistently refer to Lost Girls as pornography, feeling that the distinction between erotica and porn is "pretentious" and that "the only difference between [the two] is the income bracket of the person reading it" ("XRated"). There certainly seems to be a correlation between distinctions of genre and distinctions of class: after all, the term 'genre' entered the English language at a time when increasingly higher literacy rates and cheap mass publication might have prompted the upper strata of society to create clear boundaries between their own art and entertainment and the material available to the less cultured working class ${ }^{14}$. Regardless of whether one agrees with Moore's and Gebbie's rejection of the generic distinction between erotica and pornography, however, the graphic novel is unmistakeably aimed at a culturally literate audience, combining explicit depictions of human sexuality with discourses on repression, human nature, and the freedom of imagination (just to mention a few). Its references to history, Freudian psychoanalysis, literature, music, and art may be mystifying to readers oblivious to the intertextual layers underneath.

Part of the controversy surrounding Lost Girls is most certainly based on placing beloved icons of children's literature (such as Alice in Wonderland and Peter Pan and $W e n d y)$ in unabashedly adult situations, not only touching upon the taboo subject of underage sexuality, but also 'sullying' their reputation by presenting them in a pornographic scenario. Conversely, I would argue that literary explorations of sex, in and of themselves, hardly need to be regarded as degrading - even if they may qualify (or self-identify) as pornography. If anything, normative values that regarded sexuality as intrinsically vile and corrupting have forced the whole genre into the sordid underbelly of the entertainment industry, creating a kind of self-fulfilling prophecy. As Alan Moore put it in an interview with Dorman T. Shindler in Science Fiction Weekly:

Certainly it seemed to us [i.e. Moore and Gebbie] that sex, as a genre, was woefully under-represented in literature. Every other field of human experience - even rarefied ones like detective, spaceman or cowboy - have got whole genres dedicated to them. Whereas the only genre in which sex can be discussed is a disreputable, seamy, under-the-counter genre with absolutely

${ }^{14}$ The Oxford English Dictionary lists the term's first recorded usage in 1770, but it only entered popular usage in c.1840. 
no standards: [the pornography industry] - which is a kind of Bollywood for hip, sleazy ugliness.

Given that contemporary culture regards simulated violence- even in its ugliest and most gruesome forms - as acceptable entertainment, it seems almost bizarre that sexuality should still be a considerably greater taboo. Of course, there are occasional debates on the relationship between simulated violence and violent crime, and whether there is a direct connection between the two. Nonetheless, TV shows like Dexter or Hannibal (which place a serial killer in the role of the protagonist or antihero) are part of the weekly programme, depicting gruesome acts in such meticulous detail that it might be tempting to call them 'pornography of violence'. (In fact, several series that feature comparatively explicit depictions of sex - such as Rome, True Blood, Spartacus, or Game of Thrones - habitually connect sexuality to representations of cruelty and murder.) This phenomenon might warrant some further investigation, but in the context of this study, it is only relevant insofar as the evaluation of Lost Girls is concerned. Its pornographic nature renders it utterly taboo for any mainstream venue, even in the supposedly sexually liberated contemporary era of the $21^{\text {st }}$ century. Sexuality has always played a prominent role in Moore's oeuvre, yet it is only in this graphic novel that it supersedes more conventional conflicts and becomes the primary focus of the plot. As a result, Lost Girls has been perceived as considerably more controversial than From Hell, for example - even though the latter contains extremely brutal scenes of murder and dismemberment as it follows Jack the Ripper through the streets of Whitechapel. This discrepancy is most likely due to pornography's lack of social prestige, and any work of fiction associated with it will suffer from the connection.

Lost Girls is an attempt at "saving pornography from itself", as Scott Thill put it in another interview with Moore for the e-zine Morphizm in 2006. While undeniably pornographic in its conception and intent, it seeks to communicate more than just sexual titillation - something that cannot be said about the vast majority of pornographic fiction. One might expect that a genre that habitually oversteps the boundaries of mainstream society might offer a different, subversive perspective on a culture. Unfortunately, most mainstream pornography perpetuates some of the worst misogynist ideas that exist within contemporary Western culture: First and foremost, the genre's low status emphasizes the notion of sexuality as a supposedly shameful and lowly aspect of human nature that needs to be hidden away in a dark corner - and most pornographic media do very little to dispel that impression. Even more damning is the active promotion of misogyny, communicating a sense of loathing and humiliation for the women who 'star' in these productions. Going beyond mere objectification (which is bad enough in and of itself), many pornographic films depict women in degrading positions, show the male actors shouting abuse at their partners, and eventually conclude with undeniably humiliating variations of 
the so-called 'money shot'15. These phenomena have led many feminists to reject pornography completely, perceiving it as a mere accessory to patriarchal oppression rather than a potentially liberating and subversive medium. ${ }^{16}$ This assessment also extended to the academic study of the phenomenon, where "there was very little work on porn that did not belong to... a discourse of antipornography feminism that equated porn with men's violence against women or institutionalized male power" (F. Attwood, 3f.) until the mid-1990s.

Other voices, however, maintain that pornography in and of itself does not need to be misogynistic, and that it can be re-appropriated as a feminist medium. Over the course of the last two decades, the "unhelpful view of pornography as a monolithic entity with self-evident characteristics and functions" (ibid, 4) was increasingly challenged by academia and porn producers alike. In recent years, directors such as Erika Lust, Tristan Taormino and Candida Royalle have attempted to take the genre in a different direction, proving quite effectively that "feminist pornography" need not be an oxymoron. Various awards, such as the Feminist Porn Award in Canada (since 2006) and the German PorYes Award ${ }^{17}$ (since 2009) reflect the increasing popularity and acceptance of this new direction in a category of entertainment that was once considered the very antithesis of feminist endeavours.

The pertinent question then is: does Lost Girls qualify as feminist porn, or does it communicate another ethos? Regardless of the authors' intentions or political convictions, what does the graphic novel as such communicate to its readers? The answer to that question necessitates some further analysis.

Even though Lost Girls is most certainly a complex, intellectually stimulating text that demands a certain degree of cultural literacy from its reader, its portrayal of (predominantly female) characters might be perceived as a continuation of objectifying trends commonly associated with the genre. There are considerably more panels devoted to female nudity and sexuality than to the male equivalent, and in scenes that involve characters of both sexes, the picture tends to focus more prominently on the women. Additionally, both Gebbie's artwork and Moore's writing seize upon and allude to Victorian and Edwardian pornography - a genre that was hardly known for its egalitarian efforts. Written by male writers for an exclusively male

15 The 'money shot' is a depiction of the male climax, which usually concludes a pornographic scene (thus communicating the message that the whole proceedings were centred on the man's pleasure, with the woman as a mere accessory to the same). In its most misogynist variation, it depicts the female performer on her knees in front of the man, often suggesting that the man forces her into that position by grabbing her hair.

${ }^{16}$ For example, Alice Schwarzer initiated the "PorNo"-campaign in 1987, espousing the legal prohibition (and re-definition) of pornography as a violation of human dignity: "Die Definition geht davon aus, daß der zentrale Sinn der Pornografie die Propagierung und Realisierung von Frauenerniedrigung und Frauenverachtung ist." (48) ("The definition assumes that the intent of pornography lies in the propagation and implementation of female subjugation and misogyny." [my translation])

17 Obviously, the name PorYes is a direct reference to Schwarzer's campaign. 
audience, the prevalent attitude communicated by the genre was incredibly sexist and elitist. Alan Moore described the attitude of Victorian pornographers as follows:

We're all men, and we're upper-class men. So we can be trusted to read this without becoming depraved or going on a rape spree. Whereas, of course, people of weaker character, the lower class, women, black people, people who are closer to savages, they couldn't be trusted with it because it would probably inflame them! (Shindler)

Despite the sex-negative ethos that dominated Victorian society (and regardless of the Obscene Publications Act of 1857 that specifically prohibited the distribution of pornographic materials), an unprecedented amount of erotica was created - and marketed - in the late 1800s and early 1900s. To an extent, these publications posed a veritable challenge to the status quo by breaking prevalent taboos. Yet like their contemporary equivalent, Victorian erotica (for the most part) were not necessarily intended to promote radically different values, but instead tended to perpetuate and confirm the dominant zeitgeist in many ways. The writer and bibliographer Henry Spencer Ashbee (1834-1900) might serve as a perfect example of the Victorian sexual underground's ambivalence on this account: Ashbee assembled and indexed an enormous collection of pornographic texts (and might have been the author of $M y$ Secret Life, the erotic memoir of a Victorian gentleman). Given such liberal attitudes regarding sexuality, one might expect him to be a representative of social progress. Surprisingly, the opposite was the case: Ashbee was a staunch conservative, especially as far as women's rights were concerned, and deeply resented the progressivism that prevailed in the rest of his family. His son Charles commented on this profound rift (and the subsequent divorce of his parents) as follows:

It is at this point in Victorian development [i.e. in 1891] that we of the younger generation first became aware of a cleavage, a parting of the ways [...] My mother moved on, my father stood still [...] and a part of her tenacity was to win a wider scope and freedom in thought for herself and her children. The eighties saw a weakening of the 'patria potestas' in the home [...] Even after the law of England had been altered men still could not believe that [...] a woman might have a life and soul of her own. (qtd. in Gibson, 128f.)

Henry Spencer Ashbee's socio-political views may not apply to all his contemporaries involved in the production and consumption of pornographic materials, nor reflect the underlying ethos of every Victorian pornographic text. However, they most certainly demonstrate that liberal views on sexuality and sexual entertainment did not automatically coincide with social progressivism, and that Victorian pornography did not necessarily pose a challenge to the dominant ideology as a whole. In fact, it stands to reason that Victorian pornography primarily served as a kind of cultural 'pressure valve', providing an outlet for repressed (male) sexuality in a highly 
controlled setting - akin to carnival celebrations or similar ritualized transgressions. ${ }^{18}$

Keeping this in mind, it might be tempting to assume that by drawing upon Victorian sources, Lost Girls ultimately communicates a similarly misogynistic or objectifying perspective. Yet in spite of stylistic (and thus, ultimately superficial) similarities between Lost Girls and its parent texts and/or images, the ethos that is communicated by the graphic novel is almost diametrically opposed to what can be found in most pornographic fiction, be it historical or contemporary. Author K.A. Laity explored the moral dimension of Lost Girls by comparing it to (and measuring it against) suggestions for a feminist version of pornography put forth by Angela Carter's The Sadeian Woman. In her "polemical preface" to that study, Carter maintained:

Pornographers are the enemies of women only because our contemporary ideology of pornography does not encompass the possibility of change, as if we were the slaves of history and not its makers, as if sexual relations were not necessarily an expression of social relations, as if sex itself were an external fact, one as immutable as the weather, creating human practice but never a part of it. (1)

Following this line of thought, Carter conjures up the vision of a hypothetical "moral pornographer" (22), producing a highly subversive "critique of current relations between the sexes" (ibid.). Laity seizes upon this description and applies it quite convincingly - to Moore's and Gebbie's graphic novel. She maintains that "Lost Girls realizes the possibility of moral pornography largely through the intimate juxtaposition of words and images where the visual lushness often helps soften the jangling horrors that the narrative offers [...] giving beauty to often ugly events" (140). This portrayal of the dark sides of sexuality (without the simultaneous demonization of sexual desire as a whole) supplies the comic with a socio-political dimension, drawing attention to the ugliness of abuse and the sleazy quality of most pornography - while simultaneously offering an alternative to that.

Furthermore, Moore and Gebbie have cited The Sadeian Woman "as well as works by Simone de Beauvoir and other feminist writers" (Laity, 141) as inspirations for their project. Naturally, authorial intent and a reader's reception of a text may differ greatly, so that Lost Girls needs to be judged on its own merits and flaws rather than on the hypothetical intentions and influences of its creators. But it would be difficult to charge the comic with misogyny, given that it places its protagonists in a position

18 Something similar seems to apply to contemporary culture. Following the "Pornography Statistics" available on FamilySaveMedia.com, the pornography industry's worldwide revenues in 2006 suggest that cultures promoting repressive ideals are among the most avid consumers of pornographic material: China ( $\$ 27.40$ billion), South Korea ( $\$ 25.73$ billion), Japan ( $\$ 19.98$ billion), and the USA (\$13.33) are all known for comparatively sex-negative stances: in the three aforementioned Asian countries, public displays of affection are a strong taboo, and in certain states of the USA, even breast-feeding in public can result in charges of indecent exposure. 
where they can overcome the aftereffects of male abuse by seizing control of their sexuality and owning their desires. If anything, the graphic novel has been accused of being too gynocentric, and of providing a rather naïve dichotomy of (female) sexuality versus (male) aggression (cf. Di Liddo, 136f.). For the most part, however, negative criticism has focused not so much on the graphic novel's explicit sexual content, but on its craftsmanship. As Annalisa di Liddo noted: "[The critical response to Lost Girls] has been more negative than not. Yet, the main reason for criticism is not what one might have predicted. Lost Girls has inspired contrasting opinions less for its pornographic, supposedly offensive content than for its formal and narrative flaws" (135). Di Liddo quotes several scathing passages from negative reviews originally published in the magazines Image TexT and The Comics Journal, which deride the graphic novel for its moralistic tone and its supposedly simplistic utopian ideals (136ff.). I would contest the notion that the underlying message of Lost Girls is necessarily naïve, yet it cannot be denied that the novel is indubitably didactic in tone. Its meta-fictional commentary on pornography, literary imagination and the relationship between violence and sexual repression are quite obviously intended to communicate very specific points of view to the reader (instead of encouraging the reader to come to her/his own conclusions). As Moore has stated in the documentary The Mindscape of Alan Moore, he believes that fiction is more than just entertainment - it is an educational tool, a sociological instrument that may influence and even shape cultural reality:

Art is, like magic, the science of manipulating symbols - words or images to achieve changes in consciousness. [...] And I believe this is why an artist or writer is the closest thing in the contemporary world that you are likely to see to a shaman. I believe all culture must have arisen from cult. Originally, all of the facets of our culture, whether they'd be in the arts or the sciences, were the province of the shaman. The fact that in present times, this magical power has degenerated to the level of cheap entertainment and manipulation is, I think, a tragedy. [...] It is not the job of artists to give the audience what the audience want. If the audience knew what they needed, then they would not be the audience. They would be the artists. It is the job of artists to give the audience what they need.

Given that Moore embraces such a strong stance on the importance of fiction, it should not come as a surprise that Lost Girls betrays a certain didactic style in conveying its idea(l)s. However, this does not necessarily mean that the graphic novel is ignoring alternate points of view, or that it does not leave sufficient room for the audience to challenge the conclusions they are given. I would argue that the novel engages in a spirited dispute with its (pornographic) parent texts and with contemporary culture, challenging prevalent attitudes that are usually taken for granted. As the following pages will show, Lost Girls is more than just a piece of extravagant erotica. It is Gebbie's and Moore's attempt at portraying a utopian, altogether 
surreal space of the erotic imagination, a sexual wonderland depicting human libido as a positive force contributing to personal growth and understanding.

\subsection{Therapeutic Re-Telling}

Before delving into a more detailed analysis of specific characters and their narrative arcs, it will prove expedient to first look at the outline of the graphic novel as a whole:

Lost Girls is built upon the premise that fictional characters from several distinct novels inhabit the same reality, thus opening up the possibility that they might meet - an idea that was also explored in Moore's later (and better-known) comic book series The League of Extraordinary Gentlemen (henceforth abbreviated as The League). But whereas The League followed in the tradition of Victorian adventure fiction, showcasing how that genre served as the progenitor of contemporary superhero comics, Lost Girls follows a considerably more daring approach: it interprets the events of Lewis Carrol's Alice-novels, J.M Barrie's Peter and Wendy, and L. Frank Baum's The Wizard of $O$ z in terms of Freudian symbolism. Thus, the whimsical adventures described in these children's novels are re-written as partially suppressed memories of sexual experiences and traumata that permanently shaped the lives of the three protagonists. The title Lost Girls is an allusion and analogue to Barrie's lost boys, the band of children roaming Neverland in a state of perpetual childhood. Yet whereas Peter Pan and his companions did not want to grow up, Alice, Wendy, and Dorothy find that their unresolved issues hamper and warp their adult (sexual) life in a variety of ways. They are figuratively lost in their own past, and can only find themselves again by confronting these events once more.

The novel takes place shortly before the outbreak of World War I, and seems to assume that the formative events from the three principal parent texts transpired at approximately the time of their respective publication. Accordingly, the three female protagonists are now not only representatives of three different classes, but also of three distinct age groups: Alice Fairchild is an elderly aristocrat, Wendy Potter (née Durling) has matured into a bourgeois lady in her thirties, and Dorothy Gale is a young American farm girl who has just reached her majority. Each of them is weighed down by some pivotal past event, and each has developed distinct coping mechanisms that reflect their social standing to a certain degree: Alice (who was molested as a teenager by a friend of her father's called "Bunny") recedes into autoerotic fantasies in which she makes love to her younger self beyond the mirror, writes erotic fiction and shuns the company of men; Wendy (who experienced unbridled sexuality in her early teens in the company of the derelict working class boy Peter) has opted to excise the destructive force of sexuality from her life altogether, so that only her shadow engages in passionate love with her (almost) equally repressed husband Harold; and Dorothy pursues a life of promiscuous relationships with various people (among them a seemingly unintelligent farm hand, a cowardly 
worker, and an emotionally cold smith), fleeing the incestuous desire that connects her to her father. Alice's predilection for scandal and breaches of convention is in keeping with stereotypes of aristocratic decadence, whereas Wendy's frigidity is completely in line with the image of Victorian middle-class mores (as perceived by subsequent generations).

The graphic novel is set at the Hotel Himmelgarten (eng. 'heavenly garden') in the Austrian Alps: a setting that is more than faintly reminiscent of the sanatorium in Thomas Mann's Der Zauberberg. Like Mann's Berghof, the hotel basically serves as a parallel world, standing apart from the rest of society not only in terms of its physical location. But whereas the sanatorium is primarily a mirror of European society prior to World War I, reflecting the world at large on a smaller scale, the Himmelgarten lives up to its name by constructing an almost utopian elsewhere that transcends the rules and limitations of the surrounding culture. It is a place of unbridled erotic freedom, where guests are subtly nudged towards unleashing their consensual sexual fantasies. The white book that can be found in each room supplies them with high-class pornography inspired (or even supposedly authored) by famous artists of the fin de siècle and beyond: it is a garden of fleshly delights that would strike the conventionally pious as an abject place, founded by a degraded pornographer who fled the law after committing various crimes. The third volume of Lost Girls meditates upon this dual nature, showing that within the confines of erotic fiction, the Hotel Himmelgarten might serve as a pleasant fantasy. But once it is exposed to a more realistic interpretation, it becomes problematic: its proprietor is a degraded pornographer fleeing the law, its willing employees sex workers who are paid to provide services to the guests. The utopian setting cannot survive contact with reality.

The graphic novel's plot revolves around the 'lost girls' telling each other about their secret past, thus engaging in a form of therapeutic storytelling while simultaneously engaging in liberating (and liberated) sexual acts. Upon getting to know each other, the three seemingly disparate women realize that they do have a significant amount in common, namely their ties to a dark sexual past that is shrouded in fantasies and dream imagery. Their personal traumata shape their existence in ways that are deleterious to their happiness. Discovering this, they take turns narrating specific episodes from their lives, which allude to well-known passages from the respective parent texts by means of visual and verbal cues. Working through their respective traumas, the three women gradually gain a better understanding of their psyche and start to see through the patterns that have dominated their existence up until this point. Juxtaposed to this, the assassination of Archduke Franz Ferdinand of Austria (depicted in chapter 20 of the novel) heralds the approach of the Great War, signifying the antithesis of the blessings of Eros. Just as the three protagonists reach a new level of self-actualization and erotic fulfilment, the rest of the world is quickly plunging into darkness, preparing to destroy the isolated idyll of Hotel Himmelgarten. Despite its remote location, it cannot escape the larger events that 
surround it. Eros and Thanatos, Freud's libido and death drive, are vying for control over humanity - exemplified by an almost comedic physical struggle between Wendy's husband Harold and the Austrian Rolf Bauer which looks almost amorous to the observing Dorothy. The graphic novel concludes with the implied destruction of the abandoned Hotel Himmelgarten and a harrowing scene from the trenches of World War I, showing the peaceful face of a disembowelled corpse on the battlefield. But it still leaves room for hope in the shape of a blossoming poppy, hinting that the dance of love and death will continue.

The poppy is a recurring symbol throughout the novel ${ }^{19}$, appearing in the shape of a wall decoration (Lost Girls, 4, 1 ff.), an actual flower growing in front of the hotel $(4,8)$, a whole field of blossoms in Kansas $(24,5 \mathrm{ff}$.), and of course in the shape of opium, which is derived from it $(4,4 \mathrm{ff}$.). Its properties as an analgesic, as well as the danger of becoming physically and psychologically addicted to its recreational usage render it an adequate metaphor for the ambivalent power of Freudian libido: its influence can be both liberating and confining, benevolent and destructive - as exemplified by the lives of the three protagonists. The sexual encounters that each of them experienced in their youth were anything but harmless, including both incest and rape - two of the most timeless and ubiquitous sexual taboos in human history. At the same time, however, their libido (along with their willingness to confront their past) sets them free from the very neuroses caused by those previous events, and they leave the Hotel Himmelgarten with a sense of renewed hope and a broadened perspective that seems fundamentally at odds with the reality of the approaching war.

Sexuality holds a special place within the ranks of mankind's most fundamental urges: by means of the subconscious, it exerts an enormous power upon a person's psyche, often manifesting in ways that may run contrary to the individual's conscious wishes. ${ }^{20}$ This quality imbues libido with a considerable subversive potential, an uncontrollable factor that might disrupt the social order. However, unlike the need to sleep, eat, or breathe, sexual desire can be suppressed or deferred for extended periods of time without any immediate negative effects upon an individual's physical health. As such, it is hardly surprising that so many religious (and some secular) world views have promoted sexual repression as a virtue. Victorian (and early twentieth century) taboos and gender roles reflect this approach as well,

19 To readers from the British Commonwealth, this particular flower and its connection to World War I is also familiar in the form of the "Remembrance Poppy" traditionally worn on Armistice Day since 1921 to commemorate fallen soldiers. Moore and Gebbie adopt and subvert this symbol to signify vastly more than just blood spilt and lives lost.

${ }^{20}$ St Augustine of Hippo perceived the lack of direct control over our reproductive organs as a direct result of sin, reflecting the disobedience and deviation at the heart of all metaphysical corruption $(\mathrm{XIV}, 15)$. In the eyes of the church father - whose views were to shape the subsequent sexual ideology of the Catholic church - sexual desire is a manifestation of evil, for "[so] possessing indeed is this pleasure, that at the moment of time in which it is consummated, all mental activity is suspended." (XIV, 16) 
conceiving of unrestrained passion and carnal pleasure as a threat to the very existence of civilization. Masturbation in particular was considered dangerous "for both sexes, because it sharpened the sexual instincts - by exercising them prematurely and because it decreased self-control, the basis of civilized humanity" (Laqueur, 67).

Conversely, according to Sigmund Freud's psychoanalytical model of the human psyche (which has shaped contemporary culture's outlook on these issues on a fundamental level), the sex drive constitutes one of the most important influences in the development of our individual identity, and excessive repression almost inevitably results in neurosis (cf. Massenpsychologie, ch. IV). As such, Freudian psychoanalysis constituted a direct response to the bourgeois morality that had shaped the Victorian age (and its equivalents on the continent), trying to mend the psychological long-term effects of a cultural climate that had censored and inhibited almost all expressions of libidinal desire - especially as far as women were concerned. The oft-cited "angel in the house" (named after a narrative poem by Coventry Patmore, dedicated to his deceased wife) was essentially expected to be an asexual being, devoted to her husband and children, but lacking any libido or awareness of the taboo subject of sex beyond a selfless dedication to her partner's happiness. And even though female hysteria (a diagnosis that was applied to almost any kind of psychological ailment, ranging from faintness and anorexia over depression to sexual desire) was treated by means of pelvic massages and the use of vibrators, the Victorian medical community apparently largely failed to identify the "hysterical paroxysm" brought about by such cures as an orgasm.

The historically androcentric and pro-natal model of healthy, "normal" heterosexuality is penetration of the vagina by the penis to male orgasm. [...] This relegated the task of relieving the symptoms of female arousal to medical treatment, which defined female orgasm under clinical conditions as the crisis of an illness, the "hysterical paroxysm". In effect, doctors inherited the task of producing orgasm in women because it was a job nobody else wanted. (Maines, 3f.)

Freudian psychoanalysis (although still quite androcentric in its conception) significantly transformed the cultural status quo with regards to sexuality throughout most of Western culture, unveiling and confronting the elective blindness that had dominated Victorian middle-class culture and its nineteenth century equivalents on the continent. Roughly a century later, Freud's ideas and concepts have become a part of everyday language, and contributed considerably to the sexual revolution that gave birth to (post-) modern ways of talking and thinking about the subject.

Although Sigmund Freud is not mentioned by name in Lost Girls, the influence of his theories and conceptions of the human psyche can be found throughout the novel, and Alice Fairchild at one point alludes to his practice, suggesting that she is familiar with the fledgling discipline of psychoanalysis. Talking to the distraught Wendy Potter, who has hidden the memories of her sexual adventures behind the 
symbol of flight, Lady Fairchild declares: "Why, there is a notable professor of the mind currently practising not far from here, in Vienna. He would find your image of flight perfectly acceptable and indeed appropriate. I have no doubt you are as sane as I." (Lost Girls, 8, 8) (Only to add sardonically: "Of course I did spend a number of years in a sanatorium." (ibid.))

The graphic novel is virtually suffused with Freudian thought. In fact, Moore's inspiration for Lost Girls was based on Freud's interpretation of dreams as encoded sexual wishes:

One of my initial ideas was simply noticing that Sigmund Freud suggested that dreams of flying were, in fact, dreams of sexual expression. Connecting that with the flying themes in Peter Pan sparked the notion that it might be possible to come up with a sexually decoded version of the Peter Pan story.

(Watkins)

The formative sexual events in each of the lost girls' past are shrouded in the fantastic imagery of dreams, often rendered in so-called splash pages that halt the narrative in order to depict a pivotal scene fraught with dream imagery, hinting at issues that have been buried and hidden away in the subconscious parts of the protagonists' minds. These symbol-laden events will be at the centre of a more detailed analysis of specific characters in subsequent chapters below. But dreams (or dreamlike imagery) are hardly the only connection to Freud. The way the three protagonists resolve their personal issues strongly resembles Freud's talking cure, the fundamental principle of psychoanalysis: they speak about the events that shaped their lives, recover them from the depths of their memories, analyse their meaning and the symbols they associate with them, and thus gain insights into their psyche, resolving the buried trauma and re-integrating these suppressed aspects of their identity. In Jungian terms (which are especially applicable in relation to Wendy's narrative), they perform shadow work and re-integrate a part of them that had long been the cause of abjection.

The most contentious aspect of the connection between Lost Girls and Freudian psychoanalysis, however, is undoubtedly the topic of child sexuality and incest, which earned both the Viennese professor and the graphic novel a considerable amount of controversy. Throughout his career, Freud was accused of promoting "pansexualism" (cf. Massenpsychologie, ch. IV): His critics argued that he was sexualizing all aspects of human life and thus promoting moral corruption. The fact that he located the root cause of many psychic ailments in (excessive) sexual repression was damning enough in and of itself in the eyes of bourgeois society, but even more controversial (and important for posterity) was Freud's observation that homo sapiens was a sexual being from birth, instead of remaining asexual until the onset of puberty (cf. Drei Abhandlungen). Children had commonly be regarded as completely innocent in terms of sexuality, and to suggest that they might harbour sexual feelings - however underdeveloped or rudimentary - must have come as quite a shock to 
most conservatives. We need to keep in mind that the societal consensus in the late Victorian period and the early twentieth century perceived sexuality (especially in its auto-erotic form) as a serious threat to a person's health and sanity, and devised various means to prevent adolescents from any contact with such 'pollution'. For example, Lord Baden-Powell, the founder of the Scouting movement, specifically cautioned his followers to abstain from - as he called it - "beastliness": "This is a most dangerous thing for [a boy], for should it become a habit, it quickly destroys both health and spirits; he becomes feeble in body and mind, and often ends in a lunatic asylum..." (qtd. in Stengers, 146). Baden-Powell's advice on how to combat sexual arousal included "bathing at once in cold water, or... exercising the upper part of the body by arm exercises, boxing etc." (ibid.) - which must be considered a rather humane treatment compared to some other methods that were apparently inflicted upon adolescent boys. In its online exhibition "Brought to Life - Exploring the History of Medicine" the London Science museum presents instruments called "jugum penises", medical devices that were apparently used between the 1880s and 1920 s to 'cure' nightly effusions. The museum's website describes them as "jagged metal rings fitted to the base of the penis with a screw or clip catch". Given such extreme measures, it should not come as a surprise that the very concept of infant sexuality was highly troubling to Victorians and Edwardians alike.

It also did not help Freud's reputation as a 'pansexualist' to hypothesize that the first sexual feelings of a human being were invariably aimed at the parent of the opposite sex, such as in the case of the Oedipus complex. Incest is without doubt one of mankind's most ubiquitous taboos, yet Freud maintained that it lay at the very heart of human sexuality. And according to Alan Moore, the Victorian pornography he drew upon as a source text seemed to confirm that impression:

[So] it seems that this is something that is very prevalent in the human psyche, and it would have been cheating for us to ignore with Lost Girls. Now, obviously it's a very prickly issue in contemporary society. But it's also one that's approached with staggering hypocrisy. The same newspapers that decry the comedian Chris Morris for doing a very funny satire of the pedophile hysteria will do, a little bit further down, a column talking about the developing bust of then-fifteen-year-old singer Charlotte Church, under the headline, "Charlotte's Chest Swell With Us." (Watkins)

Indeed, the graphic novel does not handle these topics lightly. Although it grows increasingly more transgressive over the course of its three volumes, deliberately crossing the socially accepted limitations of erotica and breaking several sexual taboos, it does not do so with the purpose of endorsing them in real life. Instead, they are part of a meta-fictional discourse on the limits of the (erotic) imagination, addressing the question of whether fantasies ought to be held to the same standards as actual actions, or whether fiction ought to be granted a greater degree of liberty. 
Monsieur Rougeur, the owner of the Hotel Himmelgarten, tries to build a case for the freedom of human imagination and its expression in fiction. Commenting upon a pornographic story-within-the-story that depicts an incestuous family, he declares:

Fiction and fact: only madmen and magistrates cannot discriminate between them. You see, if this were real, it would be horrible. Children raped by their trusted parents. Horrible. But they are fictions. They are uncontaminated by effect and consequence. Why, they are almost innocent... Pornographies are the enchanted parklands where the most secret and vulnerable of all our many selves can safely play... They are the palaces of luxury that all the policies and armies of the outer world can never spoil, can never bring to rubble... They are our secret gardens, where seductive paths of words and imagery lead us to the wet, blinding gateway of our pleasure... beyond which, things may only be expressed in language that is beyond literature... beyond all words... (Lost Girls, 22, 4ff.; emphasis in original)

One might be tempted to think that this is the author speaking through one of his characters, raising a metaphorical index finger and preaching to the audience. Yet while Rougeur's words bear at least some resemblance to sentiments Moore expresses in 20,000 Years of Erotic Freedom, the graphic novel provides a decidedly more ambivalent context for this speech, encouraging the reader to question its validity. The very next chapter portrays Monsieur Rougeur as an unambiguously shady character. The three protagonists bring him to recount his past by submitting him to a form of erotic torture, prompting him to confess all his past crimes. Although the graphic novel does not clearly establish whether he is a reliable narrator in this instance, leaving the option that he might invent far-fetched tales to further humiliate himself, he confesses to maintaining a paedophiliac (and potentially incestuous) relationship with two children while working as a forger in Paris. His victims - for it would be impossible to consider them anything else - are drawn in a fashion that suggests them to be prepubescent, and the expression on their faces does not communicate any kind of pleasure of willing compliance $(23,4)$. He also insinuates that the children might have been his own (as they were the offspring of prostitutes he had intercourse with), and that he sold both the children's and his own sexual services to drunken sailors to obtain money. If his account is genuine rather than an exaggerated fantasy, this would render him a despised outcast in virtually every society throughout history. It is an intensely uncomfortable scene that stands in marked contrast to the fiction-within-the-story narrated in the same chapter. Although both tell a similar tale (portraying promiscuous sexuality between close family members of diverse ages), Rougeur's confession evokes all the horror and revulsion we might associate with a real event, while the other narration features all the blissfully innocent surrealism and lack of consequences commonly associated with pornographic fiction. The characters in the hotel's white book do not act like 
genuine human beings. They are mere conduits of transgressive sexual fantasies, acting without shame, motivation, or social context. The same cannot be said about Rougeur's victims, however: as they are part of a psychologically complex narrative with at least some remote semblance of realism, it is clear that they are exposed to a terrible fate. Raised in a whorehouse, abused by numerous adults before the onset of puberty, and ultimately abandoned by the only parental figure in their lives, these children do not exist within a fantasy that is free of consequence. The reader is forced to assume that they were left to suffer, potentially even descending into a worse life than before.

Of course, the contrast between Rougeur's confession and the almost innocent pornographic tale might only reinforce the point he made earlier: pornography does not operate by the same rules as actual life, just like fantasies and dreams. And acts that would (and must) be considered horrible in real life - or in a realistic narrative - can actually be genuinely harmless in a strictly fictional context. This interpretation is reinforced by the way the three protagonists act throughout this scene. At this specific point, they conduct themselves in a fashion that draws attention to the fictional nature of the events on hand, all but ignoring the crimes Rougeur confesses to while they engage in uninhibited sexual acts - just like the characters in the storywithin-the-story. Alice, Wendy, and Dorothy remind us that they, too, are fictional in nature, and that Rougeur's transgressions (while grievous and harmful within the reality of the graphic novel) do not bear any consequences in the real world. Nonetheless, the central argument is presented in an ambivalent manner, as Rougeur's past - albeit fictional - still elicits a decidedly negative response from the reader. Fictions may be innocent, and pornographic fantasies need not be held to the same standards as reality. Yet a moderately realistic narrative operates by a standard that is considerably closer to the real world, rendering specific acts utterly unbearable because they re-introduce the element of consequence.

It is perfectly clear, however, that Lost Girls does not condone paedophilia. After all, several traumata that the three protagonists work through in their impromptu psychoanalysis are directly related to their exposure to adult sexuality at a young age, and although they had clearly reached a certain physical maturity at the time of those pivotal events, their minds were obviously affected in a negative fashion. Di Liddo comes to the same conclusion in analysing this particular scene, stating:

The authors clearly are aware of the problematic nature of pornographic representations of children, for they have Rougeur admit he is guilty of having sex with a minor. Of course the sentence is ironic, because the man himself is fictional, but its presence nevertheless signals Moore and Gebbie's consciousness that the issue can indeed be ethically thorny. In the same way, the authors do not pretend that sex is a perfect utopia for everyone; they concede that there can be instances where it is performed nonconsensually, which obviously involves serious consequences [...] (159) 
I would go even further and assert that the serious consequences of unethical sexuality form the very core of the narrative, as each of the three protagonists struggles to come to terms with a past that involves different kinds of sexual transgression, which influenced their lives in a negative fashion. Sexuality can (and indeed does) become 'abject' in certain configurations, signifying a highly detrimental transgression of boundaries that leaves the victims mentally scarred or worse. Lost Girls communicates this clearly, despite its criticized didactic idealism: sexual acts (or fictional representations of the same) are neither good nor bad in and of themselves, but only gain a specific meaning through context and external factors. The two incestuous episodes within the story illustrate this fittingly, as do the three protagonists and their differences of class, age, and character.

As only two of these women hail from a Victorian background, and Dorothy Gale's adventures are neither geographically nor temporally compatible with the focus of this study, Gebbie's and Moore's re-writing of The Wonderful Wizard of $\mathrm{O}_{z}$. will only be referenced insofar as it touches upon the narrative arcs of the other protagonists. Instead, I will analyze the characters of Alice Fairchild and Wendy Potter née Durling, comparing their differences in terms of their class background and looking closely at their respective history. As representatives of the Victorian upper and middle-classes, correspondingly, Alice and Wendy reflect two distinct 'moral traditions' that formed the foundation of contemporary sentiments in relation to the topic of sexuality. Their differences in socialization greatly affect how they respond to their sexual awakening and sexual trauma, and also colour the responses of the social circles surrounding them. By exploring their distinct coping mechanisms, Moore and Gebbie draw attention to socio-cultural impulses of sexual repression that continue to influence and shape contemporary sensibilities, if to a considerably lesser degree than in the early 1900s.

\subsection{The World beyond Fiction's Mirror}

"I rather favour Plato's view... the ideal is the thing; the world beyond fiction's mirror, that is the true world... and we are but the faintest of reflections grown pale beneath the glass." (Lost Girls, 1, 6; emphasis in original)

The authorial decision to portray their three protagonists as women of different ages and social classes meant that they needed to create a new biography for Lewis Carroll's Alice, who was originally inspired by the daughter of an Oxford dean. Since Wendy was to herald from a middle-class background, and Dorothy was obviously working class, the third woman obviously needed to hail from the upper strata of society. Accordingly, Alice Fairchild ${ }^{21}$ is depicted as an elderly aristocrat whose

21 'Fairchild' qualifies as an aptronym, considering the character's obsession with her nubile, blonde mirror image. Finding the lost 'fair child' within herself by overcoming her dissociation is the objective of her healing process. 
position in life has allowed her a great degree of personal freedom. Her libertine sensibilities and her literary pursuits seem to suggest a liberated sexuality at first, yet the reader soon detects signs that all is not as rosy as it appears. The beginning of the graphic novel sees her practically banished to South Africa by her elder brother. In her own words, "Geoffrey just doesn't want me scandalising the home counties by escorting some lady-in-waiting to the opera" (Lost Girls, 1, 4; emphasis in original). Of course, the events that led to her unofficial exile included considerably more than just vaguely scandalous insinuations of lesbianism, as we learn at a later point in the novel: the incident in the opera actually involved some oral sex performed upon "a minor royal's cunt" (29, 7), as Lady Fairchild puts it nonchalantly. This scandal was then even further exacerbated by "a judge who interrupted a threesome including his wife and her cousin" (ibid.). While the aristocracy appears to be more accommodating than the middle-class when it comes to sexual eccentricities, this tolerance is strictly limited to 'invisible' transgressions against propriety. Public displays that might endanger a family's reputation are heavily penalized, provided that they cannot be denied. ${ }^{22}$ Alice Fairchild's stay in Africa thus serves as a means of averting public shame, as deniability was limited in these particular cases, and keeping the transgressor out of sight might achieve a similar end. Her banishment at her brother's command also reveals a lot about the politics of sex in Edwardian Britain, from the distribution of power to the double standards at work in sexual mores. For example, King Edward VII's sexual escapades were virtually public knowledge, yet this did not stop him from ascending and keeping the throne after his disapproving mother's demise. ${ }^{23}$ His dalliances with famous actresses, French prostitutes, and many others were as notorious as Queen Victoria's supposed moral rectitude (even if historical myths about her frigidity seem to be mostly apocryphal and unfounded). If Victorian fiction is any indication, the same tacit tolerance was seldom (if ever) extended to women: in novels from that era, lusting women typically need to be punished by either death, incarceration, or insanity. Today's society claims to have outlived this specific kind of sexism, yet it still boils close to the surface of our cultural heritage. Laurie Penny detects the very mechanisms that were at work in Victorian middle-class culture in commonly promoted sexual mores in the $21^{\text {st }}$ century:

In Britain, the release of an official report declaring that girls are being too 'sexualized' has coincided with parliamentary lobbies for young women to be

22 This particularly British class divide is readily apparent in 2015's "Piggate" scandal, involving Prime Minister David Cameron. Although Cameron is not part of the peerage, he has been raised and groomed within an elite that were once the virtually exclusive province of the gentry: his alleged initiation rite into a "dining club" in Oxford matched British stereotypes of the debauched ruling class and its secret excesses.

${ }^{23}$ Queen Victoria blamed Edward for the death of Prince Albert, as the prince-regent had fallen ill and died after talking his son out of an unseemly affair with an Irish actress named Nellie Clifdon. 
'taught to say no'. Join the dots with police officers telling women that 'no' is insufficient if they happen not to be dressed like a nun and an ugly picture begins to form. What we're looking at is a concerted cultural backlash against female sexual liberation. [...] Don't be fooled by the skin-mags and fleshflashing music videos. We're in the middle of a sexual counter-revolution, and it starts with the ritual shaming of women and girls for daring to be creatures of lust. (Unspeakable Things, 106ff.)

At first glance, it seems that Alice Fairchild's biography corroborates the Victorian standard narrative regarding sexually active women: not only was she banished to South Africa, but we also learn that she was confined to a mental asylum at one point. However, Moore and Gebbie did not choose to portray her as a victim of sexual feelings being diagnosed as hysteria. Instead, she was suffering from a genuine mental breakdown, induced by the strain of continued substance abuse and an extended covert relationship with a dominant lesbian teacher and her circle of equally minded acquaintances. (But more about that later.)

Neither scandals nor medical treatment managed to provoke any kind of lasting change in her, however, and she continued to practice the lifestyle she had grown accustomed to, even engaging in an affair with an African cook $(29,7)$ which, given the predominant racist sentiments of the late Victorian and early Edwardian era, most likely ruined her reputation even further. Under the pen name of Hippolyte ${ }^{24}$, she also authored and published some pornographic fiction, further confirming the impression that she is not overly concerned with (nor capable of) conforming to the norms of late Victorian/Edwardian culture, despite potentially negative social repercussions. In the beginning, these behavioural patterns seem to be the expressions of a free spirit, but as the plot progresses, both the reader and Alice Fairchild become aware of the fact that there is something compulsive about them, tying her mannerisms to a traumatic childhood experience and everything that followed from it. Given that Lost Girls was accused of being overly simplistic in its construction of a supposed sexual utopia, the problematic nature of Lady Fairchild's libertine lifestyle certainly challenges such a reading of the text. Moore and Gebbie do not locate the source of Alice's problems in her clashes with the restrictive, patriarchal society that surrounds her, of course: the dominant morality is directly linked to the slaughter of the Great War, and not a model to be emulated or condoned. Instead, it is the repression of her memories of rape and the identification of such violence with all men that defines the core of her mental problems. Violence and abuses of power, not sex or sexual feelings, are the root cause of her mental health issues.

${ }^{24}$ In Greek mythology, Hippolyte is the queen of the Amazons, and closely associated with the myths surrounding Heracles and Theseus. Alice most likely chose the name because the Amazons are known for being an exclusively female tribe of fierce warriors, who for the most part shunned the company of men - just like she does. 
Alice's re-counting of her sexual trauma marks the beginning of the re-writing of Carroll's Alice's Adventures in Wonderland and Through the Looking Glass, using the imagery of the parent texts to evoke certain states of mind. Thus, the more surreal aspects of Carroll's novels and their secondary worlds become closely associated with Alice's psyche. The bizarre images of 'Wonderland' reflect both the gradual deterioration of her sanity due to her opium addiction and the defensive mechanisms her mind uses to escape the effects of trauma. Her vivid imagination has offered her shelter from the harsher aspects of her life, and prompted her to seek a return to the innocence of her childhood in the shape of her younger mirror-self, which was generated by a traumatic experience: Lady Fairchild's 'adventures' commence with her sexual abuse at the hands of her father's oldest friend, a man she only remembers under his nickname of "Bunny" (Lost Girls, 9, 2). On the level of the plot, this memory lapse hints at repression, yet on a meta-fictional level, it clearly serves as an intertextual allusion to Alice in Wonderland. Drawing upon the image of Carroll's white rabbit, the character's nervousness and his anxious glances at the clock gain a new, sinister meaning: he is not some whimsical anthropomorphic animal running late on an appointment, but a child molester living in fear of getting caught, constantly checking the time to make sure that no one will interrupt his machinations (9, 3). And the glass of wine that seems "to refill itself" (9, 4) causing Alice to feel "that [her] body had grown suddenly too large or too small" (ibid.) is not some magic potion inciting a physical transformation, but alcohol used to dull her senses. Alice (who is fourteen years old in this iteration of the story) does not actively resist "Bunny's" groping, but she is neither a willing participant, nor does she derive pleasure from the experience: Gebbie's drawings render Alice's predicament abundantly obvious, as the girl's facial expressions communicate discomfort and confusion (cf. 9, 2ff.). Even more importantly, her passivity and the subsequent hallucinatory imagery strongly suggests that she enters a dissociative state, responding to trauma by mentally withdrawing from her own bodily sensations.

Moore's text, in turn, represents the narration of the older Alice and her retroactive awareness of what was going on at the time, creating an additional sense of detachment from the events at hand. Alice communicates this when she commences her narration by saying: "One's memory is such a curious place. There's the way things seemed, and then there's the way things were... and one is often the total reverse of the other..." ( 9,1 ; emphasis in original) Through her words (and the drawings provided to illustrate her memories), the reader gets to experience what happened to Alice Fairchild as a teenager - yet this account is always one step removed from the actual chain of events, always tinted by the elder Alice's understanding that was lacking in her younger self. Her reflection upon the topic alienates her from the girl she once was. There is an unbridgeable distance between the actual experiences of the younger Alice on the one hand, and the knowing recollections of the older Lady Fairchild on the other. That difference corresponds to the "two contrary states of the human soul" as expressed in William Blake's Songs of Innocence 
and Experience, indicating that the fourteen-year-old Alice was essentially unaware of the implications of Bunny's curious behaviour, and therefore could not cope with the situation. The older Alice, on the other hand, perfectly understands what has happened to her, yet is incapable of changing the actual events, as they are forever relegated to the realm of memory and history. This is emphasized by usage of mirror images throughout the chapter: every single panel includes a reflection - both in a literal and in a metaphorical sense of the word. When the narrative shifts to Alice's account of the past, the reader experiences (most of) the event through her eyes, as seen in various reflecting surfaces. She watches her father's friend approach in the surface of the lake $(9,2)$, sees herself mirrored in his glasses as he watches her (ibid.), and witnesses how her tormentor starts to undo her buttons in the facets of a stained-glass bottle $(9,4)$ etc. Apart from being a reference to the title of Carroll's second Alice-novel, this imagery communicates a sense of dissociation from the scene. A reflection is not identical with the object it represents - just as a narration or a memory is not identical with the actual event. In narrating these past events, the adult Alice imbues it with a level of meaning and abstraction that retroactively shapes her perception of the scene. Through fiction's mirror, the past assumes a specific shape that renders it more accessible to her mind, allowing her to derive new insights from it. Thus, the mirror signifies both the difference between Lady Fairchild and her younger self, and the difference between the narrative and the actual traumatic event. Despite their apparent similarity, there is always the difference between the idea and the actual object.

Furthermore, there is a third level of meaning imbued in this symbol: the mirror is also a representation of the girl's psychological withdrawal. Faced with events that her adolescent mind cannot fathom or process, Alice's mind retreats from the proceedings, focusing instead on her image in the mirror. Upon being molested, she recedes completely into a delusional fantasy where she makes love to her own image $(9,5 f$.$) , blocking out the reality of the situation and replacing it with a screen$ memory of her own devising. The older Alice's narration chronicles the exact moment at which the transition into complete dissociation occurs:

I fell or floated down a hole inside myself, and at its far end all that I could see was Mother's mirror, there across the room. Inside me fingers fluttered, strange birds in a deep salt pool, their movements making ripples I could neither name nor own. The birds moved faster, caught up in a race with rules beyond my comprehension; purposeful and frantic. I imagined that I heard their cries, then knew them for my own. I fell, and from the hole's far end she fell towards me, half bare, hair like wild rape, white lace petals opening about her skinny legs. His hand was hot between my thighs. I made pretence that it was hers. The mirror-glass was melting into silver, boiling into mist, and I reached out and felt young muscle in her shoulder, in her neck, the child-silk at her nape. We slid together, wet with mirror, slick as mercury, 
smeared kisses down each other's hips and rolled each other's wine upon our tongues. $(9,5)$

Alice's mind is already attempting to withdraw at the beginning of the passage, projecting feelings she "could neither name nor own" upon some imaginary "birds" (ibid.). This defensive mechanism seeks to deny a reality that her mind cannot process, completely blocking out the event at hand. This effort turns out to be unsuccessful, however, as she still realizes that it is her own cries she is hearing. The physical sensations are still there, and she cannot ignore them. It is only when she focuses on her reflection in the mirror that her consciousness can flee from the events at hand, receding into a delusional state that also serves as a screen memory for the trauma inflicted upon her. The hallucinatory fantasy of making love to herself in the mirror does not only grant Alice refuge from the actual event without the need to deny her feelings and sensations, but transfers her sense of agency back to her. By repressing Bunny's involvement in the situation altogether, she becomes the agent of her own lust, touching herself instead of being touched by somebody else. Her auto-erotic fantasy allows her to own her sensations without having to face the daunting presence of the child molester. Within the screen memory, it is not he who feels "young muscle in her shoulder, in her neck, the child-silk at her nape" - it is Alice. Instead of being abused by an unpleasant elderly man, she experiences a joyous sexual initiation at her own hands, replacing violence with tenderness and horror with ecstasy. Thus, she can put a mental wall between her trauma and her sense of sexual enjoyment, even if the event has not transpired without leaving a permanent mark upon her.

Due to the traumatic nature of her sexual awakening, she henceforth avoids the company of men, and focuses exclusively on female partners - falsely assuming that relationships with women would not exhibit the uneven power dynamic and the potential for violence and abuse that was inherent to her first sexual experience. However, her relationship with a highly dominant teacher named Miss Regent (whose family name and heart-shaped hairstyle is suggestive of the Queen of Hearts from Alice in Wonderland, fused with the Red Queen from Through the Looking Glass) turns out to be anything but unproblematic. Their romance commences with Miss Regent's self-assured advances that are every bit as demanding and domineering as Bunny's clumsy groping (if not considerably more so, given the man's apparent insecurity): the teacher is unabashedly taking advantage of the infatuated schoolgirl, luring her into a relationship that exhibits an extremely lopsided power dynamic (cf. 16, 7). Even worse, further events make it abundantly clear that this teacher habitually takes advantage of her under-aged charges, and makes Alice complicit in her depredations $(26,2)$. By her own account, Alice was "too besotted to refuse her" $(17,3)$ suggesting that she did not necessarily enjoy many of the sexual extravagances that were expected of her, but merely complied to satisfy her lover. Through Miss Regent (who becomes Mrs Redman upon marrying a rich husband who is blissfully unaware of her inclinations), Alice is introduced to a wide circle of equally 
debauched sapphists who engage in drug-fuelled orgies and invent diverse tantalizing games (that draw upon various motifs from Carroll's Alice-novels). In a text centred around more traditional, conventional morals, the gender and sexual orientation of the circle's participants would probably mark it as abject: lesbianism received less attention in Victorian times than male homosexuality, but it was just as taboo and socially unacceptable. If anything, its invisibility in public discourse removed it even further from the societal mainstream, whereas male-male-romance was at least debated as a controversy. But in Moore's and Gebbie's Lost Girls, lesbianism is not marked as abject. what renders Mrs Redman and her friends heterodox is their selfish debauchery, their willingness to treat dependents as conveniences instead of people.

Reflecting upon the past, Lady Fairchild discovers the darker aspects of her relationship with Mrs Redman: "I wanted to become a submissive reflection of her every lust... She lived in a moral mirror-world where all the values were reversed, and I was becoming lost in it with her. Helping her strip a weeping new chambermaid, ready for fucking, I thought nothing was wrong" (27,2 ff.). The older Alice is clearly aware of the abusive undertones attached to many of these past events, and even her younger self gradually came to realize that her former lover might in fact have been just as bad for her as "Bunny". Continued substance abuse eroded both her morals and her sanity:

After [facilitating my addiction to opium], my mistress enjoyed forcing me into more freakish and degrading situations. In her hands, the drugs and sex were my reins; were her spurs... Years earlier, a pink, flustered man had shoved me down a moral rabbit-hole. Now, as a drug-addicted lesbian prostitute, I realised that I was still falling. $(26,7)$

Although Alice had willingly entered this relationship with Mrs Redman, it becomes obvious that the ordeals she was placed in were every bit as traumatizing to her as the afternoon with her father's friend. Her rejection of male sexual partners did not keep her from harm. Instead, she becomes aware of the disturbing similarities between Mrs Redman and Bunny - and the fact that by staying with her, Alice becomes more and more like her former tormentor. Her mental breaking point is reached when her mistress enacts Sadeian fantasies upon the daughter of her friend Mrs White, and Alice realizes that the girl "wasn't much older than I'd been, with that awful man" (29, 4). This reference to the Marquis de Sade leads back to Angela Carter's study on the topic, and the contrast between the "holy terror of love" (176) communicated by a sexual starvation economy that can only buy liberty at the price of somebody else's brutal subjugation, and the abundance of mutual enjoyment communicated by the chapters of Lost Girls that are set in 1914. In emulating de Sade, Mrs. Redman declares her allegiance to the most oppressive aspects of late Victorian society, seizing upon power imbalances and engendering misery in order to promote her own happiness. Although her circle of Sapphists must hide from 
the public eye, it re-creates some of the worst aspects of patriarchal society and inflicts them upon those who cannot defend themselves, emulating the worst kind of pornography.

Although Alice had assisted Mrs Redman in seducing her students on previous occasions, such as a trip to the beach that recalls Carroll's "The Walrus and the Carpenter" (Lost Girls, 26, 2), there is something about Lily White that reminds her more specifically of herself, making her more intensely aware of the moral implications of the events at hand. Accordingly, she increasingly starts to feel as if she is becoming an accomplice to the very crime that marred her life, especially when Lily is tasked with pleasuring her orally during a card game. In a sudden outburst of rage, she reveals Mrs Redman's hidden schemes to an assembled company of card-playing acquaintances, and thus causes the covert circle to collapse in a scene that recalls the conclusion of Alice's Adventures in Wonderland: in Carroll's novel, the protagonist's angry outburst of "You're nothing but a pack of cards!" (116) marks the point at which Alice awakens from her dream and returns to consensual reality. In Lost Girls, it also signifies a state of awakening, although in a less literal sense. Alice Fairchild refuses to become like the person she hates most, and snaps out of her opiuminduced stupor and moral apathy. Unlike Carroll's Alice, however, Moore's protagonist is not allowed to return to the ordinary waking world, but instead becomes confined in a lunatic asylum, where she is haunted by past events and repeatedly maltreated by the female orderlies $(29,7)$. Out of all her past transgressions, it was her act of moral bravery that caused her siblings to commit her to psychiatric care - an almost Sadeian twist, recalling the unjust fate of Justine, the protagonist of the novel of the same name.

There is some insight into how Victorian middle and upper-class morality stereotypically operate here: actions that would qualify as abject can be tolerated as long as they remain invisible. Hence, prostitution and pornography do not cause a scandal in and of themselves, provided they remain firmly out of sight and allow for the comfortable illusion of a pristine, immaculate society ruled by Christian propriety. It is only when an individual disturbs this image that the esteemed society turns upon the transgressor: like an anthill turning upon a perceived intruder, they mark the abject-stained culprit as distinctly other and cast her out. Her ostracism does not hinge upon her sexual deviance, but upon her visibility. Victorian upper-class propriety demands a pristine public face, not necessarily a clear conscience or an ascetic, Christian lifestyle. It is somewhat ironic, then, that Alice's nervous breakdown and her expulsion from polite society coincides with the moment she rejects the debased circle and tries to call them out. Instead of exposing her libertine mistress and her friends, the only thing she achieves is to draw attention to herself.

Remembering these events, Lady Fairchild starts to fully realize what her subconscious mind tried to communicate to her in the shape of her dreams at the time: she remembers a nightmare in which she was hunted by an enormous male member, taking a shape reminiscent of John Tenniel's Jabberwock-illustration in Through the 
Looking Glass (Lost Girls, 29, 6). This monstrous penis-shaped creature embodies all of her fears, and is conceived of as the hidden reason behind her coping mechanisms. It clearly signifies sexual violence, rape, and abuse - and is identified with the male sex. Only in retrospect does Lady Fairchild start to comprehend that this association of abuse with men does not accurately represent reality, and that most of the sexual exploitation she suffered was perpetuated by women such as Mrs Redman and her circle of friends. As Alice puts it: "All my life, I've assumed I pursued women, but... perhaps I was just running away from men?' (emphasis in original, $29,7)$ By wrongfully associating her trauma with the male sex, she virtually blinded herself to the corruption of Mrs Redman's circle of Sadeian sapphists, and only belatedly realized that they were just as depraved as the nervous "Bunny" - if not more so. The schoolmistress's malice was not tempered by any sense of guilt or shame, and she was more than willing to corrupt all those who fell within her power, be they employees, acquaintances or minors.

This potential pathologisation of Alice's lesbianism might qualify as one of the most problematic aspects of the novel, as the 'Jabberwock'-nightmares could be read in a way that portrays her particular sexual orientation as the result of repression, thus suggesting that she is in need of being cured of her fear of men. Of course, the novel does not affirm that this applies to homosexuality in general, nor does it suggest that Alice needs to abstain from same-sex relationships to be healed. But it nonetheless ties into a deplorable narrative cliché that conceives of lesbianism as a deviant state that can be 'cured' by means of assertive male sexuality. In the context of Lost Girls, Alice's cathartic insight is brought about by her cross-dressing companions, role-playing the parts of men while the elderly aristocrat assumes the part of the innocent schoolgirl, thus re-creating the situation that traumatized her to begin with (cf. 29, 1ff.). She needs to overcome her fear of the man who once violated her to break his power over her sexual conduct, thus re-gaining her ability to relate to men as potential sexual partners. A more sympathetic reading of this conclusion could argue that the issue at hand is not Alice's attraction to women, but an irrational sense of misandry caused by her first sexual experience, coupled with a certain disdain for consensual reality as communicated by the opening statement: she was perpetually seeking for "the world beyond fiction's mirror" $(1,6)$, always yearning to be re-united with herself-as-other, the image of the younger girl that helped her to cope with the trauma of being molested. Under these auspices, it could be maintained that many of her lesbian relationships were attempts to recreate her screen memory, a quest to find her younger self in the other that was doomed to fail because "the barrier between [the worlds did not] melt any more" $(1,8)$. Instead of finding an alternative to the sexual violence that ended her childhood, she ended up in a relationship that was at least equally abusive. It was not her lesbianism that caused her psychological strain, but only the unresolved trauma in 
her past, coupled with the coping mechanisms she developed to isolate it from her conscious mind. The fact that her sexual healing occurs during an act of lesbian sex (albeit one that involves cross-dressing and role-playing) favours this interpretation, as does the observation that Alice never renounces her homosexuality, but only speculates about seeking out (the slightly effeminate) Monsieur Rougeur in Switzerland, speculating that they might "take turns being the lady" (Lost Girls, 30, 2). In her cathartic release from her traumatic memory and everything that followed from it, she has indeed re-united with her younger self, and thus managed to let go of her coping mechanism, embodied by her former fetishist attachment to her mother's mirror: "I once thought part of me was stuck inside it, but not now. We've rescued her. Now it's just a beloved old thing." (Lost Girls, 20, 3; emphasis in original). She is as partial to the world of imagination as before, but she now realizes that it is not apart from herself, but an integral part of her very nature that can never be taken away or destroyed. In the symbolic re-integration of her younger self, she has renounced her dualistic disdain for consensual reality, and replaced it with a monistic vision of a world enriched and sustained by human creativity. Letting go of the mirror, Alice once more conceives of herself as complete, not merely "the faintest of reflections, grown pale beneath the glass" (Lost Girls, 1, 6) but "positively girlish again" (30, 2; emphasis in original). She can fully own her sexuality, and no longer needs to become a mere embodiment of somebody else's lust, as she did in her relationship with Mrs Redman. She has confronted and integrated her Jungian 'shadow'-archetype, brought the abject elements within her own personality to the fore, and thus managed to escape the trauma that shaped most of her adult sexuality.

This strong focus on psychological strain, hurtful memories and even mental disease may very well diminish the graphic novel's potential for erotic escapism: Alice is not the archetypally carefree embodiment of female libido that she's presented as at first glance, thoroughly breaking with the conventions of mainstream pornography. Yet in challenging these established patterns, Lost Girls aspires to become more than just erotic fiction.

\subsection{Daunting Shadows: Fencing the Middle-class in}

"[And] that's how both my real adventures and my dream adventures began: with a vision of flying." (Lost Girls, 8, 8)

Alice Fairchild's social status (as well as her apparent indifference to public opinion) establishes a considerable contrast between her and the repressed Wendy Potter, whose conduct is more in keeping with what one might expect from a 'typical' Victorian woman. This discrepancy between the supposedly libertine aristocracy and the morally uptight middle-class has some literary precedents, such as the dynamic between the prudish schoolmistress Mina Murray and her lewd upper-class friend Lucy Westenra in Bram Stoker's Dracula (1897). In the context of that novel, it is 
quite clear how the class divide is evaluated and judged in terms of sexual morality: the morally loose aristocrat succumbs readily to the thinly veiled sexual overtures of the oriental invader, and must be put down lest she spread her corruption (Stoker, 259); the middle-class teacher, on the other hand, is horrified by the stain the foreigner's contact has left upon her (339), and can be saved from a fate similar to her friend's both due to her morally upright nature and to the power of Christian piety. Insofar as Stoker's novel is representative of the late Victorian zeitgeist at the turn of the twentieth century, it seems that at the time of the fin de siècle, the British aristocracy was perceived as morally inferior to the bourgeoisie. Lewd and shameless, Lucy Westenra must die because her loose morals contribute to a reverse colonization that turns respectable English ladies into sexually abandoned monsters. In that respect, her fate is similar to that of other transgressive female characters in Victorian literature (including several novels that tried to draw attention to societal double standards and untenable social mores, such as Thomas Hardy's Tess of the D'Urbervilles and Elizabeth Gaskell's Ruth).

Lost Girls does not judge its protagonists in such a fashion, although it draws attention to the disparity between the scandal-laden Alice Fairchild and the immaculate-but-repressed Wendy Potter. These two characters do in fact serve as foils to each other, down to the very symbols that are associated with them: Wendy's past (and the personality traits associated with it) is represented by her shadow. Drawing upon motifs from Peter and Wendy and Jungian archetypes alike, the graphic novel establishes that Wendy has all but excised sexuality from her adult life: "My own desire had scared me so badly that I locked it all away in the darkness [...]" $(27,7)$. This part of her can now only express itself in the form of her abject shadow (cf. 3, $7 \mathrm{f}$.), which Wendy associates with "sex [...], the wilderness, [and] the working class" $(27,7)$. In this, she stands in marked contrast to the aristocratic Alice, who has never tried to suppress or deny her sexual desires in spite of her traumatizing experiences. Quite the contrary, Lady Fairchild has pursued (sexual) relationships with aristocrats and South African servants alike, never expressing any desire to dissociate herself from a specific class or ethnicity. This is also (quite literally) reflected by the symbol associated with her sexual trauma: whereas Wendy wishes nothing more than to get rid of her shadow, Alice wants to become one with her mirror image. Although that image is other to her, to the point where she speaks to her younger self and kisses the looking glass $(1,8)$, it is never fully dissociated from her own identity, nor actively denied and repressed. As such, her image is not an abject as much as an object of desire - a symbol of her disjointed sense of reality. Wendy, on the other hand, is completely oblivious to her shadow, and denies any kind of sexual yearning. Even after she has started to unearth her past (and engaged in a lesbian three-way dalliance during the premiere of Stravinsky's "Le sacre du printemps" (cf. 10, 2ff.)), she still tries to fall back on her avoidance strategy. When Alice tries to seduce her, recalling the incident at the opera house, Wendy insists: "I - I don't remember anything about that night. I can't have been my right self, what with all the fuss and 
uproar." $(12,4)$. The events in the darkened opera house are vigorously relegated to Mrs Potter's shadow, the part of her that is not "right" from the vantage point of the anti-sexual ideology she espouses. From the stutter in her voice, it becomes clear that she has not actually forgotten that night, yet simply cannot acknowledge her agency, thus attributing it to temporary madness. To her mind, sexuality has become an abject that has no place within her conception of self, and is ruthlessly denied. When she is forced to listen to the amorous banter in the hotel room next to her own at an earlier point in the novel, she even scalds her hand with hot water in order to punish herself for the feelings that are brought to the fore by the situation $(5,6)$. Zoë Brigley-Thompson goes so far as to call her a "sexless prop" at this stage of the novel, "sacrificing her desire for the demands of propriety" (84). However, such a reading of the novel ignores that even at this stage, the woman underneath the carefully maintained façade can occasionally be glimpsed - especially in the aforementioned bathroom scene. It is quite clear that contrary to superficial appearances, Wendy is not an asexual being, but merely attempts to suppress her desires.

Chapter 3 (titled "Missing Shadows") not only serves as Wendy's introduction to the novel, but also establishes the profound difference between her secret self and her public persona, embodied by her shadow and her actual body, respectively: while Mr and Mrs Potter are unpacking their luggage and talk about inconsequential everyday matters, their shadows seem to acquire a life of their own, seemingly touching each other amorously and engaging in sexual acts. The effect of this discrepancy is mostly humorous, (especially when Mr Potter starts to talk about his being a "potent force" and "doing something you haven't tried before" $(3,8))$ yet it also reveals a lot about the characters and their married life - and about the suppressed desires underneath the decorous facade. If their shadows - and later conduct with other partners - are to be believed, the Potters both hide a prodigious sex drive, yet their married routine and their social expectations of what a decent middle-class marriage ought to be like fence them in, until only their shadows are still able to enjoy each other's company. Their real lives, on the other hand, revolve around the exchange of pleasant platitudes and superficial affection. The reason behind each partner's repressive behaviour is quite distinct, however: Harold Potter believes that women are essentially asexual entities, as his commentary on his wife suggests: "The idea of Wendy having anything to do with literature is simply preposterous... It's not the same for women. I mean, you look at them and it's obvious there's nothing going on. They just don't have our vision.” $(11,7)$

Even when Wendy Potter starts to realize that the other women have experiences like her own, she at first attempts to keep her distance and to listen in on their conversation in secret. This strategy is most likely meant to allow her to contemplate her own past without facing it, basically keeping it in the (Jungian) shadow. Upon being discovered and accused of voyeurism, however, Mrs Potter becomes an active 
(if at first somewhat unwilling) participant in the communal recounting of their childhood experiences $(6,7)$.

Her narration of the past is presented in narrow, tall panels with black boundaries, with a black-and-white silhouette at the top of each page. This particular style is not only suggestive of the narrow-mindedness of the world view she cultivated as an adult, but was also intended to be "reminiscent of the railings of a Victorian park", as Alan Moore pointed out in an interview with Ismo Santala. As Wendy declares that she has "locked it all away in the darkness beyond those railings" (27, 7 ), this imagery suggests that she is indeed unearthing her memories and desires from her subconscious. Even more importantly in terms of psychological symbolism, however, is the fact that in order to access Wendy's recollections, the reader has to first look at the shadowy silhouettes at the top of each page. Wendy - along with the reader - is delving into her Jungian shadow, recovering the experiences she has tried to bury within her subconscious and re-integrating this repressed side of her own personality.

Whereas Alice's pivotal confrontation with sexuality took the shape of sexual abuse, traumatizing her for years to come, Wendy's transgressive adventures started with pleasant - if highly illicit - experiences. And as the following pages will show, it is this very complicity in her own sexual awakening that lies at the heart of Mrs Potter's desire to disown her sexuality. Followed home by the working-class boy Peter (whom she and her brothers saw earlier in a park having sex with a girl), the sixteen-year-old Wendy and her younger brothers become initiated into the pleasures of masturbation and sex without fully comprehending the exact nature of their actions. They do receive instructions to keep the proceedings secret, however, thus gaining a certain understanding of the taboo associated with sex $(8,6)$. Like Alice, Wendy still views the world through rather innocent eyes at the time of her sexual initiation, but her state seems to result less from psychological immaturity than from a kind of cultivated ignorance. As sex education did not exist in Victorian times ${ }^{25}$, and traditional middle-class parents were unlikely to acquaint their children with the topic until it was absolutely necessary to do so, it is quite likely that neither Wendy nor her brothers had access to anything beyond very vague notions about human sexuality. Jan Marsh observes:

According to their own testimonies, many people born in the Victorian age were both factually uninformed and emotionally frigid about sexual matters. Historically, it appeared that the licentious behaviour and attitudes of the Regency period had been replaced by a new order of puritan control and repression - personified by the censorious figure of Mrs Grundy - which

25 Professor Michael Reiss observes: "In England from the late 19th century, a number of sex education publications were produced, mainly aimed at helping parents to enlighten their children. However, in school, little formal school sex education took place before the Second World War." 
was imposed by the newly dominant bourgeoisie, steadily permeated all classes, and lasted well into the 20 th century. ("Sex \& Sexuality in the $19^{\text {th }}$ Century")

This observation seems to contradict Foucault's well-known rejection of the 'repressive hypothesis', yet these differing points of view may not be as entirely at odds as they seem to be at first glance: the existence of a strong medical and sociological discourse on the topic of sex (as well as the ubiquity of Victorian pornography and prostitution) may very well be the result of the built-up pressure from a society that could not acknowledge sexual urges in a different manner. An analogue to this can be found in today's most repressive states, such as Iran or Pakistan. Pornography is forbidden in both of these countries, yet research conducted by the search engine site PornMD clearly establishes that "six out of top 10 countries on the planet that watch the most porn are Muslim states", with Pakistan ranking on number one and Iran taking the fourth place (cf. Postober). Repressive morality does not change the fundamental sexual urges of homo sapiens, but it may very well change how they can be expressed, or where and how people will be able to satisfy them. In the case of Wendy and her brothers in Lost Girls, their ignorance does little to curb their unconscious urges - or their curiosity about the illicit pleasures of the park. They are apparently old enough to be inquisitive about the topic, and quite eager to gain experience.

Gebbie draws the younger Wendy as a young adult who has already reached her physical maturity, although she is still young enough to feel self-conscious about her body at the beginning of her narrative arc. Wendy compares herself to Peter's girlish sister Annabelle, and self-consciously declares: "How could Peter desire me, after her?" $(15,3)$ Wendy's adult physique invokes feelings of inadequacy in her at this point, in stark contrast to a later scene in the novel. This idolization of a waifish, thin appearance reflects the impossible beauty standards promoted by the fashion industry to this day. The roots of this trend lie at least partially in the Victorian age, with corsets promoting the cult of slenderness that encourages eating disorders such as anorexia nervosa. Although "the look of overall thinness, including the fashion for boniness, did not claim its predominant place in fashion until after the turn of the century [...] body image concerns, and specifically a fear of fat, existed a century ago in incipient form" (Krugovoy Silver, 26). Wendy's troubled relationship with her own body image can be read in several ways: as a reflection of the underlying culture of shame that shapes her perception of self and her place within the world, but also as the less culturally motivated anxiety of an adolescent who has not yet come to terms with the physical changes brought about by puberty. Since young Wendy's tale includes only passing references to her upbringing, yet focuses strongly on her maturation, the second reading makes more sense within the context of the narration: her shame stands in marked contrast to the strength she finds at the conclusion of her narration, where her adult physique becomes her principal defence against a sexual predator. Nonetheless, the subtext of "anorexia nervosa as a 
semiotic system or cultural paradigm" (Krugovoy Silver, 171) is present, hinting at developments that culminate in the present state of affairs. Feminist and former anorexia nervosa-sufferer Laurie Penny conceives of the cult of thinness and the resulting mental illnesses as part of a larger sexist complex:

Of all the female sins, hunger is the least forgivable; hunger for anything, for food, sex, power, education, even love. If we have desires, we are expected to conceal them, to control them, to keep ourselves in check. We are supposed to be objects of desire, not desiring beings. We do not need food; in many ways, we are food, trainable meat, lambs queueing up in line for gravy. (Unspeakable Things, 31f.)

Wendy's tale reflects such a state of affairs in the shape of her middle-class parents and the expectations they might place on their children, and her adult life prior to her stay at the Hotel Himmelgarten does most certainly qualify as a life devoid of acknowledged hunger. Yet her experiences in the park stand in marked contrast to this, offering a first glimpse of a sexually liberated utopia - even if it does not turn out to be as harmless as it appears at first glance.

The spinney in the park, where Peter and some other derelict youths meet, gives Wendy and her brothers a means to experiment with their budding sexuality in ways that would have been impossible within the confines of middle-class society. But even though this "island" (Lost Girls, 15, 2) is perceived as paradisiacal and exciting by the younger Wendy, it becomes perfectly clear to the reader (and the mature Mrs Potter recalling these events) that there are some decidedly abject undertones to the scenario from the very beginning. Peter and the other boys wear rags, and they look "as if they'd run away from home or just got lost" $(15,3)$. Furthermore, the girl who had sex with Peter on the day before turns out to be his sister Annabel, clearly establishing that this group is unaware of - or unwilling to conform to - even the most widely accepted sexual taboos. The "lost boys" stand outside of society and its rules, driven only by desires that they can barely articulate or understand. In the absence of parental figures, they persist without any kind of socialization at the uttermost bottom of society. However, their obliviousness renders the proceedings almost innocent, as their sexual experimentation is not driven by the exploitative desires of adults. Their "games" do not cause them immediate harm and seem to be entirely joyous and pleasurable. Indeed, Wendy at first experiences her transgressions as extremely liberating, and challenges the rigid structures of her middle-class upbringing: "After everything my brothers and I had been doing, our family's respectable façade seemed such a sham. So did Society. How could everyone act so normally when they all had this heat between their legs; these things they wanted so to do?' (Lost Girls, 19, 2; emphasis in original). At this point of her narration, the younger Wendy has gained a decidedly liberated perspective, rejecting the disingenuous propriety she has been taught to embrace - yet this state is not meant to last. She soon gains a glimpse of the dangerous aspects of sexuality: this tale's equivalent 
to Barrie's Captain Hook is a dangerous paedophile that frequents the park looking for potential victims, marked by his claw-shaped, disfigured hand. The hookhanded man embodies the abject side of sexuality: the potential for violence, transgression, and force.

Just as Alice was already familiar with Bunny, Wendy knows this man through her parents: "Suddenly I recognized him. He was Captain Huxley, one of Father's colleagues from the stock exchange" $(15,6)$. This connection with the girls' parents, specifically their fathers, suggests that the darker sides of sexuality exist everywhere, and can even touch upon the innermost circle of the family. These sexual predators do not come from elsewhere, cannot be dismissed as representatives of an inferior social class or maligned ethnicity, but hail from the same social circle as the girls. This is an aspect that Wendy, in her rigorous dismissal of sexuality as unbefitting to her standing, has apparently never quite grasped. It was not the working-class boy Peter and his reckless immaturity that put her in danger (apart from the risk of an accidental pregnancy or a sexually transmitted disease), it was the captain with the disfigured hand. Although Huxley's behaviour at first appears to be quite similar to that of the "lost boys", frequenting the park in order to gratify his desires with "games", his physical maturity signifies a critical difference between them: he is not a youth experimenting with newfound sexual urges, but a man who satiates his illicit desires by forcing himself upon defenceless adolescents. The contrast between the youths and the Captain becomes quite obvious when the older man watches (and ultimately interrupts) Wendy's and Peter's tender lovemaking in the scene that follows her realization of the inherent hypocrisy underlying Victorian society. His voyeurism (and subsequent intervention by staining Wendy with his seed) mars what could have been a sublime experience for Wendy: "It was suddenly so silly and so ugly I almost wept." The Captain's presence destroys the innocence of the park, as his adult gaze turns the sweet into the sordid. Through his presence, Wendy starts to gradually perceive the events in the park through the eyes of Blakean Experience, gaining a different understanding of what's going on. This loss of innocence is also reflected by Wendy's sexual fantasies, which start to revolve around increasingly dangerous imagery. In her mind, she enacts scenarios of abduction and rape that seem quite enticing to her $(25,6)$, although they also evoke feelings of shame and guilt. For a while, however, her sexual experiments in the park continue almost in the same way as they did before, only occasionally marred by Huxley's presence. The hook-handed veteran, as the embodiment of the darker, repressed aspects of the adult world, can still be put aside if they manage to avoid him. He is an abject disturbance of the park-as-paradise, but not yet perceived as a serious danger.

When Peter's sister Annabel is brutally raped by the Captain $(27,2)$, however, things change on a fundamental level. Faced with the real consequences of their reckless games, Wendy can no longer sustain an innocent perspective of the events in the park, nor continue with the games she and her brothers engaged in at this point. In her mind, sex becomes inextricably linked to abject violence and shame, 
and this impression is only exacerbated by her observation that talking about taking revenge is sexually arousing to Peter (ibid.). At an earlier point in the novel, she had witnessed him performing oral sex on Captain Huxley for money $(25,3)$, and his wrath seems just as hypocritical as the polite society she disowned. Accordingly, Wendy breaks up with her boyfriend, finally realizing that his posturing is nothing more than the immature rambling of a teenager: "I just said, 'Peter... why don't you grow up?"' $(27,2)$ The idyll of the park has gained the stain of the abject: it is revealed to be no alternative to the repressed middle-class, but a seedy extension of the same, where people like the Captain can drop their honourable façade and live out their repressed urges. Seen through the eyes of an adult, Peter's sexuality is not an act of liberating, youthful anarchy, but merely part of the seedy underbelly of Victorian society: the pressure valve of the sex trade.

Nonetheless, Wendy's own transformation from a sexually liberated teenager into a repressed Victorian lady has not been concluded at this point. She is still haunted by her transgressive fantasies of rape and abduction, and - despite feeling both excited and ashamed by them - cannot fully distinguish between her imagination and reality. The following night, Wendy deliberately seeks out Captain Huxley in the park. She is still tempted by her fantasies, yet the actual confrontation with the rapist makes it abundantly clear to her that there is a fundamental difference between a deliberate and imaginary loss of power and the reality of being violated against one's will. Being faced with the brutish man, she finally grasps a fundamental truth about her erotic urges. "I could think about what I liked. That didn't mean I wanted it to really happen to me. That didn't mean that anyone could force it on me" (27, 5; emphasis in original). Unlike Alice, who had to withdraw from reality in order to escape trauma, Wendy moves in the opposite direction: she forsakes her fantasies and confronts the reality in front of her, refusing to be a victim. She defuses the assault by challenging Captain Huxley with her adult understanding of sexuality, showing self-confidence and courage instead of fear and helplessness.

He shuffled closer, confident now, cradling his penis in that awful pincer. He said he was going to fuck me. And I understood him. I - I pushed my bare cunt at him and asked if he didn't think I was too hairy, too old for him? Weren't my tits too much for someone who preferred flat little chests and bald little quims? Someone who was scared of grown-up women, thought they'd overwhelm him, swallow him? [I bellowed at him:] Children won't realize you're inadequate. You can pretend you are still young, like them, that the clock isn't ticking. That's why you fuck children, why you dye your hair. You're afraid of women. And you're afraid of getting old. (27, 5; emphasis in original)

The drawing that follows upon this confrontational monologue mirrors Alice's vision of the "Jabberwock" - yet in this case, it is not the female protagonist who is assailed by the monstrous genitals of the opposite sex, it is the Captain: the rapist is 
swallowed by a gigantic vagina dentata resembling the crocodile from Barrie's novel, symbolizing the fears Wendy had outlined. Wendy vanquishes her foe by bringing him face to face with his ugly self, offering up a reflection of his monstrous-yetpathetic nature and thus tipping the power balance in her own favour. By refusing to be a victim, she defuses the situation and reduces the Captain to a sobbing wreck, "crouching [and] rocking in the rain" $(27,7)$. Huxley's power fantasy is shattered by Wendy's self-confidence and brings him face to face with the ugly reality of his own impotence.

After coming to such a mature understanding of sexuality and its deviations, Wendy nonetheless decides to expunge it from her future life. Even though she has learned to comprehend the difference between fantasy and reality, the mere fact that she went to the park at night suggests to her that sexual desire is a subversive and dangerous force. The repressive values communicated by her upbringing once more start to assert themselves, and Wendy welcomes them as a defence against the abject misery she faced. This decision is probably bolstered even further when she sees Peter after an unspecified interval, working as a hardened male prostitute (27, 7). Unlike her, he continues to perpetuate the patterns of their games in the park, and - as he must exist within the confines of Victorian society - doing so has led him down towards an abject existence where sexual favours are traded for money. The transgressive power of sex now seems almost corrosive to Wendy: something that may be acceptable in children who do not know any better, but which has no legitimate place in adult society. Viewed through the eyes of William Blake's "Experience", her adventures in the park lose their charm and become abject. "In that shadowy spinney I'd played with sex, had almost been devoured by it, like Annabel. Like Peter. My own desire had scared me so badly that I locked it away in the darkness beyond those railings." $(27,7)$ So, whereas Alice Fairchild was perpetually seeking for a way to express her sexuality without evoking memories of trauma, Wendy Durling was horrified by her own secret self, opting to deny and suppress her shameful memories. This renders her an almost stereotypical representation of the sexually repressed bourgeois Victorian, who perpetuates the very societal patterns that she at one point considered a "sham". Nevertheless, her frigidity is elective rather than a genuine reflection of her nature, and her desires need to be acknowledged. Like Alice, Wendy finds that re-counting her tale liberates her, as she is able to re-integrate her shadow-self: "I - I almost felt as if telling it... owning up to it... has changed something for me. There's different possibilities now" (27, 8; emphasis in original). Her healing transformation has finally made her realize that the imagination is an enriching part of human existence rather than a fundamental threat to stability and social coherence. Her liberation does not prompt her to turn her back on society or to leave her husband; acknowledged, her shadow becomes a force for good that might greatly enrich her life. "I feel full of possibilities again, like when I was young. As if my imagination can wander where it likes..." (30, 3; emphasis in original). 
It is this freedom of the erotic imagination that is put in juxtaposition to the death principle, contrasting the salvation of the three women with the collective madness of the Great War. In the end, the women carry their gained insight into a world that is quickly plunging into bloodshed and chaos, yet will never lose the potential for a similar healing experience. As Alice expresses it: "My dear, beautiful and imaginative things can be destroyed. Beauty and the imagination cannot. They blossom, even in wartime" (30, 3; emphasis in original). Given that the years 1914 to 1921 saw the creation of James Joyce's Ulysses (which was prosecuted and banned in the United Kingdom as pornography), it seems that her prediction is not too far off the mark.

Both Wendy and Alice are healed from their respective traumas by re-integrating their symbolic other, the shadow and the mirror image, respectively. But whereas Alice had to recover from the memory of sexual abuse and the mental problems it engendered, Wendy's troubles are more closely linked to her upbringing than to the transgressive sex she experienced in the company of Peter the working-class boy. Although her sexual initiation was not without danger, her wholesale rejection of sexual pleasure had less to do with the predations of Captain Huxley than with the values she had been raised with. Her problems are directly linked to Victorian (and, by extension, Edwardian) middle-class morality, and her recovery necessitates a rejection of the societal norms that once seemed to offer security to her.

The notion that the function of culture and society consists of a taming of Man's baser instincts was popularised by Thomas Hobbes's Leviathan, and it is an idea that Moore's and Gebbie's Lost Girls rejects wholeheartedly. The graphic novel presents the Great War as the ultimate consequence of conservative morality: sexual repression in general and the oppression of women in particular create a societal climate that encourages a toxic understanding of masculinity.

\subsection{Relating the Past to the Present: Lost Girls as a Neo- Victorian Text}

As noted in 3.1, Lost Girls betrays a certain didactic quality in its discourses on art, sexuality, violence, and human nature. Di Liddo derives from several interviews that "the intention behind [Moore's] and Gebbie's effort to have pornography publicly recognized as a form of art stems from a critique of current Western society, which is excessively sexualized on its surface and hypocritically repressive in its essence" (155). This repression manifests in various ways: female nipples are rigorously censored by social networks like Facebook; breast-feeding mothers may experience negative social repercussions in many places; and images of highly sexualized women are used to advertise virtually every product, from chocolate milk to electronics. 
Keeping in mind that the Victorian age was incredibly prolific in terms of its production of pornographic materials, and entertaining the possibility that this did not happen in spite, but because of the sexually repressive climate perpetuated by middle-class conventions, the apparent sexualisation of contemporary Western society does not necessarily coincide with genuine liberation. Instead, mainstream pornography operates as a kind of cultural pressure valve, allowing for a release of pentup sexual energy without actively challenging the status quo. "Pornography keeps sex in its place. That is, under the carpet. That is, outside everyday human intercourse" (Carter, 20). In mainstream pornography, there is no real challenge to society's assessment of sexuality as something dirty, low, and abject. 'Slut shaming' is an all-too common porn trope, with pornographic actresses experiencing verbal abuse and physical humiliation from their male co-stars, reinforcing the taboo of female sexuality. Even following several waves of feminism, contemporary society's assessment of sex workers still comes awfully close of William Acton's declaration that they are "a woman with half the woman gone, and that half containing all that elevates her nature, leaving her a mere instrument of impurity" (166).

Feminist pornography such as Lost Girls, on the other hand, offers a subversive challenge to the repressive and misogynistic undercurrent that runs through contemporary Western society, substituting it with a different vision of sexuality as a potentially uplifting and liberating experience that does not denigrate women (or men, for that matter). The "thin-lipped censoriousness that posits sex, rather than sexism, as the real problem" (Unspeakable Things, 6) exhibited by parts of the feminist movement is surprisingly Victorian in its assessment of sex workers as victims-bydefault, and its insistence that pornography is a social evil in and of itself. The zeitgeist of what Laurie Penny calls a "sexual counter-revolution" (ibid., 9) demonizes female sexuality as much as the most repressive patriarchal norms, if for a different reason. In contrast to this, feminist porn like Lost Girls can truly contribute to a societal transformation, a liberation of female sexuality from the shackles of a patriarchal society considering women the exclusive property of their husbands.

It is pretty clear that in spite of its historical setting and the specifically Victorian elements in Wendy's (and, to a lesser degree, Alice's) narrative arc, Lost Girls provides a commentary on present-day culture: it creates a utopian alternate reality in the shape of the Hotel Himmelgarten, and sets it against conventions of pornographic literature that have persisted in this specific genre since the days of the Marquis de Sade. I agree with K.A. Laity that Lost Girls does indeed qualify as the kind of feminist pornography that Angela Carter envisioned in The Sadeian Woman, providing an extremely idealistic and subversive vision of erotic liberty as the antidote to the uneven power dynamics and the failures of the imagination that result in violence and tyranny. Although it can certainly be argued that this kind of idealism is misguided and unrealistic, closely resembling the ideology of the (more or less still-born) Hippie movement, I maintain that such an idealist approach is ultimately preferable to an all too convenient pragmatism, which merely reproduces 
the norms of the current status quo. Faced with the choice between Lost Girls and more conventional pornography and its tropes of misogynistic exploitation, the vision conjured up by Moore's and Gebbie's graphic novel is undoubtedly the preferable alternative. Its challenge to the still-prevalent notion of sexuality as an essentially denigrating and shameful aspect of human nature that has no place in highly esteemed literature (or at least not at its centre) may not have transformed contemporary society as of yet, but it may certainly cause readers to re-assess their relationship with their own erotic imagination, encouraging the same kind of healing process as the one the 'lost girls' go through.

Pornography has not fully outgrown the 'abject' status it held in Victorian culture, and as such still reflects some of the most negative outgrowths of that era's sexual morality: women are simultaneously objectified as desirable commodities and vilified as immoral for subjecting themselves to sexual advances (which are conceived as degrading to them). Even the supposedly liberated $21^{\text {st }}$ century hasn't discarded this particular ideological narrative as of yet, although some signs point to a potential change for the better. Interestingly, this change comes from within the porn industry, and takes the shape of feminist sex workers, directors and producers who challenge the norms of the medium and provide an alternative. "Objectification is oppressive when it erases every other form of desire apart from men's desire for women's commodified bodies. [But objectification] can be mutual. It can be fun. It can be freeing." (Unspeakable Things, 123f.) 


\section{Two Sides of the Same Coin: Michel Faber's The Crimson Petal and the White}

\footnotetext{
Whereas Moore's and Gebbie's Lost Girls contrasts Victorian repression and Sadeian exploitation with a highly idealistic sexual utopia, Michel Faber's The Crimson Petal and the White (henceforth abbreviated as Crimson Petal) offers no such escape route to its protagonists. First published in 2002, this neo-Victorian novel tells the story of a young woman who has been raised by her "fallen" mother to become a prostitute. Marked as a sex worker by her very name, Sugar is deeply traumatized by the sexual abuse she is subjected to for money. Unlike John Cleland's Memoirs of a Woman of Pleasure, this novel does not perpetuate the myth of the nymphomaniac prostitute, joyfully partaking in her own debauched existence. Quite the contrary, it is clearly spelled out that Sugar (and others like her) are little more than slaves who feign pleasure in order to survive. However, the novel makes it clear that what drives these women to prostitution is not primarily or even exclusively dire want. Crimson Petal specifically negates "popular ideas about prostitution and women's work [, which] connect it to extreme poverty and destitution rather than to the gendered limitations, constraints and exploitations inherent in the capitalist economy" (Laite, 32). Faber's fictional prostitutes are forced into sex work by the shape of the society they live in, and - as this chapter will demonstrate - their motivations are informed by more complex reasons than hopeless poverty alone.
} 
Although the plot focuses on Sugar's gradual rise from the slums (as well as on her personal maturation from an embittered cynic to an altruistic caretaker), any surcease from her abject existence never extends to the sphere of sexuality. Instead, Crimson Petal accosts its reader with a scathing portrait of Victorian middle-class gender ideology and the politics of sex, shining an uncompromising light on the dismal ugliness at the heart of a deeply patriarchal, hypocritical society. Where a more conventional retro-Victorian (or authentic Victorian) novel might introduce the ideal of traditional marriage as a counterpoint and antidote to the misery of prostitution, Faber's novel depicts both of these as astonishingly similar arrangements that do rarely allow for any genuine affection or erotic fulfilment. Wives in Crimson Petal are virtually powerless and depend just as much on the goodwill and material wealth of their husbands as prostitutes do on their patrons. There is no Hotel Himmelgarten offering sanctuary to those in search of sexual freedom, emancipation, or self-knowledge; no reprieve from society's rampant sexism and distorted power dynamics: abjection reigns everywhere in Faber's London, from the slums of the demimonde to the mansions of high society, in public places as well as in private relationships. The only relief offered to the reader comes from outside the text as such: it is the awareness of the positive societal changes that have taken place within the intervening century, eliminating some of the ills portrayed in Crimson Petal and diminishing others. Marriage laws do no longer place women in the position of second-class citizens or mere legal accessories to their husbands, for example, and even though traditional relationship models are still deeply infused with the symbolism of a stratified, patriarchal culture, the general status quo has indubitably improved.

Yet of course, it is quite clear that most of the novel's characters will not live to see those changes put into effect, and not all of the social problems depicted in this fictional version of the Victorian age have been as thoroughly resolved as many would like to think: sex work in particular is still one of society's abjects, festering deep within the collective shadow archetype of western culture. At the time of writing this chapter, there is a huge debate on how to handle prostitution in several European countries, engaging legislators and common citizens alike. The German feminist Alice Schwarzer recently published a book titled Prostitution - Ein deutscher Skandal: Wie konnten wir zum Paradies der Frauenbändler werden?26 (Henceforth abbreviated as Prostitution.) Schwarzer explicitly equates human trafficking and prostitution, arguing that the legalization of sex work in Germany has played directly into the hands of modern-day slavers (even though human trafficking is just as illegal as before), and demands a total ban of this line of business. According to her, $90 \%$ of all prostitutes in Germany are only performing such work because they are forced to do so, either by poverty or by threats of physical force (cf. Prostitution, 9). How she came by those numbers or whether they are actually correct is unclear, yet it

26 "Prostitution: a German scandal: How could we become a slave traders' paradise?" (my translation) 
does appear that she engages in a kind of rhetorical subterfuge that ultimately hurts her line of argument: if anybody who only works because they need money qualifies as unfree, then the entire concept of wage labour can basically be defined as slavery. It is true that sex work is highly stigmatized, closely connected to organized crime, and imbued with an uneven power dynamic that promotes extremely unhealthy gender roles. Schwarzer's sweeping generalization, however, may be more of a stumbling block than a stepping stone in gaining greater insight into the underlying structures. Laurie Penny astutely observes:

The net result of continued ideological wrangling between feminists, sex workers' rights activists and misogynist lawmakers has left the legal status of sex work in Britain and America an unworkable, precarious Jenga tower of muddled laws and moral equivocation, wherein women who work as prostitutes are stranded in a socio-economic no man's land, [...] just about illegal enough that the market for commercial sex remains illicit and underground, depriving sex workers of public dignity and of the full protection of the justice system, and satisfying the prudish public drive to punish those who sell sex. [...] The clunky notion that prostitution is itself violence against women - even, presumably, when both parties are male - obstructs more useful analysis. Only when one acknowledges that sex can, in theory, be sold without exploitation can one ask why it so rarely is, even in the richest societies on earth. (Meat Market, 17f.)

Even if Schwarzer's conclusions were biased and it turned out that a significantly greater number of sex workers engaged in their chosen profession voluntarily, it would still be a highly problematic trade in terms of the underlying ideology. The mere fact that the vast majority of prostitutes worldwide are female betrays much about the fundamental idea(l)s of this line of business, embodying the most deleterious aspects contemporary Western culture has inherited from Victorian times (and even earlier stages of cultural history). It perpetuates the cultural myth that men are sex-driven creatures in thrall to their "lower" urges (unlike women, who are still tacitly or openly expected to conform to a standard of asexual "purity"), promoting a decidedly negative conception of both genders as well as of sexuality in general. It is also worth mentioning that female sex workers are socially ostracized while their male customers receive relatively little negative attention, as in the recent case of "Lady Hekate", a middle-aged woman who was universally condemned and shunned by her community after a local newspaper published an article that exposed her profession (Zeit, 17 Nov 2013). It seems that nobody was interested in exposing or condemning her former clients, while she was expelled from various social functions and charitable organizations that she had attended. Of course, this disparity between the treatment of prostitutes on the one hand and johns on the other is also due to certain traditional gender conceptions, namely the notorious "Madonna-harlot-dichotomy" (Logan, 7) that has been plaguing society for hundreds of years: 
whereas men are supposedly only following their natural instincts, middle-class ideology (as inherited from the Victorians and their forebears) sees women as essentially "pure" beings who need to be protected from the corrupting influence of sexuality. Even in Victorian times, there existed a blatant "double standard of sexual morality, one that upheld different standards of chastity for men and women and carefully tried to demarcate pure women from the impure" (Walkowitz, 70).

On the other hand, the stigmatization of sex work is not only a sort of circular logic that creates and promotes the terrible conditions associated with this line of business, but it also ties into the same ideological patterns as 'slut shaming'. Female sexual autonomy has always been treated as a threat by patriarchal societies: since inheritance lines, marriages and property rights depended upon paternal security, unbridled female sexuality in particular was perceived as a danger to the very fabric of society. This is why Faber's focus on the similarities between patriarchal marriage and prostitution marks it not only as a neo-Victorian, but also as a feminist text. The problem at the heart of the suffering inflicted upon the female protagonists of Crimson Petal is not tied to the supposed immorality of sex, but to the disparity of power between different genders and classes. Laurie Penny illustrates the problem as follows:

Using the phrase 'sex work' rather than 'prostitution', something many sex workers insist upon, reframes the debate. Instead of asking what it is about sex that is so bad for women, we can start asking what it is about work that is bad for everyone. That's a dangerous question. To argue that sex work is a job 'like any other' is not to argue that it is benign, on the contrary. Most jobs are awful, and the fact that some sex workers would rather not do what they do for a living implies nothing more than that: the gas-station attendant and the shop girl would probably also rather not have to do what they do all day, although they are obliged to put a smile on it and insist that they love their work. (Unspeakable Things, 132)

This study is not the place to provide an in-depth analysis of Germany's (or Great Britain's) current legal stance on prostitution, or - even more importantly - the reasons why such liberal laws did not result in significant improvements for most sex workers. But given that Western Europe is still influenced by the remnants of a sexually repressive middle-class morality that dominated the nineteenth century, it stands to reason that contemporary European culture still fails to acknowledge sex workers as anything other than either victims or agents of spiritual (self-)pollution, and thus generates a sort of self-fulfilling prophecy; a negative feedback loop that creates and sustains the terrible conditions most prostitutes find themselves in.

Sex work isn't stigmatised because it is dangerous, it is dangerous because it is stigmatised, and that social stigma, that system of punishing and excluding sex workers from the brightly lit world of good, pure women who would 
never actually cash in on the erotic capital that is supposed to be our only power, is still with us. (Unspeakable Things, 134)

Even if human trafficking is a comparatively minor phenomenon on the demimonde's criminal fringe, the sex trade as a whole does not differ considerably from the horrors depicted in Crimson Petal, perpetuating a model of sexuality that is fundamentally antithetical to the liberal and liberated society most people believe themselves to live in. There may be considerably fewer real-world equivalents to Sugar in $21^{\text {st }}$ century Europe than there were in the slums of Victorian London, yet they still exist - and in other parts of this globalized world, they might even be considerably more numerous than in the $19^{\text {th }}$ century. ${ }^{27}$

Crimson Petal most certainly encourages readers to reflect upon such societal problems and their cultural roots. After all, it is the cultivated ignorance or, even worse, tacit complicity of the customers and their demand that makes forced prostitution possible to begin with. Yet in spite of its social criticism, this novel is not necessarily didactic in tone as much as it is darkly humorous. As mentioned before, Crimson Petal does not offer any obvious solutions to the problems it describes - it merely draws attention to them, letting readers figure out for themselves whether they are still present in the $21^{\text {st }}$ century or not. The smiles it prompts might be sarcastic or even bleak at times, yet never without a sense of sympathetic kindness at its core. Its sympathy for the victims of exploitation and its derision for the perpetrators and benefactors of the same is made manifest by the narrator's voice, directing the readers' gaze. The misery inherent to the world of Crimson Petal is tempered by the humanity of its denizens, as well as by the humour of its omniscient narrator. The society depicted therein may be cruel and dysfunctional, but benevolence persists on the level of the individual, asserting itself against the status quo.

In Angela Carter's terms, Crimson Petal endeavours to "penetrate to the heart of the contempt for women that distorts our culture even as [the narrator] enters the realm of true obscenity as he describes it" (22). Unlike Lost Girls, this novel can only be called pornographic in the most literal sense of the term, "depicting prostitutes": although Crimson Petal brims with explicit descriptions of sexual organs, bodily fluids and various sex acts, there is nothing particularly stimulating or erotic about any of them. The reader is not expected to derive voyeuristic pleasure from those passages, but is instead prompted to respond with horror, disgust and abjection. Take, for example, the scene where William Rackham forces himself upon his drugged wife, whose aversion to (and lack of understanding of) sexual contact is well-known to the reader at this point:

27 There is little reliable data on just how many prostitutes walked the streets of Victorian London, with figures from the 1860s ranging between 5,500 and 220,000. Mason calls the higher estimates "sheer moralistic fantasies" (77), which might be accurate given that the highest estimates can be found in chauvinistic French writings (ibid.). In the context of the fictional London of Crimson Petal, however, it is pretty clear that there is an abundance of "fallen women", regardless of historicity. 
"Don't be afraid, my dear heart," he whispers directly into her ear. "I'm going to... embrace you now. You won't mind that, will you? It won't hurt. You'll let me know if I'm hurting you, won't you? I wouldn't hurt you for all the world." The noise she utters as he enters her is a strange lubricious sound, pitched half-way between a gasp and a croon of compliance. He lays his whiskery cheek against her neck. "Spiders...." she shudders (Crimson Petal, 659).

Even though the passage is comparatively tame - especially compared to most sex scenes between Sugar and William -, and regardless of the fact that his entreaties are perfectly earnest, the reader (who knows more about the inner workings of Agnes's mind than her husband at this point) is still bound to feel horrified by this scene, realizing that what takes place here qualifies as rape. Drugged up and nearly unconscious, Agnes is in no position to give her consent, and even in that reduced state, her revulsion is still made manifest by her exclamation at the end. It should also be kept in mind that this particular passage is narrated from William's point of view, reflecting his interpretation of the situation at hand, so her seeming compliance may very well be something altogether different. In fact, the discrepancy between the male gaze and the actual events at hand is present in almost all of these scenes, regardless of whether they involve wives or prostitutes.

Some of these passages clearly qualify as rape (such as the one quoted above), while many others are only consensual insofar as the women do not openly resist their tormentors' advances, or even pretend to like it for the sake of their livelihood. It is made abundantly clear that this show of consent is not based on affection or even plain lust, but is the product of a systemic power imbalance that places the women (be they wives or prostitutes) at the mercy of men (be they johns or husbands). Sensual pleasure in relation to sex is virtually absent from Crimson Petal, except in the case of male characters deluding themselves about the willingness of their partners. For example, even without being acquainted with Sugar's thoughts, it is perfectly clear to the reader that the young woman play-acts her way through the encounter, and in no way enjoys the ministrations visited upon her:

"I must be going," he says, brushing her cheek with his hand. "But before I do, I... I have something more to give you." [...] Her cunt is tight, and surprisingly dry. This girl's flesh needs more moisture altogether, it seems; perhaps her diet is lacking in oily foods or an essential nutrient. [...] However, he pushes through the discomfort, wincing once or twice [...]. (128).

Throughout all of this this, Sugar painfully twists her neck back "as if for a Lamarckian feat of evolution" (ibid.) because William complained about being unable to see her face in the mirror at the head of the bed, further adding to the obvious discomfort. And if these descriptions do not suffice to drive home the discrepancy between William Rackham's perception and the actual situation, the reader is accosted to Sugar's thoughts of him a couple of pages later, where she calls him 
"Emperor Pisspants" (ibid, 132) in her mind on account of his drunken incontinence in the previous night, and expresses relief at finally seeing him gone. While William attributes her lack of a physiological response to his advances to malnutrition (and is already embarking upon a course that will lead to romantic infatuation on his part), Sugar only plays her part because it is required of her, feigning enthusiasm and offering utter compliance in order to satisfy a customer. Crimson Petal clearly qualifies as another type of post-Sadeian, feminist text, pursuing "the total demystification of the flesh" (Carter, 22). In this case, the self-inflicted delusions of the likes of William Rackham would represent the pornographic status quo, perpetuating the myth of the nymphomaniac harlot deriving just as much pleasure from her trade as her customers. The only carnal enjoyment described in Crimson Petal takes place in the minds of male characters, and is based on the kind of self-deceit that makes human trafficking and forced prostitution possible to begin with: it is the illusion of being desired, even after paying the other party for the explicit purpose of play-acting such responses. But this point of view is constantly challenged and undermined in Crimson Petal, always placed in juxtaposition to what the text establishes as the actual course of events.

Like de Sade's novels, Crimson Petal portrays a societal status quo that is largely misogynistic, patriarchal, and hierarchical in the worst sense of the term. The Victorian abject of prostitution is contrasted with a contemporary perspective on aspects of nineteenth century society that qualify as abjects in the 2010s, simmering unacknowledged under the surface of a supposedly liberated society. Whereas the Marquis de Sade's oeuvre ultimately arrived at the conclusion that the only way to individual freedom leads over the enslavement of others, Faber's novel communicates a vastly different message: in Crimson Petal, everybody falls victim to the dysfunctional norms and double standards of Victorian culture. Virtually every character is intensely unhappy, including the men at the top of the hierarchy: their marriages are dysfunctional, their relationships with their parents are strained at best, and what little sexual fulfilment can be gained is either based on self-deception or the abuse of power. Not a single sexual act in the novel is entirely free from the stain of abjection. In fact, its most erotic and tender sex scene turns out to be a dying man's hallucination as he asphyxiates in a burning room, and the woman who straddles him is not the secret love of his life but the personification of death (cf. Crimson Petal, 502ff.). Every other act of physical intimacy in the novel is either driven by pecuniary interests, or else qualifies as a violation of at least one of the involved parties. In this, the novel runs contrary to the norms of stereotypical pornography, imbuing the "libidinous fantasy" with "too much reality" (Carter, 15). As in the case of Monsieur Rougeur in Lost Girls, any potential for erotic enjoyment is curbed by a literary sense of realism that does not allow for transgression without consequence. Sexual pleasure cannot be obtained in a space that is so heavily infused with human abjection and an awareness of the causes behind this misery. Genuine affection or even lust is hard to come by in a relationship that is based on such an uneven 
distribution of power - and this applies to married couples as well as concubines. Agnes and Sugar are two sides of the same coin, two sisters in spirit in a very similar situation, like the titular crimson and white petal.

\subsection{Abject Monogamy: A Scathing Look at Traditional Re- lationship Models}

Crimson Petal assumes a decidedly cynical stance regarding traditional marriage. It is portrayed as almost indistinguishable from prostitution in terms of the victimization of women and the hierarchical position of the respective partners. The relationship between Sugar and William Rackham reads like a cutting parody of a heterosexual marriage (and the courtship that precedes it). Both of his business deals with Mrs Castaway and Sugar are strikingly similar to a proposal of marriage and a marriage contract, respectively, to the point where William even compares the proceedings to his experiences in obtaining his real wife. While signing the paper that will make Sugar his exclusive concubine, he muses: "Looking back on it now, the contract for Agnes's hand was extraordinarily laissez-faire - much less demanding of him than this one here" (Crimson Petal, 181). The similarities between this settlement and a genuine legal marriage draw attention to the power dynamic underlying both types of relationship in equal measure: both women are entirely at William Rackham's mercy, depending on his money and status in order to survive. Their sole power starts and ends with their decision to accept or reject his advances - and even that choice is compromised by material necessity. (As the novel is set in 1875, Agnes's legal status is already somewhat of an improvement in comparison to her mother's: married women in Britain only "remained in coverture until passage of the Married Women's Property [Act] of 1870" (Russett, 9), granting her any money she might earn as her own property, but still regarding anything she owned prior to her marriage as her husband's assets. This legal loophole would only be amended by another legal reform in 1883 (ibid.), meaning that bourgeois women who conformed to the ideals of their class - and therefore did not pursue a profession of their own aside from that of housewife and mother - were left in approximately the same state as before throughout the 1870s. In theory, a first victory on the road towards equality had been achieved - in practice, it still left much to be desired.)

The novel's portrayal of the dysfunctional marriage between William and the asexual, angelic Agnes not only draws attention to the similarities between prostitutes and wives under the auspices of Victorian patriarchy, but also exemplifies how Victorian middle-class gender roles are antithetical to a successful relationship. Agnes cannot be a capable mother and wife exactly because she is an ideal "angel in the house", utterly devoid of any sexual thought and persisting in a state of childlike innocence. Her grasp of the concept of sex is as shaky as her notions of procreation, and her meagre education by a girl's school that focused on supplying her with 
ladylike accomplishments did nothing to prepare her for life. Further unhinged by an undiagnosed brain tumour that will never be found because "Roentgen photography is twenty years in the future" (Crimson Petal, 235), she experiences anything pertaining to sexuality as highly traumatizing - which does not exactly help her mental state, given that era's most common treatment for psychological disease in women: her physician attributes her seizures and other symptoms of instability as hysteria (literally 'womb disease'), an affliction that was commonly treated by "genital massage to orgasm" (Maines, 1) - although it should be further noted that the female climax was regarded "as the crisis of an illness, the "hysterical paroxysm" (ibid, 3) and not a natural part of sexuality. While this "treatment" might in fact have been helpful in cases where women who were expected to conform to an ideal of angelic asexuality found themselves in a state of persistent sexual frustration, it only unbalances the fragile Agnes even further. During the pelvic massage, she withdraws into a hallucination in order to protect herself from the reality of what is happening to her:

The [physician's] words come to Agnes like overheard chatter from a railway platform opposite one's own. She is beginning to dream, her eyes shutting and her face shiny with perspiration, a dream she has already dreamed many times in her sleep, but never before while awake. The dream of a journey... His finger slides down towards the motte of blonde hair at which Agnes has glanced perhaps twenty times in her whole life, each time with shame. This time, however, there is no shame to feel, for the doctor's finger is sliding (as she perceives it in her dream) not on her body, but on a surface somewhere beyond it: a windowpane perhaps. She's in a train, and as it moves away from the station, someone on the platform outside is putting his finger against the window of her compartment. (Crimson Petal, $182 \mathrm{f}$.)

As the readers are not only given access to Agnes's feelings and thoughts, but also view the passage from a post-Freudian vantage point, it is abundantly clear to them that Doctor Curlew's treatment for a disease that has been dismissed from the diagnostic manuals more than fifty years ago is not only ineffectual, but actively damages her mind. Given that she was deeply traumatized by the events of her wedding night and the birth of her daughter, the physician's treatment could never achieve anything other than to exacerbate her psychological problems.

This scene serves to illustrate one of the most contradictory aspects of Victorian gender ideology, namely the discrepancy between the sexless ideal communicated by texts such as Coventry Patmore's "Angel in the House", and the reality of a medical practice that sought to relieve the mental stress of sexually frustrated middle-class women. Even if the 'hysterical paroxysm' or the supposed mental disease that preceded it were conceived as strictly asexual, hindsight makes it difficult to ignore the obviously erotic quality of these proceedings. Pelvic massages (and the first vibrators) were basically a remedy for a dilemma created by unrealistic gender 
roles, particularly the 'de-sexualisation' of women. Agnes Rackham is the embodiment (and parody) of the 'angel in the house'-ideal, and that is why she is bound to fail. Sexual release only harms her, and Doctor Curlew is essentially raping her by trying to treat her symptoms. Her saintly innocence causes her to repress any knowledge of sexuality and reproduction, and as such disqualifies her for the role of wife and mother that she is expected to fulfil.

Sugar, on the other hand, is intelligent, knowledgeable and resourceful, and would be more than fit to assume the duties of a middle-class lady - and those of middle-class men as well. And yet, the stigma of her profession bars any chance of a normal life for her. She is a fallen woman, marked as an outcast by her very name. ${ }^{28}$ Of course, her prodigious intellect would most likely be regarded as unwomanly under the auspices of Victorian middle-class ideology, being perceived as a flaw rather than a gift. Crimson Petal's motto, a poem written by J.J. Gray in 1880 titled "The Girls that are Wanted" encapsulates this disdain for intelligence in women rather well. After praising girls for their motherly feelings and moral purity over the course of two stanzas, it culminates in an open vilification of females with aboveaverage mental faculties: "The clever, the witty, the brilliant girl/ There are few who can understand/ But, oh! For the wise, loving home girls/ There's a constant, steady demand" (cf. Crimson Petal, unnumbered opening page). Apart from the outrageous condemnation of intelligence as an essentially undesirable quality (in women), it should also be noted how the poem infantilizes its subjects as "girls", even though it is quite clear that the text is talking about marriageable young women capable of motherhood. This profound disdain for intelligent women was even present in more progressive parts of Victorian society:

Feminist claims to intellectual equality with man and to the same education and professional opportunity were attacked by liberals - let alone conservatives; partly, no doubt, to forestall competition, but much more to prevent what they honestly believed would mean the irreparable loss of a vital moral influence... [Many] intelligent women - George Eliot, Mrs Humphry Ward [et al.] - viewed with uneasiness or apprehension any emancipation of their sex which would weaken its moral influence by distracting attention to the outside world or by coarsening the feminine nature itself. (Houghton, 352)

"Feminine nature", that elusive spectre of middle-class saintliness, did not allow for excessive intellectual acumen, as a woman's role and very essence were believed to be compromised by too much worldly knowledge. Interestingly enough, William Rackham does not seem to agree with this assessment - at least where it concerns

28 That these two characters could remind readers of William Blake's Songs of Innocence and Experience might not be entirely coincidental: Agnes's name means "lamb" in Greek, whereas Sugar is covered with angry red stripes of dry skin that are reminiscent of a tiger (cf. Faber 2002, 186), pointing to the most famous pair of juxtaposed poems within the collection. As such, they do indeed embody two contrary states of the human soul, innocence and experience. 
his illicit mistresses. Sugar's intelligence and her erudite grasp of literature contribute greatly to his infatuation with her:

Why, the girl's a prodigy! She has an amazing knowledge of literature, lacking only Latin, Greek, and the male's instinctive grasp of what is major and minor. In terms of sum total of pages, she seems to have read almost as much as he (although some of it, inevitably, is the sort of piffle written for and by her own sex - novels about timid governesses and so forth.) ... To many women - Agnes among them, unfortunately - Swift is the name of a cough lozenge, or a bird to be worn stuffed on their bonnets. (Crimson Petal, 111)

Although William's sexism is blatantly obvious, colouring all of his perceptions, he finds himself drawn to a woman who so openly defies expectations and conventions alike. Sugar's knowledgeable words may not cause sufficient cognitive dissonance in his mind to make him question social conventions, yet he nonetheless finds it more than appealing, contrasting it with the cultivated ignorance he experiences in women of his own class. On a more cynical note, her intelligence might even reaffirm his gender bias, as prostitutes were supposed to be women "with half the woman gone, all that elevates her nature" (William Acton, qtd. by Shaw, 124). With this in mind, Sugar might be regarded as a perversion of nature - a half-male, halffemale aberration that has crossed the supposedly natural boundaries attributed to her sex. Even her physique - described as "stick-thin, flat-chested and bony, like a consumptive young man, with hands almost too big for women's gloves" (Crimson Petal, 27; emphasis added) seems to support such an interpretation. And of course, it is this deviant facet of her nature that might qualify her exceptionally well for her profession, as prostitutes were commonly regarded as a "necessary evil to protect the pure, who otherwise might unwittingly provoke the male to rape them" (Kent, 62). There might still be a difference between the way William Rackham regards Sugar and the way he looks at other prostitutes (who, to him, are "indivisible from the muck that surrounds them, like rats" (Crimson Petal, 128), yet in the end, even his infatuation does not seem to extend past the attachment somebody might feel towards a prized possession.

Agnes and Sugar serve as foils to each other, and most likely are supposed to be the titular "Crimson Petal and the White". Nonetheless, they are not necessarily placed in total juxtaposition to each other, as they encounter very similar problems - especially in their relationship with William Rackham. In fact, the novel suggests that in spite of all of their fundamental differences of appearance and character, their experiences mirror each other to a certain degree - albeit experienced through very different lenses. Both characters feel repelled by the sexual advances of men, and only suffer through these experiences because open resistance is not an option for either one of them. In Agnes's case, a refusal would be considered further proof of her unhinged state, while Sugar would lose her patrons and find herself starving on the streets. But while Agnes's waking mind barely comprehends what is 
happening to her during sexual encounters, Sugar is all too aware of what her customers have been on about since she was thirteen years old. Innocence and Experience, William Blake's "two contrary states of the human soul", are not opposed to one another, but exist side by side, colouring the individual's perception of reality. With this in mind, it might not be too surprising that Sugar and Agnes become allies in the last third of the novel: both of them depend upon William Rackham's goodwill, yet neither of them truly loves him. Their shared plight establishes a sense of solidarity - at least as far as Sugar is concerned. Agnes is unaware of the young prostitute's identity, and knows nothing of her status as a concubine. Instead, she perceives Sugar as an angelic being, sent to help her against the predations of a maledominated world: an estimation that, all esoteric flights of fancy notwithstanding, turns out to be surprisingly accurate in the end. The two of them are instantly drawn to each other, even before Sugar joins the Rackham household. This character constellation naturally undermines the expectations readers might hold with regards to a typical plot involving a love triangle - but as has been noted before, Crimson Petal eschews stereotypical conceptions of romance, and instead focuses on the abject ugliness at the heart of traditional relationship models. Given the legal status of Victorian wives, it could even be maintained that in spite of their differences in terms of social status, Sugar and Agnes are in an almost identical situation: in legal terms, Victorian wives ceased to be independent persons. It was impossible for them to testify against their husbands in a court of law, as they were legally regarded as the same entity. Likewise, as noted before, legal property was only partially granted to them (cf. Buckner, 137). Accordingly, Victorian wives were in many ways just as disenfranchised as the sex workers operating in the lawless space of the demimonde. They could not be easily cast off (as divorce was still comparatively difficult for both involved parties), yet their husbands possessed almost unlimited authority over them - a topic that has been raised by various Victorian novels, such as Wilkie Collins's The Woman in White or Emily Brontë's Wuthering Heights. The ease with which William could have his wife confined in a lunatic asylum is indicative of this. Under these auspices, it should hardly be surprising that the hardened prostitute Sugar should come to feel sympathy and solidarity for the ailing Agnes, protecting her from harm to the best of her abilities.

The highly sarcastic comparison between the socially accepted institution of marriage and the highly illicit patronage of a prostitute is carried even further when William obtains a flat for Sugar, mirroring the nuptial tradition of moving to a new house:

"Where," murmurs Sugar, "are we going?" [...] "That's for me to know," teases William gently, stroking her shoulder in the dimness of the cabin, "and you to find out." Sugar loathes pranks and riddles of all kinds. "How exciting!" she breathes, and presses her nose to the window. William finds this child-like curiosity adorable - and a most pleasing contrast to the way the newly-married Agnes behaved on the day he took her to her new home. 
Agnes looked behind her all the way, however much he implored her not to;

Sugar is looking ahead with naked anticipation (Crimson Petal, 284).

As the passage acquaints the reader with Sugar's true feelings on the matter at hand, the irony of having William muse about her feigned enthusiasm can hardly be missed. Nonetheless, his assessment is correct insofar as it characterizes the two women and the fundamental differences between them rather well: the innocent Agnes is constantly pining for an idyllic childhood cut short by the death of her father, whereas Sugar desires nothing more than to leave her traumatic past behind. William Rackham's recollection of his wedding day also serves to illustrate just how immature and child-like Agnes actually was at that point of their relationship, suggesting that her husband could have known just how fragile she was, yet chose to ignore the signs.

Sugar's relocation to an independent flat differs from a traditional marriage in one crucial point, however: she does not cohabitate with her benefactor, but instead has the house all to herself, being able to pursue her own projects, become acquainted with the Rackham business, visit the opera, and manage her day according to her own desires. This places her in a position that is vastly superior to that of any Victorian wife (except for widows), even if she is still utterly dependent on William's goodwill and money. Her position is precarious, and she is aware of the fact that she needs to gain a better hold on William's affection if she wants to avoid a return to her previous existence. Yet for what it is worth, it still supplies her with an audacious amount of autonomy and independence.

Sugar, William, and Agnes form a triangle that demonstrates how hierarchical patriarchy is virtually antithetical to any notion of romantic love: as the female half of the populace is utterly at the mercy of the male half, relationships are inextricably linked to economic self-interest rather than affection. Crimson Petal does not promote the point of view that men are necessarily benefactors of this arrangement, however, regardless of their greater privileges and rights. Everybody suffers from the dysfunctional system and the ideology that maintains it, be it in the form of sexual frustration, a lack of affection and love, or impossible standards attached to the respective gender roles. Victorian society fails these characters on account of its economic structure, its sexual ideology, and even its ideal of domesticity. It is hardly a coincidence that all of the main characters (and even most minor characters) hail from broken families.

William and Henry Rackham witnessed an ugly divorce in their childhood, as their cuckolded father supposedly banished his wife after learning of her infidelity:

[If] the arrival of his wife took [his employees] unawares, her departure, nine years later, surprised no one. Indeed, her adultery seemed to be common knowledge long before he, its victim, learned of it; most galling, that. Then there was endless speculation about whether he disowned her, or if she ran off willingly. What did it matter? She evaporated from his life, leaving behind 
two infant boys. [...] Years went by, the boys grew up with no ill effects whatsoever, and business prospered [...]. (Crimson Petal, 165)

This passage is obviously narrated from the perspective of Henry Rackham, Sr., as suggested by the phrase "most galling, that". Accordingly, his assessment of the situation may not be entirely accurate, especially as far as the mental state of his children is concerned. Given that Rackham, Sr. is described in terms of an uncaring workaholic married to his business (ibid.), and considering that both of his sons experience substantial difficulties in establishing and maintaining relationships in their adult life, it seems pretty clear that the divorce did not pass them by without leaving a mark. The way Henry Calder Rackham reminisces about his wife and the way he dealt with her after becoming aware of her extramarital affair suggests that she was little more than a trophy to begin with - and his attitudes might very well have influenced his sons. The boys grow up to be two extremely different men, yet they are united in their inability to sustain healthy relations with women. In many ways, Henry Rackham, Jr. is established as a foil to his younger sibling William: he is high-principled, caring, and altruistic, whereas his brother qualifies as a self-obsessed libertine adhering to very loose morals. Seeking refuge in the Christian faith, and embracing an ascetic path that denies the flesh, Henry has turned his back on his father's way of life, whose pragmatic entrepreneurship has very little in common with the quixotic idealism exhibited by his first-born son. But Henry's religion does not necessarily turn out to be a viable alternative to Victorian middle-class society, at least as far as sexuality is concerned. If anything, his faith only emphasizes the most repressive and anti-sexual aspects of the Victorian zeitgeist, alienating him from his emotions and desires. Accordingly, he is unable to confess his feelings to the widowed Mrs Fox, even though their mutual affection is the only romantic bond that is described as genuine in the context of Crimson Petal. ("The love I spoke of is real. It is the love of two friends for their God, and for each other" (Crimson Petal, 190), the narrator declares.) Likewise, Henry feels that his sexual longing renders him unfit for priesthood, leaving him in an abject in-between-state of self-inflicted torment. Accordingly, his religion must be considered a spiritual dead end, hampered by excessive strictness and stuck in a past that is quickly disappearing, as evidenced by his rejection of Darwinian evolution (cf. 196). Tragically, his acknowledgment of his feelings for Mrs Fox indirectly leads to his untimely demise, as his burning of Christian pamphlets and sermons sets fire to his rooms and kills him (cf. $501 \mathrm{ff}$.). It is not so much a rejection of his prior religious beliefs as it is a moment of intense self-loathing, because he feels that his sexual desire for his widowed friend makes him unfit for the career he wanted to pursue. This problematic conception of sexuality connects his version of Christianity to the wider Victorian zeitgeist, for his high opinion of Mrs Fox coincides with the false conviction that she qualifies as an asexual saint, and would be horrified if she were to discover his feelings. Where William harbours a very low opinion of women in general, reflecting the negative sexism of that era, Henry once more represents the opposite end of 
the spectrum: he idolizes women as saintly (and therefore asexual) beings. His unachievable ideal of sexless purity makes it impossible for him to pursue a functional relationship.

William, of course, does not fare much better. As has been mentioned before, Agnes's childlike innocence renders her utterly incapable of leading a normal life but it would be short-sighted to place the blame for their dysfunctional relationship at her feet. After all, Agnes's ignorance has been deliberately cultivated by educators and (step-) parents alike, supplying her with feminine accomplishments but leaving her entirely oblivious with regards to both sexuality and reproduction. Her contact with the male gender has been severely limited, prior to her marriage: there were no boys at her boarding school. Likewise, she did not even receive any information with regards to menstruation, as evidenced by her traumatized diary entries. ("Here you see my own blood, Agnes explains underneath, Blood from deep within me, flowing from a bidden wound. Whatever killed my Mama, now kills me. But why? Why, when I am Innocent?" (Crimson Petal, 600; emphasis in original) Apparently, nobody ever saw fit to explain her monthly courses to her, as her horror at seeing her own blood flow persists into her married life. It is this lack of communication, the explicit contradiction of wanting to preserve and protect her innocence while simultaneously expecting her to understand certain fundamental principles of sexuality that contributes greatly to her fragile state of mind. Accordingly, her wedding night alone might have sufficed to unhinge her: her diary entries suddenly stop for a few weeks after becoming Mrs William Rackham (cf. Crimson Petal, 661), indicating that she withdraws completely from reality. And of course, both her pregnancy and the birth of her child destabilize her even further. In her recollection, she did not give birth to a daughter, but was possessed by a demonic entity:

[I]nside me the demon squirms. I feel it pushing and lungeing [sic] in rage and terror, but my Sister has a way of causing my belly to open up without injury, permitting the demon to spring out. I glimpse the vile creature only for an instant: it is naked and black, it is made of blood \& slime glued together; but immediately upon being brought out into the light, it turns to vapour in my Holy Sister's hands. Falling back in exzaustion [sic], I see my belly shrinking (Crimson Petal, 662).

Agnes's Catholicism alone might have sufficed to arouse suspicions of irrationality or even madness in the eyes of her fellow Victorians, as this religion was strongly associated with all sorts of deviant behaviour ever since the heyday of the Gothic novel (cf. O' Malley, 76). Whereas Anglicanism was considered the very embodiment of British common sense and the values of the Victorian middle-class, Catholicism was commonly associated with rank superstition and sexual perversion (ibid., 90-92). Accordingly, Agnes's religious convictions (combined with her delusions) might very well serve as a parody of Victorian anxieties with regard to 
Catholic Christianity. Her delusions can be read as mystic visions, like those of revered saints such as Teresa of Avila.

The text also suggests that nobody (except perhaps for Sugar, after reading the buried diaries) has ever been aware of what was going on in Agnes's mind. Doctor Curlew rationalizes her symptoms in terms of the medical status quo of his time, while her husband simply keeps their daughter Sophie out of sight, never really learning why Agnes would deny her existence to begin with. Estranged from each other and their daughter alike the Rackhams live side by side without being able to communicate, wallowing in their respective misery. Agnes herself sums it up perfectly in a moment of peculiar insight commonly associated with the saintly and the insane: "You know, I’ve never liked this place. [...] It smells... it smells of people trying terribly hard to be happy, without the slightest success" (Crimson Petal, 690).

The Rackhams serve as an example of the internal inconsistencies of Victorian middle-class ideology and its 'separate spheres'. Even their daughter Sophie suffers from the dysfunctional gender roles her parents embody: Agnes cannot fulfil her role as mother and housewife because her angelic (and pathological) innocence renders her incapable of both tasks. Her 'accomplishments' cannot help her to organize and maintain the household, and no other form of education has ever been provided for her. She lives in a world that revolves almost exclusively around social gatherings, fashion, and popularity contests - strikingly similar to the kind of life she most probably led at her boarding school. William Rackham, on the other hand, is expected to devote himself to business and the outside world: raising a child is not part of his duties, and he does not quite know what to do with his daughter Sophie even when they meet - which is a rare occurrence, thanks to explicit instructions to keep her out of sight. "[Well-behaved] children are neither seen nor heard" (Crimson Petal, 160), according to Sophie's governess, modifying a famous proverb that originally referred to young women (cf. Martin). In its original form (i.e. "children should be seen but not heard"), it was an admonition against 'loud' behaviour, advocating obedient silence but not the kind of total invisibility propagated in this case. It may not even be William Rackham's intention to be negligent, as he would like to resemble the kindly father figure "depicted in ladies' journals" (Crimson Petal, 160), yet that would necessitate a kind of family life that simply does not exist in the Rackham household. Her mother has repressed the very knowledge of Sophie's existence, and her father feels it necessary to avoid causing any distress to his ailing wife. Accordingly, the Rackham's daughter bears all the signs of prolonged neglect, wetting her bed at night and believing that her primary duty is to be unobtrusive (cf. 550f.).

If the child is the father of the man, as William Wordsworth put it in his poem "The Rainbow", then the characters of Crimson Petal (and the society they live in) have been set up to fail from the start. In no other case is this more apparent than with the prostitute Sugar - yet at the same time, she seems to be the only one who manages to break free from the shackles of her upbringing. 
She is the very embodiment of her mother's sins: if not for her conception, the self-styled Mrs Castaway would never have descended into the Orcus of the London slums. ${ }^{29}$ Sugar's psoriasis could be the result of her mother's unsuccessful attempts at aborting her, and its patterns of dry skin seem to embody the guilt that weighs both of them down, looking "like the scars of a thousand flagellations" (Crimson Petal, 212). Indeed, these marks start to itch when Sugar finds herself in her mother's presence, urging Sugar to scratch until she bleeds (ibid. 307), connecting her congenital condition to the mental torment she experiences at her mother's hands. Judging by the young woman's subjective perception of Mrs Castaway, the relationship between these characters has always been dysfunctional in the extreme. The mother made sure that her daughter shared in her misery even when the girl was still a toddler, "pulling the sheets off Sugar's half-frozen body [, declaring:] 'That's what God does [...] He loves to do that" (cf. 451).

Sugar's very name bears witness to the fate her mother apparently intended for her from birth: it instantly marks her as a prostitute, proclaiming to the world that she belongs to the demimonde, and is a commodity to be bought like candy. And indeed, Mrs Castaway forced her daughter into prostitution at the tender age of thirteen, telling her in an eerie echo of her earlier torments that "she needn't shiver any more: a kind gentleman had come to keep her warm" (ibid. 306). In context, this euphemism was not even intended for her daughter, but for her customer: Mrs. Castaway is quite deliberate in her attempts to make the girl suffer. Adding insult to injury, the embittered, 'fallen' woman even taught her daughter to read and write not with the intent of granting Sugar a chance at obtaining a better life, but for the sole purpose of heightening the girl's awareness of the misery that surrounded her, lest her torment should be dampened by long familiarity (cf. ibid. 598). Like a variation of Charles Dickens's Miss Havisham (who may very well have served as a model for this particular character), Mrs Castaway not only shows grim determination to emphasize and perpetuate her own suffering, but also to inflict it upon her child, determined to turn Sugar into her very own image. And at the beginning of Crimson Petal, her plans even seem to have succeeded for the most part. Sugar rages against the world, venting her torment by means of her brutal revenge fantasies. She understands the society that surrounds her, the culture that abuses and rejects her

${ }^{29}$ It is possible (if not exactly likely) that Crimson Petal contains a genuinely Dickensian twist: William and Sugar could potentially be half-siblings, and Mrs Castaway might be none other than the disowned Mrs Henry Calder Rackham. The time frame - judging by Sugar's and William's respective age - certainly seems to fit this hypothesis, lining up the time of the girl's birth with Rackham Sr.'s nasty divorce. Likewise, both Sugar and the Rackham brothers are redheads, which, although not spectacularly uncommon, might at least serve as a further indicator of a shared heritage. But whereas this connection would certainly have been a major plot point in a Charles Dickens novel, it is just indicated by the faintest of hints in Crimson Petal, and never truly relevant to the overarching story. In fact, it stands to reason that most readers won't even notice this possibility. 
- and with that understanding comes a deep loathing, even as she would wish for a better life.

But how can Sugar escape this fate? In a pseudo-Victorian novel, the answer would be perfectly clear: her saviour would take the shape of a kind and loving suitor, lifiting her up from the gutter and eventually not only showing her that the society she once despised was not as bad as she thought, but also making her a part of that established order. Matrimony would signify redemption and bliss, a safe haven for the Ciderella-esque heroine. There would be little (if any) challenge aimed at the patriarchal and sexist norms at the heart of Victorian (and, to a lesser degree, contemporary) culture, and the conclusion would be a reconciliation on the middleclass's terms.

On the surface, Crimson Petal bears some faint resemblance to this scheme, insofar as Sugar can only escape her mother's brothel due to William Rackham's infatuation, and her further development as a character would be impossible without his patronage. Their arrangement - no matter how dishonest - turns out to be mutually beneficial, as well as surprisingly stable: their mutual love of literature provides them with opportunities for conversation; Sugar escapes from the slums and does not have to endure the unwelcome attentions of dozens of johns, and William experiences some relief from the trials of his dysfunctional marriage. More than that: he gains not only a lover, but also a capable businesswoman who almost singlehandedly manages his father's company (cf. Crimson Petal, 317) without hurting his ego. Sugar, in turn, discovers high art, and sees her burning rage at male-dominated society dwindling to a more manageable level. Within the confines of her own home, she experiences a first semblance of peace, and has pause to reflect upon her own place in the world. They are eminently good for each other, even if their insincerity and the fleeting nature of sexual desire always place their liaison on feet of clay.

But as noted before, their relationship reads more like a parody than a genuine romance. William's infatuation is sincere, yet at no point of the story does he harbour any intention of making Sugar anything other than his whore. Immediately following a scene that reads like a parody of a marriage proposal, for example, still reeling with the joy of securing her assent ("Yes! She said yes!" (Crimson Petal, 181), he already contemplates how easily he might shirk his contractual obligations to her: " $[\mathrm{W}]$ hat could she possibly do? Pursue and imaginary man through the courts of Whoredom? Regina hears the case of 'Castaway' versus 'Hunt'? Stop scribbling, woman, and leave room for the signatures" (ibid.). Even though his derision is mostly aimed at Mrs Castaway, his attitude reveals a lot about the way he regards his commitment to Sugar: no matter how much he desires her, it is clear that he could - and would - discard her at a whim if he felt like it, without suffering any legal repercussions.

Naturally, Sugar's affections are no more genuine than his. Her motivation is entirely self-centred, and she merely learns to respond to his whims. When asked 
by William whether she likes him, her reply reads like a summary of their relationship and the dishonesty at its very heart:

Oh William, yesssss," she says. "You're my rescuer, aren't you? My champion..." She cups his genitals in her rough palm. "I can scarcely believe my good fortune." He stretches, closes his eyes in languor. [...] How much money will she ask for this time? [...] It occurs to her - well, no, she suspected it from the moment she first looked in his eyes - that for all his transgressive posturing he is an infant searching for a warm bed to sleep in. If she will but smooth his greasy golden curls off his sweaty brow, he'll give her anything she asks for in return (Crimson Petal, 187).

Once more, the apparent romance is rendered absurd by the insertion of pornographic imagery, and is then utterly destroyed by Sugar's musings on the matter.

Keeping this in mind, it is perfectly obvious that the stereotypical path of redemption is not an option here: their relationship may be the key to her rise through the ranks of Victorian society, helping her escape her mother's brothel and even letting her secure a position within the Rackham household, it is clear that William - nor any other male character - can ever be the key to her salvation. Instead, she finds it in the shape of a child: the bond between Sugar and Sophie Rackham, which seems to compensate for all of the broken childhoods in the novel, enables her to escape the fate that her mother had intended for her, gradually slouching off the hurtful lessons that Mrs Castaway imparted. Early on in the novel, it is established that Sugar identifies strongly with suffering children, seeing her own suffering mirrored in their plight: almost against her will, she gives money to a begging child (Crimson Petal, 45), and she tries to look after Christopher, the abused son of a fellow prostitute in Mrs Castaway's brothel. But at that point of her personal development, she is still in no position to truly reach out to them, as she is far too preoccupied with protecting herself from harm. Her bond with Sophie differs from these previous instances insofar as she is truly in charge of the child, and thus in a position to effect some major changes in the life of the neglected Rackham daughter. By becoming a substitute mother to Agnes's disowned child, Sugar ultimately frees herself from the persisting influence of her cynical mother, shedding the protective carapace of hatred that was expressed in her written revenge fantasies. Upon meeting Sophie, she finds her own neglected childhood reflected by the girl's, and uses her memories of Mrs Castaway's 'education' not as a model, but as a cautionary tale. Sugar's treatment of Sophie is constantly juxtaposed and contrasted with recollections of the abuse the former prostitute suffered at her mother's hands. The cycle of abuse could easily continue, as Sugar finds cynical comments spoken by her mother's voice at the back of her tongue (cf. Crimson Petal, 573). But instead of "[d]ressing the lamb for the kill" (566, emphasis in original) (as Mrs Castaway described the purpose of her lessons), Sugar genuinely tries to help Sophie, providing her with the kindness and attention she needs in order to develop normally. 
But of course, even this relationship is not entirely free of the stain of abjection. Sugar is not Sophie's biological mother, but only her governess. Her position is once more entirely dependent on the goodwill of her employer, William Rackham. And the greatest threat to her happiness comes in the shape of a potential child of her own, which would proclaim her illicit affair to the world and instantly advertise her status as a 'fallen woman' to the world. Even though she has outlived Mrs Castaway's corrupting influence, she must terminate her pregnancy, knowing fully well that a failure to do so would damn both her and her unborn baby to an existence in the hellish underworld that she sought to leave behind. Her attempts at aborting the foetus show an ambivalence that's still underlying all of her actions, even if they are not the result of cynical self-centeredness, but of the constraints Victorian society places upon her. She has become a better person, yet her circumstances do not allow her to realize the fullest potential of that transformation. Victorian middleclass morality prohibits her from carrying the pregnancy to term without suffering another fall, and thus her hand is forced: she needs to perform the very act that might have ended her own life prematurely - an act that is rendered even more tragic by its futility.

And of course, even though Sophie Rackham blossoms under Sugar's tutelage, the prostitute's decision to abduct the child is still extremely problematic, especially given that she has not secured the girl's consent at all. Even if the readers are strongly encouraged to believe that Sophie would relapse into a state of neglect in the Rackham household, and potentially grow up to be another vapid trophy wife, her abduction remains ethically problematic. Faber expanded upon this narrative strand in the novella "A Mighty Horde of Women in Very Big Hats", Advancing, showing how Sophie has grown up to be a well-educated suffragette artist - yet still yearns for her lost past. But of course, this ambivalence only serves to illustrate the point Crimson Petal tries to make: under the auspices of Victorian patriarchy and the values it promotes, genuine, functional relationships can only blossom underneath the surface of society, tacitly defying the propagated norms of the day. It is a society that creates monsters like Mrs Castaway, who are simultaneously victims and perpetrators of abuse; a society that confines people like the prostitute Caroline to miserable slums, to be used and abused for small amounts of money; a society that, last but not least, even promotes the misery of those who are apparently its overprivileged benefactors: for in spite of their high social status and power, men like William Rackham are intensely unhappy people, bound by an ideology that cripples their family life and hobbles their ability to sustain healthy relationships with their wives and children. It could be argued that Crimson Petal mostly deals with a bygone culture, and thus does not qualify as an act of social activism: after all, the Victorians and their dominant morality have been gone for a long time, and many of the deficiencies portrayed in the novel have long since disappeared. Social progress has occurred, women's rights (as well as workers' rights) have improved considerably. And yet, the Victorian age still serves as a mirror for our own times, highlighting 
flaws that persist as a part of the collective cultural subconscious. Sexism and patriarchal structures inherited from the past influence the way people perceive the world and each other in the present. Faber uses the sphere of sexuality to reveal hidden power dynamics, to uncover the monstrous side of Victorian middle-class morality and its gender conceptions, and to satirize the conventions of the historical novel and its customary portrayal of romantic relationships. There is no genuine romance to be found in this novel; only something that looks quite similar, but turns out to be genuinely ugly at a closer glance. It is even possible to view the relationships portrayed in Crimson Petal as a commentary on our own society and the way Western culture relates to sexuality. After all, the most traditional forms of marriage (and the customs attached to it) may still bear a striking resemblance to those depicted in the novel, down to the uneven distribution of power. When prospective husbands ask for their future father-in-law's consent to the match, for example, they are symbolically perpetuating the values of a time when females were second-class citizens, bartered and traded between males like prized goods. As Anthony James Hammerton points out:

Heightened criticism did not signify the end of patriarchal power in marriage, as its decline in the early twentieth century suggests. Rather, patriarchy in the home made further adaptations to the increasing pressures, remaining subject to others in the future. The critical discourse which targeted masculinity produced no revolution in marital relationships, but, in opening $\mathrm{p}$ male behaviour in marriage to public gaze and censure, it laid the groundwork for deeper questioning of conjugal performance, which, in the late twentieth century, has finally been taken up again. (169)

Likewise, the sex trade in all of its more abusive and criminal variations is still a sordid reality, including human trafficking and forced prostitution. In Victorian times as well as now, people who are known to be sex workers might have a hard time being accepted by the rest of society, even if they leave their profession behind. Unfortunately, even feminist endeavours have not necessarily helped sex workers:

Prostitution had been a dangerous symbol for feminists and socialists to wield: it was a powerful parable about the consequences of sexual and economic inequality. The criminalization of prostitution helped to defuse this symbolism and to dis-implicate the state and capital from the causes and maintenance of prostitution [, and] to make prostitution about specific demons in society that could be managed by specific laws, rather than a sign of something very wrong in the fundamental structure of society or the state itself. [Prostitutes] lost a great deal of their metaphorical and sentimentalized status: pathologized and professionalized, women who sold sex became part of a marginalized world of deviance and crime. (Laite, 216) 
As the example of "Lady Hekate" has shown, they are often exempted from professions such as educator or teacher even today, as their occupation is still regarded as inherently degrading and polluting. In many ways, society has not progressed much in this particular instance, even if society's commonly held self-image portrays contemporary Western culture as sexually liberated and open-minded.

Crimson Petal's portrayal of the disastrous consequences of Victorian gender ideology and a patriarchal, impermeable class society may inspire its readers to reflect upon their own ethos, and the historical setting creates a sense of distance that might be necessary to evaluate their own cultural norms from a detached vantage point. The Victorian age thus becomes a looking-glass for present-day British culture and, by extension, the West as a whole. The novel subtly encourages us to face the bleakest abjects within the dark subconscious of our own society, to acknowledge them as the result of the very system we live in - and to attempt to change it.

The novel manages this in large part by means of its unusual narrator figure, which contributes considerably to this Jungian Shadow-work, placing the readers in a very uncomfortable role indeed. Starting with the very opening lines, they are torn from their comfort zone, forced to imagine themselves as part of the setting they are placed in, and to experience all the horrors and sensations of a Victorian slum in late November.

\subsection{Following the Prostitute: A Journey into Abjection}

Crimson Petal is hardly the first neo-Victorian text employing a meta-fictional narrator: John Fowles's genre-defining novel The French Lieutenant's Woman famously introduced its author as a self-aware character within the fictional world described therein, commenting upon the act of creating the text and adjusting it to the changed zeitgeist of the twentieth century. Since then, the "double temporal consciousness" (Kohlke \& Gutleben, 2) created by such an approach has become one of the defining features of neo-Victorian fiction in general: it is this dual awareness in particular that makes it possible for this genre to discover "ideological blind spots" (ibid.) within the Victorian spirit of the age (as expressed by canonical novels of that era), and to re-connect these issues to contemporary society.

In the case of Crimson Petal, however, it is not the author-as-character who addresses the readers directly - it is the novel itself. The narrative conceit at the heart of Crimson Petal places the readers in the position of a prostitute's customers, and the novel in the role of a sex worker who lures them in. Like a hellish version of Dante's Beatrice, this guide leads 'her' charges straight into darkness, always making sure to describe the human misery around them in uncompromising detail (cf. Crimson Petal, 3ff.). It is a setup that is deliberately designed to make the readers feel uncomfortable, placing them all too close to the abject demimonde of Victorian London, while simultaneously denying them the fully immersive (yet dissociated) 
illusion of a classical realist mode of narration. They do not get to perceive the events through the eyes of a character, but are placed within the very scenario unfolding before them, almost (but not quite) becoming a part of the fictional world. At the same time, the narrator makes sure to remind the readers of their status as outsiders in unfamiliar surroundings, far removed from both the fictional setting and the historical era they are plunged into. They are like hapless johns who have been lured away from the main streets, stumbling ever deeper into a Victorian slum. Expecting some easy entertainment and frivolous escapism, they are instead brought face to face with abjection. Like a wily prostitute, the novel has advertised its charms, and was bought in order to divert its customers: "Certain expectations were aroused. Let's not be coy: you were hoping I would satisfy all the desires you're too shy to name, or at least show you a good time" (Crimson Petal, 3). And indeed, the novel's layout might have tempted readers to wrongfully assume they were faced with a stereotypical historical romance novel: for example, the chapter headings given to Crimson Petals five parts seemingly indicate a fairly common rags-to-riches motif all too common in retro-Victorian fiction. It starts on "The Streets", closely followed by "The House of Ill Repute"; thence, the plot progresses through "The Private Rooms and Public Haunts" to "The Bosom of the Family", and finally to "The World at Large". Without any additional information, readers might very well assume that these titles point to a typical Cinderella-motif, following the journey of a fallen woman who manages to rise through the ranks of society, potentially by means of romantic affiliations. What follows could easily be a rags-to-riches plot, or a pious tale of redemption akin to the one found in Wilkie Collins's The New Magdalen. In that case, the abject reality of prostitution would only serve as a starting point for a ritual cleansing process, most likely establishing the thesis that good middle-class morals and traditional relationship models could easily purge such smudges from society as a whole, if applied correctly. The novel-as-narrator, however, makes sure to dispel any such misconceptions in the very opening lines:

Watch your step. Keep your wits about you; you will need them. This city I am bringing you to is vast and intricate, and you have not been here before. You may imagine, from other stories you've read, that you know it well, but those stories flattered you, welcoming you as a friend, treating you as if you belonged. The truth is that you are an alien from another time and place altogether (Crimson Petal, 3).

By immersing the readers into the fictional setting (while simultaneously highlighting their foreignness), the narrator refuses to let them keep a comfortable distance to the proceedings at hand. Use of the present tense serves to reinforce a sense of immediacy, prompting the readers to imagine that the sensations described by the text are assailing them during the very act of reading.

But what exactly could the "other stories" (ibid.) mentioned in the quotation above be? What texts does the narrator potentially have in mind here? Given the 
context, this reference could be aimed at both authentic Victorian novels (such as Charles Dickens's Oliver Twist or Elizabeth Gaskell's Ruth), or it could refer to virtually any contemporary retro-Victorian novel set in the nineteenth century: the Victorian slum has become an almost ubiquitous ingredient of such fiction. Yet in most of these cases, the abject horror of poverty has become little more than a part of the setting, as much of a staple as references to the Black Death might be in a historical novel set in medieval times. Even though authentic Victorian novels were often intended as a form of social criticism, condemning some of the negative side effects the Industrial revolution unleashed upon society, their place within history sees to it that their socio-political commentary has become a part of the setting rather than a message that is of immediate relevance to contemporary readers. In the context of retro-Victorian historical novels, Dickensian slums do indeed tend to be little more than local colouring, as detached and distant from the readers' own lives as the crusades or the Reign of Terror. As terrible (and potentially historically accurate) the depicted events might be, the reader will not experience them firsthand, but instead be a spectator who can derive cathartic enjoyment from the protagonists' trials and tribulations. Crimson Petal's narrator, on the other hand, does not grant its readers such a passive role. They are brought into immediate contact with the misery of the poorest Londoners, ushered into a dark underworld by an insistent narrator figure that puts its audience in the position of fictional characters.

Now that you're actually here, the air is bitterly cold and you find yourself being led along in complete darkness, stumbling on uneven ground, recognizing nothing. Looking left and right, blinking against an icy wind, you realize you have entered an unknown street of unlit houses full of unknown people [...] Sleet stings your cheeks, sharp little spits of it so cold they feel hot, like fiery cinders in the wind (3).

This focus on the readers' sensory perceptions lends the fictional setting a sense of physicality: the narrator does not merely describe these impressions as if they happened to somebody else, but instead demands that we subject ourselves to them in our imagination. The fourth wall is not so much broken as it is rendered permeable, blurring the lines between the fictional setting and the reality of the people engaged in the act of reading the novel. Crimson Petal thereby not only defies and subverts the norms of classical realism, but also puts its audience in an abject in-between place that fosters an awareness of the readers' temporal distance to the events at hand while simultaneously plunging them into the setting as if they were time-travelling characters within the fiction. The description of the physical surroundings evokes a sense of danger as well as discomfort. And once more, the imagery of the narrator-as-prostitute and the reader-as-customer serves as the overarching metaphor. It is an image that requires the readers to put themselves in a decidedly uneasy position: they are not only stained by the literal filth of the London slum, but also become tainted by the abject situation and its ethical implications. By being 
described in terms of a prostitute's customer, the narrator insinuates that the readers are complicit in a system that creates and perpetuates the misery on hand, all for the sake of entertainment. And although this may be a rather harsh interpretation of the relationship between reader and novel, it certainly serves the narrative purposes behind the metaphor. The readers must experience discomfort, must encounter Victorian abjection on a more immediate level than they are used to, for only then does the meta-fictional frame narrative realize its full potential. Crimson Petal is supposed to take the readers out of their comfort zone, confronting them with the darkest side of the Victorian era without allowing them to be mere tourists, sitting at a comfortable distance and watching the events unfold passively. Accordingly, the novel-as-prostitute becomes an agent of post-Sadeian abjection, luring the readers ever deeper into the darkness. The narrator's insistent pull mimics the grip of a sex worker who tries to steer her john towards her dismal abode - or in this case, the room of the first genuine literary character within the fictional setting: ${ }^{30}$

Caroline the prostitute defies the rules of conventional story-telling, as her life does not follow a plot with beginning, middle, or ending. She has a tragic past (cf. 13ff.), which might qualify as a vignette in and of itself: a story that highlights her journey towards prostitution as a result of personal tragedy and an inhumane economic system. Yet at the point at which she first appears, her life lacks any upward or downward momentum. It is not a story any longer, but just an existence. ${ }^{31} \mathrm{Her}$ introduction also exemplifies the ties between physical and psychological abjection, as the narrator prompts the readers to join Caroline in her soiled bed.

In the corner of the otherwise empty room sags the bed, a wrinkled and halfunravelled thing like a bandaged limb that has been unwisely used for a rough, dirty chore. The time has come, at last, to use this bed for sleeping. Gingerly, Caroline inserts herself between the sheets and blankets, taking care not to tear the slimy undersheet with the heels of her boots... Yes, it's all right. She's sleeping now. Lift the blankets and ease your body in. If you are a woman, it doesn't matter: women very commonly sleep together in this day and age. If you are a man, it matters even less: there have been hundreds here before you. (Crimson Petal, 8f.)

Confronted with all sorts of gross bodily fluids (that would never have appeared in an authentic Victorian novel, and rarely are described in such horrid detail in more conventional historical fiction), the readers cannot help but feel disgust at coming into close contact with all of these abjects. The bed itself serves as a manifestation

${ }^{30}$ Neither the narrator nor the reader is a full-fledged part of the fictional reality, as they do not interact with any of its denizens. Even though the narrator describes how the readers experience certain features of the environment and sometimes pretends that other characters might in fact notice them, they appear to be invisible spectators.

31 Caroline returns at several points of the novel, interacting with both Sugar and Henry Rackham. But her own life never undergoes any kind of change, and is caught in an endless routine. 
of Caroline's trade, as much used and abused as she is on a daily basis. Each stain and excretion bears witness to the situation of the person occupying it, and the aperture's derelict state speaks of the crushing poverty she finds herself in. It is virtually impossible to romanticize any aspect of this scenario, and the novel clearly does not aim to do so. Quite the contrary, at this point as well as throughout the later chapters, prostitution is consistently portrayed as a sordid business born of material want, hypocritical morality, a hierarchical class society and - at times physical force.

Even more important regarding the narrative mode, however, is the fact that Caroline's introduction marks the point at which the self-aware narrator gradually shrinks into the background, to be replaced with a more conventional mode of personal narration relating the events through the eyes of various characters. Or, as the novel-as-prostitute puts it: "Of course - didn't I mention this? - I'm about to leave you. Yes, sadly so. But I'll leave you in good hands, excellent hands" (Crimson Petal, 6). The omniscient, self-aware narrator does not disappear as quickly as this passage suggests, though. Whenever the readers are addressed, it re-emerges to direct the readers' gaze, deliver comments on the events at hand or point out the differences between the Victorian era and contemporary cultural standards. After the readers have been accosted to a song about the horrifying conditions in a nineteenth century workhouse, for example, the narrator comments:

You who... are visiting the Fireside [Inn] for the first time, may wonder: how can these revellers sing of horror in such jolly voices? See them tap their feet and nod their heads to the plight of the destitute - is no other part of them moved? Why yes, of course it is! They fairly worship at the altar of pity! But what can be done? Here in The Fireside, no one is to blame (except perhaps God, in his infinite wisdom). Wrapped up in a good tune, poverty takes its place of honour amongst all the other singalong calamities: the military defeats, the shipwrecks, the broken hearts - Death itself (Crimson Petal, 101).

What the narrator describes here is the way people tend to deal with a society's abjects - not only in Victorian times, but today as well. Although they are completely aware of the human misery that exists all around them, they attribute it to systemic problems that are completely disconnected from their own existence, not only denying all personal responsibility, but also any chance of changing the status quo. Although they cannot ignore that these abjects exist, nor rationalize them as a necessary evil, they cannot fully acknowledge how their own places and deeds within society contribute to these phenomena. Laurie Penny describes this problem in relation to the systemic problems of patriarchy and neoliberalism:

Society tends to discourage us from thinking structurally. Pondering upsetting things like poverty, racism and sexism as parts of a larger architecture of violence does not come easy in a culture that prefers that we all see ourselves as free-acting individuals. (Unspeakable Things, 67) 
For most people, 'the system' is something that happens to them, not something that they see themselves as complicit in. Faber's narrator does not specifically point to the fact that this attitude persists in the present day as well, and that the systemic problems addressed here have never been thoroughly resolved - yet the average reader will most likely notice the parallels between the past and the present, perhaps even feeling her- or himself described by those lines. We may not witness horrors comparable to those of a Victorian slum in front of our own doorsteps, but due to advances in communication technology, we are all too well aware of the sweat shops existing in places like Bangladesh or China - and the fact that many (if not most) of the products we buy were produced in those places, under conditions that rival (or occasionally even surpass) the misery described in Victorian novels. As the narrator does not offer any kind of solution to these problems, the tone of the novel is not so much didactic as it is grotesque, drawing attention to the most distorted and ridiculous aspects of Victorian culture and, by extension, our own. It holds a mirror to the ugliest tendencies hiding underneath the surface of society, and forces its readers to confront these elements with a mixture of mirth, empathy, and disgust.

Over the course of the novel, however, the narrator figure does gradually recede further into the background, making way for what appears to be a more traditional third-person narration. Events are mostly related through the highly subjective perspective of characters within the novel, often encouraging identification with the protagonist Sugar. Thus, the readers are lulled into a false sense of security, potentially forgetting about the novel-as-prostitute's original admonishment and assuming that the unfolding plot will lead into familiar waters. As the story progresses, the novel's narration appears to become more and more conventional, just as the plot seemingly progresses in the direction indicated by the chapter headings. The readers immerse themselves into the escapist illusion of the fictional world and assume that their reading experience will be just like the "other stories" (Crimson Petal, 3) after all. Nothing could be further from the truth: Just as the plot reaches its climax, the narrator-figure re-appears to rip the readers out of the immersive illusion of the fictional world. The fate of several main protagonists is completely unresolved, indicating neither tragedy nor fortunate turns. Instead of resolving the plot, the novelas-prostitute declares that business is now concluded, and that the readers ought to leave. Thus, the readers are once more placed in the position of a bewildered john who has lost himself in the proceedings at hand, only to find that he is once more left in an altogether unromantic back-alley, where he finishes his business with a sex worker who has no interest in placating his romantic illusions beyond this point.

And to you also: goodbye. An abrupt parting, I know, but that's the way it always is, isn't it? You imagine you can make it last forever, then suddenly it's over. I'm glad you chose me, even so; I hope I satisfied all your desires, or at least showed you a good time. How very long we've been together, and how very much we've lived through, and I still don't even know your name! But now it's time to let me go (Crimson Petal, 895). 
The novel's conceit is brought to a fitting conclusion here, giving a double meaning to the term "climax". With Sophie Rackham's abduction (and her father's frantic search for both his lost daughter and his former mistress), narrative tension has risen to the point where the readers are expecting some kind of traditional conclusion, either by showing Sugar's ultimate downfall or her fortunate escape from the clutches of the law.

Such satisfaction is denied, however: Closure is deliberately withheld, just as genuine affection is ultimately lacking from the sexual transactions between most sex workers and their customers. Fittingly, this exchange takes place exactly where the novel commenced: in the slums surrounding Caroline's abode. Thus, the readers are both literally and metaphorically returned to the abject location where they first entered the world of Crimson Petal, once more forced into the position of estranged and self-aware spectators in front of a shattered fourth wall. They are compelled to perceive themselves as strangers once more, "alien[s] from another time and space altogether" (3), departing the fictional world with a nagging sense of dissatisfaction.

The decision to withhold a proper, stereotypical conclusion to the plot flies right in the face of Victorian literary conventions - and also estranged most readers used to more conventional retro-Victorian historical novels, judging by the vast amount of angry letters Michel Faber received from his fans. "Quite a few of them described themselves as 'in shock' or 'desperate"'(The Apple, xii), Michel Faber points out in the foreword to The Apple, a volume of short stories set in the same fictional setting as Crimson Petal. A young author from Texas even complained: 'Novels aren't supposed to just stop! Novels aren't like real life. Novels are supposed to have satisfying tight endings" (ibid.).

Once more, comparisons with John Fowles' The French Lieutenant's Woman are in order. Like Crimson Petal, Fowles' novel does not culminate with a traditional conclusion, but instead breaks the fourth wall - in that case, by providing several distinct endings that the reader has to choose from: most notably among these are the final two conclusions, juxtaposing a sentimental, Victorian ending with a less romantic conclusion that sees the female protagonist rejecting the marital advances of her suitor (cf. Fowles, $419 \mathrm{ff}$.), thus corresponding to the jaded sensibilities of a post-modern audience.

Both of these texts deliberately break with the narrative conventions of the traditional Victorian novel, yet whereas Fowles contrasts different zeitgeist-phenomena, Crimson Petal withholds any genuine closure altogether, paradoxically creating a kind of hyper-realism that defies the tacitly agreed-upon principles of story-telling. The reader does not receive any clues that would hint at Sugar's destination, nor do we learn what becomes of Mrs Fox, William Rackham, Agnes, or any of the other major and minor characters that are still alive at the time of the story's culmination. Attentive readers might have noted that Sugar's departure in the bus already hints at a final farewell, as she notices how people all around her remind her of other characters in a way that suggests a leave-taking: 
Strange, though, how she's convinced - just for a second - that she recognises almost every upturned face she glimpses! Isn't that Emmeline Fox, trotting along under a parapluie? No, of course it isn't... But look there: surely that's Doctor Curlew? Again, no. And those two swells, punching each other roguishly on the shoulder - could they be Ashley and Bodwell - or whatever their names were? No, these are younger men, barely out of school. [...] At Marble Arch, a man boards the omnibus, drenched to the skin [...] It's Henry Rackham, thinks Sugar (Crimson Petal, 870 f.).

Of course, Sugar's observations can be attributed to the paranoia of a fugitive, watching for any signs of detection and seeing seemingly familiar faces at every corner. But on a meta-fictional level, it is also a farewell to the vast plethora of characters the novel has acquainted its readers with, especially since the people Sugar believes to spot include persons that have already died at this point, such as William's brother Henry. ${ }^{32}$ It's as if the author, being in total control of the fictional world he has created, paraded them all in front of our eyes once more, even if only in the protagonist's thoughts. Accordingly, readers might have guessed that this was Sugar's final appearance in the novel, as the procession of characters even indicates that she and her abducted charge are now joining the ranks of those who have escaped from the narrator's omniscient gaze. Nonetheless, the novel-as-prostitute's sudden dismissal of the readers is indubitably intended to shock. William Rackham's quest for his daughter suggested that some further conclusion was forthcoming, that Sugar's fate would be determined in some fashion. Instead, the story "just stop[s]" (The Apple, xii), as the young author from Texas put it. This deliberate disillusionment is in keeping with the overall portrayal of a fictional world that does not seem to contain any unspoiled romance or affection, and tends to revolve around games of power and status. The novel-as-prostitute has provided all that she has been paid for, and will not lift another finger, now that her business with the readers is concluded.

Michel Faber explained this particular narrative choice in an interview with Harcourt Trade Publishers as a means of granting his literary creations some degree of freedom:

In its early versions, the story ended tragically. I was manipulating the characters like prisoners, knowing full well what their fate would be. As I've grown older I've come to the conclusion that life doesn't have to be a deterministic nightmare. I gave Sugar a chance to rescue herself and she took it ("Between the Lines").

Of course, that is but one out of many possible ways of reading the novel's conclusion, as an author's intent does not ultimately determine a text's meaning. But it is

32 His presence at this point can also be read as a premonition of doom, suggesting that Sugar has drawn close to the realm of the dead. 
certainly true that any traditional ending would have demanded Sugar's ultimate downfall, or else sacrifice all plausibility on the altar of sentimentalism. Faber's choice is in keeping with the benevolent, sympathetic tone that the narrator betrays in spite of all cynicism and dark humour. The novel-as-prostitute refuses to succumb to the internal logic of the system it describes, and instead grants readers the gift of hope, trusting to the strength of their imagination..$^{33}$

Another potential reading is connected to the question of the narrator's identity: while there is no conclusive evidence for or against this hypothesis, it is possible to attribute the narration to Sugar. A hint at this is contained in the phrase "Watch your step" (Crimson Petal, 3), which serves as the narrator's opening line. It re-appears once more at a pivotal point of the (pseudo-)romance between Sugar and William Rackham, this time uttered by the young prostitute:

Just three words, if spoken by the right person at the moment, are enough to make infatuation flower with marvelous speed, popping up like a nub of bright pink from unfurling foreskin. Nor need those three magic words be "I love you". In the case of Miss Sugar and George W. Hunt [William's pseudonym], venturing out into dark wet streets after heavy rain, walking side by side under gas-lamps and a drained empty sky, the three magic words are these: "Watch your step." (Crimson Petal, 115)

The grossly pornographic image used by the narrator suffices to contrast what might have been a romantic atmosphere with grotesque humour, reminding the readers that this is not a stereotypical tale of love, but a story told by a cynical prostitute. It also encourages the readers to once more identify with the hapless john an uncomfortable notion, but one that can hardly be contested: for weren't they drawn into the novel by these very words, following the narrator wherever she intended to lead? But how should or could this narrator be identified as Sugar? Another hint at this possibility is contained in the shape of Sugar's autobiographical novel: at first, it is little more than a cathartic fantasy that allows her to unleash her hatred and anger upon those who have harmed her. An accusation aimed at a society that would allow for the misery visited upon her, an exclamation of fury and vengeance for everything she had to suffer (cf. Faber 2002, 245f.). But beyond mere wish-fulfilment, it is also intended for publication: "Meritless pornography gets published, and so do respectable novels politely calling for social reform [...] Yes, there must be receptive minds out there in the world, hungry for the unprettified truth - especially in the more sophisticated and permissive future that's just around the corner" (ibid, 246).

${ }^{33}$ Faber's novella "A Mighty Horde of Women in Very Big Hats, Advancing”, published in The Apple, actually provides some answers to the question of Sugar's and Sophie's fate, suggesting that they escaped to Australia and built a new life there. As an adult, Sophie eventually returned to England in the early 1900s, only to find her parents' house inhabited by strangers and her father's company defunct. 
In this first draft, the thinly disguised version of Sugar is intended to die - just like she was in earlier versions of Faber's novel. Yet the more Sugar matures over the course of Crimson Petal, the more she is embarrassed by her own prose and the simplistic rage contained therein (cf. 443 f.). At this point, she still intends to keep some of the material she has already written, being loathe to part with the innumerable pages that have dominated her life for so long, but the manuscript is lost during her flight from the Rackham household - suggesting the possibility that she might have written a new version at a later point in her life, containing a more complex message than: "Vile man, eternal Adam, I indict you!" (ibid., emphasis in original).

The narrator's voice most certainly matches both Sugar's relentless commitment to confront the abject horrors that surround her, and the kind-hearted compassion that lies at the heart of her character, as evidenced by her successful efforts to be a better mother (figure) than Mrs Castaway. Regardless of whether the readers embrace this hypothesis with regards to the narrator's identity or not, however, the effect of the conclusion remains mostly the same:

Apart from providing the possibility of a fortunate ending for the female protagonist, Crimson Petals abrupt and inconclusive ending validates the initial declaration that this novel differs significantly from "other stories" set in the Victorian era. Most Victorian and pseudo-Victorian novels provide the sort of "satisfying tight endings" (The Apple, xii) demanded by the Texan fan, and even those texts that culminate in a relatively open ending take care to provide sufficient closure for potential readers, providing hints and clues that outline several potential outcomes. Crimson Petal, on the other hand, does nothing of the sort. The readers are left in the same in-between state as in the beginning, estranged from the fictional world and abandoned by the narrator. As such, they are once more forced to identify with William Rackham, who is left in a similar state of dissolution. Like him, they wanted to know where Sugar went after her flight from Chepstow Villas. And like him, they expected that the turn of events would take them to her hiding place. In expecting a conventional ending, they have become part of the patriarchal system that William Rackham belongs to, anticipating another conclusion in the style of Madame Bovary, Anna Karenina, or Tess of the D'Urbervilles: the fallen woman has to die, if not for her own transgressions, then to become a sacrificial lamb for the sins of an inhumane society.

But to a certain degree, the readers are redeemed by the fact that even Sugar could not envision a more positive ending for her fictionalized self, because the internal logic of the world described in her novel as well as in Crimson Petal demands nothing less than her obliteration. An all-out positive ending would feel artificial and false, so the narrator's abrupt departure provides sufficient freedom to the readers' imagination, allowing them to conclude the story on whatever note seems most applicable to them. 


\section{Sexual Deviation: Beyond Heteronormativity}

Thou shalt not lie with mankind, as with womankind. It is abomination. (Lev. 18, 22; King James Version)

[T] here is nothing "loathsome" in itself; the loathsome is that which disobeys classification rules peculiar to the given symbolic system. (Kristeva, 92)

Abjection has always been strongly connected to religious taboo and concepts of spiritual impurity. As religions constitute complex semiotic systems, interpreting and sorting reality into specific value categories, the in-between state of the abject constitutes a threat to the symbolic order by defying its supposedly clear-cut boundaries. Whereas certain aspects of existence, such as corpses or excrement, are always challenging the subject-object dichotomy, religion tends to find abjects in less obvious places: In a religious setting, the abject often encompasses aspects of existence that are not universally regarded as detrimental or unhealthy, such as dietary habits or non-normative sexuality. Such taboos seem utterly random when viewed from an outsider's perspective, and tend to lack any grounding in an evaluation of tangible harm. (In contemporary times, believers sometimes try to rationalize these prohibitions and taboos. For example, the German Islamist Pierre Vogel defended the baram-status of pork by pointing to the potential health risks associated with this kind of meat in a widely circulated Youtube video. Apparently, even an authoritarian believer such as Vogel felt the need to find some rational justification for what might 
otherwise be regarded as a random prohibition, even though he puts strong emphasis on the fact that Allah's word alone ought to suffice as the sole reason for keeping the taboo.)

However, such prohibitions make sense when viewed from within a specific world view, following the internal logic of the symbolic order. The underlying mechanics may not be readily apparent to people who embrace these respective ideologies, but semiotic analysis may bring it to the fore: Julia Kristeva devoted an entire chapter of her essay Powers of Horror to the semiotics of Biblical abomination, arguing that the Abrahamic concept of impurity is closely tied to a "cathexis of maternal function - mother, women, reproduction" (91): female sexuality is strongly invested with culture-specific meaning, and thereby creates diverse seemingly idiosyncratic taboos and norms. She builds a strong case for this hypothesis, showing how this specific aspect shows up again and again throughout the foundational texts of this Abrahamic religion. Reproduction is very important in the context of the Tanakh, yet the associations that come with it are not universally positive. Both childbirth and menstruation are connected to spiritual impurity by the Old Testament scriptures, and the birth of a female child is penalized more heavily than the birth of a boy (cf. Lev. 12, 1-6). ${ }^{34}$

This somewhat tense relationship with sexuality is also underlying many other rules established by the Old Testament: Mosaic Law not only sets narrow parameters for permissible forms of heterosexual intercourse, it also penalizes many different kinds of non-normative sexuality, including same-sex intercourse between men. ${ }^{35}$ Curiously enough, Kristeva's otherwise thorough exegesis of Leviticus and the Prophets barely touches upon the issue of homosexuality, giving it no more than a passing mention in a short paragraph on sexual identity (cf. 103). Kristeva's omission might stem from her different focus - namely to outline and analyse the symbolic order presented in the Old Testament regarding abjection in general. Yet it is also possible that her negligence is due to the fact that same-sex attraction was still treated as a mental disorder when Powers of Horror was published in 1980. If Kristeva, as a psychoanalyst following in the tradition of Freud, maintained that homosexuality was indeed pathological, then it might explain why she did not comment any further on this particular abject. Science did not necessarily dispose of such random cultural norms and taboos when the influence of religious tradition started to dwindle. In fact, pseudo-scientific arguments were used to defend established norms well into the $20^{\text {th }}$ century, such as allegedly 'natural' gender roles, the

\footnotetext{
${ }^{34}$ Even though Kristeva does not specifically draw attention to it, the Genesis myth recorded in Gen 2, 19-25 serves to illustrate the problematic relationship with femininity and reproduction even further: in this episode, the first man is conceived of as the progenitor of the first woman, supernaturally giving birth to his partner. This inversion might certainly be interpreted as an attempt at bolstering the patriarchal claim to hierarchical superiority, while demoting women to the status of a mere afterthought to creation.

35 The Old Testament is surprisingly silent when it comes to female homosexuality, and only a single passage in the entire Biblical canon in a Pauline epistle references the phenomenon at all.
} 
supposed superiority of the 'white race', the fabled health risks associated with masturbation - or the condemnation of homosexuality. Confirmation bias based on cultural norms may have influenced research results even when the scientists in question did not deliberately seek to arrive at a predetermined conclusion.

The religious condemnation of same-sex intercourse did not end with the Old Testament: unlike dietary restrictions or other taboos, homosexuality is still listed as a sin in the Christian scriptures. In fact, Paul's first Epistle to the Romans even broadens the scope of the taboo by including women, constituting the only reference to lesbianism in the entire Bible:

For this cause God gave them up unto vile affections: for even their women did change the natural use into that which is against nature: And likewise also the men, leaving the natural use of the woman, burned in their lust one toward another; men with men working that which is unseemly, and receiving in themselves that recompence [sic] of their error which was meet. (Romans 1, 26-27; King James Version)

Due to the cultural climate generated by the Abrahamic religions, even secular schools of psychology only ceased to regard homosexuality as a mental disorder near the turn of the $21^{\text {st }}$ century, with the World Health Organization declassifying it as a mental disorder as late as 1990 (cf. Boersma).

It may not be entirely coincidental that homosexuality was also mostly absent from early neo-Victorian texts, yet became one of the focal points of the genre from the late 1990s onward. This pattern corresponds to the evolution of a broad societal consensus on the topic, gravitating towards a more accepting stance over the course of several decades. In 1967, John Fowles still maintained in The French Lieutenant's Woman that stereotypical Victorians would not even have had the words to conceive of lesbianism:

Incomprehensible? But some vices were then so unnatural that they did not exist. I doubt if Mrs. Poulteney had ever heard of the word 'lesbian'; and if she had, it would have commenced with a capital, and referred to an island in Greece. [...] But what of Sarah's motives? As regards lesbianism, she was as ignorant as her mistress. [...] No doubt here and there in another milieu, in the most brutish of the urban poor, in the most emancipated of the aristocracy, a truly orgastic [sic] lesbianism existed then; but we may ascribe this very common Victorian phenomenon of women sleeping together far more to the desolating arrogance of contemporary man than to a more suspect motive. (154ff.)

Even keeping in mind that Fowles's narrator tends to be sarcastic in his anachronistic comparisons between Victorian and $20^{\text {th }}$ century society, it appears that these lines were written at a time when homosexuality was still commonly regarded as a mental disorder, and homosexual behaviour was criminalized. His reference to the 
"most brutish of the urban poor" (along with the decadent upper classes) strongly suggests a link between lesbianism and moral degradation. Considering the legal situation in Great Britain, the Sexual Offenses Act 1967 permitted homosexual acts between two consenting adults above the age of 21, but only if they took place "in private" (1), and only in England and Wales. Societal consensus was still far removed from any genuine acceptance of homosexuality, and it would take almost half a century until the scales would finally tilt in the opposite direction. Fowles is correct to assume that the term "lesbianism" would not have been commonly associated with female homosexuality in 1867: the first documented usage of the term occurred in 1870, and the corresponding usage of "lesbian" is not attested before 1890 (cf. Online Etymology Dictionary). However, it would be wrong to assume that Victorians were unable to communicate the idea of female homosexuality, as they simply used other words to describe it: "tribadism", for example, was used to describe female homosexual intercourse from 1811 onward, and the term "tribade" (i.e. a lesbian) had been in use since 1600 (ibid.). To proclaim that most Victorians were oblivious to the possibility of female homosexuality and could not express it qualifies as a continuation of the 'repression myth', and does not do justice to the historical situation. It does, however, reveal a lot about how Fowles constructed a specific cultural identity for his contemporary Great Britain by contrasting it with this fictionalized version of the past. In this, as in many other aspects, The French Lieutenant's Woman became the progenitor of the neo-Victorian genre and its focus on $19^{\text {th }}$ century abjects. Fowles's novel establishes sexuality in general as closely linked to abjection in Kristeva's sense of the term, and contrasts the titular heroine's outcast status with the supposedly more liberal norms of the twentieth century. However, 'slut shaming' exists even today, double standards in relation to female sexuality in particular are still a ubiquitous reality, and 'queer' people in particular still face violence and ostracism in many circles.

Although the topic of homosexuality is not quite as ubiquitous in neo-Victorian fiction as feminist motifs are, it nonetheless constitutes a persistent and recurring topic. The mere fact that it is still a contentious issue in current socio-political debates renders it a perfect candidate for auto-ethnographic endeavours, especially since the heteronormativity associated with the patriarchal core family is so firmly rooted in Victorian middle-class morality. In fact, even the arguments brought up by social conservatives in order to justify legal and social discrimination against nonnormative sexuality are still virtually identical to those brought up by Victorian detractors. For example, the opening line to a British court ruling from 1866 reads disconcertingly familiar to anyone who has been following recent discourses on the topic: "Marriage as understood in Christendom is the voluntary union for life of one man and one woman, to the exclusion of all others" (Courts of Probate and Divorce). While this particular case was not specifically concerned with homosexuality, but instead aimed at outlawing polygamy as practiced by the early Mormon Church, it nonetheless affected all other conceivable relationship models for more 
than a hundred years to come. It remained in effect until the early 2000s, with the first legal same-sex marriages in England and Wales taking place on March 29th, 2014, following a decade of so-called civil partnerships that granted some (but not all) legal rights to same-sex partners. ${ }^{36}$

While homosexuality was made taboo and declared pathological on many different levels ranging from the religious sphere to pseudo-scientific rationalizations, it is easiest to track its place within the societal consensus by looking at the legal dimension of persecution: Throughout the Victorian era, reforms tended to tighten the circle of the legally permissible in relation to homosexuality, culminating in the so-called Labouchere Amendment of $1885^{37}$, which extended the list of impermissible homosexual acts from "sodomy" (defined as anal intercourse) to "any act of gross indecency with another male person" (Criminal Law Amendment Act 1885). This hastily drafted law made it considerably easier for the authorities to prosecute male homosexuals without having to provide evidence that anal intercourse had taken place. Due to its vague wording, virtually any sexual act between two men could be penalized. ${ }^{38}$ Last but not least, the bill reduced the sentence for male homosexual intercourse from imprisonment for life to two years in prison - a mixed blessing, as it significantly limited the legal penalty while simultaneously making convictions considerably more likely. This law very much reflects the ambivalences inherent to the Victorian age and its treatment of homosexuality, as Matt Cook points out:

The nineteenth century witnessed an unprecedented rise in the numbers of men punished for simply having sex with each other. Never before in the history of Britain had so many men been arrested, convicted, [and imprisoned] for homosexual offenses... However, even though the [Victorian age] saw the rise of moral policing and punishment on a new scale, and the attempt to erase same-sex desire even from language itself, there were also signs of hope and life. (A Gay History of Britain, 107)

The "positive signs" Matt Cook refers to are cases of clandestine or open resistance to the societal mainstream: individuals or small groups campaigning for change, adding to the discourse that would eventually transform the broader status quo

\footnotetext{
36 cf. BBC News: „Same-sex marriage now legal as first couples wed“, 29 March 2014.

${ }^{37}$ Section 11 of the Criminal Law Amendment Act 1885 is strongly associated with Liberal MP Henry Labouchere, who was the driving force behind its addition to the bill (which originally aimed at protecting underage girls from being abducted and/or forced into prostitution).

${ }^{38}$ Lesbians are curiously absent from the bill, giving rise to the popular legend that Queen Victoria refused to give her Royal Consent before any such passages were removed - not because she wanted to defend female homosexuality, but because she supposedly refused to believe that women were capable of such abominable actions. As in the case of many other tales associating the Queen with sexual repression and prudery, it turns out that this story is entirely apocryphal: not only did the text never include any references to lesbians to begin with, the Queen also lacked the constitutional option of blocking a law in such a manner without causing a major political scandal (cf. Sweet, 199).
} 
many decades later. ${ }^{39}$ Yet I would go so far as to claim that this ambivalence extends even beyond the confines of open resistance. There were some positive aspects to the Victorian age as far as non-normative sexualities were concerned: the year 1861 saw the official abolition of the death penalty for 'buggery' (cf. ibid., 109), and the last convicts to be executed for this offense had been hanged in 1835, before Queen Victoria ascended the throne. Likewise, the contemporary concept of homosexuality (as an essential aspect of an individual's identity) originated in the nineteenth century, even if it first happened in the form of a pathologisation that persisted for decades to come ${ }^{40}$. In spite of all attempts at censoring, silencing, or oppressing (deviant) sexuality, Foucault observes that the late 1800s witnessed "a veritable discursive explosion" (The History of Sexuality, 17) on the topic of sex and sexual deviancy. The Victorian era also saw an unprecedented proliferation of erotic fiction which also included tales of homosexuality. Although strictly illegal, such underground publications speak of a vivid sexual culture that belies all notions of prudery commonly associated with the period. A good example of the wide range of "deviant" material (and the literary quality these texts could aspire to) can be witnessed in La Caritilie's The Collector's Edition of Victorian Lesbian Erotica. Some of these tales might have been intended for male heterosexual audiences - a trend that continues in contemporary pornography - yet some were also aimed at a female readership: "There even existed how-to books on lesbian sex, The Horn Book, and travel guides, The Pretty Women of Paris, that instructed where one might enjoy such pleasures" (3). Contrary to popular opinion, "the love that dare not speak its name" 41 actually did proclaim itself, if only covertly and without broad societal acceptance. It may have done so under constant threat from potential legal repercussions (at least in the case of male homosexuality), but it undoubtedly existed beyond the boundaries of the societal mainstream.

The most significant difference between the late Victorian age and the early twenty-first century does not necessarily lie in the opinions expressed by the different sides of the debate: instead, the balance between the supporters and the opponents of LGBT rights has shifted. Whereas even medical practitioners insisted on treating homosexuality as a psychological disorder until way into the second half of the twentieth century, it has now been recognized as a natural condition - and current laws in Western countries increasingly reflect this particular insight. As noted previously, the dispute today bears a significant similarity to its Victorian equivalent,

${ }^{39}$ Cook locates "the beginnings of a modern gay movement... in three overlapping areas of British culture" (108): the aestheticist movement of the 1880s, scientific research establishing "the normality of homosexual desire" (109), and individual authors drawing upon these sources to contribute a different voice to the societal consensus.

40 The term homosexuality was popularized by Krafft-Ebing's Psychopathia Sexualis, which listed it among a wide range of (supposedly) pathological manifestations of the sex drive.

${ }^{41}$ This oft-quoted phrase which is used to describe homosexual love originated in Lord Alfred Douglas's poem "Two Loves", and featured prominently in Oscar Wilde's indecency trial. ("Testimony of Oscar Wilde") 
most notably on the part of social conservatives and their arguments from nature (or religion). At this point, however, it seems as if reactionary forces are finally losing ground. Nonetheless, the struggle for recognition and equality has not been won yet, and so neo-Victorian fiction can sharpen our awareness for the historical roots of the controversy. The religious taboos that influenced and shaped Western attitudes towards homosexuality may have existed long before the rise of the middleclass and the advent of Victorian morality, yet it was the nineteenth century that gave the discourse on sexuality its current shape, as Michel Foucault demonstrated in his History of Sexuality.

In this context, it is almost impossible not to mention the neo-Victorian novels of Sarah Waters, which - although quite distinct in tone and content - always feature a lesbian protagonist and deliberately use terms that have undergone some distinct shifts in meaning in the intervening century: specifically, she draws upon 'queer' terminology, encouraging readers to detect this 'double temporal consciousness' and to read her novels as historiographic metafiction instead of straightforward historical fiction. "Waters's recuperation of the past in these fictions is explicitly politically motivated; she seeks to 'queer' official versions of history by incorporating those figures who have previously been excluded" (Hadley, 89).

However, since Waters's Affinity will take a prominent place in the subsequent chapter on spiritualism and non-normative world views, these novels will not be the focus of this particular section. Instead, this chapter will concentrate on three neoVictorian novels whose portrayal of (male and female) homosexuality is considerably less overt. Like Waters's novels, they are 'queering the past', bringing to light that which was hidden from public sight in the Victorian era. But unlike Tipping the Velvet et.al., they are not primarily focusing on their protagonists' sexual orientation, instead only treating it as one among several different aspects of note. Helen Humphreys' Afterimage, Gyles Brandreth's Oscar Wilde and the Candlelight Murders, and Colm Toibín's The Master may appear to be almost entirely distinct texts in terms of their genre, style, and content, yet they still share a common thread: all three of these novels feature protagonists who struggle with their sexuality and their identity, at a time when deviations from the heterosexual norm were heavily penalized and commonly resulted in social ostracism or even legal repercussions. Their reaction to the tyranny of the supposedly 'normal' is handled quite differently by each of the authors, and not each of the characters is granted a positive sense of closure. But it is exactly these differences that make a direct comparison of these novels worthwhile, highlighting how the topic is handled by different texts.

\subsection{Afterimage: The Tyranny of the Norm}

Humphreys's Afterimage is a highly ambitious novel about identity, belonging, memory, and art. In spite of its comparatively short length, it manages to explore a wide array of ideas and concepts, among them the possibility of same-sex 
relationships within the context of a society that considers them anathema. The dysfunctional relationship between its two female protagonists, the aristocratic photographer Isabelle Dashell and her maid-turned-model Annie Phelan showcases how same-sex desire was rendered almost incommunicable by the standards of Victorian mainstream society, existing only on the abject margins of the collective cultural consciousness. As such, the titular afterimage refers not only to the photography that takes place in the novel, but also serves as a symbol of the lingering influence certain key moments may impress upon an individual's psyche, shaping their identity.

According to Helen Humphreys, "[t]he photographs in Afterimage are loosely imagined renderings of a series of photographs taken by the Victorian photographer Julia Margaret Cameron of her housemaid, Mary Hillier" (249)..$^{42}$ In spite of this explicitly named and detectable source of inspiration, the characters are neither thinly nor thickly veiled versions of their historical counterparts: The aristocratic Isabelle Dashell bears little resemblance to Margaret Cameron, and the same applies to the maid Annie Phelan and her historical counterpart, Mary Ann Hillier. Apart from the element of photography and the difference in class between artist and model, there is virtually nothing within their respective biographies that would suggest similarities with Humphreys' novel. Mary Ann Hillier was born on the Isle of Wight, not in Ireland, and Mrs. Cameron was more than thirty years her senior. And while it is obvious that the young parlour maid was a source of inspiration for the photographer, particularly with regard to religious motifs, nothing suggests that the two were romantically involved. However, a link to the history of homosexuality might present itself in the shape of the famous author Virginia Woolf, daughter to Cameron's niece and favourite model Julia Prinsep Jackson. As part of the Bloomsbury Group, Woolf shunned the bourgeois sexual mores of Edwardian Britain, embracing a considerably more liberal approach to sexuality and relationships that also included a romance with fellow author Vita Sackville-West (Boynton \& Malin, 580). Their romance was immortalized in Woolfs novel Orlando, which in turn holds a prominent place in gender studies and transgender studies due to its gender-fluid protagonist. In relation to Afterimage, it is a very tentative link to the non-fictional inspiration behind the text, yet it is nonetheless present.

But would it be prudent to call Afterimage an example of lesbian fiction? On the one hand, it includes a lesbian romance, yet while it certainly qualifies as a central element of the plot, it is not the novel's defining feature. What differentiates this novel from Sarah Waters's Tipping the Velvet, for example, is its lack of ideological focus and socio-political intent. While both of these texts qualify as coming-of-age stories chronicling the self-discovery of a young woman, and both involve a relationship where one partner refuses or is incapable of 'coming out of the closet', their focus is decidedly different. Whereas the journey of Waters's protagonist Nan

42 Most editions of the novel also use one of Cameron's photographs of Hillier for the cover, emphasizing the intertextual relationship between Cameron's art and Humphreys's novel. 
is centred on her sexuality, Humphreys' Annie Phelan is much more concerned with (re-) discovering her Irish identity, broadening her horizon, and achieving a selfdetermined life. Afterimage may 'queer the past' simply by virtue of referencing a homosexual relationship in Victorian Britain, yet the novel does not place all of its emphasis on that particular aspect. In fact, most of the conflict stemming from this particular character constellation is more closely related to issues of class than to issues of gender, as a further analysis of the text will show: the reason why Isabelle Dashell cannot acknowledge her feelings for Annie Phelan is explicitly linked to her status as a maid, not to her femininity.

Afterimage seizes upon two distinct literary genres of the past: the gothic novel and the sensation novel. Especially the latter is tied to late Victorian society, and has been repeatedly described as 'domestic gothic'. The distinct link to gothic literature consists of Annie Phelan's religious affiliation: in British gothic novels, Roman Catholicism not only highlights the foreignness of the (usually continental) setting, but also contrasts it with the supposedly more rational climate provided by Anglicanism. In this particular tradition, Catholics were strongly associated with sexual transgression - to the point where the term "perversion" lost its religious connotations and gained a sexual dimension. Prior to the early 1800s, the term had been roughly synonymous with "heresy", referencing doctrinal differences in theology. But from the second half of the 1800s onward, it was increasingly used in the way it is applied today, describing deviant sexuality:

[Perversion] was the dominant term used by evangelical polemicists for Anglican converts to Rome, implying a turning away from the truth rather than towards it. [...] The OED lists citations for the overtly religious connotations $[\ldots]$ through 1847. The first listed usage of perversion [meaning "sexual disorder"], in a medical dictionary of 1892, certainly predates Freud; here it explicitly means homosexuality: "A passion for the sex to which the sufferer belongs, instead of the normal inclination to the opposite sex." The latter half of the century thus saw the emphasis of "perversion" move specifically from one to the other of those two culturally linked categories of social organization, religious and sexual deviance. (O’Malley, 91f.)

Annie Phelan is a Catholic - and, at least according to the norms of Victorian society, a pervert in more than one sense. Her religious affiliation not only marks her as a foreigner, an Irishwoman in England, it also links her to the devious and sexually depraved villains of the Gothic tradition, the depraved monks of Lewis, Maturin, and others. In this context, it does not even matter that her religion frowns upon same-sex relationships. The sheer fact of her association with Catholicism all but predestines her to the role she plays, at least in a Gothic setting. She is instantly marked as 'other', the odd-one-out who serves as a catalyst and harbinger of change. Afterimage subverts the norms of the genre, however, going against the grain of the Gothic tradition - and also inverting the conventions of the sensation novel: 
Sensation fiction such as Mary Braddon's Lady Audley's Secret or Ellen Wood's East Lynne features female characters that violate societal norms and are subsequently punished for their transgressions. Even when these texts engender sympathy for their 'fallen' heroines, the internal logic of the genre demanded their eventual punishment. Death, or a state similar to death, was the only possible conclusion, as vice was to be punished just as surely as virtue was to be rewarded. Afterimage violates this trope: Annie Phelan is not punished for her deviance from Victorian norms. At no point of the novel does her transgression of class boundaries and sexual mores jeopardize her social standing, but instead serves as a means of empowerment and self-actualization. Even her final departure from the Dashell household (and the termination of her relationship with the lady of the house) is treated as a further step towards re-connecting with her Irish past and her surviving family members. Isabelle Dashell, on the other hand, suffers because she cannot discard her ingrained societal norms. Her tragedy is not based on her sexual deviance, but on her inability to truly step outside of the value corset society puts her in. She is damned to a life of pretence and (self-) deception, yet ultimately, it is a cage of her own making. The door has been opened at several points, yet she refused to step through. Conformity dooms her - in sharp contrast to the conventions of the sensation novel, where adherence to social mores and conventional piety would have been treated as a positive quality.

These two characters serve as foils to each other, just as Sugar and Agnes contrast with each other in Faber's The Crimson Petal and the White. Whereas Annie is a penniless orphan whose upbringing at the hands of a staunch Anglican mistress rendered her somewhat of a subversive, Isabelle has tried to step out of the shadow of her family's aristocratic heritage but remains very much under the influence of her formative years. Their respective development proceeds in opposite directions, with Annie gradually finding and developing her identity while Isabelle loses hers to the pressure of societal norms and ingrained behavioural patterns. Afterimage relates a pivotal point in the lives of its protagonists. Each of them is questing for a sense of belonging and identity that they have not attained yet, and they eventually become involved in a triangular relationship that sees them attempting to achieve self-actualization through their interactions with the others and their respective desires. However, this quest is rendered somewhat ineffectual by their inability to understand each other properly. Their respective goals and dreams cloud their perceptions, making it impossible for them not to project their own expectations unto the others. Class, gender, and religion become almost insurmountable obstacles to their ability to relate to each other, and the representatives of Victorian morality worry at their self-image by urging them to conform to very specific norms.

Isabelle Dashell and her husband Eldon aspire to be unconventional, yet their upbringing and peer pressure from other members of society foil their attempts to a certain degree: Isabelle has defied prominent social conventions by marrying below her station; she and her husband have renounced Christianity in favour of 
agnosticism, and her passion for photography as a new art form puts her at odds with the 'separate spheres'-ideology held by many of her contemporaries, such as the celebrated male artist living next door. The couple even employed an unmarried maid impregnated by her previous employer: they give sanctuary to a woman who would have been considered virtually untouchable by virtue of her status as a 'fallen woman'. In spite of this penchant for unconventional conduct, the Dashells have not managed to create a proper niche for themselves. Isabelle in particular still very much tries to be a part of genteel society, and struggles to reconcile her life with the ideals her parents instilled in her. Homo-erotic desire (for servants far below her station) is at odds with that, naturally, and thus the lady of the house ultimately struggles hard against her conscious and subconscious urges..$^{43}$

Cut loose from the moorings of biographical writing and hard historical fact, Humphreys' Afterimage serves as a kind of archetypal hero's journey for its principal characters, first and foremost the Irish-born maid Annie Phelan. Her arrival at and departure from the Dashell estate mark the novel's beginning and ending, respectively, and she serves as the catalyst for almost everything that happens in-between. She is also the only character whose quest for self-discovery culminates positively, whereas the other protagonists fail (or at the very least do not survive their moment of glory, as in the case of Eldon Dashell's heroic yet needless sacrifice.) Annie's employment changes the internal dynamic of the Dashell household: Repressed desires are brought to the fore, and people are forced to confront deep-seated conflicts that have been boiling below the surface for an extended period of time. She is the catalyst for the emergence of suppressed material that has been both literally and metaphorically locked away, including her own past.

Even before assuming the position as a model and muse for the lady of the house, Annie Phelan experiences an unprecedented degree of freedom in the Dashells' employ that allows her to explore her own identity. As an Irish orphan who grew up as a servant girl in London, she had already been estranged from her cultural roots by mere geography. But her alienation went even further than that, since her former mistress refused to address her by her real name and enforced a strict, stiff-necked Anglicanism in her household that made it virtually impossible for Annie to be herself. This is in keeping with her status as a colonial 'other': her mistress was actively depriving her of her native identity, attempting an assimilation process that would turn Annie into a 'proper' English maid. Accordingly, the employer's behaviour can not only be read as an example of excessive moralism, but also reflects anxieties against 'reverse colonialization' within Victorian society at large. A large influx of Irish refugees would have been perceived as a threat to the

\footnotetext{
${ }^{43}$ It is interesting to note that the factor of class plays such a huge part in Isabelle's mental rejection of her lesbian romance, as her heterosexual marriage is already such a blatant violation of Victorian upper-class morality. Marrying below one's station was a scandal in and of itself, but doubly condemning for women, as the husband was usually the one who defined the couple's future standing in society.
} 
collective British identity, and thus the 're-education' of Irish children qualified as a protective measure to integrate them into established structures. Only books provided some sense of autonomy for Annie Phelan, but even these were an illicit joy that had to be kept secret from her employer.

Mostly left to her own devices by the Dashells, Annie can ponder the fate of her family, discover her place in the world, and - most importantly for this chapter explore her sexuality. When she notices that the power dynamic between Isabelle and herself is not as one-directional as both of them assumed, it marks a profound transformation in how she perceives reality. And when Isabelle initiates thinly veiled erotic advances, she gradually seizes the initiative.

Isabelle Dashell, however, does not view Annie Phelan as a social or intellectual equal. In her mind, the servant girl is a perfectly pliable, simple-minded servant who only does as she is told, and any events that would jeopardize this concept are deeply troubling to her. In posing Annie, Isabelle tries to maintain the belief that it is just her own creative genius that facilitates the image, and that the servant is only a lifeless prop. In the same vein, Isabelle tries to mould Annie into a semblance of her childhood friend Ellen, a servant girl with whom she was involved in an almost symbiotic relationship. At the same time, she always finds Annie deficient in this regard, and is disappointed that the Phelan girl does not live up to the status of being her twin in spirit. To her, Annie is just a means to an end, not an end in itself: a canvas that she can project her desires onto. Accordingly, their relationship - although clearly fraught with romantic overtones - is characterized by considerably power imbalances and covert struggles for dominance. By contrast, Annie's platonic relationship with Eldon, Isabelle's estranged husband, appears to be more equally yoked. The middle-aged geologist perceives the maid as a kindred spirit, offering her free access to his library in exchange for intellectual companionship. It serves as a foil to the quasi-lesbian romance, just as Isabelle serves as a foil for Annie. These two characters are almost diametrical opposites: Annie is low-born, has lost touch with her familiar history, and yet is free to determine her own path in life because of this lack of a secure mooring. For her, connecting with her lost roots is a desirable goal, and her position in life turns out to be not quite as powerless as it would appear. Isabelle, by contrast, is shackled by her aristocratic heritage, even though she tried to defy it throughout her adult life: marrying beneath her station, pursuing a career as an artist, and even making some tentative efforts to re-create her lost childhood romance are all acts of defiance against the tyranny of societal convention, yet at the same time, she remains a slave to it. Her craving for approval from the misogynistic painter who lives in the neighbourhood already suggests that she is less liberated than she would like to be, and her reaction to the kiss she shared with Annie further confirms this impression.

Within the novel, objections to the lesbian romance - whether in the form of an internal monologue or overt criticism from without - always focus on the class boundary between the involved parties. By contrast, their sex is never alluded to: 
when Eldon suspects that there is an emotional tie between Annie and Isabelle, he reprimands his wife of her station and the glaring unseemliness of being too familiar with one's servants: an objection that can only be construed as dishonest and hypocritical in the light of his own friendship with the servant girl. Yet his criticism apparently weighs heavily on Isabelle, as she cannot bring herself to acknowledge her emotions. Pronounced worries about class boundaries appear almost alien to a $21^{\text {st }}$ century audience, but apparently formed a central aspect of Victorian objections to same-sex sub-cultures: "Such cross-class transgression was a key component of homosexual scandal - and indeed sexual scandal more generally - in the 1880s and 1890s" (Cook, A Gay History of Britain, 38). By citing news coverage of the so-called Cleveland Street Scandal of 1889 (which involved high-ranking members of British society frequenting a male brothel), Cook demonstrates how Victorian audiences apparently considered the class difference between prostitutes and customers to be the most outrageous aspect of the proceedings - more so than the gender of the involved parties.

The most pivotal point in the relationship between Isabelle and her servant comes when Annie decides to kiss her mistress, momentarily tipping the power balance between them. Both women are keenly aware of this, and their respective reaction is coloured by this realization: whereas Annie Phelan feels deeply empowered by the egalitarian nature of that clandestine romantic encounter, Isabelle is unsettled to the point where she needs to suppress the very memory of that event. Annie's proactive behaviour is a direct challenge to the status quo, and as such imperils Isabelle's conception of herself as an artist and aristocrat, whose life takes place above and beyond the intellectual grasp of mere servants. Even though her reminiscences about the low-born Ellen are filled with a certain egalitarian spirit (insofar as they revolve around fantasies that virtually merge their identities into one) the prospect of realizing and actualizing her desires with Annie Phelan is deeply frightening to her. Whenever Annie exhibits signs of individuality and initiative, the photographer feels ill at ease. Her desires are self-contradictory, as she simultaneously wishes for an almost symbiotic transcendence of class and gender, yet at the same time cannot entertain the thought of a self-determined servant seizing the initiative or operating on the same intellectual level as she. The very notion is an existential threat to the social stratification at the heart of Victorian society, since such an occurrence challenges the validity of the class divide. Accordingly, Isabelle repeatedly asserts that Annie is not her intellectual or social equal, and negatively contrasts the servant with the fantasy-twin Ellen. As a result of this discrepancy between Isabelle's perception and reality, the aristocrat is profoundly unsettled by Annie's competent handling of the camera, and downright unhinged by their shared kiss.

In many ways, their relationship was dysfunctional from the start, always revolving around a covert power struggle between mistress and maid. Annie Phelan seeks to assert herself, just as she did in her prior position. Her defiance is not so much 
an act of rebellion as a quest for a certain autonomy of self: she cannot be a mere accessory to Isabelle's will, just as she could not accept her former employer's habit of referring to servants within a specific position by the same name, denying their individuality. Her role as a model requires her to become the receptacle of the photographer's vision, yet she quickly realizes that the process of creating these artworks is a collaborative effort, and that her own involvement is not a strictly passive endeavour. When she notices that she can exert some influence on Isabelle, Annie is almost jubilant. Such an exchange of power not only allows her to draw closer to her mistress, but also gives her an idea of her own distinct identity and will. In this regard, their relationship is indeed doomed to fail from the start, as their expectations of each other are fundamentally at odds. Annie's kiss only brings to light what has been present under the surface all along: in spite of all her unconventional aspirations, Isabelle lacks the courage to step outside of the symbolic order that has been ingrained into her when she was a child. Where both Eldon and Annie see a self-confident woman who easily manages to navigate the complex undercurrents of social interaction with other members of the upper class, Isabelle herself feels insecure and in desperate need of approval. This becomes especially apparent when the Dashells stage a dinner party in order to celebrate Isabelle's success as an artist. Her thoughts reveal the full extent of her self-doubt, coupled with her desire to belong.

Why has everything gone so horribly wrong? Isabelle looks around the table at her guests. Perhaps the sad truth is that she is only accepted within this society because she is the daughter of a Lord. They don't care a whit about her identity as an artist. They are moved only by the status of the peerage. Why did she imagine that they would care about her gold medal from Dublin? And is that why Robert Hill went on about Ireland and drove Annie Phelan from the room? Because Isabelle's award was from Dublin? (Humphreys, 198)

Annie Phelan, however, only sees the self-confident Lady traversing the room with ease (cf. 194), and her admiration for (and attraction to) her employer is largely owing to this (faulty) perception.

Based on this discrepancy, and the almost diametrical nature of their respective personalities, Annie and Isabelle experience their kiss as a pivotal moment that sends their thoughts and feelings in virtually opposite directions. Isabelle represses the very memory of the event, and tries to order Annie to do the same. And once more, her reaction also focuses strongly on the factor of class:

Because I was upset by the earlier events of the evening. Because I was in the room with the carriages and that always unsettles me. Because, when I first saw her, there in the dark, she looked like Ellen. It seemed like all those years ago and I stumbled into that old moment without thinking. She stepped out from the trees, and I had arrived. Because I didn't plan for it to happen. 
Because Annie Phelan is my maid. Because it could easily have been a dream, could have been some imagined continuation of my act as Sappho. Because I would never allow myself to want her. Again. Because I am dead inside now. Because I am dead inside. (Humphreys, 213f.)

This interior monologue encapsulates Isabelle's side of the relationship, outlining her desires, fears, and reservations in turn. It starts with relatively neutral rationalizations, progresses towards her fantasies about Annie Phelan being like a second Ellen, and then quickly turns into a thorough mental rejection of the event. The turning point once more focuses on the factor of class, and on the critical loss of control and initiative that imperils the aristocratic photographer's conception of self: "Because I didn't plan for it to happen. Because Annie Phelan is my maid" (ibid.). The servant's social status is both what attracts and repels Isabelle: on the one hand, she wants to escape the trappings of wealth and class, yearning for the simpler life of her youth as embodied by her idealized version of Ellen. On the other hand, she clearly wants to maintain her sense of intellectual and social superiority and is unable to acknowledge the possibility that Annie might in fact seize the initiative and transgress the boundaries that separate them. The fulfilment of Isabelle's desire is also her deepest fear, and thus she turns upon herself, figuratively killing herself in the process.

This passage is directly juxtaposed with a similar interior monologue on the part of Annie Phelan: as Isabelle's foil, her train of thought carries her in the opposite direction, but even more importantly, it reflects her personal journey and the way her relationship with the aristocrat furthers her process of self-actualization. Since Annie is a pious Christian, both by virtue of the education she received at the hands of her abusive former mistress and due to her Irish roots, it could be expected that her reaction might be tinged with guilt and remorse: after all, arguments against homosexuality were traditionally based on religious taboos. Yet in her mind, the event is not only fundamentally positive, but even serves to reaffirm rather than challenge her faith:

Why did she do it, and why, even with that admonishment from Isabelle to undo the entire event, is Annie not sorry about that kiss? [...] Because she was not afraid, was not behaving like a servant, but as an equal. [...] Because God was gone from her. Because God was suddenly back. [...] Because it was what she wanted to happen. Because Isabelle Dashell kissed her back. (Humphreys, 209f.)

Her reference to a loss of "God" alludes to the Dashells' agnostic atheism, and what it meant for Annie Phelan: it was both a liberation and a further estrangement from her roots. Compared to the rigid faith and strict morality of Annie's Anglican London employer, the Dashells' lack of religious sentiment or daily ritual must have felt like being let out of a cage. She experienced an unprecedented degree of freedom in virtually every part of her life, from having free access to books to questioning 
dubious conventions. Yet there was also a sense of unease about the abandonment of religion, as suggested by her reluctance to let go. Relinquishing Christianity would have meant alienation from her Irish heritage, even if it also gave her the freedom to seek for an identity of her own. Her fledgling romance is most certainly in violation of Catholicism's traditional dictums regarding sexual relationships, suggesting that she needs to abandon this world view to a certain degree in order to pursue her sexual desires.

As such, her observation that "God was suddenly back" (ibid.) has a wide range of potential meanings: it may indicate that Annie has rediscovered feelings of awe and transpersonal meaning (which she formerly associated with religion) in her emotions for Isabelle; yet it may also suggest that Annie's newfound sense of autonomy and personal power has given her the strength to assert her own religious beliefs against the general tenor of the rest of the household. Or the phrase could actually encompass both of these readings: Annie's kiss was an act of emancipation, of asserting her own will instead of following orders or the general consensus. It was an erotically fulfilling moment invested with emotions akin to a religious awakening, giving birth to a new Annie Phelan who was neither the covertly seditious London servant nor the passive model Isabelle Dashell envisioned. In spite of her mistress's denial of the entire event, and strict instructions to bury its very memory, Annie feels validated by the fact that the kiss (and thus, her desire) was reciprocated.

In the end, Helen Humphreys' novel affirms the young maid's need for selfactualization, and suggests that her quest for her familiar roots will be successful by revealing that she still has got living relations on Ireland (who know of her existence at this point). Even if her romance fails, its taboo status has not ruined her life, and there is no indication that she will face any sort of ostracism because of it.

The same cannot be said about Isabelle Dashell: her need for societal approval stunts her potential for growth, and causes her to sabotage and terminate a relationship that she greatly wished for. Her efforts to conform to the tyranny of the 'normal' render her a mere husk of a person, perpetually at odds with her own desire.

In punishing the conformist and rewarding the aberrant, Afterimage inverts the conventions and norms of the sensation novel, and subverts stereotypical Victorian values by portraying the abject of homosexuality as relatively unproblematic, while the real problem is located within the corset of arbitrary norms and stifling social conventions. Homosexuality is not abject by nature, but only construed as such by the arbitrary norms of Victorian culture - and it is these norms that cause harm. Freed from such constraints, the novel argues, same-sex love can be as liberating and transformative as its normative Victorian equivalent, as demonstrated by Annie Phelan's perception of events. In a nineteenth century text, the Irish maid would have been abject by default: either in the role of antagonist or tragic anti-hero, her defiance would have inevitably culminated in tragedy, turning her into a cautionary tale. Instead, the lesbian, Catholic, Irish servant with egalitarian aspirations leaves in peace, and may very well find a better future. 


\subsection{Oscar Wilde and the Candlelight Murders: The Love that Dare Not Speak its Name}

In contrast to this, Gyles Brandreth's Oscar Wilde and the Candlelight Murders (henceforth abbreviated as Candlelight Murders) paints a very different picture of same-sex romance in the late 1800s. At first glance, it is a comparatively light-hearted crime fiction novel: a classical murder mystery based on the conceit that Oscar Wilde and his biographer Robert Sherard solved a crime in the manner of Sir Arthur Conan Doyle's Sherlock Holmes and John Watson, respectively. Wilde is portrayed as a competent student of Doyle's Great Detective, emulating his method of deduction in order to identify the murderer of a male prostitute. On the surface, the novel is nothing more than a pastiche based on an interesting idea - something akin to a piece of creative Sherlock Holmes fan fiction as written by an Oscar Wilde fan. Yet the novel does not lack its subtleties, particularly with regard to Wilde's sexuality and the foreshadowing of the tragedy that is to follow a couple of years after the events of Candlelight Murders. Sherard - as the somewhat unreliable narrator and Watson stand-in - often relates details or events that already point the informed reader at what is to come, even while he is trying to downplay their significance. For example, the murder is tangentially connected to the aforementioned Cleveland Street Scandal of 1889. In the novel, police inspector Fraser names this particular scandal as the reason for his refusal to look into the murder of Billy Wood:

"I lied, Mr Wilde, to protect you [...] If I had so much as begun an official investigation, having embarked upon it, I could not have stopped it - wherever it might have led [...] Number 23 Cowley Street and 19 Cleveland Street - were they not both, equally, dens of iniquity, houses of corruption? And Billy Wood - whatever has become of him - was he not [...] a lad who sold his body for money, an unfortunate boy caught up in a vicious and degrading trade?" (Brandreth, 112)

It later turns out that this explanation is in fact just an alibi, and that Fraser was forced to protect the murderer in order to keep his own homosexuality - and his relationship with Billy Wood - a secret. But nonetheless, his allusion to the Cleveland Street Scandal and the very real danger connected to being identified as homosexual establishes the cultural climate in which the novel is set: unlike Afterimage, Candlelight Murders does not construct a fictional space where homosexuality might lead to a fate other than social ruin and legal persecution. The full weight of the Labouchere Amendment hangs like a palpable threat over the characters' heads, and influences their investigation of the murder.

In a similar vein, Robert Sherard (writing in the late 1930s) already knows what Oscar Wilde will have to face, and occasionally alludes to the ruin and shame of the notorious indecency trial in retrospect, looking at the events with the benefit of more than four decades of hindsight. Both Sherard and the reader are aware that 
whatever scandal might be averted in this story, tragedy will strike in 1895 , destroying Wilde's whole existence.

Brandreth's narrator may or may not reflect the author's potential uneasiness around the topic of homosexuality ${ }^{44}$, but Sherard's unmistakable discomfort colours the entire narration. He is an unreliable philanderer whose passions betray a lack of sense and responsibility, yet his confrontation with the homosexual underground scene of London repeatedly causes him to wax judgmental - even while specifically exempting his friend Oscar from harsh criticism. Most tellingly, the narrator laments that these "deviants" do no longer subscribe to the "don't ask - don't tell"-mentality of the Victorian age at the time of his writing:

I do not believe that the word "homosexual" was known in 1890. If it was, I never heard it. Nowadays, at any cocktail party, you can hear expressions such as "homo" and "queer" bandied hither and yon without embarrassment, but the Victorian age was more discreet - and none the worse for that. Nowadays, what Oscar and his friend, Lord Alfred Douglas, came to call "the love that dare not speak its name" can be heard bellowing its universal presence from the rooftops, but then it was different. Fifty years ago a man of the world would doubtless have been familiar with the phenomenon of sexual inversion, but it was not a subject that he would have expected, openly, to discuss. (Brandreth, 221f.)

Robert Sherard's musings betray his ongoing uneasiness around the topic - and his preference of a time when such abjects were properly hidden. He is able to overlook Oscar Wilde's sexual "sins" - but only as long as he can safely ignore them and pretend that they do not exist. What he proposes is certainly not acceptance, nor tolerance, either: misfits are to hide their abject nature from the rest of society, and their abnormal behaviour is to take place behind closed doors, where decent folks are not exposed to it and can pretend that it does not exist. In this, he echoes late Victorian mainstream society, even if certain minority groups did envision a more tolerant society:

[There] were other stirrings of protest against Victorian morality. One of these came from the writer and poet George Ives, who [founded] a secret society devoted to setting "all loves free". The society, which began in the mid-1890s, was called the Order of Chaeronea, after the battle of the same name in $338 \mathrm{BC}$ when the Theban Band, a Greek force made up entirely of friends and lovers, was slaughtered by the Macedonians. The membership was small, and the society remained dedicated to discussion and support rather than active campaigning. However, [the] existence of Ives' Order of

${ }_{44}$ According to his personal website, Gyles Brandreth was a Member of Parliament for the Conservative Party from 1992-97, and while some voices within that party have been supportive of (or even actively campaigning for) equal rights for homosexuals, the Tories as a whole tend to embrace decidedly more reactionary values. 
Chaeronea demonstrates the confluence of certain sources of opposition to the prevailing morality of the period. (Cook, London and the Culture of Homosexuality, 138)

Robert Sherard is not exactly described as a moral authority, however; so his judgment carries comparatively little weight: beyond infatuation, he shows very little regard for the women closest to him, freely cheating upon his fiancé with a woman who, to his knowledge, has already promised her hand in marriage to another. Such blatantly harmful acts undermine the weight of his pronouncements, and hardly compel the readers to share his opinions.

It cannot be determined whether Gyles Brandreth's sentiments in the real world echo those of his somewhat unreliable narrator, but the readers' sympathies are directed in a manner that leaves room for several potential interpretations. This includes readings that would challenge Sherard's version of events, such as the insistence that there is an essential difference between Oscar Wilde and the other members of the secretive homosexual club. Sherard is quite insistent on this point:

Bellotti's 'boys' were the type of young men of whom Mr Justice Wills was speaking [when he convicted Oscar Wilde at the culmination of the indecency trial of 1895]: that I must accept. What I do not accept, however, is that Oscar was ever the centre of any circle of corruption. [...] If, on occasion, in moments of weakness, in the privacy of a darkened room, Oscar succumbed to the sins of the flesh, so be it. It happened. It was his way. It does not make him a corrupter of youth. [...] The same could not be said of Gerard Bellotti. (Brandreth, 169f.)

The fictional Bellotti is described as a pimp specializing in male prostitutes, who actively recruits young men to attend his 'club'. Since procurement is indeed not a crime that can be laid at Oscar Wilde's feet, Sherard's objection is at least somewhat valid. But it is not a coincidence that the narrator describes the acceptable kind of homosexual acts as taking place in "the privacy of a darkened room" (ibid.). To Sherard, what was then called 'sodomy' clearly qualifies as an abject, and triggers the associated feelings of revulsion, discomfort and aversion. He could never countenance a state of affairs where homosexual couples were treated as normal, or received the same rights as heterosexual unions. His lament about the loose morals of the late 1930s may very well qualify as a commentary on the contemporary status quo - even if the reader does not agree with him.

In the context of the Sherlock Holmes-pastiche, Sherard serves as the stand-in for Dr Watson, whereas Oscar Wilde assumes the role of the Great Detective - not only on account of his investigative methodology, but also in terms of his eccentricities. Where Robert embodies the 'normal Victorian male', Oscar stands apart from the societal mainstream. And like Sherlock Holmes, Oscar Wilde is the tale's true protagonist, driving the plot while Sherard's part is mostly constrained to the role of passive spectator and witness. Unlike his biographer, the Irish playwright engages 
the readers' sympathies, and his flaws - as well as his potentially non-normative sexuality - do not necessarily jeopardize this positive impression from the vantage point of a $21^{\text {st }}$ century audience. Even his final attempt at denying his orientation (which would nowadays be categorised as bisexuality, if Wilde's attested romantic relationships are any indication) does not count as a victory for heteronormativity, but only emphasizes the negative image of a society that renders such obfuscation necessary.

The novel emphasizes the implied condemnation of Victorian mores and the effect they had on non-normative, 'abject' individuals by revealing that the murder at the heart of the plot was committed by a heterosexual woman. The sexual deviants who had served as the main suspects throughout most of the narration are entirely innocent, whereas the culprit deliberately uses the threat posed by the Labouchere Amendment to blackmail the victim's lover into complicity and to obfuscate her crime. Had her murdered rival been a woman instead of a young man, Inspector Fraser might have arrested her on the spot - but since any such step would have jeopardized his very existence, he had no way to do so without destroying himself. The tyranny of the normal becomes instrumental to the crime, and the abject status of male homosexuality forces it into a semi-criminal half-world that is only one step removed from other illicit acts, be they prostitution or murder.

Brandreth's narrator does not live to see a time when homosexuality was decriminalized (and would not have welcomed the prospect, if his comments on the topic are any indication). But the contrast between the contemporary readers' reality and the Victorian society depicted in the novel is readily apparent, and allows for the conclusion that it is not sexual deviance that is the problem here - it is a morality that regards it as abject. In this, Candlelight Murders comes to a similar conclusion as Afterimage, but whereas the latter rewards one of its protagonists for her refusal to conform, Brandreth's novel offers no alternate scenario: Wilde's tragedy looms inevitably within the distance, and his persistent clash with convention will be his downfall. Only Sherard's hints at a future where such stifling norms may gradually disappear, alluded to in his lament of the loose morality he witnesses in his senescence, give some potential for hope. Arguably, those passages might serve as more of a nod to the present day than to the late 1930s, given that the Labouchere Amendment was still in full effect at that point of history, and that even famous war heroes such as Alan Turing were not immune to persecution as late as the 1950s. Oscar Wilde might have suffered, but the reader is already familiar with a different socio-cultural situation.

In a conversation with me some time after Oscar's death, Arthur Conan Doyle likened what he called "our friend's pathological obsession with masculine youth and beauty" to his creation Sherlock Holmes's addiction to morphine and cocaine. "In my experience", said Conan Doyle, "great men are frequently shot through with an obsessive or addictive strain that may seem 
aberrant - even abhorrent - to the rest of us. It does not diminish their greatness. It may make us more aware of their humanity." (Candlelight Murders, 170)

Sherard's attempts to re-define it as a merely aesthetic preference for youth and beauty in all of its forms are revealed to be nothing but rationalizations, mirroring Wilde's line of argument during his trial. He maintained that his relationship with Lord Alfred Douglas was literally based on Platonic love, and lacked any carnal dimension:

"The Love that dare not speak its name" in this century is such a great affection of an elder for a younger man as there was between David and Jonathan, such as Plato made the very basis of his philosophy, and such as you find in the sonnets of Michelangelo and Shakespeare. It is that deep, spiritual affection that is as pure as it is perfect. It dictates and pervades great works of art like those of Shakespeare and Michelangelo, and those two letters of mine, such as they are. It is in this century misunderstood, so much misunderstood that it may be described as the "Love that dare not speak its name," and on account of it I am placed where I am now. It is beautiful, it is fine, it is the noblest form of affection. There is nothing unnatural about it. It is intellectual, and it repeatedly exists between an elder and a younger man, when the elder man has intellect, and the younger man has all the joy, hope and glamour of life before him. That it should be so the world does not understand. The world mocks at it and sometimes puts one in the pillory for it. ("Testimony of Oscar Wilde")

In the end, it mattered little whether Wilde consummated his relationship with Lord Alfred Douglas or not: he was on trial for being noticeably divergent from the cultural norm, for being perceived as an abject that needed to be expelled from the community in order to purge it ${ }^{45}$. This climate of censure and prosecution permeates Candlelight Murders from beginning to end, be it in the motives behind the initial murder, in the shape of Bellotti's clandestine club for 'inverts', or in the way the homosexual inspector Fraser is driven to kill just to protect the secret of his sexual orientation - even if it means protecting the murderer of his beloved Billy Wood.

However, it bears pointing out that the main antagonist of Candlelight Murders is not Fraser - who merely serves as an unwilling accomplice - but his heterosexual fiancé, Miss Sutherland (who maintained an affair with Robert Sherard). She used Fraser's fear of being discovered in order to force his cooperation, weaponizing the abject status of homosexuality and the threat posed by the Labouchere amendment.

${ }^{45}$ Certain parallels to this can be detected in the legal trials of Michael Jackson, who was accused of child molestation in 1993 and 2003, respectively. Although there was never any conclusive evidence of sexual misconduct in either case, the mere fact that he conducted sleepovers with underaged boys was enough to permanently tarnish his reputation and ruin his career in the public eye - at least for as long as he was alive. 
Brandreth's novel certainly does not leave much room for homosexuality as a positive experience within the confines of late Victorian society: what little joy the 'inverts' of 1889 may experience takes place in brothels and secret meeting rooms, deep within the sordid underbelly of London. It is linked to prostitution, and its illegal status contributes to the crimes committed within the novel. Nonetheless, homosexuals are consistently portrayed as victims of a reprehensible social status quo, and even Fraser (who murders two people in order to protect his secret, and conceals the murder of a third) is more of a victim than an antagonist.

Miss Sutherland's crime was primarily motivated by jealousy and hurt feelings: a common enough trope in detective fiction. What makes her stand out as a villain is her perusal of homosexuality's abject status in order to torment her former lover and compel his cooperation: The Criminal Law Amendment Act 1885 becomes a murder weapon of sorts, and Victorian society basically renders male homosexuality abject by declaring it to be so. In this light, Robert Sherard's nostalgia for the discretion of the 1880s and 1890s becomes positively reprehensible, defending the very structures that would ruin his friend's life. The tyranny of the norm reigns supreme in Candlelight Murders, and even such unconventional individuals as Oscar Wilde cannot escape it indefinitely. The indecency trial of 1895 also plays some part in establishing the cultural climate of the third novel to be analysed here, Colm Toibín's The Master.

\subsection{The Master: A Life of Denial}

The Master is set just a few years after Candlelight Murders, and references Oscar Wilde and the indecency trial in several key scenes: Wilde serves as a foil to the fictionalized novelist Henry James, who is here portrayed as a repressed homosexual. Unlike the Irish playwright, James is a creature of strict Victorian morality, a humourless servant at the altar of propriety who sacrifices his personal happiness to the Way Things Are and the tightly circumscribed area of the socially permissible. Where Wilde meets his accusers head-on, barely recognizing the threat to his own existence as he exchanges witticisms and quips with the prosecutor, James would never even write down his secret desires in the privacy of his own room. Toibín's James regards Oscar Wilde as a coarse and unruly individual, fundamentally at odds with his own persona on almost every conceivable level, artistic as well as personal. James's disdain for An Ideal Husband not only reflects the difference between the Irish playwright's style and his own dramatic endeavours, but also signifies their diametrically opposed personalities. The success and failure of their respective plays stands in marked contrast to their private fortunes, as the indecency trial (as well as his poor financial skills) lead to Wilde's ruin in spite of his successes as a playwright.

Like Isabelle Dashell in Afterimage, Henry James is his own gaoler, and like the photographer, he ultimately refuses himself the opportunity to be true to his own desires when he rejects the subtle advances of the Irish officer Hammond. Yet 
Toibín does not portray Henry James's choice as a tragic failure along the lines of Afterimage's conclusion. Instead, the novelist's repressed desires become one of the wellsprings of his artistic endeavours, even if they render him unhappy.

The main difference between these two repressed characters and their ultimate fate lies in the way they relate to their homosexual desires: Isabelle is fundamentally at odds with herself, simultaneously wanting to embrace her lesbian desires and to be accepted by society. This dissonance creates an unsolvable dilemma that dooms her relationship from the start. By contrast, James acknowledges his homosexual urges, yet never allows them to be more than a suppressed yearning. His persona is built around the concept of Victorian propriety, and any concession to his innermost urges would constitute a threat to his identity. Thus, his final refusal to be a lover, even under the most discreet of circumstances, is not so much a tragic failure as an affirmation of his self-image. Like the titular character of his failed tragedy Guy Domville, Henry James chooses asceticism over indulgence, and values his ideals more than his individual happiness.

His consistent refusal to indulge and embrace a quality within himself that he considers abject is celebrated as a kind of ritual purging, a masochistic purification rite that repeatedly sees him courting temptation while refusing to go the final step towards fulfilment. When he lingers in front of a male suitor's house throughout the night, never taking the final steps to the door, his self-imposed suffering gains an almost religious, ritualistic quality.

As night fell, he knew that he himself on the unlit street could not be seen, and he knew also that he could not move, either to return to his own quarters or - he held his breath even at the thought [, twenty years later,] to attempt to gain access to Paul's rooms. [...] He wondered now if these hours were not the truest he had ever lived. The most accurate comparison he could find was with a smooth, hopeful, hushed sea journey, an interlude suspended between two countries, standing there as though floating, knowing that one step would be a step into the impossible, the vast unknown. (Toibín, 10; my emphasis)

Toibín's protagonist is aware of his ambivalence, of being literally suspended between two equal forces drawing him in opposite directions. It is quite telling that he conceives of this state as the "truest he had ever lived" (ibid.): neither his concordance with Victorian morality nor his repressed desire strikes him as the true essence of his personality; instead, it is this tormented in-between that encapsulates his true being, his self-image. His desire will never be acted upon, never even allowed to manifest on paper, in the secrecy of his own rooms - and yet, it will always be with him.

It might be expected that this starting point is used to initiate some kind of character development, culminating in some form of positive or negative transformation, yet Toibín's novel takes a decidedly different turn. As Adam Mars-Jones put it in his review of The Master in The Guardian: 
The pillars of the narrative are failure, avoidance, renunciation and withdrawal. Unpromising quartet, but appropriate to a life without obvious eventfulness, and a work with a strong, negative dynamic, structured round the missed opportunity, the faulty choice, the golden bowl with its latent crack, the "beast in the jungle" whose annihilating leap is delayed and delayed.

The persistent pull of diametrically opposed impulses fuels the artistic endeavours of Toibín's fictionalized Henry James, just as daily events serve as a source of inspiration for his novels and short stories.

When James bids the potential suitor Hammond farewell near the conclusion of the novel, the personal narration characterizes the declined courtship as a kind of self-effacing, masochistic triumph: tragic, but also necessary. James excises the abject, banishes it from the symbolic order he has embraced and internalized, and thus emerges with a feeling of purification - even if it is tinged with regret and unfulfilled desire. He sacrifices his happiness on the altar of propriety - but in doing so, he remains true to his identity as he wants it to be.

His voluntary assimilation to society's norms has its limits, however. James never marries, and therefore lacks one of the most central elements of Victorian middle-class norms: a family of his own. Given how much importance is given to the sanctity of marriage and the domestic sphere in Victorian literature and iconography, it is difficult to imagine that anybody could deviate from this standard without drawing attention. In Toibín's novel, this consistent refusal contributes to the untimely death (and potential suicide) of Constance Fenimore Woolson. Although it is perfectly clear that James values her greatly, and even loves her as a friend, he cannot accept her advances. James's friend Francis Boott tells him in thinly veiled terms that Constance loves him, and that her mental state has improved considerably because of him:

"We both noticed the change in her over the past few weeks, when your arrival was increasingly certain. You know, she grew much happier and wore lighter colours and smiled more. It was unmistakable. [...] [T] he problem is - what will she do when you go? That is what Lizzie and I worry about. Not about you being here and seeing so much of her, but about your not, if you get my meaning." "I will do my best", Henry said. He knew the remark sounded weak, but as it made Francis Boott smile at him warmly, almost radiantly, he did not correct himself. (Toibín, 238)

James's "best", in this case, amounts to keeping things exactly as they were, never addressing the issue to Constance, and watching in some distress just how much his presence or absence influences her mood and health. Their relationship becomes abject, as Henry James neither rejects nor accepts her advances properly, and Woolson is unable to process her feelings. This factor might not have been the immediate cause of her untimely demise (and potential suicide), but James's efforts certainly did little to prevent it. 
'Confirmed bachelors' might have endured fewer negative social repercussions than spinsters, yet they were still an aberration, drawing suspicions of hiding an even more abnormal desire. By contrast, Oscar Wilde (who did not necessarily seek to avoid scandal and unconventional behaviour otherwise) was married and had fathered two sons, thus conforming to Victorian standards much more closely than Henry James ever would. Of course, Wilde's marriage to Constance Lloyd did nothing to prevent the scandal that ruined him and his family: at one point of The Master, Henry James reflects upon this particular tragedy:

He imagined Oscar Wilde's two sons, their names changed and their fate uncertain, watching from a window as their mother departed. He wondered what they feared most now when night came down, two frightened children in the unforgiving city, its shadows steep and sombre, half knowing why their mother had left them in the care of servants and haunted by unnamed fears and barely grasped knowledge and the memory of their evil father who had been shut away. (Toibín, 82)

These particular musings may potentially contribute to the fictionalized Henry James's refusal to entertain the idea of a marriage for propriety's sake. His aversion to scandal is not a purely egotistical impulse, but also stems from his desire not to offend others.

This is the fundamental discrepancy between Oscar Wilde (as portrayed in both Candlelight Murders and The Master) and Henry James: the Irish playwright does not shy away from drawing attention to himself, does not opt to ultimately hide from others or from himself, and is not daunted by the prospect of scandal even when it leads to his ruin. The American novelist fails to comprehend how any person could act this way, just as he fails to understand how anybody could be entertained by Wilde's plays. To James, both Wilde and his writings are coarse, unrefined, loud, and vulgar - and the outcome of Wilde's trial only seems to bolster James's impression. Because of this, his refusal to acknowledge his desires remains a pyrrhic victory, as he wants to conform to Victorian conventions and notions of propriety, even within the safe harbour of his own mind. While Wilde becomes a victim of the tyranny of the norm, James is its (willing) prisoner - and his own gaoler. José Yebra fittingly describes him as "traumatophilic and (self-)evasive, [...] both a mirror of current anxieties about masculinity, gayness and AIDS as well as a response to them" (69). The repression of Henry James's unconscious urges renders the author a fundamentally unhappy individual, but it also defines him as a person and as an artist. This sublimation of trauma into art enables him to create the fiction he becomes famous for, yet it is not without its problems. His relationship with the women closest to him borders on a form of psychic vampirism, "as his deliberate 'murder' of American girls through absence and neglect responds to aesthetic reasons, enabling him to redirect reality into the realm of literary possibility" (Yebra, 64). Toibín's version of James is a highly problematic individual that does not so 
much strive to overcome the marginalization and silencing of the minority group he belongs to (as neo-Victorian protagonists tend to do), but instead becomes invested in maintaining the status quo. The energy he draws from suffering, repression, and deprivation (and the insistence with which he seeks these negative emotions out) border on the pathological, even if his fiction seems to validate his choices.

Repressed aspects of the self can grow to monstrous proportions, resurfacing as a destructive force that turns the creative genius into a form of madness. The next chapter will explore these individual and cultural shadow-selves as portrayed within neo-Victorian fiction, ranging from actual madmen to unjustly pathologized eccentrics who just happen to deviate from the norm. 


\section{Madness and Subversion: Victorian Spiritualism and Occultism}

Societal abjects are hardly limited to the sphere of gender and sexuality: any point of view that challenges or subverts the established social and symbolic order can be regarded as potentially toxic or pathological. Whereas previous chapters focused almost exclusively on various forms of sexuality, the focal point here may seem virtually unconnected at first glance. The following pages will demonstrate that there is a connection, however: In the case of the Victorian era, this process of 'othering' the non-normative also applied to new religious movements like Spiritualism. Throughout the second half of the nineteenth century, occultism, cults and pseudo-sciences flourished and grew, enjoying an unprecedented degree of popularity among a significant portion of the middle and upper classes. ${ }^{46}$ Unlike Roman Catholicism, which had been vilified as 'other' by the British gothic novel as well as by diverse Anglican theologians (and was strongly associated with the Continent), these new ideologies were enmeshed with Victorian middle-class culture, and thus fell into the abject in-between state; they were a part of society, and yet stood in direct conflict with Victorian middle-class orthodoxy and traditional Christianity.

\footnotetext{
${ }^{46}$ Key dates with regard to Victorian occultism include the American Fox sisters' first reported contact with a spirit in 1848 , the foundation of the Theosophical Society in 1875 , and the formation of the Hermetic Order of the Golden Dawn in 1888.
} 
Just as pornography and the sex trade were booming businesses in spite (or because) of the period's repressive morality, mediums and messages from the beyond were all the rage in spite (or because) of the Victorian Christian piety.

As the influence of traditional religion waned in the light of new scientific discoveries and a mundane society radically altered by technological innovations, people kept looking for new ideologies to give meaning to the chaotic, swiftly transforming world around them. Tradition was becoming an important concept in a society faced with the swift changes brought by industrialization and rapid progress. By idealizing, codifying, or sometimes even all but inventing the past, people used traditions "to inculcate certain values and norms of behaviour by repetition, which automatically implies continuity with [history]" (Hobsbawm, 1). Others, however, did not look back in order to establish a sense of communal identity, but instead turned to new, alternate world views which were supposed to be an 'update' of outdated predecessors. Darwin's theory of evolution had all but shattered Biblical literalism, and new technologies were quickly opening up entirely new points of view - but could not fill the void left by traditional religion on their own. Apart from new political ideologies (which were to shape most of the twentieth century), a revival of 'occult' world views gained increasing popularity in the waning years of the Victorian era.

Throughout most of the twentieth century, occultism was regarded as a reaction against the Enlightenment and its focus on reason and science, such as in James Webb's seminal The Flight from Reason. Since these movements centred so much on the spiritual, the unconscious parts of the mind and the supernatural sphere suggested by diverse mythologies, it seemed reasonable to perceive them as the antithesis of the age of Reason and its profound disdain for the numinous and the mythical. However, this approach to the subject matter fails to account for the various movements' self-avowed goal of re-aligning science and spirituality. In many ways, most occult movements were another outgrowth of the Enlightenment project, constituting a third strand of influence between religious traditions on the one hand and scientific rationalism on the other. Nowadays, ethnologists recognize the various religious, philosophical and spiritual movements grouped under the umbrella term 'occultism' as a vital element of burgeoning modernism. They are not so much antithetical to science and the ideals of the Enlightenment, but instead tried to give traditionally religious beliefs a scientific basis. (Based on the lack of scientific discoveries that would bolster their hypotheses, these traditions did not succeed in that goal, yet their approach was indubitably indebted, rather than in opposition to science.) Priska Pytlik describes these ambivalences in Okkultismus und Moderne:

Im Spannungsfeld von Aufbruchsstimmung und Fin de Siècle, von Fortschrittseuphorie und Wertezerfall, Orientierungs- und Transzendenz-verlust bewegten sich auch ersatzreligiöse Bewegungen und alternative Heilslehren, die sich primär in den Metropolen herausbildeten. Mit einer Vielzahl von heterogenen Ansätzen entwickelte sich eine Kultur, die vor allem zu 
Rationalismus und Materialismus eine Gegenposition bezog. [...] Mit seinen Praktiken orientierte sich der Okkultismus an wissenschaftlichen Methoden und technischen Neuerungen und zeigte sich davon überzeugt, das Okkulte und Übersinnliche auf experimentellem Wege im Dienste der Aufklärung erklärbar machen und so gleichfalls einen Beitrag zur Bekämpfung des Aberglaubens leisten zu können. Er stellte sich in den Dienst einer Fortschrittsidee, die ihre Berechtigung aus dem Gedanken zog, dass es Dinge gibt, die zwar noch nicht nachgewiesen sind, gerade deswegen aber doch erforscht werden müssen. (12f.) $)^{47}$

Pytlik further alludes to scientific discoveries in the closing decades of the nineteenth century which shattered the far-spread notion of a completely decoded, mechanist universe (cf. 10ff.). When new data started to suggest that there were still unaccountable gaps in Man's understanding of Nature, occultist movements would declare that they might serve as the bridge between science and religion, contributing to a more complete decoding of the natural world instead of rejecting the Enlightenment project.

Nonetheless, the establishment was wary of such new developments, recognizing - often correctly - that they might be harbingers of change, and a threat to the societal status quo. Spiritualism in particular was suspect, as it often elevated women to a position of authority by pointing to the very qualities that were otherwise used to justify their confinement to the private sphere. And their progressive spirit was hardly limited to spiritual matters, either. Tatiana Kontou observes: "Interestingly, the growing debates on women's rights, fertility control, anti-vivisection, temperance and education forged strong links with spiritualism and theosophy, consolidating the trafficking of ideas between the supernatural and the cultural" (Women and the Victorian Occult, 3). In spite - or perhaps because - of the huge popularity of séances among the Victorian middle and upper classes, practitioners were maligned by the establishment. Drawing upon Yuri Lotman's Universe of the Mind: A Semiotic Theory of Culture, Miriam Wallraven describes the problems faced by Victorian mediums as follows:

Occult women writers [during the Victorian era] are confronted with a double marginalization in patriarchal society: they are displaced due to their gender and thus largely excluded from the production of knowledge and the

47 Poised ambivalently between a spirit of optimism and the fin de siècle, between faith in progress and declining values, loss of orientation and lack of a sense of transcendence, surrogate religions and alternate ideologies of salvation formed in the great cities. Through a multitude of heterogeneous approaches, a culture which opposed the doctrines of rationalism and materialism developed. [...] In its practices, occultism drew on scientific methods and technological innovations, firmly believing that the occult and supernatural could be experientially explained in service to the Enlightenment, contributing to the elimination of superstition. It stood in service to an idea of progress which drew its validation from the approach that some as of yet unsubstantiated, supposedly numinous phenomena validated further research. 
master discourses and they are marginalized due to the fact that their spiritual beliefs depart from institutionalized religions. (117)

Exclusion and marginalization were not the only threat Victorian spiritualist had to deal with, however. In some cases, their beliefs were pathologized, diagnosed as mental illness, and used as a justification for institutionalization, as in the historical cases of Louisa Lowe and Georgina Weldon: Both women hailed from a middleclass background, leading comfortable and comparatively conventional lives until they decided to leave their husbands. And both were diagnosed as insane on account of their spiritualist affiliations. Lowe had been unhappily married to a clergyman, keeping up appearances for many years before deciding to divorce him. Her conversion to Spiritualism coincided with her final rejection of his authority.

Her interpretation of [Spiritualist messages obtained per automatic writing, stating that she should be guided by her conscience alone] made her position crystal clear: she must turn her back on the conventional authority of church and husband - both, of course, represented by the one man - and begin to make her own way. Like her contemporaries, Annie Besant and Anna Kingsford, Louisa was rejecting Anglicanism and husband in one clean sweep. The religious imperative gave her the assurance she required [to end her marriage]. (Owen, 176)

Apparently, Lowe's husband had repeatedly pronounced her mad even prior to her conversion to Spiritualism, as her unconventional beliefs clashed with the orthodoxy he embraced (ibid., 169). But after she moved out of their home, the clergyman took steps to have her incarcerated in an asylum: her defiance of the established social order and holy tradition alike were sufficient proof of madness. The two doctors required by law interviewed her under false pretences, and cited her spiritualist beliefs as signs of mental illness in their official report. She was committed to an institution, and later became an active advocate within the Lunacy Laws reform movement because of her personal experiences during this period of her life. Throughout her incarceration, her spiritualism was repeatedly cited as the reason for her confinement.

The spiritualist Georgina Weldon faced a similar predicament after separating from her husband in 1875. Both her family and her ex-husband were scandalized by her unconventional beliefs and practices:

She was an advocate of female suffrage (although never actively involved herself in the suffragette campaigns), supported a variety of progressive issues, and was a devoted spiritualist. [...] If such goings-on had remained private the family might have turned a blind eye. As it was, Georgina had a genius for publicity and kept her causes in the forefront of public attention. (Owen, 160f.) 
It may not be possible to reconstruct the exact motives behind Henry Weldon's decision to have his wife declared insane, but her conduct - along with her allowance of $f, 10,000$ per annum (cf. Owen, 161) - might certainly have influenced his attempt at having her silenced and removed from the public eye. In this case, the endeavour was not successful, and Mrs Weldon became a very outspoken campaigner for reform, last but not least since the legal status quo did not even allow her to press charges against her husband. What both of these cases demonstrate is the relationship between spiritualism, female emancipation, and the pathologisation of any world view that posed a direct challenge to the established symbolical order.

At first glance, the Spiritualist movement does not seem to present a strong link to present societal conflicts, as the phenomenon started to dwindle after the 1920s and séances are no longer a common practice. Apart from manifestations in popular culture (for example in horror films or in toys such as Ouija boards), Spiritualism in and of itself is mostly of historical relevance. If there are any mediums left, their numbers are too small to register within the collective cultural consciousness. This does not mean that there are no parallels to present-day areas of conflict, however. Spiritualism proper might be practically extinct, yet the reasons why society regarded it as an abject (and occasionally treated it as pathological) are still relevant, and are echoed by current discourses. The Spiritualist movement exhibited a strong subversive streak, because the very qualities attributed to the female gender in order to classify women as submissive and inferior to men qualified them for a privileged position in a séance: their receptiveness became a source of authority and power, putting them in leadership roles. As Jill Galvan remarks: "On both sides of the Atlantic, spirit channelling quickly became marked as feminine" (4). Male mediums were not unheard of, but the female gender (as defined by the Victorian middle and upper classes) seemed especially suited to serve as a messenger for the Great Beyond. The movement's rejection by society at large was therefore closely tied to the 'Woman Question': it seemed to embrace the dominant cultural morality of its day, and yet derived a wholly different societal arrangement from it that elevated women to a station above their usual sphere of influence ${ }^{48}$.

It is this focus on feminine power and the subversion of stereotypical gender roles that connects spiritualism to the sexual topics of the preceding chapters: neoVictorian fiction explores these phenomena in a manner that defies the ordered, chaste, strictly patriarchal image of the Victorian era that was painted by the most popular literature of that historical period.

\footnotetext{
48 Spiritualism was not the first religious movement within the British Empire's cultural sphere to embrace egalitarianism. Christian denominations like the Quakers or the Methodists had already confronted and undermined the status quo, yet failed to change society as a whole and/or relapsed to a more conservative stance over the course of the nineteenth century. "Early Weslyan [sic] theories of social equality had enabled women to argue for female spiritual authority and the right to teach, [but] in a nineteenth-century replay of earlier Puritan struggles, respectable Methodism sought to suppress its preachesses" (Owen, 15).
} 
Both as a symptom and as a cause of societal changes, Spiritualism could not escape being branded as abject by the champions of conservatism and orthodoxy. In its vacillation between scientific progress and spiritual counter-revolution against the enlightenment project, its acceptance of Victorian gender stereotypes in combination with its subtle defiance of the established patriarchal structures, Spiritualism remains a phenomenon that receives a considerable amount of attention in neoVictorian fiction. As Rosario Arias and Patricia Pulham note in their introduction to Hauntings and Spectrality in Neo-Victorian Fiction: 'We suggest that the Victorians' own engagement with the past, or perhaps more accurately critical evaluations of such interactions, inform contemporary debates on postmodern modes of nostalgia" (xiii). Neo-Victorian historiographic meta-fictions constitute an attempt at conjuring up spirits of the past, mirroring the memory work portrayed in the texts. Just as the characters try to conjure up the shades of their lost loved ones in order to recreate a past that ended with their untimely demise, the novelists reconstruct a fictionalized version of the Victorian era in an attempt to explore its connection to the present. As Mark Llewellyn puts it:

Metafictional texts, by their very nature, are more about the moment of their writing than the setting of that writing, and metahistorical novels, the genre into which often the most interesting and stimulating neo-Victorian fiction falls, are as much concerned with the historical moment that is now as they are with the nineteenth century. By casting the fiction and the fakery of the séance, of the ghost and of the spectral itself back to us as contemporary readers, [the authors] are multilayering the notion of textual haunting, and possibly even challenging our 'faith' in the postmodern text and its own séance-like trickeries. (40f.)

Not every neo-Victorian text necessarily portrays the séances as fraudulent, yet even in cases where the fictional universe does allow for the possibility of supernatural events and genuine spirits communicating with the world of the living, his point still stands. There is a correspondence between the characters' attempts at communicating with the past and the authors' (and readers') exploration of the Victorian epoch through the lens of fiction. In fact, the first text to be analysed here seizes heavily upon Alfred Lord Tennyson's In Memoriam A.H.H., a poem that could be read as the author's attempt at resurrecting the spirit of his departed friend by means of poetry, conjuring up more than just fading memories through verse and metre. Fiction may not create an entirely accurate picture of the past, and ultimately tell us more about ourselves than about a bygone era we are re-creating. Yet in that nostalgic process of creation, we may indeed gain a better understanding of phenomena within our contemporary era that are rooted in the past. 


\section{1 "The Conjugial Angel": The Medium as Gifted}

A.S. Byatt's Angels and Insects explores two very distinct strains within the cultural history of the Victorian era, juxtaposing two novellas that embody either one of them: "Morpho Eugenia" embraces a prosaic, matter-of-fact style and compares social mores to the complexities of state-building insect societies, whereas "The Conjugial Angel" is suffused with poetry, fanciful imagery and potentially supernatural occurrences. In the context of this chapter, only the second novella will be of particular interest, and their plots are only loosely connected by the appearance of a single marginal character called Arturo Papagay. Yet while it is possible to read each of them as an isolated, self-contained text, they are obviously meant to be compared and contrasted, as indicated by the title Angels and Insects. Byatt constructs the scientific sphere of Darwinian biology and the spiritual sphere of séances and Swedenborgian theology as two very distinct realities, and yet both take place in the same world, the same culture, the same time period and society. The two novellas are not put side by side as ideological opponents, nor do they contain any kind of judgment that would elevate one above the other. Instead, each of them portrays a self-contained scenario that operates by the rules of the underlying world view.

"The Conjugial Angel" is a densely written, highly complex text on issues of gender, loss, sexuality, art, memory, and the unconscious. Its title references a specific metaphysical concept established by the eighteenth century mystic Emanuel Swedenborg, whose writings were highly influential for the Spiritualist movement of the Victorian era. This concept is of some importance to the issue of gender roles and the conflict between men and women within the text, and is explained by a member of the Swedenborgian New Jerusalem Church, Mr Hawke:

So two married partners in Heaven are not called two, but one angel, and this is what is meant, Swedenborg tells us, by the Lord's words: "Have ye not read, that he which made them at the beginning made them male and female. And said, For this cause shall a man leave father and mother, and shall cleave to his wife: and they twain shall be one flesh? Wherefore they are no more twain, but one flesh. What therefore God hath joined together, let no man put asunder." (Byatt, 242)

Marriage was at the very core of Victorian middle-class morality, circumscribing its gender roles, its conception of the core family, and the ideal of domesticity. Swedenborg's depictions of celestial love must have seemed highly desirable to those who believed in Victorian family values - and yet, they also created some significant problems, especially in conjunction with the concept of immortal spirits. What if a widowed or otherwise bereaved partner (re-)marries, as in the case of Emily Jesse née Tennyson, the bride-to-be of the prematurely departed Arthur Hallam? Her efforts to summon the ghost of her deceased fiancé call almost her entire adult life into question, as she spent several decades happily married to her husband Captain Richard Jesse. One might expect that Victorian society would regard such a ghoulish 
obsession with a deceased man (whom she did not even marry) as unhealthy, yet the opposite is the case: both Hallam's relatives and her own family were comfortable with the notion of having her become a living memorial and eternal widow to the departed, and regarded her decision to 're-marry' as scandalous, apparently expecting her to remain a mourning spinster for the rest of her existence. The poet Elizabeth Barrett, a close friend of both families, apparently described her as a "disgrace to womanhood' and 'a climax of badness"' (Byatt, 201; emphasis in original), especially since Mrs Jesse continued to accept annual funds from her deceased fiancé's father. In this case at least, the Victorian obsession with preserving and reconstructing the past through memory work superseded the cult of matrimony, rendering Emilia Tennyson abject on account of her will to live. It is especially telling that Barrett's accusations aim at Mrs Jesse's supposed lack of femininity, virtually accusing her of infidelity and selfishness. The Victorian ideal of womanhood conceived of the female sex as passive, receptive and utterly devoted to the needs of their husbands - all of which clashes with the notion that a woman might put her own interests above those of a man or, in this case, his spectral memory. Fidelity is presented as the ultimate virtue - even if the marriage wasn't consummated, and even if the partner is deceased. This state of affairs is not very dissimilar from an Indian tradition brought up by Mrs Papagay at a later point in the novella: "In India, [...] I believe it is enjoined on widows to place themselves beside their dead masters on the funeral pyre, and voluntarily submit themselves to incineration. I find that hard to imagine, yet it is done, it is even, we are told, usual." (Byatt, 241). Victorian society did not go quite as far, yet the Swedenborgian conception of a conjugial angel formed from the union of two married partners certainly does not leave much room for re-marriage. Given the different roles projected upon husband and wife, and the traditional conceptions and symbols associated with marriage, it is obvious that women are expected to basically subsume their very identity under that of their partners. The (historically documented, if in this case fictionalized) societal backlash against Mrs Jesse bears testimony to this, as does the way others interpret her desire to communicate with Arthur Hallam's ghost. Most participants of this spiritualist circle perceive Mrs Jesse's endeavours as an attempt at re-establishing contact with her one true love, rendering her current husband Captain Jesse little more than a placeholder. Yet just as Mrs Jesse disregarded societal expectations in the case of her marriage, her intentions in this case are not what her acquaintances expect: "She had wanted so much to speak to lost Arthur, to be reassured that she was forgiven for not having been able to be what Arthur's sister Julia Hallam called a 'dedicated Nun" (Byatt, 251; emphasis in original). She does not want her lost fiancé back: she seeks an opportunity to let him go, to finally put a satisfying conclusion to a narrative that had haunted most of her life's story. If anything, her memories of Hallam (including excerpts from his letters) suggest that their relationship already exhibited some decidedly negative patriarchal traits during their short engagement: "I do not think women ought to trouble themselves much with theology' [, Arthur Hallam 
wrote to her.] He had treated her like mixture of a goddess, a house-angel, a small child and a pet lamb. This was, she supposed, not unusual." (Byatt, 250f.) She experienced a considerable level of discomfort at this condescension, yet tolerated it because she regarded it as normal - and therefore, inescapable. Her marriage to Captain Jesse contrasts drastically to this, as shown by the novella's conclusion. He is not presented as an intellectual or a poet, but it is clear that he greatly admires his wife, considering her as his equal or even superior rather than a subservient partner. And Mrs Jesse realizes that she has no wish to return to Arthur Hallam, neither now nor in the afterlife the séances hint at:

Mrs Papagay was made intensely happy by this exchange [between $\mathrm{Mr}$ and Mrs Jesse]. Who would have thought it, she said to herself, and yet, how right, it was only when the Angel threatened her with the loss of the husband she had taken for granted that she really saw him, saw him in terms of his loss, his vanishing, that was implied, and was driven to imagine existence without him. She knew she was romanticising, but she was filled with a kind of bubbling delight at the spectacle of the looks, shrewd and wondering together, that passed between these two elderly people [...] (Byatt, 330; emphasis in original)

The women in The Conjugial Angel are clearly not in a subservient position, both in terms of their status as medium and in terms of their marital arrangements. However, their status is challenged and covertly assaulted by Mr Hawke, who serves as the novella's nearest equivalent to an antagonist. If Mrs Papagay and Sophy Sheekhy embody different versions of the empowered female medium, then Mr Hawke is the subversive male dominator who tries to re-assert control by claims of encyclopaedic erudition. His pontifications on the Bible and Swedenborg's writings serve as his means of claiming superiority over the predominantly female Spiritualist circle he participates in. "

Emily Jesse was not quite sure how he had made himself so central a figure, since he had exhibited no mediumistic powers up to that point [, and also noting that] more orthodox Swedenborgians [than him] looked askance at what they saw as the loose and dangerous power-play of the spiritualists." (Byatt, 215f.)

Mr Hawke has no real authority within the Swedenborgian New Jerusalem Church, and therefore apparently perceives the small circle as an opportunity to gain status and prestige on account of his familiarity with diverse scriptures. At first, his endeavours seem to aim mostly at winning sexual favours, as he is the only unmarried man in attendance, and Mrs Papagay notes that he "liked female flesh, and thought much and very frequently about it" (ibid., 219). His behaviour indicates that he mostly conceives of women in terms of sexual objects, whose whole purpose of existence revolves around patriarchal matrimony. His seemingly harmless quest for 
sexual favours reveals a distinctly more toxic attitude when his clumsy attempts at courting Mrs Papagay do not bear fruit. His erudition, first used to gain status and prominence within the circle, now becomes a weapon to strike back, and he quickly seizes upon some of the Bible's (and Swedenborg's) most misogynous passages in order to chastise and condemn the female sex for their sensuous temptations:

And Swedenborg taught that the Lord successively put off the Human assumed from the mother, and put on the Human from the Divine in Himself. He had two states on earth, one called the state of humiliation or exinanition, the other the state of glorification or union with the Divine, which is called the Father. [...] His Crucifixion was a necessary shedding of the corrupt humanity He had from the mother, in order to experience glorification and union with the Father. (Byatt, 322; emphasis in original)

This cycle (i.e. sexualizing women and then condemning them for being a temptation) is a common element of misogyny, and closely connected to the need to control and oppress female sexuality under the auspices of a patriarchal social structure. It constitutes an approach to femininity that stands in marked contrast to the prescriptive gender conception of the 'angel in the house', yet draws upon the same notions of supposed female weakness and subservience.

[There] was another Victorian discourse of 'the feminine', a discourse concerned with female depravity, bestiality, and rampant sexuality, and one which displaced these elements on to the very poor and the insane. It can be located as a subtext of medical psychology, a subterranean theme of respectable literature, and an insistent signifier within pornographic literature.

(Owen, 7)

The discrepancy between femininity as otherworldly saintliness embodied in middle- and upper class women and femininity as earthly sinfulness as demonstrated by the lower strata of society is a continuation of the traditional Christian sinner-saintdichotomy, which regarded women as either sexless virgins or fallen (but potentially redeemable) agents of corruption. The main difference between Victorian domestic angels and their theological predecessors lies in the thorough condemnation of sexuality by the church fathers. For example, St. Jerome, who translated the Bible into Latin, declares: "Eve in paradise was a virgin ... understand that virginity is natural and that marriage comes after the Fall" (Knight, 120). Other notable theologians such as St. Augustine or St. Albertus Magnus echo this sentiment, and their disdain for sexuality exerts some influence upon Catholic sexual morality to this day. In sharp contrast to this, Victorian middle-class ideology (and, by extension, Spiritualism) embraced a "sentimentalisation of home and hearth" (Owen, 29), exalting motherhood and marriage instead of declaring them the results of spiritual degradation. 
Mr Hawke embodies a Victorian morality that tries to accommodate and assimilate Spiritualism into the established symbolic order, and then turns hostile when these attempts do not bear the desired fruit. His extensive Swedenborgian quotations represent an attempt at re-appropriating patriarchal power within the Spiritualist movement. He claims theological authority, asserting dominion over the orthodox interpretation of the received messages and the metaphysical processes involved by referencing copious amounts of supposedly authoritative source texts. In sharp contrast to the intuitive, unguided and unconscious processes conducted by the female mediums, he is constantly categorizing, rationalizing and arguing. His exegesis of passages relating to the conjunction of the sexes in a single angelic being echoes the legal status quo in Britain prior to the Married Women's Property Act of 1882 (with further concessions added in 1884): up until that point, wives ceased to be regarded as independent legal persons to be distinguished from their husbands. They could not own property of their own, could not sue or be sued in their own name, and could not press charges against their partners, because they were regarded as one and the same legal entity. In light of this, the image of an angelic marriage where partners fuse into a single being starts to look far less benign than it might appear at first - and Mr Hawke's later remonstrance shows that he does not interpret it in an egalitarian manner, either. Citing I Corinthians, he declares: "For the man is not of the woman; but the woman of the man. Neither was the man created for the woman; but the woman for the man." (Byatt, 324)

In spite of all this, he does not pose a genuine threat to the women involved. Instead, he is characterised in parodist terms, an impotent interloper who insisted on being part of the circle, and yet never gains the exalted position - or the sexual gratification - he craves. His misogynist outbursts - delivered after a failed seduction attempt that left him mortified and humiliated - may poison the climate of the Spiritualist circle, yet his sentiments are not accepted with deference. Instead, both the hostess and her husband put Mr Hawke in his place. In sharp contrast to him, the other members of the circle embody a different model of society and the relationship between men and women: not a matriarchy, but instead an approach that resembles Riane Eisler's concept of a "partnership model of social organization" (Eisler, xix), in contrast to a "dominator model" (ibid.). Eisler holds that the opposite of a male-dominated society is not a female-dominated equivalent, but an egalitarian arrangement that does not discriminate against either gender. The functional relationships in "The Conjugial Angel" seem to reflect this ethic, even if this causes them to clash with Victorian middle-class mainstream society. To a socially conservative Victorian, such an even distribution of power might look like an inversion of the natural order of things, a blurring of spheres that are supposed to be separate, and an unbiblical defiance of the sacred laws of matrimony. Such a marriage might not be regarded as sufficiently abnormal to trigger feelings of abjection, but it might very well encourage contempt towards the supposedly weak husband, who fails to 'wear the trousers'. Captain Jesse certainly seems to enjoy a very small degree of 
social acceptance, even if the text specifically links his outcast status to his tendency to talk too much. He may not be exceptionally intelligent, and this might cost him some social status; but neither does he tell his wife that she is excluded from debates in lieu of her womanhood, like her deceased fiancé did. While such a liberal attitude is certainly commendable, it is not entirely unproblematic, either, as his passivity in resisting his wife's attempts at summoning the spirit of Arthur Hallam apparently endangered their relationship, judging by Mrs Jesse's comments: "' [] have tried to be understanding, I have tried to be patient, I have respected - ' you tried too well, we both -" (Byatt, 329). Apparently, Mrs Jesse wants her husband to interfere, to demonstrate that he wanted her to be his wife, and not Arthur Hallam's. It is only when they speak up that they finally recognize how fond they are of each other. Yet apart from this lack of communication, their previous mutual solidarity also gave them strength. When Mr Hawke tries to enforce the traditional male-dominator model, the Jesses stand united in their resistance, reprimanding the misogynist for his criticism and dispelling the glamour of power that he had acquired. This confrontation may contribute to the imminent collapse of the Spiritualist circle, but it reflects their relationship rather well:

"And the sons of God saw the daughters of men that they were fair" [, Captain Jesse interjected.] There was a silence. Mr Hawke said, "Excuse me - I fail to see the relevance -" "I just like the sound of that saying, Mr Hawke, it cheers me, it suggests a kind of happy union of the earthly and the heavenly, you know, the beauty of women, and the admiration of the sons of God for that, in the oldest days you know, in Paradise, I suppose. [...]" (Byatt, 323f.)

His exegesis clashes with traditional Biblical exegesis - as Mr Hawke immediately points out - yet it communicates a much more benevolent metaphysical model that comes closer to the imagery of the "conjugial angel". Captain Jesse's "happy union of the earthly and the heavenly" does not rely upon a hierarchy based on gender, but on a harmony between the two. He clearly does not perceive himself as the patriarchal head of his family, giving his wife free reign and even aiding in her pursuit of Arthur Hallam's shade. Their marriage may not find approval in polite society on account of Emilia Tennyson's prior engagement, yet it turns out to be a functional, happy relationship nonetheless.

Similarly, the medium Mrs Lilias Papagay is characterized as an unconventionally egalitarian person who was part of a fulfilling marriage and learned to embrace her own sexuality, in sharp contrast to the Victorian ideal of the innocent domestic angel: "Arturo had taught her much and she had been an apt pupil. He had gained courage to tell his wide-eyed wife of what he had seen in various ports, of women who had entertained him - he went so far, and further, as he saw that his surprising wife did not take umbrage, but evinced detailed curiosity." (Byatt, 220) It is this highly unconventional nature that not only rendered her a happy wife, but also a capable medium. In this, she clearly defies Victorian conceptions of femininity, 
which would require a decidedly more passive approach to the subject matter. Lilias Papagay is anything but passive: her imagination is constantly active, and the text leaves room for the possibility that her mediumistic readings are entirely mundane, a combination of psychological insight and intuitive flashes (cf. Byatt, 187f.). In sharp contrast to this, her friend and co-worker Sophy Sheekhy is positively haunted by visions and altered states of consciousness, to the point where she no longer wants to actively pursue such visitations. She corresponds more closely to the traditional requirements that connect the Victorian feminine ideal and the qualities of a medium: "passivity (to the will of a foreign personality), sensitivity (to the elusive nature of that will), and a strong spiritual sensibility" (Galvan, 4). Her abilities give her a relatively steady source of income - yet they may also pose a genuine danger to her mental and physical health. The visions she receives over the course of the novella grow increasingly horrifying, until her channelling of the spirits starts to resemble a seizure in the final séance:

[Sophy was] turning a terrible colour, ash and plum and lapis blue together, her lips moving numbly. She snorted, she sucked desperately for breath, as though her life was being sucked out of her. [Her] little heels drummed on the carpet, her spine arched and jerked. Her eyes were open and unseeing. Nothing so dreadful had happened to her before. (Byatt, 330)

Spiritualism may grant Victorian women a degree of power that they do not otherwise enjoy in Victorian society, but in the context of Byatt's novella, a genuine talent for contacting the dead is characterized as more of a curse than a blessing. Sophy Sheekhy lost her previous position as a maid on account of her uncanny visions (ibid., 187), and only became a medium in order to provide for herself. In her case, the text does not leave much room for any ambiguity: she clearly is haunted by the dead and other preternatural visions, as evidenced by her ability to see Alfred Tennyson in his bedroom (ibid. 293). Whatever power or status she might gain on account of her extraordinary abilities is counterbalanced by the price she has to pay for it.

Regardless of this, the two women clearly manage to secure a niche within the wider fabric of Victorian society, without having to fall into subservient roles. Spiritualism is their means of living a (mostly) respectable, financially secure life. As mediums, they need neither husbands nor employers to get by, and still have access to polite society. Their source of income may not be entirely secure, as can be seen at the conclusion of the novella: they have to rely on loyal patrons, and the disbanding of Mrs Jesse's circle poses an financial crisis to them - but they still possess a degree of autonomy that was unavailable to most women in the 1870s. Interestingly enough, their cohabitation is not portrayed as problematic or frowned upon by polite society, as contemporary readers might expect. An all-female household of unrelated women would have certainly resulted in rumours of lesbianism in a conservative twentieth or even twenty-first century setting. (Byatt herself used a similar 
arrangement to strongly hint at a lesbian relationship in Possession: $A$ Romance, even if the relationship remained similarly invisible in the Victorian timeline.) The possibility simply does not seem to occur to people who were socialized in the nineteenth century (or at least in Byatt's interpretation of the same), rendering lesbians more than just abject: they become void, mere ghosts who remain undetectable to all but themselves and those similarly 'afflicted'. This phenomenon plays a prominent part in Sarah Waters's second novel Affinity, where spectrality becomes a sleight-of-hand for social and sexual abjects hiding beneath the surface of Victorian society.

\subsection{Affinity: The Medium as Fraud}

Sarah Waters's Affinity exhibits a much less sympathetic point of view in relation to Spiritualism: the novel focuses on the fraudulent aspects of the movement, enmeshing both the readers and the female protagonist in an elaborate confidence trick that leaves the main character broken and ruined. Whereas "The Conjugial Angel" constructs a fictional universe where genuine mediums exist alongside less supernatural (but nonetheless benevolent) practitioners who simply convey their psychological insights by spiritualist means, Affinity's Selina Dawes is nothing more than a fraud. And yet, Waters's literary subterfuge manages to draw attention away from the details that would call the medium's abilities into doubt until it is too late for the protagonist. The novel's means of achieving this sleight-of-hand are manifold, and include not only stylistic and linguistic aspects of the text itself, but also intertextual factors. Affinity obviously shares some core elements with Waters's debut novel Tipping the Velvet: a (neo-)Victorian setting, lesbianism, and the deliberate usage of 'queer' language to convey a double meaning - once within the historical setting, and once to the contemporary reader. So when the tragedy-stricken middle-class lady Margaret Prior first meets the imprisoned medium Selina Dawes, who was arrested after one of her clients was hurt during a séance (which the attending doctor calls "queerer business than he thought" (Waters, 3)), informed but unwary readers may swallow the bait as readily as a con artist's mark. It is an obvious - and therefore tempting - connection: both spiritualism and lesbianism are regarded as abject by Victorian mainstream society, and since many mediums were simultaneously involved in other areas of social progress, it is easy to see how this particular form of occultism might serve as a vector for further "queer" imagery. As both homosexual relationships and spiritualism were marginalized or even penalized during the Victorian era, as embodied by the supposedly wrongfully imprisoned Selina as well as by the suicidal outcast Margaret, readers are lulled into linking the two issues, and thinking of the gaoled spiritualist in positive terms. Everything seems to fall neatly into place: the readers discover that Margaret is indeed homosexual, haunted by her father's death as much as by her lover's decision to marry her brother instead, and a romance with Selina Dawes appears to be a fitting conclusion. Both could stand 
united against a patriarchal society that shuns or expels them as abject, and each one's struggle could be regarded as a mirror of the other.

By choosing the form of an epistolary novel, and restricting the readers' perspective to the diaries of Margaret Prior and Selina Dawes, respectively, important clues are misrepresented, even though the critical information is all there. The readers' suspension of disbelief is used against them, resulting in a twist ending that reveals the novel's medium to be a con artist conducting a devious scheme to escape prison. There is a lesbian romance involved, of course, but it is not the one that the reader (or Margaret) so readily envisions. Waters reveals it in the novel's opening lines, albeit in a manner that is easily overlooked: Peter Quick, the supposed spirit with his "great dark whiskers \& his shining hands" (Waters, 3), is none other than Ruth Vigers, Selina's accomplice and lover. In focusing on the potential romance between the two point-of-view narrators, and the expectation that the problematic situation they each find themselves in might be resolved, readers could easily miss another aspect: class struggle. Selina's and Ruth's deception - both in the past and in relation to Margaret Prior - relies on the virtual invisibility of servants, who rarely register as human beings in the minds of their employers. The deception works because Margaret Prior (and potentially the naïve reader) wants to believe, or perhaps even needs to do so. Her clandestine romance with the prisoner must seem both liberating and healing to her, mending the psychological wounds inflicted on her by her ex-lover, and simultaneously offering her a new perspective on life and society that differs considerably from that of the oppressive people that surround her at home. Yet even though she develops some class consciousness, reflecting upon her privileges as a lady, she remains oblivious to Vigers's role in the elaborate drama staged for her benefit (or rather harm). Mark Llewellyn sums this aspect up brilliantly:

While observation and looking is the key to Affinity, we don't really 'see' what is presented to us. Indeed, in terms of spectrality we are blind to the Marxist implications of the term. For what we see $(\mathrm{k})$ in this version of neo-Victorian fiction is satisfaction for our interest in the Victorians and hidden sexuality. We ignore the original 'spectres of Marx' declared in The Communist Manifesto ("A spectre is haunting the continent of Europe") when we fail to realize that the servant in the household carries the key to the narrative. This exploitation of our cultural weak spots (inherited from the Victorians like so much else?) serves to play in a sophisticated way with the spectral presences we will permit ourselves to see and those we will not. We are prepared, potentially, to suspend our disbelief through the narrative of Affinity and believe that Selina is able to contact the spirit world and transplant herself to Margaret's bedroom rather than acknowledge the presence of the servant woman Ruth Vigers. (30) 
The confidence trick works brilliantly, both on Margaret Prior and - potentially on the reader. However, where does that leave the societal issues raised by the rest of the novel as a means of artful misdirection? Does the final plot twist not validate the terrible system installed at Millbank, where men like Mr Shillitoe prohibit female prisoners from even speaking without being spoken to first? Does it not prove Mrs Prior right, who urges her daughter to desist from visiting the prison, and is scandalized by Margaret's behaviour? If Spiritualism, that obvious stand-in for marginalized and maligned sub-cultures, is just an elaborate ruse conducted by sexually deviant criminals for personal gain, then isn't the establishment correct to persecute them? Every new insight that Margaret has gained over the course of the novel, every shred of emancipation or empowerment was a lie, a fiction, a tempting bait left dangling for her to grasp and hold on to. Her final suicide is more than just a personal defeat - it also casts doubt upon the ideals she pursued.

Nonetheless, Affinity is anything but a conservative cautionary tale about the dangers of deviance or the need for conformity. If Margaret Prior had surrendered to societal pressures or never gone to Millbank to begin with, she might have escaped the trap laid out for her - yet it would have been an unbearable existence, too. She envisions an alternate scenario that comes close to this during her final moments, and chooses death over it:

And then - what? Then years of staring grief, and then more laudanum, or chloral again, or morphine, or paregoric - I never tried that. Then the couch for half a year, just like before, and visitors walking tip-toe to my door... And then the gradual re-absorption into Mother's habits - cards with the Wallaces, and the creeping hand upon the clock, and invitations to the christenings of Prissy's babies. [...] No. (Waters, 349f.; emphasis in original)

Conformity and suppression are not viable alternatives to the path Margaret chose, and her tragedy is not based on her defiance of Victorian norms or her refusal to pretend to be something she's not, but on her inability to see the signs of deception and pinpoint the culprit(s). Thinking back on the events, she realizes that her devious maid was virtually invisible to her: "I could not even recall the details of her face, her look, her manners. I could not say, cannot say now, what shade her hair is, what colour her eye, how her lip curves - I know she is plain, plainer even than I." (ibid, 340) The novel makes no attempt at painting Ruth Vigers as anything other than the antagonist. Selina Dawes's imprisonment was caused by 'Peter Quick's' tendency to manhandle the victims of their deception, evidenced in the novel's very first scene, and she is characterized as a manipulative, cynical woman who feels nothing but disdain for her victims. And yet, her hatred of those "pale English ladies" (ibid. 352) is not entirely without cause or justification. As a servant, she is a non-entity to them, a living utility tool rather than an individual, a faceless name to be called upon by her supposed betters. She exists within polite society without ever being a part of it, abject by virtue of her class. Like suppressed impulses in the 
unconscious, Ruth Vigers has festered and grown into something monstrous, turning her will to visiting harm upon those who have treated her as something lessthan-human. Georges Letissier even goes so far as to equate servitude with a form of slavery: "Ruth is the Priors' servant, and this is where the family as famulus - that is, an obedient slave - comes in" (374). We may not applaud her for deriving pleasure from having middle-class ladies pay for the privilege of being fondled by her alter ego Peter Quick, and we are certainly not encouraged to identify with her - yet she is obviously a product of Victorian society. Her deception relies entirely upon her status; she weaponizes her social stigma and turns it upon those who slight her so habitually. Without the class boundaries of Victorian society, she would not only be powerless - she would most likely not be the person she is.

To conclude, Affinity may not treat spiritualism as anything other than a confidence trick (after lulling the readers into thinking that it may serve as an analogy to lesbianism and female emancipation), yet it is most certainly not a defence of the Victorian status quo or its reactionary remnants within contemporary society. The novel's antagonist may be a representative of three distinct marginalized groups (a spiritualist, a lesbian, and a working class woman), yet that does not tarnish these demographics by association. Instead, Ruth Vigers is a product of the oppressive norms within Victorian society, turning upon the same to bring harm like a repressed shadow clamouring to the surface of the psyche.

\subsection{In the Red Kitchen: Mediumship as Repressed Trauma}

Whereas A.S. Byatt's "The Conjugial Angel” embraces a kind of magical realism that allows for actual ghostly invitations, and Sarah Waters's Affinity exhibits a cynical rationalism dispelling any such notion, Michèle Roberts's In the Red Kitchen may qualify as a third approach lying somewhere between the two. All three of these are feminist texts giving voice to historically marginalized women, yet Roberts's short novel exhibits the strongest focus on the pathologisation of non-normative or marginal perspectives. It tells the stories of three protagonists separated by time and space, yet drawn together by shared childhood trauma, unconventional perceptions, biographical details, or - in relation to the Egyptian princess Hat and the $20^{\text {th }}$ century Londoner Hattie - even a name.

[In the Red Kitchen deliberately] refrains from constructing a singular, unified account of women's history in favour of promoting plurality and a variety of historical experience by offering women's histories, rather than History. By presenting a plurality of voices, granting none a privileged position in the narrative, the novel manages to defy the totalizing, speaking-for-all singular point of view. [...] The assumption of personal voice in the often conflicting narratives prevents any one of them from being presented as the "historical 
truth', the master narrative that operates to subordinate all the others.

(Golda-Derejczyk, 54f.)

This Bakhtinian polyphony encourages readers to conceive of the presented fictional universe as something other than 'objective reality', allowing each narrator's subjectivity to reveal itself as a valid form of interpreting the world around them and communicating something about each protagonist's personality. As such, the question of whether ghosts actually exist in the fictional setting of In the Red Kitchen is not only moot, it misses the point. It is irrelevant to the story whether the spirit guide summoned by Flora Milk is an actual ghost from the past, a psychic projection of the $20^{\text {th }}$ century inhabitant of her home, or just a manifestation of her own subconscious and repressed childhood trauma. The potentially supernatural phenomena within the novel are supposed to elude the kind of rational categorization associated with the male-dominated Enlightenment project, offering a decidedly different, less clearly delineated idea space in its place, a "hysterical history" (Rowland, 206) that is opposed to authoritarian, patriarchal attempts at controlling and defining it.

This conflict is also present in the plot itself, specifically in the abusive relationship between Flora Milk and Sir William Preston, the husband of her 'friend' and patron Minnie. There is an enormous power imbalance between the two from their very first encounter, based on gender, class, and education. Flora seeks his approval and patronage in order to be accredited as a genuine medium by polite society, and William exploits this dependence by involving her in a series of supposedly scientific experiments that enable him to elicit sexual favours from her. Flora's descriptions of his behaviour bespeak a manipulative, classist mind set; he has little compunction about using her for his personal gratification on account of her inferior status, and considers her an exotic pastime. Their affair entails no affection on his part at all. "[He] liked Hattie to move freely, to dance even, if she felt like it; he thought that was what I was like amongst my own people in Hackney, he expected a certain coarseness. It excited him. Also it allowed him to stay cold, in control (Roberts, 108; my emphasis)." Flora clearly understands that William does not consider Hattie, the spirit guide who is supposedly the female pharaoh Hat, to be a person separate from herself, but instead sees their nightly 'experiments' as a means of rubbing shoulders (or other body parts) with a woman of low birth, believing that she must lack the frigid morality of genteel middle-class ladies on account of her uncouth upbringing. ${ }^{49}$ These 'abandoned' moments also allow him to devise a means of disposing of her, while maintaining his façade of respectability - the "elevated nature of his scientific calling" (Roberts, 98), as his wife calls it - and convincing others (or perhaps even himself) that he is doing the medium a favour. By bringing her to the Salpetrière Hospital run by Dr Charcôt, he seeks to dispose of his affair, have her confined as a mental patient, and gain

${ }^{49}$ This is another example of different Victorian discourses of femininity, and the distinct link between the gender role of the domestic angel and the middle-class. 
scientific prestige by turning his deed into an essay on the connection between spiritualist mediumship and female hysteria. As mentioned before, the sinner/saint dichotomy corresponds closely to the class divide in certain Victorian gender discourses: but if genuine femininity can only be found in "the figure of the perfect Victorian lady, a quiet, delicate, submissive creature" (Owen, 7), then working class women - particularly those who did not fit this bourgeois vision of asexual virtue must be something other than feminine by default. The historical cases of Louisa Lowe and Georgina Weldon (both of whom were part of the middle-class) already showed how deviations from the norm of the domestic angel could be potentially pathologized, yet the implications for the lower strata of Victorian society are even worse than that. In the context of In the Red Kitchen, the very attributes that Sir William Preston projects upon Flora Milk on account of her working class background are the symptoms he cites as a justification for his attempt at having her hospitalized in a mental institution. These traits are not even a part of her social identity, but a performance she put on in order to please him. Her sexuality, her mediumistic practices and her spiritual beliefs are all used against her in order to diagnose her with a mental disease: hysteria. The French psychologist Jean-Martin Charcôt (as the embodiment of the male-dominated natural sciences and their unconscious enmeshment with the dominant patriarchal ideology) is only too willing to support this diagnosis. Unlike the other characters in the novel, Jean-Martin Charcôt is an actual historical person, whose name is only spelled marginally differently in the novel ${ }^{50}$.

[He is the embodiment of one] of the most insidious of institutions - medical practice - that controlled female identity[, which] was legitimised and enshrined in discursive practice by the new science of psychoanalysis, which came to represent a new way of thinking about sexuality (female sexuality in particular) [...] The theories of Jean-Martin Charcôt informed Freud's early work on women and hysteria and, to a degree, challenged the orthodox Victorian psychiatric view that hysteria was simply a physical problem." (Jones, 88)

Charcôt's studies on hysteria may have challenged the ancient belief that the symptoms associated with this particular malady (now long gone from diagnostic manu-

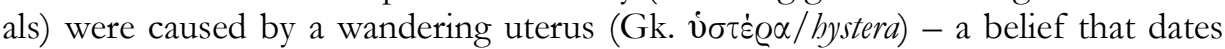
back to Greek antiquity and is attributed to Hippocrates. However, his method of diagnosing the illness were highly dubious, as seen in Roberts's novel: Charcôt hypnotizes Flora, giving her suggestions that encourage her to manifest the symptoms he expects to see in a woman afflicted with this particular mental disease. While

\footnotetext{
${ }^{50}$ Several other characters in the novel were clearly inspired by historical persons, but their names have been slightly modified. Hat King/Hattie corresponds to the female Pharaoh Hatshepsut, Flora Milk is based on the Victorian medium Florence Cook, and William Preston is based on Sir William Crookes, a renowned scientist who vouched for the genuinely preternatural nature of Ms Cook's spirit manifestations. (cf. Kontou, Spiritualism and Women's Writing, 81f.)
} 
William is eager to mislead Flora deliberately by refusing to translate what he explains to be "all technical medical details, too complicated to translate" (Roberts, 124), the French doctor is simply not interested in anything she has to say: "He doesn't want me to speak. He wants me to mime, and the doctors and students will do the guessing" (ibid. 126). She is silenced not only on account of her inability to speak French, but on account of being a woman, whose mental health and identity is circumscribed and defined by the men around her. Unlike these professionals, Flora grasps instinctively that the performance Charcôt stages with his female patients amounts to little more than stage hypnosis, and interprets it all as a sort of circus performance. Her mistranslation of the overheard French words "isterry" and "famm" (ibid., 124) as "female history", the history of Women, conveys an accidental insight that is not lost on the informed reader:

The subversive quality of the incident lies in Flora's unconscious and unintended interpretation of women's history as hyster-y. In one innocent phrase, she lays bare the long-term association between femininity and irrationality made by patriarchal historical accounts, and challenges the persistent cultural association of women and insanity. (Golda-Derejczyk, 55)

In this particular scene, In the Red Kitchen demonstrates how male-centred science and medical practice served as instruments of power, conveniently treating spiritualism (and susceptibility to hypnosis) as a symptom of mental illness. This consolidation of patriarchal power revolves around science, reason, and the 'best interests' of women as determined by men. The attitude of these scientists reflects what Adorno and Horkheimer called the failed "Enlightenment Project": the dream of pure Reason, breeding as many monsters as the sleep of the same. The novel may not assert that spiritualism is a genuine supernatural phenomenon, yet it portrays Flora's 'gift' as something that clearly does not qualify as a mental disease, even if it diverges from the ordinary frame of mind. She is victimized on account of her low social status, her lack of a formal education, her non-normative beliefs, and even her sex. Unlike Georgina Weldon and Louisa Lowe, she has virtually no means of defending herself on the men's terms - yet her unusual insights help her to see through William's deception and escape the danger she is in before she can be hospitalized: Hattie, her spirit guide, becomes the externalized avatar of her anger, an embodiment of all the downtrodden women in the novel.

William's voice is hearty and false. It's the same voice he uses to Minny when barring her from our evening séances. Minny and I are his children, fragile, to be coaxed into sensible behaviour. How much Minny must hate me for what I've done to her. I recognize that, for the first time. Minny's hatred pushes my head round to look at the photographs again. The mad girl in white. But she's not mad, she's angry. (129f.; my emphasis) 
Whereas Flora has been heeding society's expectations of what a woman ought to behave like, 'Hattie' foregoes all passivity and flies into action, fleeing the asylum. It is no coincidence that immediately prior to this, the medium realizes how much she has hurt Minny Preston: the decisive fury manifested by her alter ego is more than just her personal emotive response to the abuse she has suffered at the hands of William and Dr Charcôt. It stems from a sudden realization of her former lover's deception, and through this, of all the degradation and harm a society run by men like him visits upon all women: Flora, Minny, the supposedly insane girl in the photograph, the hypnotized women in Charcôt's demonstration. The difference of class that separates the medium and her condescending patron is negligible in comparison to the gender hierarchy that treats women similarly to children. In this, Roberts's focus is the diametrical opposite of Waters's in Affinity, where a Marxist perspective superseded feminist concerns. The stories of the female narrators in In the Red Kitchen tell histories of subjugated women, brought up to turn upon themselves and each other, becoming active agents in their own oppression. Any impulse that would challenge the gender hierarchy is regarded as pathological, insane, abject. Under the auspices of Victorian patriarchy, any woman who ceases to be quiet, asexual and submissive also stops being a 'real' woman. Just like prostitutes were considered something less-than-women, supposedly adulterated by an altogether unfeminine sex drive, Flora's behaviour is treated as a symptom of mental illness as soon as it clashes with middle-class morality.

During and after her harrowing experiences in Paris, Flora Milk acknowledges that she, not her 'spirit guide', had sexual contact with Sir William, and that the relationship with her male benefactor was exploitative in nature. This could be read as an admission of fraud, or at the very least an acknowledgment of the wholly psychological nature of her altered states of consciousness. If Flora was the one who had illicit sexual contact with her patron, does that mean Hattie is not a ghost, but - to use modern psychological terms - a dissociated aspect of her own personality, probably linked to the sexual abuse she suffered at the hands of her father at an early age? It is a logical conclusion - and yet, Flora's visions apparently do enable her to get in contact with some of the other protagonists, suggesting a preternatural dimension to her mediumship. Thus, reading Flora's abilities as wholly contained within her own psyche rather than as something transcending the boundaries of her personal subconscious might qualify as an unnecessary either/or-categorization: In the Red Kitchen encourages the acceptance of paradox, the acknowledgment that even a self-contradictory narrative may be valid as an expression of a specific subjective narrator's mindscape. In this novel, science is closely associated with patriarchy, and its adherents treat it as a totalizing system that fundamentally 'defines women into submission'. In the Victorian age, scientists have become the arbiters of the maledominated status quo, fulfilling the same role as the Egyptian priests who erased King Hat's very existence from history after her passing. Keeping in mind how the nineteenth century tried to find a scientific basis for its idiosyncratic cultural norms 
(gender roles, colonialism, education), and how the stirring of suppressed female sexuality was classified as a form of mental disease, namely hysteria, it becomes easy to see why science may be part of the problem in the context of this novel, particularly in its Victorian guise. If Flora's subjective experiences do not reflect the male consensus, then - according to the internal logic of the Victorian symbolic order she must be insane or deceptive. Her séances become an expression of mental illness, and her subjective experience of reality is rendered a symptom that needs to be cured, instead of a valid way of perceiving the world.

For the most part, spirituality in general and altered states of consciousness in particular have not had the best of standings in the eyes of Victorian psychiatry and psychology - or even several decades later. Pioneers like Sigmund Freud linked it to neurosis (cf. "Totem und Tabu", to mention a prominent example), arguing that religion itself was little more than a childish, totemistic phase in mankind's collective history, a developmental hiccup that needed to be eventually discarded in order to reach maturity and embrace the light of reason. The problem with this assessment is not necessarily that it interprets the origins and purposes of religion incorrectly: many religious rituals bear a striking resemblance to those enacted by mental patients suffering from obsessive compulsive disorders, and the common image of a monotheistic deity certainly exhibits strong regressive tendencies, allowing the believer to re-create a seemingly secure reality as experienced in his childhood, with an invisible god-parent establishing clear-cut rules and protecting him from harm. Islamic bathroom etiquette (derived from the peculiar habits of the prophet Mohammed), for example, extends to much more than just common-sense rules relating to hygiene and good manners. Several hadith report that the prophet "would enter the toilet with his left foot, and exit with the right foot [and wash himself exclusively] in odd numbers i.e. 1, 3, 5 or 7 times" (Zikr). He'd also recite protective prayers against evil spirits before entering the privy, cover his head, take care not to face away from or towards the Kaaba, and follow several other established patterns (ibid.). While such ritualistic behaviour may just be an expression of deliberate devotional ritual, it clearly resembles the impulses of people who suffer from obsessive-compulsive disorder: accordingly, psychologists like Freud were quick to see the parallels and seize upon them.

What makes this approach so dubious, however, is its totalizing tendency, reducing extremely heterodox socio-cultural phenomena to a one-dimensional scale by viewing it exclusively through the lens of psychopathology. Freud's stance on religion encapsulates the problem of the Enlightenment project and its elective blindness towards its own unconscious underbelly, an equally faith-based scientism exhibiting the same aspects as the religions it condemns. A Dangerous Method by John Kerr illustrates how both Freud and his psychoanalytical society developed strong cultish tendencies, with Freud as a charismatic leader who surrounded himself with malleable sycophants echoing his very sentiment instead of providing constructive criticism. People who deviated from the party line were mercilessly ostracized and 
purged as heretics, as in the case of the falling-out between Sigmund Freud and Carl Gustav Jung. Especially in Freud's later days, his manner of talking about psychoanalysis betrayed a strong sense of mission, a zeal to persevere in opposition to a public that was perceived as a hostile out-group. His commitment to the Enlightenment and his disdain for religion and irrational superstitions did not prevent him from reproducing the very mentality that renders many religious world views toxic. On the contrary, his conviction of his own rationality might have actively blinded him to the unconscious processes that poisoned the Psychoanalytical Society, believing to the end that he was only defending a radically unconventional, but accurate model of the human mind. The personality cult around his own person, the hostility towards dissenters, even the incestuous nature of scientific publications that only sought to echo his own sentiments could all be rationalized away. In light of this, a self-contradictory point of view such as Flora Milk's may be highly preferable to the single-minded, yet narrow perspective of a committed Enlightenmentrationalist. Her séances may be at least partially fraudulent, a means of getting by financially in a society that leaves very few opportunities to a person of her class and gender, yet in the context of this novel, they do convey some deeper insights, both into her own psyche and into the lives of other women.

In neo-Victorian fiction, altered states of mind often serve to allow suppressed material from the psyche to surface, bubbling up from the unconscious. Since the Victorian zeitgeist as portrayed in these texts is so antithetical to the free articulation of non-normative sentiments, it takes such catalysts to bring to the fore what cannot otherwise be expressed. In Flora's case, this is exactly what happens in the Salpetrière in Paris: her sudden insight into the subtle undercurrents of the events that surround her (and her own part in them) takes the shape of visions and externalized images, allowing her to escape and to see through her self-deceptions, if only momentarily.

\subsection{Penny Dreadful: Mediumship as Aberrancy}

A less benevolent outcome of such moments of insight is presented in the second episode ("Séance") of the neo-Victorian television series Penny Dreadful51. During

${ }_{51}$ The series' premise is similar to Alan Moore's The League of Extraordinary Gentlemen, combining several well-known characters from Victorian fiction with original creations, only focusing more strongly on gothic themes and early $20^{\text {th }}$ century horror film adaptations. Its title, an allusion to the cheap literature colloquially known as 'penny dreadfuls', suggests that the show does not take itself seriously at all. However, its take on many classics proves surprisingly astute and true to the spirit of the source material. 
the titular séance, Vanessa Ives, the female protagonist, becomes seemingly possessed by a familiar ghost: Peter Murray, her childhood friend and the son of Sir Malcolm, another lead character. Peter died because his father allowed him to accompany him on an expedition to Africa, even though everyone (Vanessa and Sir Malcolm included) knew that Peter was too physically weak to survive the ordeal (as the audience learns in a later episode). Vanessa talks with the voice of a little child at first, mimicking the innocence and idealism that drove Peter to his doom. Her accusations take the form of a re-creation of the young man's gradual realization that he is dying of dysentery, culminating in his pleas to have a mountain named after him by his venerated father.

The most interesting aspect of this scene - apart from an amazing performance by actress Eva Green - is the fact that it needs not be interpreted as a supernatural event, but may be an expression of Vanessa's suppressed feelings. While the show takes place in a fictional universe where preternatural occurrences are possible or even common, Vanessa's plot line in particular is intensely psychological, playing with the notion that most (or even all) of it may, in fact, just be a product of her mind. As a devout (if unconventional) Catholic, Vanessa knows a thing or two about repression - and her Jungian 'shadow' has grown to tremendous proportions as a result. The trance she enters allows her to voice feelings of rage and disgust at Sir Malcolm, the man who signed his own son's death sentence by taking the young man on an expedition to Africa. As she recounts Peter's ignoble death of dysentery, his forgotten corpse in an unmarked grave, and the fact that his father did not even grant him his dying wish, Vanessa unleashes all her pent-up anger. Such an overt expression of rage, however, is utterly at odds with Victorian notions of genteel femininity. A woman shaming a gentleman in front of a semi-public audience would be utterly anathema even if Vanessa did not deliver her message in a manner that suggested demonic possession. Indeed, her behaviour is so far removed from the culturally acceptable that the only way for any onlooker to rationalize it would be either in terms of mental disease or preternatural evil. It is not a cathartic experience for anyone involved: her words are hurtful, traumatizing, and cruel. They contribute nothing to the resolution of the conflicts that have been brought to the fore, but only put a strain on the relationship between the protagonists. Even as a parlour game, the séance in the scene carries the atmosphere of an illicit pleasure embraced by a decadent high society in search of forbidden titillation. But with Vanessa's lapse into possession, it becomes a genuinely horrific transgression of social boundaries that elicits responses of horror and disgust instead of risqué pleasure.

A later episode ("Closer than Sisters") reveals that Vanessa not only feels partially responsible for the fate of Peter: she bears an even stronger sense of guilt in relation to Sir Malcolm's daughter Mina Murray, and his pain and culpability are only a mirror for the troubled medium's own. Vanessa does not experience this surfacing of suppressed material as liberating: she escapes the building in a state of shock, fearing the loss of control that the ritual has induced in her. As a faithful 
Catholic and a Victorian upper middle-class lady, Vanessa has been brought up to regard herself as her worst enemy, who needs to be kept in check by religious observances and sheer willpower. Her sense of guilt plays a significant part in her lapses into darkness, yet also contributes to her ability to withstand it.

Penny Dreadful seizes upon Victorian notions of society as a force for penning in mankind's most destructive impulses, and nowhere does this become more apparent than in the female lead character, who - unlike many others on the show - is a wholly original creation. Vanessa is a prime example of a woman whose Victorian socialization has allowed her darker, repressed aspects to fester in the unconscious recesses of her mind. The séance brings her into contact with a side of herself that she desperately tries to rein in with fervent Catholic prayers and a tendency to look at herself with utter loathing. The series is brimming with supernatural elements and yet, Vanessa's troubles are presented in a way that always leaves room for a more mundane interpretation of the events at hand, locating the source of her troubles within rather than without. The séance takes place at a time when the audience knows virtually nothing about either Vanessa Ives or Sir Malcolm, so her shocking display of spirit-possession serves as a first hint of both of their backstories, as well as their connection to each other.

Spiritualism brings truths to the fore that cannot be uttered in a fully lighted room filled with members of polite Victorian society. It confronts Sir Malcolm with his shame, with the futility of his life's work in the face of his son's premature demise and his inability to make amends for it. Yet this unexpected explosion of suppressed feelings also renders Vanessa abject to society, as the other guests are visibly horrified by her display and the host later comments that he does not intend to invite her back.

Following the premise of a shared fictional universe incorporating separate Victorian primary texts, Vanessa Ives's (and, by extension, Sir Malcolm Murray's) character arc is based on Bram Stoker's Dracula. But it is not so much a straightforward adaptation of the source material as a contemporary response to the sexual morality and the conception of femininity put forward in Stoker's text. Spiritualism does not play a prominent part in the episode that establishes the closest ties to this literary (and, in relation to the composition of some scenes, also cinematic ${ }^{52}$ ) source, "Closer Than Sisters", yet the unconscious and the suppressed are of utmost importance in its context, and set the scene for Vanessa's mediumistic activities.

Bram Stoker's Dracula is fraught with late Victorian anxieties, specifically in relation to reverse colonization and unrestrained (female) sexuality. These two issues are inextricably linked, as the British Gothic tradition juxtaposes English self-control and civilization with the loose morals of the continent and even more savage

52 A key scene takes place in a hedge maze, where young Vanessa witnesses a secret rendezvous between Sir Malcolm and her mother. These visual cues are an obvious homage to Francis Ford Coppola's 1992 film Bram Stoker's Dracula, where Mina Murray stumbles upon a similar sexual encounter between her friend Lucy and the bestial count Dracula. 
parts of the world. The novel opens with Harker's observation that he left the West behind as soon as his train departed Budapest, suggesting that whatever awaits him further east is part of a barbaric sphere: "The impression I had was that we were leaving the West and entering the East; the most Western of splendid bridges over the Danube, which is here of noble width and depth, took us among the traditions of Turkish rule" (Stoker, 9). The Orient is clearly conceived as alien and potentially hostile here, with the historical trauma of the Ottoman Empire's military expansionism still firmly remembered. But at least equally important as the factor of cultural 'otherness' is the issue of gender. It is not a coincidence that the narrator's first glimpse of true monstrosity takes the shape of three sensuous female vampires in an erotically charged setting. Nor is it accidental or inconsequential that these vampiric brides remain nameless monsters whose sole character trait is their unshackled sexuality. Time and again, the novel establishes female sexuality as "the devil's gateway" (to quote the church father Tertullian on the matter of women and their supposed wiles). Indeed, the suppression of female sexuality was one of the well-nigh universal cultural constants throughout the agrarian age, and a cornerstone of traditional patriarchy. Dracula does not seek to conquer England by brute force, but by corrupting its prim morals from within, targeting those who come closest to the supposedly child-like savages of the east - English women:

His female victims - Lucy Westenrae and Mina Harker nee Murray - serve as foils for each other, embodying the degenerate morals of the rich upper class and the proper conduct of the middle-class, respectively. The message sent by the novel is clear: Lucy betrays her lack of moral fibre early on in the novel, as she allows three men to court her simultaneously, and seems positively eager for Dracula's corrupting influence when he starts to stalk her. Therefore, she must fall and has to die. In sharp contrast to this, Mina Murray is such a prim person that she cannot even stand the thought of having her bare feet seen in public, coating them with mud to make the bare skin less visible in the darkness. When the vampiric count finally assaults and contaminates her, she recoils from her own spiritual and sexual corruption ("Unclean, unclean!" (Stoker,339)), and perseveres on account of her staunchly Victorian morality.

Penny Dreadful seizes upon motifs and characters from the novel, but gives them an entirely different spin. There are still two female characters who serve as foils for each other, but the dynamic between these two differs considerably from Stoker's original. Mina Murray remains comparatively unchanged as far as her character traits are concerned, but she and Vanessa Ives are no longer representatives of different classes and their respective moralities. Vanessa's parents and the Murrays are neighbours of equal social standing, the only (significant) difference between the two being their religion: the Ives family is Catholic, instantly linking them to the British Gothic tradition. Even without her other traits, this distinct 'otherness' marks Vanessa as potentially abject. 
More important to this chapter, however, is the repressed darker side with its occult powers that is simmering under the surface of Vanessa's mind, who - reminiscing over her childhood - finds that it had always been a part of her. She is no meek and proper middle-class maiden, even if she would clearly prefer to be. In the first flashback scene of the episode "Closer Than Sisters", we see her urging her friend Mina to swim out into the ocean as far as they can go, revealing a dark and potentially self-destructive streak in her personality. Vanessa likens the prospect of the beckoning sea to "a witch's spell", thereby betraying a deep fascination with the forbidden and the obscure. This obsession of hers becomes even more pronounced when she discovers that her mother has been pursuing an illicit affair with Mina's father, Sir Malcolm: Watching those two have sex in a hedge maze reminiscent of Francis Ford Coppola's 1991 film Bram Stoker's Dracula, Vanessa feels that she has partaken of a hidden world: "more than the shock, the sinfulness, was this: I enjoyed it." The event marks a sexual awakening, as well as a progression into adulthood. Whereas Mina remains childlike and angelic in her innocence (at least to the knowledge of Vanessa), the young Miss Ives feels permanently transformed by this sudden revelation of a whole world hidden behind propriety and custom.

Unlike her friend Mina, who seems content with the superficial surface of polite Victorian society, Vanessa is elated by the discovery of a darker, seedier reality manifesting underneath - and simultaneously feels an immense sense of guilt and shame. This powerful ambivalence is the key to her bouts of destructive 'demonic possession', as manifested during the séance in episode two. The potentially supernatural (and almost certainly malevolent) abilities exhibited by Vanessa are also strongly linked to her repressed sexuality. In "Closer than Sisters", giving in to the temptations of a sinister spirit appearing to her in the shape is Sir Malcolm not only restores her to normal health after a lobotomy had previously reduced her to a bedridden cripple: it is also portrayed as a sexual consummation with an invisible partner. Likewise, the episode "Possession" links her state of being inhabited by an evil spirit to her dalliance with Dorian Grey: her uninhibited state of sexual pleasure results in a horrid transformation that can only be ended by an exorcism. Vanessa's aggressive outbursts and sexuality stand in sharp contrast to her public persona and her penchant for fervent Catholic prayers. Ultimately, she seems to be at war with herself, having denied her supposedly 'filthy' instincts for so long that they've become part of a darker personality hiding within her psyche.

This new interpretation of Dracula's morality regarding female sexuality differs significantly from the original novel's, yet it also stays true to the spirit of its source material by creating a $21^{\text {st }}$ century equivalent to Stoker's underlying message. The conflict no longer focuses on English frigidity as a bastion against Oriental lewdness, but on the protective function of socialization against the destructive, unconscious impulses lurking within each individual. It is hardly a coincidence that Vanessa's second bout of possession occurs not during another séance, but after engaging in passionate sex with Dorian Grey. She could not possibly deviate further 
from the staunch Catholic morality of her upbringing: after all, the Church holds to this day that sexual intercourse is only permissible under the sacrament of marriage, and then only sparingly, for the purpose of begetting children. Pope John Paul II. stated in a General Audience in 1984:

At the center of the spirituality of marriage, therefore, there lies chastity not only as a moral virtue (formed by love), but likewise as a virtue connected with the gifts of the Holy Spirit—above all, the gift of respect for what comes from God (donum pietatis). This gift is in the mind of the author of the Ephesians when he exhorts married couples to "defer to one another out of reverence for Christ" (Eph 5:21). So the interior order of married life, which enables the manifestations of affection to develop according to their right proportion and meaning, is a fruit not only of the virtue which the couple practice, but also of the gifts of the Holy Spirit with which they cooperate. (emphasis added)

In Penny Dreadful, however, morality is not a sufficient safeguard against the monsters that lurk within and without. Vanessa's Catholic fervour does not starve out her suppressed darker side - it seems to render it more powerful in the long run. Even more tellingly is the fate of Mina Murray: unlike her best friend Vanessa, she feels perfectly at home within the confines of Victorian domesticity. She does not break the rules, she is alienated by her friend's 'un-English' religion (as demonstrated in the flashback scenes from "Closer than Sisters), and she shows not the slightest interest in (or knowledge of) the occult side of human nature. Yet she is the one who becomes the vampire's bride, a creature of darkness who seeks to lure Vanessa to her doom. Throughout the first season of Penny Dreadful, the protagonists operate under the misconception that Sir Malcolm Murray's daughter is still holding on to her human self, and tries to call for help by contacting her mediumistic friend Vanessa. Yet gradually, they start to grasp that it is a deliberate ruse designed to lure Vanessa to her doom (and into the arms of the unnamed master behind the scenes, who has yet to be identified as Count Dracula). "Grand Guignol", the concluding episode of Penny Dreadful's first season, reveals the formerly angelic Mina to be an utterly inhuman creature that revels in her own damned state - not quite unlike Lucy Westenrae in Stoker's novel: her staunch middle-class morality did nothing to save her, while her cultivated ignorance of the darker sides of mankind rendered her vulnerable to the depredations of her sinister master.

Vanessa and Mina are juxtaposed both in terms of character and in terms of their colour scheme, with the blonde Mina always appearing in light tones and the raven-haired Vanessa preferring darker shades. This suggests a strong opposition between the two characters, yet by the time the audience meets these characters in the series, their contrast does no longer correspond with the usual associations. Mina is no longer an innocent middle-class maiden, but a ravenous vampire used as bait for the mediumistic Vanessa. And even before Miss Murray's sinister 
transformation, she had already lost her naiveté, because her best friend Vanessa had betrayed her by seducing Mina's fiancé on the night before their wedding (cf. "Closer than Sisters"). As a transformed thrall, Sir Malcolm's daughter revels in her sinister freedom, scoffing at the morality embraced by ordinary mortals and perceiving them as a weakness.

Vanessa, by contrast, abhors the monstrous side that surfaces when she uses her mediumistic talents, and is driven by feelings of guilt and self-loathing. For her, the freedom granted by séances and spirit-possession is no freedom at all: even if it may allow her to vent her feelings outside of the confines of middle-class propriety, the experience strikes her as destructive rather than liberating. Vanessa knows the darkness within and without, and it is this knowledge that allows her to escape its lure at several points in the series. She may consider these aspects of her life a source of shame and terror, yet they also provide a valuable tool in combating the forces of evil - just like Mina Harker's corruption in Stoker's Dracula.

Accordingly, it could be argued that the morality communicated by Penny Dreadful is surprisingly reactionary. Indeed, this impression is affirmed by the series' second season, which introduces a coven of witches as the primary antagonist. These witches (who are led by the medium who helmed the aforementioned séance in the previous season) subvert the Victorian power structure by corrupting male authorities and manipulating them into doing their bidding: a highly problematic portrayal of female power that draws upon misogynist stereotypes. This impression is exacerbated by the character of Dr Frankenstein's 'bride', who is characterized as a psychopathic monster along the same lines as Dorian Grey, because she no longer feels constrained by the gender roles projected upon her. Woman, freed from the constraints placed upon her by society, becomes a monster that needs to be stopped or killed.

Yet at closer view, matters are decidedly more ambivalent than they appear at first glance. Vanessa Ives does not persist due to acts of submission to male authority or societal mores in either season, nor does the show's version of Mina Murray become an undead monster because she is a 'fallen' woman: comparing the fictional biographies of both of these characters, it is abundantly clear that Vanessa is more at odds with Victorian middle-class conceptions of genteel femininity than her friend and neighbour. The young Miss Ives seduces Mina's fiancé mere hours before the wedding - an act that would surely have necessitated her downfall and death in a piece of authentic Victorian fiction. Vanessa's resistance to the sinister forces trying to seduce her, on the other hand, stem directly from her painful knowledge of the world's less wholesome aspects. This contrast between the 'pure' Mina who is turned into a monster and the 'fallen' woman whose occult powers and carnal knowledge do not prevent her from resisting the pull of destructive forces is visually brought to the fore in the flashback episode "Closer than Sisters": the two women (seemingly) meet on the beach where the audience first saw them together as young girls. The dark-haired Vanessa is clad in black, while the blonde Mina 
appears entirely in white. Western colour symbolism immediately attaches specific meaning to this colour coding, characterizing Miss Ives as evil (or at the very least dubious), and Miss Murray as good (or innocent). Since their friendship was destroyed by Vanessa's betrayal, the viewers are quite likely to interpret the scene in such a fashion, yet its culmination betrays this as a filmic sleight-of-hand. At this point of the story, Mina has already become a creature of darkness, and Vanessa only perceives her as a vision due to her mediumistic talents. Vanessa Ives's resistance to the dark (male) master behind Mina relies on her knowledge of evil, and it is only her 'fall' which enables her to retain self-control at critical points in the narrative. Mina Murray lacked these qualities on account of her ladylike purity, and thus became the vampire's thrall. In short, Penny Dreadful inverts Bram Stoker's underlying theme of female 'virtue' as the safeguard against a reverse colonization, and instead establishes Vanessa Ives as a heroine who persists not in spite, but because of her outcast status and her occult powers. Penny Dreadful thereby sends a mixed message that negates some of the gender ideology underlying its source text Dracula, yet does not necessarily replace it with a genuine feminist message. The fallen woman - here represented by an abandoned, monstrous Mina Murray - still has to die, while only those who subject themselves to a strict morality and repress their desires get to survive. In this, the series' first season ends on a note that comes surprisingly close to the ideology underlying Bram Stoker's novel. The one motif that ties all of Penny Dreadfuls narrative strands together is the need to overcome base urges through self-restraint, be it in the case of Vanessa Ives's demonic possession (after engaging in sexual relations with Dorian Grey), the American werewolf Ethan Chandler (whose murderous, bestial side lacks any self-control), or even Dr Frankenstein (whose curiosity and need to create gives birth to literal monsters). This praise for the virtue of the norm(al) does not feel out of place in a Victorian setting, but it is equally at home in contemporary society: in spite of the post-modern era's sense of disconnectedness from the past, Western culture stands in unbroken continuity with a tradition that defined blatant deviation not only as a form of (mental) illness, but as moral failure. In fact, following Foucault, these two concepts might be closely linked: Identifying mental illness as a process of diseased minds rather than the result of external factors such as vapours or evil spirits "gives madness a new content of guilt, of moral sanction, of just punishment" (Madness and Civilization, 158). Foucault's controversial thesis sees modern psychiatry as little different from the abuses of mental health institutions in the Soviet Union during the 1950s:

Soviet psychiatrists of the 1950s disgracefully organized themselves into the medical arm of the Gulag state. Political dissidence became prima facie evidence of impaired reality testing, of "sluggish schizophrenia." We like to believe in the benefits of scientific progress, but for Soviet inmates, progress was prefixed with a minus sign; every apparent advance in psychiatric technology left them more tightly controlled and worse off. (Lakritz) 
It is this underlying need to purify, to purge and obliterate the abnormal elements within our respective societies, that lie at the heart of the subject-abject-relation. Yet any attempt at ridding ourselves of that which is 'abject' within our respective cultures tends to produce eminently negative results. Alan Moore's From Hell depicts just such an attempt at purification, and its consequences turn out to be anything but constructive, as the following chapter will demonstrate. 


\section{Conclusion: Abject Mirrors}

"It is beginning, Netley. Only just beginning. For better or worse, the twentieth century. I have delivered it." - "Dr. William Gull/Jack the Ripper" in Alan Moore's From Hell

This cryptic line, delivered by fictionalized serial killer Jack the Ripper, may seem virtually inexplicable at first glance, even within its literary context. Uttered in the wake of a gruesome murder, there is nothing in the deed that would signify connection to future events at first glance. And yet, this utterance not only holds the key to Moore's graphic novel From Hell, but also encompasses and summarizes the underlying hypothesis of this study (as the following chapter will demonstrate).

Collective cultural identities are constructed along similar lines as individual identity constructs, and in both cases, the unresolved inconsistencies, repressed issues, and internal paradoxes worry at the notion of a monolithic 'self like a sore tooth. These abjects, which are neither 'I' nor 'other', need to be purged or resolved in some fashion, and neo-Victorian fiction achieves this in relation to societal areas of conflict the contemporary era inherited from the past. This is why issues like gender roles and sexuality are featured more prominently in this sub-genre than Victorian foreign trade policy, for example. The Victorians, due to their place within history, have become our symbolic immediate ancestors: theirs was a culture transformed by industrialization, subject to all the pivotal social and technological changes that would usher in (post-) modernity. If the whole of the Victorian era is 
a historical mirror for the present, then the 1880s are indeed the birthplace of the twentieth century, as Alan Moore points out in the appendix to From Hell:

In 1880, both Joseph Swan and Thomas Edison independently produced a practical electric light bulb, and a year later, in 1881, The electric tram first ran in Berlin. Cell division was first described by the German anatomist, Walther Fleming, in 1882, while between 1881 and 1885, Pasteur used attenuated bacteria to confer immunity to anthrax and rabies. In 1884, H C Maxim invented the steam turbine. Karl Benz, a German engineer, invented the motor car in 1885. Two years later, in 1887, radio waves were produced for the first time by Heinrich Hertz. Perhaps most ominously, in 1881, American physicists Albert Michelson and Edward Morley proved that aether did not exist, a discovery which was to lead to the theory of relativity and thus, inexorably, towards Hiroshima.

Things would seem to have been just as turbulent on the political front. Aside from the Mahdi uprisings, which represent the modern western world's first confrontation with the world of Islam, there were various other events that would have serious repercussions in our own twentieth century. In 1884, France took Indochina, arguably the first in a sequence of events culminating in the Vietnam war. The same year, in Prussia, the Zionist movement held its first conference, while throughout the decade anti-semitism became popular throughout Europe, particularly following the publication of Edouard Drumont's La France Juive in 1886... [The] problems between England and Ireland were accentuated throughout the decade by England's continuing refusal to grant Ireland home rule, along with the subsequent Fenian bombings in both England and Ireland. In many ways, it seems to me that the $1880 \mathrm{~s}$ embody the essence of the twentieth century, not only in terms of politics and technology, but also in the fields of art and philosophy as well. The suggestion that the 1880s embody the essence of the twentieth century, along with the attendant notion that the Whitechapel murders embody the essence of the 1880s, is central to From Hell, and we shall no doubt return to it later in this appendix. (I, 13f.)

Moore's list of scientific discoveries, technological inventions, and socio-political events is already quite voluminous, but by no means exhaustive. It would defeat the purpose of this chapter to amass a complete list of developments, but it may be prudent to reference some critical points relevant to the abjects discussed previously: Richard Freiherr von Krafft-Ebing's Psychopathia Sexualis (which was most influential in establishing the term 'homosexual') was published in 1886 - one year after the passing of the Labouchere amendment, which made it easier for British authorities to persecute homosexual men. On the other hand, the Criminal Law Amendment Act 1885, which preceded the aforementioned section with its criminalization of homosexual 'gross indecency', addressed some relevant issues in relation 
to human trafficking, prostitution, and women's rights, signifying some small improvement over the previous status quo.

The year 1887 marked the founding of the Society for Psychical Research (SPR), a non-profit organization dedicated to studying, evaluating, and potentially defrauding preternatural phenomena such as the ones associated with Spiritualism and mediumship. One of its earliest members, the author Sir Arthur Conan Doyle, would later become a firm believer in séances, as did some other notable scientists of the late 1800s. Yet on a larger scale, the SPR accelerated Spiritualism's eventual decline by exposing more and more phenomena as nothing more than parlour tricks. While the spiritualist movement's star was waning, however, other forms of occultism (or the Western esoteric tradition) blossomed throughout the decade: London's Isis-Urania Temple was founded in 1888 by the Hermetic Order of the Golden Dawn, a secret society devoted to the study of ritual magic. Unlike Freemasonry (which drew upon similar roots), the Golden Dawn was explicitly open to members of both sexes (cf. King, 35), continuing the trend of female emancipation shared by other 'occult' movements of the day ${ }^{53}$. As mentioned in chapter six, occultist groups such as these perceived themselves as part of the avant-garde, bridging the gap between religion and science and promoting a synthesis that reconciled the Enlightenment with spirituality. But seen from the outside, they were mostly regarded as abject. Charles Webb's assessment in the early 1970s mirrors the position held by the societal mainstream, in the 1880s as well as later:

Das Okkulte ist verworfenes Wissen. Es kann Wissen sein, das von der herrschenden Kultur aktiv verworfen wurde, oder Wissen, das sich freiwillig von den Gunstbezeugungen seiner Zeit zurückgezogen hat, weil es erkannt hat, dass es mit der herrschenden Lehre nicht vereinbar ist. Der Begriff „okkult“ bedeutet ,verborgen“, und in dieser Vorstellung liegt der Schlüssel zu dem bedrohlichen Erscheinungsbild des Okkulten ${ }^{54}$. (Webb, 309; emphasis in original)

Christian churches employ the term 'occult' to this day to denounce specific practices, phenomena, or movements as potentially dangerous and malignant, while scientifically minded individuals would condemn the same as eminently irrational beliefs which are antithetical to a culture governed by knowledge and reason. In short,

${ }^{53}$ Moore seizes upon the Order's egalitarianism by depicting a confrontation between the misogynist Sir William Gull/Jack the Ripper and the poet and Golden Dawn member William Butler Yeats, whom Gull addresses specifically to voice his disdain: "You are but a splinter, split from the bough of Masonry... no longer nourished by its truth nor anchored by the roots of its tradition, soon to wither." (From Hell, ch.9, 15)

54 "The Occult is discarded knowledge. It can be knowledge that has been actively dismissed by dominant culture, or knowledge that has voluntarily withdrawn from the appreciation of its era because it has realized that it is incompatible with the dominant ideology. The term "occult" means "hidden", and in this image lies the key to the occult's sinister appearance." (my translation) 
occultism (as a phenomenon that exists within Western culture but without the range of the commonly acceptable) is a typical example of a cultural abject.

Sir William Gull in Alan Moore's From Hell is indubitably identified as an occultist steeped in masonic lore, but he also perceives himself as an agent of Reason defending the rule of Man (as the embodiment of rational thought) against Woman (as the embodiment of the unconscious). His intentions are revealed in an extended tour of London, where he explains the mythical history attached to certain land marks and locations in the city while simultaneously unveiling the logic behind the murders he is about to commit.

Sometimes an act of social magic's NECESSARY; man's triumph over woman's INSECURE, the dust of history not yet SET'TLED. Changing times erase the pattern that constrains society's irrational, female side. Our workers, lately given VOTES, now talk of SOCIALISM, talk of RIGHTS, riot in Trafalgar Square and won't quit 'til they are shot, whereon their fury DOUBLES! King Mob's clamour drowns out Apollonian debates. Reason BESIEGED: For all our science we are become an age of table rappers, tealeaf readers and Theosophists [...] The séance parlour's murmurings; the gutters' pandemonium... these threaten Rationality itself. Our Suffragettes demand that women vote, and have equality! They'd drag us back to that primordial nursery, the rule of instinct and the tyranny of mother's milk! We can't have that. (From Hell, 4:30; emphasis in original)

Unlike most other fictionalizations of the Whitechapel murders, Moore's From Hell does not follow the conventions of crime fiction; its choice of the murderer's identity is loosely based on the so-called 'royal conspiracy hypothesis' first suggested by Stephen Knight in Jack the Ripper: The Final Solution. It is a rather spurious proposition involving a secret wedding between Prince Albert Victor and a Catholic working class girl, a blackmail attempt by the bride's friends, and political murders that were made to look like the work of a madman. While not a very plausible scenario in terms of historical veracity, it is apparently well-suited for fictionalizations of the case, if the numerous novels based on Knight's book are any indication ${ }^{55}$. For Alan Moore (and his version of Sir William Gull), however, the Royal conspiracy is little more than a pretext. The graphic novel's focus does not lie so much on following the (fruitless) investigation or spinning conspiracy theories, but on drawing a portrait of the culture that gave rise to such monstrous deeds, and the consequences these implied for a future whose roots lie in this particular era. Moore's Jack the Ripper is the incarnation of Victorianism's shadow archetype, the ugliness boiling under the surface not in spite, but because of the dream of Reason and everything it brought to the table of Western civilization. In Gull's mind, the murder of the blackmailing prostitutes is not so much an act of political expedience as of symbolic

55 Fictionalizations include novels such as Anne Perry's The Whitechapel Conspiracy or Robin Paige's Death at Whitechapel, as well as at least one play (Doug Lucie's Force and Hypocrisy). 
ritual: an educational, instructive act that signifies the triumph of logic over irrationality in the same way as the slaying of the chaos goddess Tiamat at the hands of Marduk in Babylonian mythology did ${ }^{56}$. A Jungian reading of this type of myth interprets it as follows:

In the fight with the dragon the hero battles the regressive forces of the unconscious which threaten to swallow the individuating ego. The forces, personified in figures like Circe, Kali, medusa, sea serpents, Minotaur, or Gorgon, represent the Terrible side of the Great Mother. The Hero may voluntarily submit to being swallowed by the monster, or to a conscious descent into Hades so as to vanquish the forces of darkness. This mortifying descent into the abyss, the sea, the dark cave, or the underworld in order to be reborn to a new identity expresses the symbolism of the night-sea journey through the uterine belly of the monster. It is a fundamental theme in mythology the world over - that of death and rebirth. All initiatory rituals involve this basic archetypal pattern through which the old order and early infantile attachments must die and a more mature and productive life be born in their place. (Kalsched \& Jones)

In Moore's interpretation, this initiation takes an infinitely darker turn, even though it is carried out in the same spirit. Dr Gull is a man of science, a firm believer in progress and rationality, and his actions embody the darker, repressed side of the age of Enlightenment - the same spirit that gives birth to the industrialized efficiency of Nazi death camps or the cold logic behind weapons of mass destruction. In this light, Gull's comment regarding the birth of the twentieth century becomes clearer: Gull achieves almost exactly what he set out to do, but it is not necessarily what he anticipated. During his final murder, he catches a more thorough glimpse of the future he helped to create, and is horrified by what he witnesses: the cold, passionless drudgery of a late twentieth century office, filled with technological marvels that fail to excite the yuppie employees using and operating them.

Where comes this dullness in your eyes? How has your century numbed you so? Shall man be given marvels only when he is beyond all wonder? [...] With all your shimmering numbers and your lights, think not to be inured to history. Its black root succours you. It is INSIDE you. [...] You are the sum of all preceding you, yet seem indifferent to yourselves. A culture grown disinterested, even in its own abysmal wounds. [...] How would I seem to you? Some antique fiend or penny dreadful horror, yet you frighten me. You have not [sic] souls. With you, I am alone. (From Hell, 10:21f.; emphasis in original)

${ }^{56}$ Gull's hallucinations upon murdering the prostitute he believes to be Mary Kelly turn him momentarily into a representation of the Babylonian deity, while his victim becomes the slain dragon. (cf. From Hell, 10: 19) 
Sir William Gull's protests remain unheard, nor does his belated insight cause him to consider his deeds in a different light. Yet this future he witnesses is born of the very spirit he wanted to promote through his misogynistic ritual murders: he has symbolically slain the unconscious in the name of reason and individuation, and the resulting culture embraces an almost sociopathic atomist individualism. Gull sought to ritually slay the Dionysian aspects of existence - and has seemingly succeeded, to his own horror. Margaret Thatcher's invocation of (supposedly) Victorian values created an icy socio-cultural climate in Great Britain, and From Hell (whose first volumes were published in the late 1980s) comments upon the latter half of Thatcher's years as prime minister. In this, Moore echoes the central thesis of Adorno's and Horkheimer's Dialektik der Aufklärung, perceiving the age of Enlightenment as a failure that results in a new kind of barbarism. The cultural pessimism of the Frankfurt school was largely motivated by the events of the first half of the twentieth century, when Western civilization spiralled into two world wars and ended up embracing authoritarian ideologies like Stalinism, fascism, or national socialism. But it was in the waning years of the twentieth century that Adorno's and Horkheimer's assessment finally culminated in what neo-conservative thinkers like Francis Fukuyama positively lauded as The End of History and the ultimate triumph of capitalism. In Dialektik der Aufklärung, this phenomenon is regarded as a symptom of doom rather than victory:

Der mythische wissenschaftliche Respekt der Völker vor dem Gegebenen, das sie doch immerzu schaffen, wird schließlich selbst zur positiven Tatsache, zur Zwingburg, der gegenüber noch die revolutionäre Phantasie sich als Utopismus vor sich selber schämt und zum fügsamen Vertrauen auf die objektive Tendenz der Geschichte entartet ${ }^{57}$. (Adorno, 48)

The inability to even conceptualize an alternative to the status quo is symptomatic of the ideological foundation of late capitalism now commonly called neoliberalism. Proponents of a globalization that expands the power of the economically privileged (banks, corporations, etc.) at the cost of worker's rights, environmental protection, and consumer's rights commonly use a terminology that conceives of their reforms as a type of natural law: an inevitability that can be no more opposed than the seasons or the tides. This kind of thinking was present in the cold war dichotomy of East vs. West as well, since both ideologies painted their goals in terms of a historical determinism rooted in the Enlightenment. Both systems were descendants of the cult of Reason, and inherited its more problematic aspects, yet the collapse of the Soviet Union created the temporary impression that the failure of one system proved the other right. Twenty years later, a global financial crisis, a widening

57 'The people's mythical academic respect for the given, which they create incessantly, becomes a positive fact in itself, a stronghold, against which revolutionary fantasy cowers in shame at its own utopianism and degenerates into docile faith in the objective tendency of history." (my translation) 
gulf between the wealthy elite and the average citizen, the rise of a new right-wing populism, and - last but not least - anthropogenic global warning, deforestation and environmental degradation (which remain unresolved in spite of some lacklustre agreements on the international stage) have all but dispelled this notion of a positive free market utopia characterized by individual liberty and prosperity, yet the notion that no alternative is even thinkable remains strong.

Sir William Gull's speech (and Adorno's analysis) touches upon ideological foundations that made this supposed 'end of history' possible: In denying, demonizing, and repressing the unconscious and the mythical, the age of Enlightenment and its heirs became oblivious to their own blind spots and subconscious elements, basically turning Reason into a myth that could not be denied or contested. To deny the dominant ideology would be the equivalent of denying Reason, and such an act could only be committed by fools and madmen. This attitude is underlying Dr Gull's ritualized murders in From Hell, striving to preserve the Victorian patriarchy as the embodiment of the Enlightenment. Yet the Ripper's actions create a cultural climate that produces worse things than just post-modern ennui. The dream of Reason gives birth to monsters that are every bit as gruesome as those produced by its sleep, and Jack the Ripper is one of them. He becomes an avatar of his culture's darkest aspects, the incarnation of the Victorian age's most sinister Jungian shadow. From Hell illustrates the misogynist violence boiling just under the surface of Victorian society by showing how several people delight in writing letters in which they assume the identity of Jack the Ripper before sending them to the police or press. They are men from all ages and classes, delighting in the illicit pleasure of becoming 'Jack the Ripper' in spirit and committing their fantasies of violence against women to paper (cf. From Hell, 9:36). 'Jack' has already started to become a myth, an archetype who persists in the collective imagination, and whom people evoke to give voice to their own repressed darkness. Paul Begg notes how shortly after the actual events, the Ripper underwent a "strange transformation from real life murderer to... ultimate representation of human evil, a 'lurker in the shadows', the personification of the feared and the unknown" (XI). This figure apparently held an enormous appeal for many, if the faux letters delivered to newspapers and the police in 1888 are any indication.

Moore uses the events surrounding the Ripper case to establish a link to another pivotal historical event: chapter five of the graphic novel opens with a vision visited upon the Austrian Klara Hitler (during the conception of her son Adolf, no less), who sees the doors of Hawksmoor's distinctive St. Giles church break open in a flood of blood that swallows the Jewish people who pass it by and carries them away. Alois Hitler tries to reassure his wife that it was but a nightmare, telling her that everything is going to be fine now - while the image zooms in on Klara's stomach, hinting at the pregnancy that will culminate in the birth of Adolf Hitler and hence, the holocaust (cf. From Hell, 5:2). Once more, the link between the Jewish genocide and the Ripper murders appears to be flimsy at best, and downright 
spurious at worst at first glance. Yet the graphic novel may actually impart a relevant point even beyond what Moore himself asserts in the novel's appendix:

The rationale behind the scene presented here is the somewhat resonant chronological coincidence that links the onset of the Whitechapel murders with the conception of Adolf Hitler. Born in April 1889, simple arithmetic places Hitler's conception some time around the July or August of the previous year. For obvious reasons, I've chosen August, in order to present the striking juxtaposition of a sudden inexplicable wash of blood occurring in one of the world's most populous Jewish quarters at almost the precise moment that the future Reich-Chancellor fused into being from the no doubt splendid genetic material of his mother and father. (From Hell, I:18)

Moore's inspiration as described here is a typical case of Jungian synchronicity, i.e. a series of seemingly coincidental events with no causal link that are nevertheless meaningfully connected (in the mind of an individual). But the association fits the underlying theme of establishing the 1880s as the spiritual birthplace of the twentieth century: antisemitism had been an abject undercurrent in European culture for more than a millennium, but the waning years of the Victorian era saw a new quality of hatred arising within Western societies. Pseudo-scientific racism and nationalist ideologies imbued hatred against Jews and other ethnic minorities with qualities that had been missing from the primarily socio-religious animosities of previous eras. Before, the offending otherness of minorities was located in their refusal to become a part of mainstream culture and their insistence to hold on to their own religious and ethnic identity; but in light of racist hypotheses, even assimilation was no longer an option, or could even be held against these groups. At the onset of the historical Jack the Ripper-case, the London public was quick to suggest a Jew was responsible for the grisly murders - a detail that also makes an appearance in Moore's fictionalized version. ${ }^{58}$ Apparently, anti-Semitic sentiment was rising high in Whitechapel, even leading to demonstrations in the streets (cf. Begg, 157). This smouldering, irrational hatred could not only be felt in London's slums, but was soon to manifest in other parts of Europe as well: Following the assassination of Tsar Alexander II, a wave of pogroms swept the Russian empire between 1881 and 1884 as the Jewish minority was blamed for the murder. Over the course of the next twenty years (which included an even more violent series of Russian pogroms between 1903 and 1906), up to two million Jews fled Russia and sought refuge in Western countries, erroneously believing that xenophobic animosities and anti-Semitic tendencies would be less pronounced there. 1894 would see the French Dreyfus affair (where an assimilated Jewish officer was falsely condemned on account of his ethnic

\footnotetext{
${ }^{58}$ Following the murder of Mary Ann Nicholls, the first victim, the press attributed the crime to a Jewish bootmaker nicknamed "Leather Apron". Moore has Inspector Abberline cynically comment upon this spurious accusation: "Oh... and he's said to be Jewish. That should improve the spirit of cheery cooperation around Whitechapel” (From Hell, 6:17)
} 
background), and in 1903, the Russian publication of the forged Protocols of the Elders of Zion would exert a baleful influence on the entire Western world. The anti-Semitic sentiment surrounding the Whitechapel murders is therefore one of many early symptoms of the cultural climate that would eventually culminate in the Holocaust, even if the attacks upon the women had nothing to do with racism.

In the context of From Hell, William Gull/Jack the Ripper ceases to be a mere person and becomes a transpersonal archetype, the personification of misogynist violence echoing back and forth through time and 'inspiring' other serial killers throughout the nineteenth and twentieth century at an ever-increasing rate (cf. From Hell, 14:12ff.). As Zoë Brigley-Thompson puts it in her analysis of the graphic novel: "Gull represents the sexual domination of women not by isolated madmen, but by 'civilized' society in general" (82). Psychotic murderers are but the most extreme symptoms of a deeper malaise at the heart of our culture, a deep-seated misogyny that persists in spite of all aspirations to enlightened liberalism. But the graphic novel is not an altogether bleak vision: in the events surrounding Gull's final and most gruesome murder, it is strongly hinted that he (and the police) misidentified his final target, Mary Kelly, allowing her to escape the city and return to Ireland. Upon his deathbed in a lunatic asylum, Gull receives a vision that jeopardizes the vision of Woman Subdued and Patriarchy Ascendant that he sought to create, calling his success into question. He sees an Irishwoman surrounded by her children (who bear the names of the other murdered prostitutes), and even though he fails to comprehend that this is Mary Kelly, he is beset by primal fear: "Why am I being shown this? I don't know these people. I have never seen this woman in my life, and yet... and yet within her eyes, that terrible ferocity. I am afraid of her" (From Hell, 14:23). Kelly senses his presence and fends him off like an evil spirit, telling him to return to hell (ibid.), which seemingly causes him to drift away into what he assumes to be his ascension to godhood, but what might in fact just be his final demise. This vision of a rural idyll stands in marked contrast to the rest of Gull's near-death epiphanies, and can be read as a form of resistance against the cultural strains Gull wanted to create with his symbol-laden ritual: Archetypal Woman is alive, and She is not subdued or afraid, but strong in her personification as Mary Kelly. Just as Gull has become the personification of Patriarchy's Shadow, Kelly has become the embodiment of his nemesis, contesting the abject fate allotted to her on account of her nationality, class, and gender. The subjugation of the unconscious and the triumph of a hollow, technocratic patriarchy is not complete. The possibility of positive change remains - as in the struggle for women's, workers', and LGBTQI* rights along with many other contested fields.

As for Jack the Ripper's apotheosis: the graphic novel opens and culminates with the image of a dead gull lying on a beach, strongly suggesting that whatever he aspired to be has gone the way of all flesh. The most problematic undercurrents of the Victorian zeitgeist may have given birth to the horrors of the twentieth century, but they are not the only influences at work. To Moore's heavily fictionalized 
version of William Gull (as to other Victorian or even contemporary defenders of traditional patriarchy), women who challenge the established social order are abjects in themselves. Shockingly, most of the popular theories surrounding the Whitechapel murders reflect this. Moore observes: "Everyone seems agreed that Kelly was the real target. [...] The underlying assumption remains unstated: She must have done SOMETHING to deserve THAT" (From Hell, II:6, emphasis in original). Victim-blaming is symptomatic of the sexist currents that persist in Western culture to this day, especially in relation to sexual offenses or if the crime in question involved sex workers. As recently as November 2015, the attorney of former MMA athlete and alleged rapist Jonathan "War Machine" Koppenhaver claimed that his client could not have possibly raped ex-girlfriend and adult actress Christy Mack because she was involved in the porn business, performing sexual acts professionally. "Mack, 23, was left with 18 broken bones, a broken nose, missing teeth, a fractured rib and a ruptured liver after Koppenhaver broke into her Las Vegas home on August 8, 2014" (Bluth, Daily Mail). To the court's credit, it appears that this legal manoeuvre turned out to be anything but successful. Yet it still bespeaks a tacit assumption that is all too commonly held: the victim must have done something to deserve her fate. Maybe her skirt was too short. Maybe she drank too much. Maybe she provoked him. Laurie Penny sums it up succinctly in Unspeakable Things:

Rape culture means more than a culture in which rape is routine. Rape culture involves the systematic suspicion and dismissal of victims. In order to preserve rape culture, society at large has to believe two different things at once: that women and children lie about rape, and that they should also behave as if rape will be the result if they get into a strange car, walk down a strange street, or wear a sexy outfit, and if it happens, it's their own fault. (148f.)

This particular heritage of the Victorian age persists in our culture; not openly, but closely underneath the surface. Yet there is change, too. When pornographic actress Stoya broke her silence about having been raped by her co-worker and ex-boyfriend James Deen, she did not expect any kind of support.

[...] I didn't feel as if I could press charges because the U.S. court system rarely metes out anything that looks like justice when sex workers are involved. Social media seemed to be the most appropriate and only real option. But I doubted I would be believed, and I worried the company I co-own with Kayden Kross would suffer. Most of all, I was afraid that speaking would only serve to fuel the arguments of outside groups who aim to dictate how we adult performers do our jobs and whether we're legally allowed to do them at all.

Instead of being silenced, instead of being not heard, something very different occurred. When I finally spoke in those two tweets on the 28th of November, people listened. Other women began to come forward, and a lot of 
people in pornography showed their support. Significant companies responded, and they did so swiftly. I'm grateful for the solidarity of the people who believe me and the other women who have spoken out, and I'm proud of the industry I work in. (Stoya, "Graphic Descriptions")

Rape culture still exists - yet so does a new awareness of its existence. To bring abjects to the light of day means to rob them of their most subversive power, just like the suppressed impulses within our individual Jungian shadow. The cultural pessimism communicated by From Hell and the Frankfurt school misses one particular detail: people are not passive recipients of mass culture, nor are historical influences a one-directional affair.

Neo-Victorian fiction is all about actively engaging the past, about memory work, about unearthing the most unfortunate and reprehensible heirlooms buried at the foundation of our collective cultural identity constructs and bringing them to the light of day. By projecting a contemporary perspective into the past, neo-Victorian texts engage in a dialogue with cultural and literary history - sometimes literally, as in the case of pastiches and re-writings that draw upon specific parent texts. Just as Salman Rushdie asserts that "the Empire writes back to the Centre" (qtd. in Ashcroft) in post-colonial literature, neo-Victorianism addresses a bygone era whose heritage is still with us - and tends to focus on its darker or problematic aspects. Changing the past may be an impossibility - but changing our perception of the same is a different matter entirely. Just as the characters in Lost Girls unravel their individual neuroses by looking closely at their biographies, contemporary culture can gain a better understanding of its unresolved cultural issues by locating them in the past. When Sarah Waters transposes 'queer' language to a Victorian setting in what Helen Davies calls "subversively 'talking back' via re-citation" (136), for example, she may create a mostly fictional anachronism; but at the same time, she gives a voice to a minority that could not express itself in that historical era, and was rendered virtually invisible and mute by canonical nineteenth century fiction.

Just as speculative fiction tends to reveal more about the era it was written in than about the future scenarios or alternate worlds described therein, neo-Victorian texts explore the present day within the (fictionalized) past - not necessarily as a mere projection, where the Victorian era serves as little more than decoration; but as the seed of contemporary culture within its historical predecessor. There are still plenty of traces of the dysfunctional gender roles and relationship models depicted in Michel Faber's The Crimson Petal and the White which are still inherent to Western culture in the twenty-first century. By figuring out where they originated, we may gain a greater awareness of these phenomena within our own daily lives, potentially even resolving them. The cultural abjects of the Victorian age may not be identical with our own, but the overlap is considerable enough to allow for some speculative exploration. Neo-Victorian fiction draws attention to the ugly sides of the past, the underbelly of a society that is popularly regarded as the epitome of repression. 
If the unresolved abjects of the Victorian era gave birth to the horrors of the twentieth century by persisting in the unconscious layers of our cultural identity, then neo-Victorian fiction's "memory work" (as Kate Mitchell calls it) may perform an important task in shining a light into these dark corners and forcing us to confront them. In contrast to Adorno's bleak vision of a culture of passively consuming audiences, neo-Victorian texts are a direct response to the tacit omissions, marginalized taboo subjects and buried skeletons of a past canonized in certain works of literature that still exerts some influence on contemporary cultural identity constructs. Even From Hell, whose depiction of a patriarchal cult of Reason and the monsters it gives birth to corresponds so closely to the pessimism of the Frankfurt school, is an active engagement with the past that encourages readers to confront the darkness buried within history by means of fiction. Gull may accuse the people of the late 1980s he encounters in his vision of being oblivious to their connection to history, but the same cannot be said about those who read the graphic novel: if only by virtue of reading From Hell, they have caught a glimpse of the strings that tie the 1880s to the present.

Whereas authentic Victorian literature tends to be sanitized, sexless, and - most importantly of all - very much in line with the cultural zeitgeist that gave birth to it, neo-Victorian fiction has the potential to transform contemporary perceptions of this bygone era. It encourages readers to challenge historical myths about the Victorian past (and present-day culture's relationship with the same): In realizing both the commonalities and differences between the Victorians and ourselves, and in locating the roots of our own world views, taboos, and contentious topics within the pivotal societal changes of the age of industrialization, we may gain a new understanding of our collective cultural identity. The heritage of Victorian societal abjects still weighs upon contemporary society, as seen by issues such as sexism, the discrimination of non-normative sexual orientations and gender roles, or even the pathologisation of unusual world views. Accordingly, an exploration of Victorian culture and history may very well hold the key to a process of understanding and healing, even if it takes place in 'mere' fiction. The Victorian Age is the present day's Jungian shadow: it is both 'other' and self, like the photograph of a notorious grandparent whose features bear a striking resemblance to our own, and who is known for some unpleasant deeds or personal beliefs. In talking back through speculative fiction, repressed and unpleasant truths can be brought to the fore, and old wounds may finally mend.

This study put a strong emphasis on Victorian abjects surrounding the issues of gender and sexuality: even in the discussion of non-normative world views and Spiritualism, women's rights et al. always came back into focus. Without a doubt, this particular area of conflict is one of the pivotal points of neo-Victorian fiction as a genre, infusing the past with voices that challenge traditional norms of patriarchal oppression. However, these are hardly the only Victorian abjects that still exert some influence upon contemporary society. Future research may focus on issues 
like colonialism and racism, socio-economic class conflict, or environmental degradation and pollution as abject outgrowths of industrialism. While none of these topics occupy the same central space in neo-Victorian fiction as sexuality and gender, they are clearly present in some texts, and merit further analysis. It may also be prudent to ask why the heritage of colonialism does not feature even more prominently in the genre, especially compared to the 'Woman Question'. Racist and Imperialist discourses are not deliberately omitted from neo-Victorian fiction, of course: Peter Carey's Jack. Maggs or Belinda Starling's The Journal of Dora Damage, for example, examine colonial prejudices as a central motif, and the subject is raised in some of the texts previously discussed in this study as well. But in contrast to the ubiquitous female protagonists struggling against patriarchal society, colonialism occupies a less prominent place in the genre. In light of the current geo-political situation, this apparent lack of a pronounced interest in the subject is surprising, and certainly invites additional research.

Observing neo-Victorianism through the lens of Julia Kristeva's concept of abjection and the abject provides a valuable perspective on the genre, focusing the researcher's view on one of the most distinctive differences between authentic Victorian literature and contemporary re-writings. The deliberate inclusion of previously unmentioned or marginalized taboo subjects separates neo-Victorian fiction from its pseudo-Victorian equivalent, which primarily seeks to emulate historical parent texts. Virtually every neo-Victorian novel, short story, or film is brimming with elements that would have been utterly unmentionable in polite nineteenth century circles. This marks these texts as anachronistic, but it also demonstrates that they are not mere pastiches of the Victorian literary canon. Neo-Victorian re-writing is not an emulation, but a dialogue with the past: it encourages readers to re-examine traditional conceptions of Victorian culture, to become more aware of the repressed material under the surface of nineteenth century literary 'classics', and to potentially locate traces of these within contemporary society. This study has provided future researchers with a tool that enables them to become aware of this particular element of the genre, and invites further inquiries into the topic.

Neo-Victorian authors use the Victorian age as a projection of the current era's Jungian shadow, urging contemporary readers to recognize themselves within the Victorian 'other'. This moment of acknowledgement re-introduces notions of continuity to a post-modern consciousness used to a sense of disconnectedness from the past, yet simultaneously encourages a conscious break with traditional norms inherited from the Victorians. Readers may become more aware of their norms' indebtedness to history, only to discover that a considerable portion of this heritage may be toxic. But unearthing the proverbial skeletons in the basement of contemporary culture provides a sense of closure that is missing in a society that merely ignores its connection to the past. Fiction provides an opportunity to trace cultural scars, discover their origin - and heal them. 


\section{Bibliography}

Acton, William. Prostitution Considered. 1857. Reprint. New York: Routledge, 2012.

Adorno, Theodor, \& Max Horkheimer. Dialektik der Aufklärung: Pbilosophische Fragmente. 1944. Reprint. Frankfurt am Main: Fischer Taschenbuch, 2003.

Arias, Rosario, \& Patricia Pulham, eds. Haunting and Spectrality in Neo-Victorian Fiction: Possessing the Past. London: Palgrave Macmillan, 2010.

Ashcroft, Bill, Gareth Griffiths, \& Helen Tiffin. The Empire Writes Back. 1989. $2^{\text {nd }}$ ed. New York: Routledge, 2002.

Attwood, Feona, ed. Porn.Com: Making Sense of Online Pornography. New York: Lang, 2010.

—. "Porn Studies: From Social Problem to Cultural Practice." Porn.Com. Ed. Feona Attwood. New York: Lang, 2010. 1-13

Attwood, Nina. The Prostitute's Body: Rewriting Prostitution in Victorian Britain. London: Pickering \& Chatto, 2011.

Augustine. "The City of God." Trans. Marcus Dods. Nicene and Post-Nicene Fathers, First Series, Vol. II. 1887. Ed. Philip Schaff. Web. 12 Jun 2013.

Barrie, James M. Peter Pan. 1911. Reprint. London: Penguin, 1995.

Baum, Lyman Frank. The Wonderful Wizard of $O$ \%: Chicago: Hill, 1900. Kindle file.

Belsey, Catherine. Critical Practice. 1980. Oxon: Routledge, 2006. 
Begg, Paul. Jack the Ripper: The Definite History. London: Pearson Education, 2003.

Blake, William. Songs of Innocence and Experience. 1789. Facsimile. London: Tate, 2007.

Bluth, Jacqueline. "MMA fighter War Machine 'blew a kiss at prosecutor' while his defense attorney claimed he couldn't have raped his ex because she was a porn star.” Daily Mail, 24 Nov 2015, Web. 28 Jan 2016.

Boersma, Nik. "World Health Organization issues statement condemning LGBT 'conversion' therapies". Global Alliance for LGBT Education. Web. 26 Sep 2015.

Boynton, Victoria, \& Malin, Jo. Encyclopedia of Women's Autobiography: K-Z. London: Greenwood, 2005.

Braddon, Mary Elizabeth. Lady Audley's Secret. 1862. Reprint. Oxford: Oxford UP, 1998.

Bram Stoker's Dracula. Dir. Francis Ford Coppola. Columbia Pictures, 1992.

Brandreth, Gyles. Oscar Wilde and the Candlelight Murders. London: John Murray, 2007.

—. "Gyles Brandreth: Author, Broadcaster, Actor, Entertainer." Gyles Brandreth. Web. 14 Oct 2014.

Brantlinger, Patrick. "What is 'Sensational' about the 'Sensation Novel'?", Nineteenth Century Fiction, vol. 37, no. 1, 1982, pp. 1-28. Web. 28 Oct 2012. $<$ http://www.jstor.org/stable/3044667>

Brigley-Thompson, Zoë. "Theorizing Sexual Domination in From Hell and Lost Girls - Jack the Ripper versus Wonderlands of Desire." Sexual Ideology in the Works of Alan Moore. Ed. Todd A. Comer \& Joseph Michael Sommers. London: McFarland and Company, 2012. 76-87.

Brontë, Charlotte. Jane Eyre. 1847. London: Penguin, 1996.

Buckner, Phillip Alfred, and R. Douglas Francis, eds. Rediscovering the British World. Calgary: Calgary UP, 2005.

Bullen, J.B., ed. Writing and Victorianism. London: Longman 1997.

Burton, Anthony. "The revival of interest in Victorian decorative art and the Victoria and Albert Museum." The Victorians since 1901. Ed. Miles Taylor and Michael Wolff. Manchester: Manchester UP, 2004. 121-137.

Byatt, Antonia S. Angels and Insects: Two Novellas. New York: Random House, 1992.

Byatt, Antonia S. “The Conjugal Angel.” Angels and Insects: Two Novellas by Antonia S. Byatt, New York: Random House, 1992, pp. 187-337.

Carroll, Lewis. Alice's Adventures in Wonderland \& Through the Looking Glass. 1865 \& 1871. Reprint. New York: Signet Classic, 2000.

Carroll, Samantha J. "Putting the Neo' Back into Neo-Victorian: The Neo-Victorian Novel as Postmodern Revisionist Fiction." Neo-Victorian Studies 3:2 (2010), pp. 172-205. 
Carter, Angela. The Sadeian Woman. An Exercise in Cultural History. 1979. London: Virago Press, 2006.

Carey, Peter. Jack Maggs. London: Faber \& Faber, 1997.

Cleland, John. Fanny Hill: Memoirs of a Woman of Pleasure. 1749. London: Penguin, 2012.

Collins, Wilkie. The New Magdalen. 1873. Stroud, Gloucestershire: Sutton, 1995.

Comer, Todd A., and Joseph Michael Sommers. Sexual Ideology in the Works of Alan Moore. London: McFarland, 2012.

Cook, Matt. A Gay History of Britain: Love and Sex between Men Since the Middle Ages. Oxford: Greenwood World, 2007.

-. London and the Culture of Homosexuality, 1885-1914. Cambridge: Cambridge UP, 2003.

Courts of Probate and Divorce. "Hyde v. Hyde and Woodmansee". United Settlement. Web. 18 Mar 2014.

Criminal Law Amendment Act. Swarb.co.uk. Web. 18 Mar 2014.

Darwin, Charles. On the Origin of Species: By Means of Natural Selection or the Preservation of Favoured Species in the Struggle for Life. 1859. Reprint. London: John Murray, 2010. Kindle file.

Davies, Helen. Gender and Ventriloquism in Victorian and Neo-Victorian Fiction: Passionate Puppets. Chippenham: Palgrave Macmillan, 2012.

Dawkins, Richard. The God Delusion. New York: Bantam Books, 2006.

Dickens, Charles. Great Expectations. 1861. Reprint. London: Penguin, 1994.

Di Liddo, Annalisa. Alan Moore - Comics as Performance, Fiction as Scalpel. Jackson, MS: UP of Mississippi, 2009.

Eisler, Riane. The Chalice \& the Blade: Our History, Our Future. 1987. Reprint. San Francisco: Harper Collins, 1995.

Ellis, Steve: Virginia Woolf and the Victorians. Cambridge: Cambridge UP, 2007.

Faber, Michel. "A Mighty Horde of Women in Very Big Hats, Advancing." The Apple. Edinburgh, Canongate, 2006, pp. 135-199.

- The Apple: New Crimson Petal Stories. Edinburgh: Canongate, 2006.

—. The Crimson Petal and the White. 2002. Reprint. Orlando, Fl.: Harcourt, 2003.

Foucault, Michel. The History of Sexuality - Vol. 1: An Introduction. 1979. Transl. Robert Hurley. Reprint. New York: Vintage Books, 1990.

-. Madness \& Civilization: A History of Insanity in the Age of Reason. 1965. Reprint. New York: Vintage Books, 1988.

Fowles, John. The French Lieutenant's Woman. 1969. Reprint. London: Vintage, 2004. 
Freud, Sigmund. An Outline of Psychoanalysis. 1940. Reprint. Trans. James Strachey. Blacksburg, VA: Wilder Publications, 2010.

—. Drei Abhandlungen zur Sexualtheorie. 1905. Reprint. Wien: Franz Deuticke, 1922. Kindle file.

- The Interpretation of Dreams. 1913. Reprint. Trans. A.A. Brill. New York: Bartleby.com, 2010. Web. 25 May 2013.

-.Massenpsychologie und Ich-Analyse. Wien: Internationaler Psychoanalytischer Verlag, 1921. Kindle file.

—. Totem und Tabu. 1913. Reprint. London: Imago Publishing, 1940.

—. The Uncanny. 1919. Reprint. Trans. David McLintock. London: Penguin, 2003.

Fukuyama, Francis. The End of History and the Last Man. 1992. Reprint. New York: Free Press, 2006.

Gaiman, Neil. “Lost Girls redux.” Neilgaiman.com. 19 Jun 2006. Web.

Galvan, Jill. The Sympathetic Medium: Feminine Channeling, The Occult, and Communication Tecbnologies, 1859-1919. London: Cornell UP, 2010.

Gibson, Ian. The Erotomaniac - The Secret Life of Henry Spencer Ashbee. London: Faber and Faber, 2001.

Giorcelli, Christina, \& Paula Rabinowitz, eds. Fashioning the Nineteenth Century. London: University of Minnesota Press, 2014.

Golda-Derejczyk, Agnieszka. "Repetition and Eternity: The Spectral and Textual Continuity in Michèle Roberts's In the Red Kitchen." Haunting and Spectrality in Neo-Victorian Fiction: Possessing the Past. Ed. Rosario Arias and Patricia Pulham. London: Palgrave Macmillan, 2010. 45-57.

Hadley, Louisa. Neo-Victorian Fiction and Historical Narrative: The Victorians and Us. New York: Palgrave-Macmillan, 2010.

Hammerton, Anthony James. Cruelty and Companionship. Conflict in nineteenth-century married life. London: Routledge, 1992.

Heilmann, Ann, \& Mark Llewellyn: Neo-Victorianism. Basingstoke, Hampshire [England]: Palgrave-Macmillan, 2010.

Hobsbawm, Eric, \& Terence Ranger, eds. The Invention of Tradition. 1983. Reprint. Cambridge: Cambridge UP, 2009.

Holy Bible, The. King James Version. Bibleserver. Web. 10 Sep 2014.

Houghton, Walter. The Victorian Frame of Mind 1830-1879. London: Oxford UP, 1957.

Humphreys, Helen. Afterimage. 2000. Reprint. London: Bloomsbury Publishing, 2001.

Idelson, Bianca Jaccarino. "Psychoanalytic Views of Cross-Dressing and Transvestism." Fashioning the Nineteenth Century. Ed. Christina Giorcelli and Paula Rabinowitz. London: University of Minnesota Press, 2014. 12-23. 
"Interview with Michel Faber." Between the Lines. Harcourt Trade Publishers. Web. 17 Sep 2013.

Jenkins, Alice, ed. Rereading Victorian Fiction. New York: St. Martin's, 2000.

Jones, Adele. "A Feminist Act of Adaptation: Identities and Discourses in Michèle Roberts's In the Red Kitchen”. Neo-Victorian Studies 2:2 (Winter 2009/10), 86-108. Web. 05 Mar 2015.

Joyce, Simon. The Victorians in the Rearview Mirror. Athens, Ohio: Ohio UP 2007. "jugum penises." Brought to Life. London: Science Museum, 2009. Web. 29 Apr. 2013.

Jung, Carl Gustav. Archetypen. 1934. Reprint. München: Deutscher Taschenbuch Verlag, 2001.

—. Psychology and Religion: West and East. 1938. Reprint. New York: Pantheon Books, 1970.

—. „Über die Archetypen des kollektiven Unbewussten.“ Archetypen. Ed. Carl Gustav Jung. München: Deutscher Taschenbuch Verlag, 2001. 7-44.

Kalsched, Donald, and Alan Jones. "Myth and Psyche - The Evolution of Consciousness". C.G. Jung Foundation for Analytical Psychology, Inc. Web. 08 Jan 2016.

Kate \& Leopold. Dir. James Mangold. Buena Vista, 2001.

Kerr, John. A Most Dangerous Method: The Story of Jung, Freud, and Sabina Spielrein. 1994. New York: Vintage Books, 2011. Kindle file.

Kent, Susan. Sex and Suffrage in Britain 1860-1914. Princeton: Princeton UP, 1990.

King, Francis, ed. Ritual Magic of the Golden Dawn. Rochester, VT: Destiny Books, 1997.

Kirchknopf, Andrea. "(Re-)Workings of Nineteenth-Century Century Fiction: Definitions, Terminology, Contexts", Neo-Victorian Studies 1:1 (Autumn 2008), pp. 53-80.

Knight, Margaret. Honest to Man: Christian Ethics Re-Examined. London: Pemberton, 1974.

Knight, Stephen. Jack the Ripper: The Final Solution. 1974. Reprint. London: HarperCollins, 1994.

Kohlke, Marie-Luise. "Introduction: Speculations in and on the Neo-Victorian Encounter", Neo-Victorian Studies 1:1 (Autumn 2008), pp. 1-18.

Kohlke, Marie-Luise, and Christian Gutleben, eds. Neo-Victorian Families: Gender, Sexual and Cultural Politics. New York: Editions Rodopi, 2011.

Kontou, Tatiana. Spiritualism and Women's Writing: From the Fin de Siècle to the NeoVictorian. London: Palgrave Macmillan, 2009.

Kontou, Tatiana, ed. Women and the Victorian Occult. Abingdon, Oxon: Routledge, 2011. 
Krafft-Ebing, Richard von. Psychopathia Sexualis: mit besonderer Berücksichtigung der konträren Sexualempfindung; eine medizinisch-gerichtliche Studie für Ärzte und Juristen. 1885. 16th revised edition. Stuttgart: Enke, 1924.

Kristeva, Julia. Powers of Horror, An Essay on Abjection. 1981. Trans. Leon S. Roudiez. Reprint. New York, NY: Columbia UP, 2002.

Krugovoy Silver, Anna. Victorian Literature and the Anorexic Body. Cambridge: Cambridge UP, 2002.

Kucich, John, \& Dianne Sadoff, eds. Victorian Afterlife. Minneapolis: University of Minnesota Press 2000.

Lacan, Jacques. Écrits. A Selection. 1966. Trans. Alan Sheridan. London: Routledge, 2005. Kindle file.

La Caritilie, Major, ed. The Collector's Edition of Victorian Lesbian Erotica. New Milford: Magic Carpet Books, 2006.

Lady Hekate. “Lieber Sexarbeit als Hartz IV.” Zeit online, 17 Nov 2013. Web.

Laite, Julia. Common Prostitutes and Ordinary Citizens: Commercial Sex in London, 1885 1960. Houndmills, Basingstoke, Hampshire: Palgrave Macmillan, 2012.

Laity, K.A. “'Avast, Land Lubbers!' - Reading Lost Girls as a Post-Sadeian Text.” Sexual Ideology in the Works of Alan Moore. Ed. Todd A. Comer and Joseph Michael Sommers. London: McFarland, 2012. Ch. 11. Kindle file.

Lakritz, Kenneth. "Michel Foucault's Madness and Civilization: A History of Insanity in the Age of Reason". Psychiatric Times. 09 Jun 2009. Web. 12 Dec 2015. < http://www.psychiatrictimes.com/articles/michel-foucault $\% \mathrm{E} 2 \% 80 \% 99 \mathrm{~s}$-madness-and-civilization-history-insanity-age-reason\#sthash.8aGRHvNG.dpuf>

Laqueur, Thomas W. Solitary Sex - A Cultural History of Masturbation. Brooklyn, NY: Zone Books, 2003.

“lesbian.” Online Etymology Dictionary. Web. 23 Sep 2014.

Letissier, Georges. "More Than Kith and Less Than Kin: Queering the Family in Sarah Waters's Neo-Victorian Fictions." Neo-Victorian Families: Gender, Sexual and Cultural Politics. Ed. Marie-Luise Kohlke and Christian Gutleben. New York: Editions Rodopi, 2011. 365-391.

Lewis, Matthew Gregory. The Monk. 1796. Reprint. London: Penguin Classics, 1999.

Llewellyn, Mark. "Spectrality, S(p)ecularity, and Textuality: Or, Some Reflections in the Glass." Haunting and Spectrality in Neo-Victorian Fiction: Possessing the Past. Ed. Rosario Arias and Patricia Pulham. London: Palgrave Macmillan, 2010. 23-42.

Logan, Deborah Anna. Fallenness in Victorian Women's Writing. Marry, Stitch, Die, or Do Worse. London: University of Missouri Press, 1998. 
Lord Davies of Abersoch. Women on Boards. 2011. Web. 16 Mar 2012. <www.bis.gov.uk/assets/biscore/business-law/docs/w/11-745-women-onboards.pdf $>$

Maines, Rachel P. The Technology of Orgasm. "Hysteria," the Vibrator, and Women's sexual satisfaction. Baltimore: John Hopkins UP, 1999.

Mann, Thomas. Der Zauberberg. 1924. Reprint. Frankfurt a.M.: Fischer, 1991.

Marcus, Steven. The Other Victorians. New York: Basic Books, 1964.

“Married Women’s Property Act 1882.” Legislation.gov.uk. Web. 23 Feb 2015.

Marsh, Jan. "Sex \& Sexuality in the 19 ${ }^{\text {th }}$ Century." The Victoria and Albert Museum. Web. 01 March 2015.

Mars-Jones, Adam. “In His Master's Voice.” The Guardian. 22 Feb 2004. Web. 12 Jan 2015.

Martin, Gary. "Children should be seen and not heard", The Phrase Finder: Phrase Dictionary - Meanings and Origins. Web. 10 Dec 2013.

Mason, Michael. The Making of Victorian Sexuality. 1994. Reprint. Oxford: Oxford UP, 2003.

Maturin, Charles. Melmoth the Wanderer. 1820. Reprint. Oxford: Oxford UP, 1998.

McLuhan, Marshall. The Gutenbery Galaxy: The Making of Typographic Man. 1962. Reprint. Toronto: University of Toronto Press, 2002.

Mitchell, Kate. History and Cultural Memory in Neo-Victorian Fiction: Victorian Afterimages. Basingstoke: Palgrave-Macmillan, 2010.

Moore, Alan. 25,000 Years of Erotic Freedom. New York: Abrams, 2009.

Moore, Alan, Eddie Campbell and Pete Mullins. From Hell. 1996. Reprint. Marietta: Top Shelf Productions, 2006.

Moore, Alan, and Kevin O’ Neill. The League of Extraordinary Gentlemen: Volume One. La Jolla, CA: America's Best Comics, 2000.

Moore, Alan, and Melinda Gebbie. Lost Girls (Vol. I-III). Marietta: Top Shelf, 2006.

Nicholson, Helen, Roy Porter and Bridget Bennett, eds. Women, Madness and Spiritualism (Vol. I \& II). New York: Routledge, 2003.

Nünning, Ansgar, ed. Metzler Lexikon Literatur-und Kulturtheorie. 3rd ed. Stuttgart: Metzlersche Verlagsbuchhandlung, 2004.

Nünning, Vera. Kulturgeschichte der englischen Literatur: Von der Renaissance bis zur Gegenwart. Tübingen: Francke, 2005.

“Obscene Publications Act 1857.” Legislation.gov.uk. The National Archives. Web. 09 Jun 2014.

“Obscene Publications Act 1859.” Legislation.gov.uk. The National Archives. Web. 09 Jun 2014. 
O’Malley, Patrick R. Catholicism, Sexual Deviance, and Victorian Gothic Culture. Cambridge: Cambridge UP, 2006.

Owen, Alex. The Darkened Room: Women, Power, and Spiritualism in Late Victorian England. 1989. Reprint. London: University of Chicago Press, 2004.

Patmore, Coventry. The Angel in the House. 1862. Reprint. North Charleston: CreateSpace, 2013.

Penny, Laurie. Meat Market: Female Flesh under Capitalism. Winchester, UK: Zero Books, 2010. Kindle file.

—. Unspeakable Things. London: Bloomsbury, 2011. Kindle file.

Perfect, David. "Gender Pay Gaps." Equality and Human Rights Commission, Briefing Paper 2. 2011. Web. 12 Mar 2012. <http://www.equalityhuman-

rights.com/uploaded_files/research/gender_pay_gap_briefing_paper2.pdf $>$

Pope John Paul II. "Christian Spirituality of Marriage Possible only by Living According to the Spirit." General Audience. 14 Nov 1984. Web. 10 Feb 2016. <http://www.piercedhearts.org/jpii/theology_body_audiences/november_14_1984.htm>

"Pornography Statistics". Family Safe Media. Web. 13 May 2014. <http://www.familysafemedia.com/pornography_statistics.html>

Postober Staff. "Top Ten Countries that watch the most Porn". Postober. 17 Jan 2015. Web. 05 Mar 2015. <http://postober.com/general/top-10-countriesthat-watch-the-most-porn/>

Pytlik, Priska. Okekultismus und Moderne: Ein kulturbistorisches Phänomen und seine Bedeutung für die Literatur um 1905. Paderborn: Schöningh, 2005.

Reiss, Michael. “A brief history of sex education”. OpenLearn: The home of free learning from the Open University. 16 Sep 2005. Web. 13 Oct 2014.

<http://www.open.edu/openlearn/body-mind/health/health-studies/briefhistory-sex-education $>$

Rhys, Jean. Wide Sargasso Sea. 1966. Reprint. London: Penguin, 2001.

Roberts, Adam. Science Fiction. 2nd ed. New York: Routledge, 2006.

Roberts, Michèle. In the Red Kitchen. 1990. Reprint. London: Minerva, 1991.

Rowland, Susan. "Women, Spiritualism and Depth Psychology in Michèle Roberts's Victorian Novel.” Rereading Victorian Fiction. Ed. Alice Jenkins. New York: St. Martin's, 2000. 201-214.

Russett, Cynthia Eagle. Sexual Science. London: Harvard UP, 1989.

"Same-Sex Marriage now legal as first couples wed". BBC.co.uk. 29 Mar 2014. Web. 08 May 2014. <http://www.bbc.com/news/uk-26793127>

Santala, Ismo. "Interview: Alan Moore." ReadySteadyBook: A Literary Site. 23 Oct. 2006. Web. 21 Jun 2013. 
Saussure, Ferdinand de. Course in General Linguistics. 1983. Reprint. Trans. Roy Harris. Chicago: Open Court, 2007.

Schwarzer, Alice. "Die Begründung - Warum ein Anti-Pornographie-Gesetz her muß." PorNO - Opfer und Täter. Ed. Alice Schwarzer. Köln: Kiepenheuer \& Witsch, 1994. 43-53.

-. Prostitution: Ein dentscher Skandal - Wie konnten wir zum Paradies für Frauenbändler werden? Köln: Kiepenheuer \& Wisch, 2013.

"Sexual Offenses Act 1967". Legislation.gov.uk. The National Archives. Web. 10 July 2014.

Shaw, Marion. Alfred Lord Tenmyson. London: Harvester Wheatsheaf, 1988.

Shastri, Sudha. Intertextuality and Victorian Studies. Hyderabad: Orient Longman, 2001.

Shindler, Dorman T. "Alan Moore leaves behind his Extraordinary Gentlemen to dally with Lost Girls." Science Fiction Weekly \#485. SciFi.Com, 7 Aug. 2006. Web. 28 Apr. 2013.

Starling, Belinda. The Journal of Dora Damage. London: Bloomsbury, 2007.

Stengers, Jean, and Anne van Neck. Masturbation: The History of a Great Terror. Trans. Kathryn Hoffmann. Basingstoke: Palgrave Macmillan, 2001.

Strachey, Lytton. Eminent Victorians $3^{\text {rd }}$ Edition. 1918. Reprint. New York: Capricorn Books, 1963.

Stoker, Bram. Dracula. 1897. Reprint. London: Penguin Popular Classics, 1994.

Stoya. Graphic Descriptions. 17 Dec 2015. Web. 02 Feb 2016.

Sweet, Matthew. Inventing the Victorians. London: Faber and Faber, 2001.

Taylor, Miles, and Michael Wolff, eds. The Victorians since 1901. Manchester: Manchester UP, 2004.

Tennyson, Alfred. In Memoriam A.H.H. 1849. Reprint. North Charleston: CreateSpace, 2012.

Tertullian. "On the Apparel of Women." Trans. S. Thelwall. From Ante-Nicene Fathers. Vol. 4. Ed Alexander Roberts, James Donaldson, and A. Cleveland Coxe. (Buffalo, NY: Christian Literature Publishing Co., 1885.) Revised and edited for New Advent by Kevin Knight. Web. 07 Jan 2016.

$<$ http://www.newadvent.org/fathers/0402.htm>

"Testimony of Oscar Wilde". Wilde Libel Transcript. UMKC School of Law. Web. 08 Aug 2014.

The Mindscape of Alan Moore. Dir. DeZ Vylenz. London: Shadowsnake Films, 2005. Web. 3 Apr 2013.

Thill, Scott. "We are All Complicit - An Interview with Alan Moore." Morphizm. Morphizm.com, 19 Sep 2006. Web. 11 Jun 2013. 
“tribadism.” Online Etymology Dictionary. Web. 23 Sep 2014. < http://www.etymonline.com/index.php?term $=$ tribadism\&allowed_in_frame $=0>$

Toibín, Colm. The Master. 2004. Reprint. Chatham, Kent: Picador, 2005.

Urban, Hugh. Magia Sexualis: Sex, Magic, and Liberation in Modern Western Esotericism. Berkeley: University of California Press, 2006.

"Victoriana", OED Online. June 2012. Oxford UP. 15 July 2012. $<$ http://www.oed.com/vie/entry/223223? redirectedFrom=victoriana>

Vogel, Pierre. "Warum essen Muslime kein Schweinefleisch". Youtube. Web. 05 July 2015.

Walkowitz, Judith R. Prostitution and Victorian Society: Women, Class and the State. Cambridge (UK): Cambridge UP, 1980. Web.

Wallraven, Miriam. '"A mere instrument' or 'proud as Lucifer'? Self-Presentations in the Occult Autobiographies by Emma Hardinge Britten (1900) and Annie Besant (1893)". Women and the Victorian Occult: 116-137.

Waters, Sarah. Affinity. 1999. Reprint. London: Virago Press, 2003.

Waters, Sarah. Tipping the Velvet. 1998. Reprint. London: Virago Press, 2001.

Watkins, Gwynne. “The Brothers Freud- Alan Moore talks about his 336-page fairy tale porno". Nerve. Nerve.com, 3 Aug 2006. Web. 11 Jun 2013.

Webb, James. Die Flucht vor der Vernunft: Politik, Kultur und Okekultismus im 19. Jabrbundert. 1974. Reprint. Trans. Michael Siefener. Wiesbaden: Marix, 2009.

Wood, Ellen. East Lynne. Oxford: Oxford UP, 2005.

Woolf, Virginia. "Mr. Bennett and Mrs. Brown". The Hogarth Essays. 1924. Web. 12 August 2012. <http://www.columbia.edu/ em36/MrBennettAndMrsBrown.pdf $>$

"X-Rated: Anarchy in the UK". Comics Britannia. Prod. BBC 4. Bristol: BBC. 24 Sep. 2007. Youtube. Web. 16 May 2013.

Yebra, José M. "Neo-Victorian Biofiction and Trauma Poetics in Colm Tóibín's The Master". Neo-Victorian Studies 6:1 (2013), pp. 41-74. Web. 05 Oct 2015.

Zikr. "Sunnah of Going to the Bathroom (Toilet)". Web. 02 Mar 2016. $<$ http://www.zikr.co.uk/content/view/72/113/> 